\author{
UNIVERSIDADE DE SÃO PAULO \\ INSTITUTO DE RELAÇÕES INTERNACIONAIS
}

ERIKA MARIA MEDINA BARRANTES

COHESIÓN SOCIAL Y DEMOCRACIA: NUEVA

FORMULACIÓN PARA LA CONSTRUCCIÓN DEL

DESARROLLO EN UN MUNDO GLOBALIZADO

São Paulo

2016 
UNIVERSIDADE DE SÃO PAULO

INSTITUTO DE RELAÇÕES INTERNACIONAIS

PROGRAMA DE PÓS-GRADUAÇÃO EM RELAÇÕES INTERNACIONAIS

\section{COHESIÓN SOCIAL Y DEMOCRACIA: NUEVA FORMULACIÓN PARA LA CONSTRUCCIÓN DEL DESARROLLO EN UN MUNDO GLOBALIZADO}

ERIKA MARIA MEDINA BARRANTES

Tese apresentada ao Programa de PósGraduação em Relações Internacionais do Instituto de Relações Internacionais da Universidade de São Paulo, para a obtenção do título de Doutor em Ciências

Orientador: Prof. Dr. Amâncio Jorge de Oliveira

São Paulo 
Autorizo a reprodução e divulgação total ou parcial deste trabalho, por qualquer meio convencional ou eletrônico, para fins de estudo e pesquisa, desde que citada a fonte.

Catalogação da Publicação

Instituto de Relações Internacionais da Universidade de São Paulo

MEDINA, Erika.

Cohesión Social y Democracia: Nueva formulación para un mundo globalizado. / Erika Medina.; orientador Amâncio Jorge de Oliveira - São Paulo, 2016.

$\left(n^{o}\right) \cdot p$.

Tese (Doutorado) --Universidade de São Paulo, 2016.

1. Cohesión Social. 2. Democracia. 3. América del Sur. I. Oliveira, Amâncio Jorge de. II. Título. 
"El hombre no puede estar atado a propósitos superiores y seguir las reglas de la sociedad, si no ve o percibe nada por encima de él, a lo que siente que pertenece: liberar al hombre de toda presión social significa abandonarlo a sí mismo y desmoralizarlo".

Emile Durkheim 


\section{Agradecimientos}

La realización de un doctorado implica un cambio profundo en todos los niveles que conforman la vida de una persona, es una lucha extremamente solitaria en la cual la constancia se define como el único medio para llevar a cabo esta difícil tarea. Por medio de estos párrafos me gustaría expresar un agradecimiento sincero a todos aquellos que tuvieron un papel importante en este camino desafiante, largo y exhaustivo que me propuse andar durante estos cuatro años.

A la Coordenação de Aperfeiçoamento de Pessoal de Nível Superior-CAPES a través del convenio PEC-PG, apoyo sin el cual habría sido imposible alcanzar los resultados de esta tesis, que permite el desarrollo de muchos investigadores extranjeros en Brasil y abre las puertas a un intercambio profundo en términos culturales, que en mi caso particular permitió crear raíces profundas con este país que nunca deja de asombrarme y del cual me encanto cada día mas.

A la Universidad de São Paulo y al Instituto de Relaciones Internacionales IRI-USP, agradezco el amplio apoyo institucional y estructural. A mi orientador el Prof. Amâncio Jorge de Oliveira por su comprensión y observaciones a lo largo de esta investigación, a la Prof. Janina Onuki, por sus constantes palabras de aliento y orientaciones. A Giselle Castro, de la Secretaria del IRI, por el apoyo y la paciencia con las miles de solicitudes y procesos que implican la realización de un doctorado.

A la Familia Tequia, por las cuales siento un cariño inmenso y que han sabido apoyarme en todos los momentos de mi vida "brasilera" a pesar de la distancia. A la familia Machtura, que me ofreció su amor de forma incondicional en estos cuatro años y abrió las puertas de su hogar haciéndome sentir en casa, lejos de la mía. A Ana Lucia Gazzola y Sueli Pires, seres humanos maravillosos sin los cuales este doctorado no habría sido una realidad, agradezco su apoyo y amistad a pesar de la distancia.

A mis amigos de siempre y para siempre, Ana Paula Becker, Alejandra Tequia, Francys Pérez-Vera, Norelys Lucena Gaby Marrero, Alejandra Rodríguez, Dany Di Giacomo, Ana Saavedra, Adriana Terán, Alejandra Valdivieso y Tomas Mujica, gracias totales por ser presencias incondicionales y atemporales en mi vida. 
A la familia que escogí en São Paulo, que supieron darme apoyo y cariño en los peores momentos, cada uno tuvo un papel esencial en este recorrido, no tengo palabras para agradecer lo que Uds. significan para mí y lo que significaron en esta fase de mi vida, a mis hermanos de vida Matheus Soldi Hardt y Fernando Mouron, Isabela Mazão, Mariana Coelho, Francisco Urdinez, Lucio Salles, Uira Souto, Daniela Melo, Robert McDonell, Mariana Bernussi y Livia Martins, mi admiración y amistad incondicional para siempre.

A Rafael Machtura, que se convirtió en la razón para continuar, para no desistir, convirtiendo este período tan difícil en una de las épocas más felices de mi vida solo por tenerlo a mi lado, haberlo encontrado hizo que todo valiese la pena, sin ti nada de esto sería posible, te amo.

A mi familia, fuente eterna de inspiración y espina dorsal. A mis tíos por sus constantes palabras de aliento, a mis primos por su cariño y complicidad en todos los momentos de mi vida, a mi abuelita Rosa y Victoria de las cuales aprendí la fortaleza de comenzar una vida en otro país, mis valores y la importancia de los lazos que solo pueden ser generados a través del amor, a mi hermana, mi otra mitad, que supo levantarme cuando sentí que todo estaba perdido y creyó en mi durante todo este proceso. Finalmente, mis padres, a los que les debo todo y más un poco, a quien admiro como profesionales y como los seres humanos maravillosos que son, supieron darme la fortaleza para enfrentar este desafío a pesar de la distancia y los momentos difíciles, no existen palabras que expresen mi gratitud, solo puedo finalizar diciendo que esta tesis y lo que soy es por causa de ustedes. 


\section{RESUMEN}

"Cohesión social", es un concepto que se refiere al proceso permanente de desarrollo de un conjunto de valores y desafíos compartidos, vinculados con la búsqueda de igualdad de oportunidades dentro de una sociedad. Esta tesis busca evaluar el impacto de la cohesión social en la calidad democrática, por medio de una investigación cuantitativa y sistemática, demostrando su relevancia para el desarrollo económico, político y social, a través de una revisión profunda de la literatura, que reafirma la relevancia de las políticas sociales en estas dinámicas. El analisis sera realizado en 3 niveles. En primer lugar, un análisis global con la implementación de un modelo que vincula los dos conceptos centrales para 118 países. En segundo lugar, un nivel regional observando los procesos de cohesión en América del Sur y Europa del Este, regiones que sufrieron reformas sociales profundas durante los años noventa por medio de programas que buscaban disminución de las brechas sociales, evaluando sus características estructurales y como ha sido fortalecido el sentido de pertenencia a partir de políticas sociales. Finalmente, el nivel estatal por medio del análisis del caso venezolano, país caracterizado por procesos de polarización política y exclusión, los cuales se han incrementado durante los últimos 15 años, analizando el papel de las organizaciones de la sociedad civil (OSC) en este contexto, siendo consideradas como actores catalizadores de la participación ciudadana y la cohesión dentro de la sociedad. En definitiva los procesos de cohesión son el resultado de una responsabilidad compartida por los derechos y el bienestar de todos los actores que conforman una sociedad. Esta tesis busca enfatizar la relevancia de la dimensión social en la búsqueda de una democracia con calidad, por medio de un dialogo profundo con la literatura pertinente, tomando en consideración el comportamiento de un conjunto de países y regiones en un periodo de tiempo definido, análisis que se constituye como un ámbito teórico-metodológico que debe proseguirse en nuestra disciplina.

Palabras Clave: Cohesión Social, Democracia, Calidad Democrática, Desarrollo, Globalización. 


\begin{abstract}
"Social cohesion" is a concept that refers to the ongoing developing process of shared values and challenges related to the search for equal opportunity within a society. This thesis aims to assess the impact of social cohesion in the quality of democracy through a quantitative, qualitative and systematic research demonstrating its relevance to the economic, political and social development, through an exhaustive review of the literature, reaffirming the importance of the social policies in these dynamics. This analysis shall be conducted on 3 levels, first with a global evaluation by implementing a model that binds the two central concepts for 118 countries, secondly a regional evaluation of the cohesion processes in South America and Eastern Europe, regions that suffered deep social reforms during the nineties through programs seeking the reduction of social gaps, evaluating their structural characteristics and how it has been strengthened the sense of belonging through social policies, finally, the state level through the assessment of the Venezuelan case, a country characterized by processes of political polarization and exclusion, which have increased over the last 15 years, analyzing the role of civil society organizations (CSOs), actors being considered as catalysts for citizen participation and cohesion within the societies. In sum, cohesion processes are the result of a shared responsibility of rights and welfare of all the actors in a society, this thesis seeks to emphasize the importance of the social dimension in the search for a democracy with quality, through a deep dialogue with the relevant literature, taking into account the behavior of a group of countries and regions in a defined period of time, this type of analysis is a theoretical and methodological scope to be pursued in our discipline.
\end{abstract}

Keywords: Social Cohesion, Democracy, Quality of Democracy, Development, Globalization. 


\section{RESUMO}

"Coesão social" é um conceito que se refere ao processo permanente de desenvolvimento de um conjunto de valores e desafios compartilhados, vinculados á busca de igualdade de oportunidades dentro de uma sociedade. Esta tese procura avaliar o impacto da coesão social na qualidade da democracia por meio de una investigação quantitativa e sistemática demostrando sua relevância para o desenvolvimento económico, político e social, através de uma revisão profunda da literatura, reafirmando a relevância das políticas sociais nestas dinâmicas. A analise será realizada em 3 níveis, em primeiro lugar una análise global com a implementação de um modelo que vincula os dois conceitos centrais para 118 países, em segundo lugar um nível regional observando os processos de coesão na América do Sul e o Leste Europeu, regiões que sofreram reformas sociais profundas durante os anos noventa por meio de programas que buscavam a diminuição das brechas sociais, avaliando suas caraterísticas estruturais e como tem sido fortalecido o senso de pertencimento a partir das políticas sociais, finalmente, no nível estatal por meio da análise do caso venezuelano, país caraterizado por processos de polarização política e exclusão, os quais tem se incrementado durante os últimos 15 anos, por meio da observação do papel das organizações da sociedade civil (OSC) neste contexto, sendo consideradas como atores catalizadores da participação cidadã e a coesão dentro da sociedade. Em definitiva, os processos de coesão são o resultado de uma responsabilidade compartilhada pelos direitos e o bem-estar de todos os atores que conformam uma sociedade, esta tese enfatiza a relevância da dimensão social na busca de una democracia com qualidade, por meio de um dialogo profundo com a literatura pertinente, tomando em consideração o comportamento de um conjunto de países e regiões em um período de tempo definido, análise que se constitui como um âmbito teórico-metodológico que deve prosseguir-se na nossa disciplina.

Palavras Clave: Coesão Social, Democracia, Qualidade da Democracia, Desenvolvimento, Globalização. 
A mis padres, 


\section{LISTA DE SIGLAS}

ALOP- Asociación Latinoamericana de Organizaciones de Promoción

BID-Banco Interamericano para el Desarrollo

BM-Banco Mundial

BTI- Berthelsman Stiftung Institute Transformation Index

CAN- Comunidad Andina de Naciones

CEAAL- Consejo de Educación Popular de América Latina y el Caribe

CEPAL- Comisión Economica para América Latina

CESAP- Centro al Servicio de la Acción Popular

CE- Comunidad Europea

CEDICE- Centro de Divulgación del Conocimiento Económico para la Libertad

CIDH-Comisión Interamericana de Derechos Humanos

CISOR- Centro de Investigación Social

COFAVIC- Comité de Familiares de las Víctimas de los sucesos ocurridos entre el 27 de febrero y los primeros días de marzo de 1989

CONADI- Corporación Nacional de Desarrollo Indígena de Chile

CONAIE- Confederación de Nacionalidades indígenas en Ecuador

CONAPES- Consejo Nacional de Política Económica y Social

CONALCAM- Ministerio de Planificación del Desarrollo, Coordinadora Nacional para el Cambio

CONAPSO-Consejo Nacional de Política Social

DIBEN- Dirección de Beneficencia y Ayuda Social.

DESA-Departamento de Asuntos Sociales y Economicos 
ENRI-East- Interplay of European, National and Regional Identities: nations between states along the new eastern borders of the European Union

ESB- Estrategia Social Boliviana

EUROIDENTIDADES- Proyecto para la evolución de la Identidad Europea

EUROSTAT- Estadísticas Europeas

FMI-Fondo Monetario Internacional

FONCODES- Fondo de Cooperación para el Desarrollo Social del Perú

FSE- Fondo Social Europeo

FUNDEB- Fundo de Manutenção e Desenvolvimento da Educação Básica e de Valorização dos Profissionais da Educação

FUNDEPRO- Fundación para el Debido Proceso

IBGE- Instituto Brasilero de Geografia y Estadística

IDH-Índice de Desarrollo Humano

IFEX- Intercambio Internacional por la Libertad de Expresión

INAME-Instituto Nacional del Menor del Uruguay

INEFOP- Instituto Nacional de Empleo y Formación Profesional

INJ- Instituto Nacional de la Juventud de Chile

LODSPAN- Ley de Defensa de la Soberanía Política y Autodeterminación Nacional

MERCOSUR-Mercado Común del Sur

MCI-Memorandum Conjunto de Integración

NAPS- National Action Plan on Social Inclusion

NUPP-Núcleo de Pesquisas en Politicas Públicas de la Universidad de São Paulo 
OECD- Organización para la Cooperación y Desarrollo Económicos

OMC-Organización Mundial del Comercio

ONG- Organización no gubernamental

OSC- Organización de la Sociedad Civil

PANES- Plan de Emergencia Social

PHARE- Programa de Asistencia para la Restructuración de las Economías de Polonia y Hungría

PIB- Producto Interno Bruto

PLANE- Plan Nacional de Empleo de Emergencia de Bolivia

PNUD-Programa de las Naciones Unidas para el Desarrollo

PRIO- Peace Research Institute Oslo

PRODEPINE- Proyecto de Desarrollo de los Pueblos Indígenas y Negros del Ecuador

PROMUDEH- Ministerio de Promoción de la Mujer y el Desarrollo humano del Perú

PROPAIS- Programa de Lucha contra la Pobreza y Apoyo a la Inversión Social de Bolivia

PROVEA- Programa Venezolano de Educación-Acción en Derechos Humanos

RAIS- Red de asistencia e integración social del Uruguay

RAS- Red de Apoyo Social

REDLAB- Red Latinoamericana y del Caribe por la Democracia

RPS-DIC- Red de Protección Social- Desarrollo Integral Comunitario

SERNAM- Servicio Nacional de la Mujer de Chile 
TGN-Tesoro general de la Nación Boliviana

TIC-Tecnología de Información y Comunicaciones

UE-Unión Europea

UNESCO-Organización de las Naciones Unidas para la Educación la Ciencia y la Cultura

UNRISD- Instituto de Investigación de las Naciones Unidas para el Desarrollo Social USP-Universidad de São Paulo

IPYS- Instituto de Prensa y Sociedad 


\section{ÍNDICE DE GRAFICOS Y TABLAS}

Gráfico 1. Tendencia de la relación entre la cohesión social y la calidad de la democracia en América del Sur.

Gráfico 2. Tendencia de la relación entre la cohesión social y la calidad de la democracia en África Sub-sahariana.

Gráfico 3. Tendencia de la relación entre la cohesión social y la calidad de la democracia en Asia Central.

Gráfico 4. Tendencia de la relación entre la cohesión social y la calidad de la democracia en Europa del Este.

Gráfico 5. Tendencia de la relación entre la cohesión social y la calidad de la democracia en Medio Oriente.

Gráfico 6. Tendencia de la relación entre la cohesión social y la calidad de la democracia en Sudeste Asiático.

Gráfico 7. Tendencia de la relación entre la cohesión social y la calidad de la democracia en África del Sur.

Gráfico 8. Muestra del Nivel de Cohesión Social en Europa, período 1989-1995.

Gráfico 9. Muestra del Nivel de Cohesión Social en Europa, período 2009-2012.........

Gráfico 10. Periodos de Ingreso en la Unión Europea

Gráfico 11. Comportamiento del Nivel de Dificultad en Europa del Este.

Gráfico 12. Tendencia de la relación entre la cohesión social y la calidad de la democracia en Europa del Este.

Gráfico 13. Gasto público social como porcentaje (\%) del producto interno bruto (PIB) (América del Sur)

Gráfico 14. Índice de concentración de Gini para América del Sur.

Gráfico 15. Comportamiento del Indicador Nivel de Dificultad en América del Sur....

Gráfico 16. Tendencia de la relación entre la cohesión social y la calidad de la democracia en América del Sur.

Grafico 17: Comparación del Nivel de Dificultad. 204

Gráfico 18. Fortalezas y debilidades internas de la sociedad civil según actores clave. 226

Gráfico 19 Participación en redes de las organizaciones de la sociedad civil a nivel 
nacional e internacional ................................................ 233

Gráfico $20 \quad$ Participación en Redes Nacionales.......................................... 235

Gráfico $21 \quad$ Participación en Redes Internacionales................................. 236

Gráfico 22 Percepción de las alianzas entre las Organizaciones durante los últimos 5

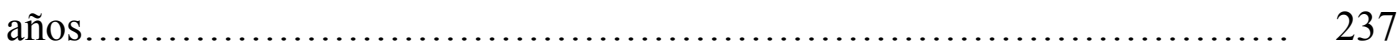

Gráfico 23 Apoyo gubernamental para la realización de sus objetivos.................. 237

Gráfico 24 Fuente de apoyo gubernamental para la realización de los objetivos de las organizaciones de la sociedad civil........................................ 238

Gráfico 25 Impacto de la polarización política en la relación entre las organizaciones de la sociedad civil y las instituciones públicas......................................................................

Gráfico 26 Red de organizaciones de la sociedad civil en derechos y participación ciudadana por grado (degree)

Gráfico 27 Vínculos de organizaciones de la sociedad civil en derechos y participación ciudadana con plataformas de redes nacionales e internacionales.

Tabla 1. Tipologías de la Cohesión Social............................................... 34

Tabla 2. Patrones de Causalidad......................................................... 40

Tabla 3. Resultado de los Modelos de Regresión......................................... 87

Tabla 4. Areas relevantes para la implementación de políticas sociales................... 99

Tabla 5. Dinámicas Cohesión/ Desarrollo............................................... 100

Tabla 6. Croacia: Relación Cohesión Social/ Calidad de la Democracia.................. 109

Tabla 7. Bulgaria: Relación Cohesión Social/ Calidad de la Democracia................. 112

Tabla 8. República Checa: Relación Cohesión Social/ Calidad de la Democracia.......... 114

Tabla 9. Estonia: Relación Cohesión Social/ Calidad de la Democracia................... 117

Tabla 10. Hungría: Relación Cohesión Social/ Calidad de la Democracia................. 120

Tabla 11. Letonia: Relación Cohesión Social/ Calidad de la Democracia.................. 123

Tabla 12. Lituania: Relación Cohesión Social/ Calidad de la Democracia................. 126

Tabla 13. Polonia: Relación Cohesión Social/ Calidad de la Democracia.................. 129

Tabla 14. Relación Cohesión Social/ Calidad de la Democracia........................... 132

Tabla 15. Eslovenia: Relación Cohesión Social/ Calidad de la Democracia................ 135

Tabla 16. Eslovaquia: Relación Cohesión Social/ Calidad de la Democracia.............. 137

Tabla 17. Argentina: Relación Cohesión Social/ Calidad de la Democracia................ 155 
Tabla 18. Bolivia: Relación Cohesión Social/ Calidad de la Democracia................ 160

Tabla 19 Gobierno FHC, estrategia de Desarrollo Social............................... 162

Tabla 20. Brasil: Relación Cohesión Social/ Calidad de la Democracia.................. 164

Tabla 21 Chile: Relación Cohesión Social/ Calidad de la Democracia.................... 168

Tabla 22 Colombia: Relación Cohesión Social/ Calidad de la Democracia.................. 170

Tabla 23 Ecuador: Relación Cohesión Social/ Calidad de la Democracia............... 176

Tabla 24 Paraguay: Relación Cohesión Social/ Calidad de la Democracia................. 180

Tabla 26 Perú: Relación Cohesión Social/ Calidad de la Democracia...................... 184

Tabla 27. Uruguay: Relación Cohesión Social/ Calidad de la Democracia................ 189

Tabla 28 Misiones Sociales implementadas durante el mandato de Hugo Chávez....... 194

Tabla 29 Venezuela: Relación Cohesión Social/ Calidad de la Democracia.............. 196

Tabla 30 Principales características de la Sociedad Civil Venezolana.................. 219

Tabla 31 Medidas de la Unión Europea para abordar las Amenazas a la Cohesión

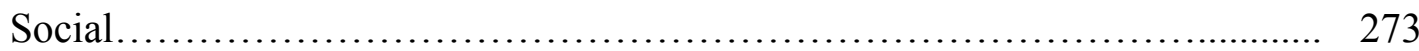

Tabla 32 Indicadores de cohesión social de la Unión Europea (indicadores “Laeken”) 275

Tabla 33 Documentos vinculados a la Cohesión Social dentro del Mercosur............... 277

Tabla 34 Documentos vinculados a la Cohesión Social dentro de la CAN................. 282 


\section{INDICE}

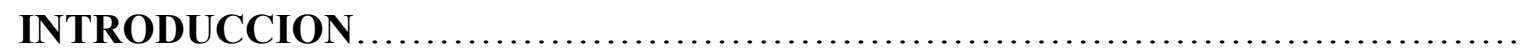

1. COHESIÓN SOCIAL Y CALIDAD DEMOCRÁTICA: VÍNCULOS, INTERACCIONES E IMPACTO EN LA CONFIGURACIÓN DE UNA NUEVA VISIÓN DE SOCIEDAD.

1.1 Cohesión Social, un asunto radicalmente humano, paradigma de una nueva visión de sociedad a través del sentido de pertenencia.

1.2 Cohesión Social, relaciones causales, dilemas y propuestas en el contexto contemporáneo.

1.3 Calidad Democrática y su trascendencia como estructura social.

1.3.1 Concepto de democracia como framework de desarrollo dentro de la visión sociopolítica

1.3.2 Democracia con calidad, objetivo de las sociedades contemporáneas........... 51

1.4 Niveles de Interacción entre la Cohesión Social y la Democracia..................... 58

1.4.1 Dimensión Política................................................... 58

1.4.1.1 Legitimidad..................................................... 59

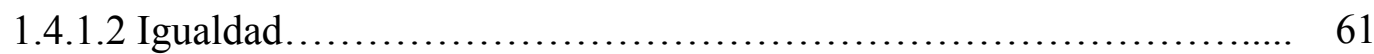

1.4.1.3 Principio de Ciudadanía........................................ 67

1.4.2 Dimensión Socioeconómica.............................................. 71

1.4.2.1 Desarrollo Económico.................................................. 71

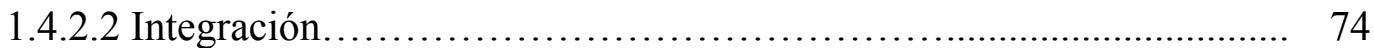

1.5 Impacto de la Cohesión Social en la Calidad Democrática, una evaluación cuantitativa 78

1.5.1 Operacionalización de la investigación......................................... 79

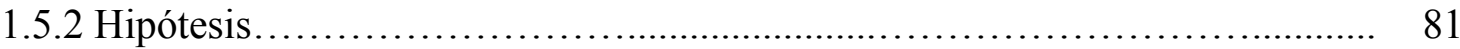

1.5.3 Datos y Metodología........................................................... 82

1.5.4 Test empírico: Resultados.................................................... 84

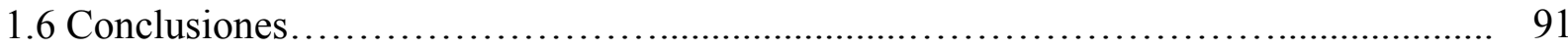

2. TIPOLOGÍAS REGIONALES, POLÍTICAS DE COHESIÓN SOCIAL Y SU IMPACTO EN LA CALIDAD DEMOCRÁTICA: EUROPA DEL ESTE Y SU 


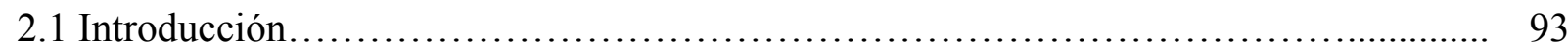

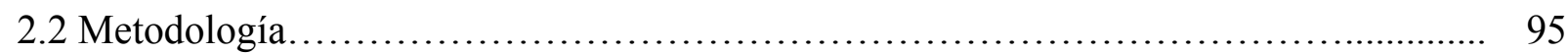

2.3 La Cohesión Social vista como política y su impacto en la sociedad................. 96

2.4 Europa del Este y el impacto de las políticas de cohesión social..................... 102

2.5 Especificidades de las políticas de cohesión dentro de los países de Europa del Este... 107

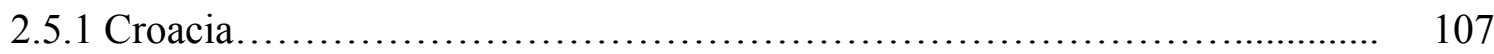

2.5.2 Bulgaria........................................................ 110

2.5.3 República Checa _................................................ 112

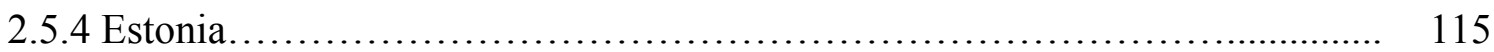

2.5.5 Hungría............................................................ 118

2.5.6 Letonia.............................................................. 120

2.5.7 Lituania................................................................... 123

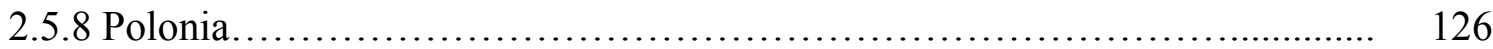

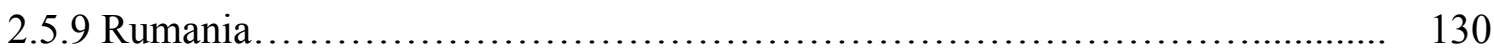

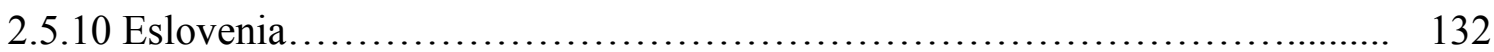

2.5.11 Eslovaquia.................................................... 135

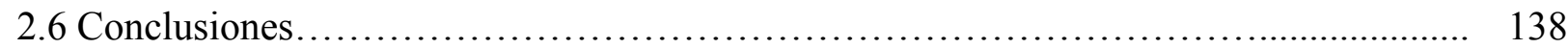

3. TIPOLOGÍAS REGIONALES, POLÍTICAS DE COHESIÓN SOCIAL Y SU IMPACTO EN LA CALIDAD DEMOCRÁTICA: AMÉRICA DEL SUR Y SU ENFOQUE SOCIAL

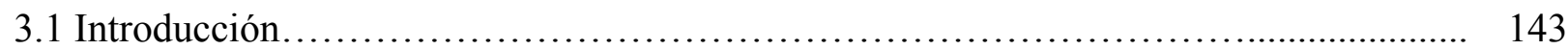

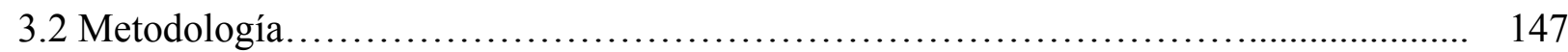

3.3 Políticas de Cohesión Social en la Región Suramericana........................... 148

3.4 Especificidades de las políticas de Cohesión Social en los países suramericanos....... 152

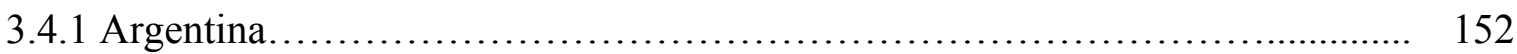




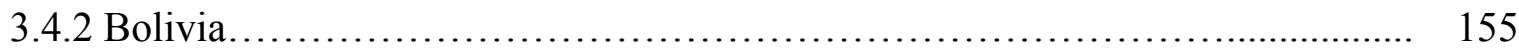

3.4.3 Brasil...................................................................... 160

3.4.4 Chile....................................................................... 165

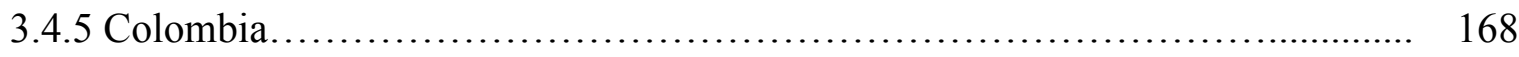

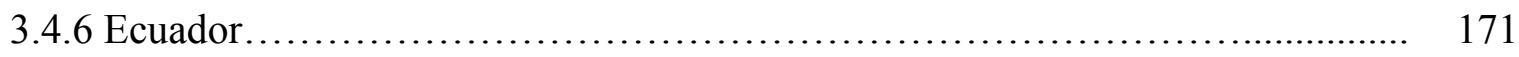

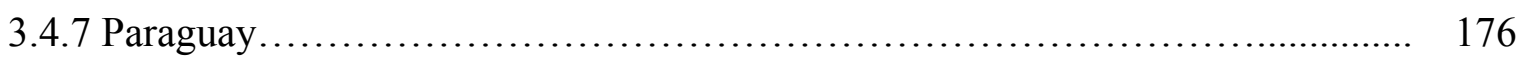

3.4.8 Perú....................................................................... 180

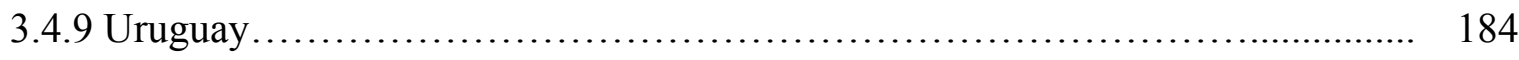

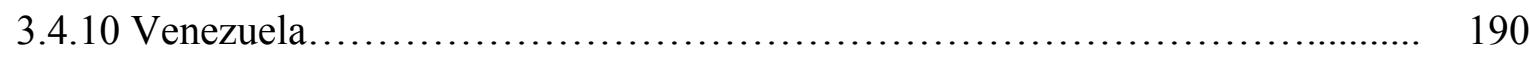

3.5 Síntesis de la implementación de las políticas sociales en América del Sur............. 196

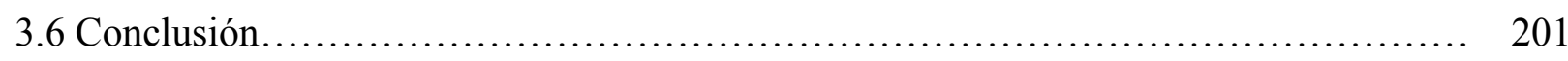

4. VULNERABILIDAD DEMOCRÁTICA Y COHESIÓN SOCIAL, CASO VENEZOLANO: EL PAPEL DE LAS ORGANIZACIONES DE LA SOCIEDAD CIVIL EN EL FORTALECIMIENTO CIUDADANO_................................ 209

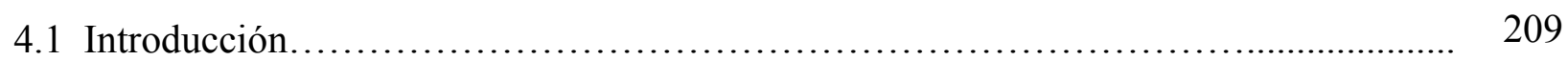

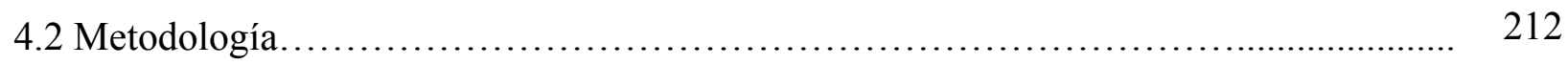

4.3 Sociedad civil organizada y su papel como promotora de la cohesión................... 213

4.4 Organizaciones de la sociedad civil como mecanismo de cambio social: Venezuela, polarización y exclusión ciudadana.

4.5 Participación Ciudadana y Derechos Civiles en Venezuela: Características, actuación

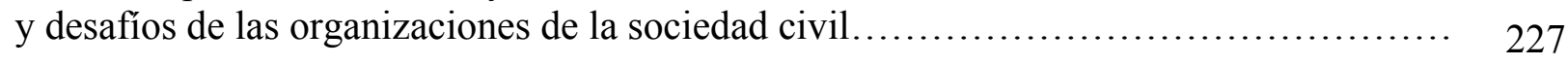

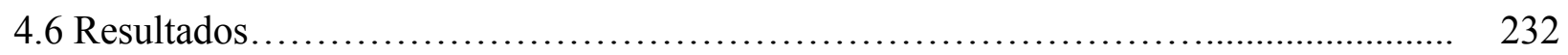

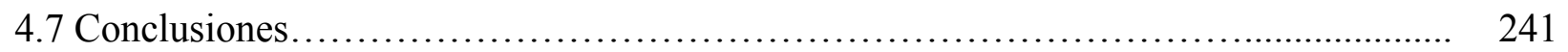

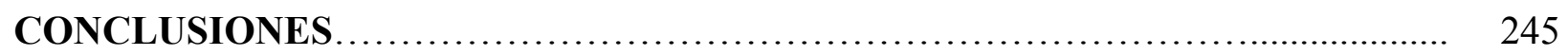

REFERENCIAS BIBLIOGRAFICAS ........................................ 251 
APENDICE 1- Revisión de las políticas de Cohesión Social en la Unión Europea.

APENDICE 2- Revisión de las políticas de cohesión en los Mecanismos de integración CAN y MERCOSUR ............................................................ 277

APENDICE 3- Entrevista Prof. Dr. José Briceño Ruiz............................. 284

ANEXO 1- INDICADOR NIVEL DE DIFICULTAD (BTI) CLASIFICADO POR REGIONES 


\section{INTRODUCCIÓN}

En este trabajo se aborda el papel de la cohesión social como proceso catalizador de la ética democrática, refiriéndose al proceso permanente de desarrollo de un conjunto de valores y desafíos compartidos, vinculados a la búsqueda de la igualdad de oportunidades dentro de una sociedad, haciendo énfasis en las dinámicas que buscan evitar el distanciamiento entre los miembros que las componen, tanto individuos como instituciones, suponiendo su participación en asuntos públicos dentro del espectro institucional y gubernamental.

Por medio de esta investigación se busca interpretar el impacto que estas interacciones individuo-sociedad generan en los sistemas nacionales, en un contexto caracterizado por procesos de globalización, que resultaron en un cambio radical en la forma en que se estructuran las comunicaciones e intercambios de los individuos en todos los niveles (culturales, sociales, políticos y económicos).

En este sentido, la cohesión es interpretada como un elemento base para la reinvención de los Estados nacionales dentro de estos procesos, en un escenario fragmentado, caracterizado por migraciones internacionales y urbanas, conflictos armados, así como transformaciones culturales, que afectan a las sociedades y sus estructuras.

En un primer momento, la investigación busca llenar vacíos académicos por medio del establecimiento de un dialogo entre las literaturas que observan a la cohesión social exclusivamente como un factor de la actividad humana, en términos culturales, económicos, políticos y sociales, así como aquella que la interpreta como las relaciones sociales verticales y horizontales entre los miembros de una sociedad que deben ser clasificadas de acuerdo a su naturaleza, campo explorado de forma superficial debido a su complejidad. Nosotros daremos relevancia a dos de sus elementos constitutivos, el capital social y las redes sociales, los cuales son ejecutados a partir de la integración y la participación ciudadana.

Existen muchos estudios que priorizan de forma exclusiva la influencia de elementos económicos y políticos en la consolidación democrática, con este trabajo se pretende dar relevancia al impacto que tienen las dinámicas de inclusión/exclusión de una sociedad, consideradas como factor influyente en estos procesos, siendo implementadas a partir de la participación ciudadana y el establecimiento de un sentido de pertenencia dentro de los individuos que conforman una sociedad. En este sentido, este trabajo pretende ser una contribución particular a partir del establecimiento de una estructura conceptual para estas dinámicas complejas y abstractas. 
En un segundo momento, se busca establecer el vínculo cohesión social/calidad de la democracia, por medio de la evaluación de cómo los gobiernos nacionales generan niveles de confianza social, a través de la implementación de políticas inclusivas y efectivas que se enfocan en las ventajas de asociación, explicando el compromiso cívico de los ciudadanos a partir de una idea de unidad social y el efecto que esto tiene en el fortalecimiento y la consolidación democrática.

Las políticas efectivas en términos de cohesión están caracterizadas por objetivos e instrumentos que buscan el desarrollo social a partir de la reducción de las vulnerabilidades y una mayor igualdad de oportunidades dentro de las sociedades, siendo consideradas como la herramienta más importante para modificar la distribución del bienestar dentro de las sociedades, de acuerdo con (ESPING-ANDERSEN, 1990) es una de las instituciones principales que intervienen en la producción y distribución de los bienes y mejoran el tejido social de la población.

Con estos objetivos y por medio de una indagación amplia en la literatura de este campo de investigación, a través de fuentes académicas así como de organizaciones internacionales vinculadas a esta área, se establece la hipótesis central a ser probada de forma tanto cualitativa como cuantitativa, definida como: los procesos de cohesión social a partir de la instrumentalización de políticas públicas efectivas tienen un impacto en el fortalecimiento de la calidad democrática. Por medio de la cual se define como nuestra variable independiente a la cohesión, la calidad de la democracia como nuestra variable dependiente y las políticas efectivas como variable interviniente de este proceso.

Al desarrollar nuestra hipótesis buscamos presentar un enfoque nuevo en la forma de entender los procesos sociales en el mundo contemporáneo y la influencia que estos ejercen en la consolidación del sistema político, definido como democracia a nivel mundial. Con base en este escenario, concentraremos nuestra tarea, en la deducción de indicadores, suficientemente significativos, para que traduzcan, de forma operativa, toda la complejidad de relaciones existentes entre la cohesión social y la calidad de la democracia para la concepción de un modelo teórico congruente en términos cuantitativos y cualitativos.

Investigaciones previas demuestran que los lazos sociales en un país, influencian el fortalecimiento de sus instituciones (Barro, 1999; Sorj; Martucelli, 2008, entre otros), es con base en estas propuestas que queremos demostrar que existe un vínculo fuerte entre estos dos conceptos a través de una evaluación cuantitativa, tomando en consideración el comportamiento 
de una serie de países durante un periodo de tiempo definido, análisis que constituye un ámbito teórico-metodológico que debe proseguirse en nuestra disciplina.

Una vez testada la hipótesis, nuestros objetivos serán analizar los siguientes aspectos a partir de dos niveles de análisis:

1. Macro-Comparación Regional: por medio de una evaluación de cómo se dieron los procesos de cohesión a partir de la implementación de políticas sociales en dos regiones específicas, Europa del Este y América del Sur.

2. Meso-Caso Nacional: evaluación del caso venezolano de cohesión a partir del análisis de la polarización de la sociedad y el impacto en las organizaciones de la sociedad civil en las dinámicas de inclusión.

Estos niveles de análisis refuerzan el papel de la cohesión dentro de una sociedad por medio de postulados que la colocan como catalizadora de una serie de procesos. Primero, que a mayor grado de cohesión social, más apoyo recibirán aquellas políticas públicas de carácter universal que tienen resultados sociales positivos. Segundo, cuanto más cohesionada sea una sociedad, más aceptabilidad de las normas de conducta y valores compartidos de las instituciones sociales. Tercero, mayores niveles de cohesión social conllevan a más participación en la sociedad civil y refuerzan el capital social.

Tomando en consideración estas relaciones causales, la estructura de la investigación estará dividida en cuatro capítulos que buscaran explicar los niveles en los cuales debe ser interpretada la cohesión social y el impacto que esta tiene a nivel individual/ regional/ internacional. El primer capítulo busca dar respuesta a las aproximaciones teóricas de los dos conceptos centrales de nuestra investigación, cohesión y democracia, por medio de una revisión de la literatura definiendo los vínculos e interacciones entre ambos objetos.

La cohesión dentro de este primer capítulo será interpretada como un asunto base para los paradigmas humanos, por medio de un análisis de las estructuras abstractas que se vinculan al sentido de pertenencia de los individuos. Esta estructura conceptual se relaciona a la idea de una sociedad que ofrece oportunidades para el desarrollo de las capacidades de todos sus miembros de forma colectiva, lo cual implica una serie de dimensiones mucho más profundas que afectan las interacciones entre los actores, inclusive, aquellas que se refieren al impacto en la institucionalidad de los Estados, presentadas a lo largo de esta investigación.

En lo que se refiere a la calidad democrática esta será evaluada desde una perspectiva multidimensional, tomando en consideración los aspectos procedimentales o institucionales y a 
su vez evaluando los aspectos sustantivos vinculados a la idea de valores. En el mundo contemporáneo, el fortalecimiento institucional ha contado con el papel relevante de la sociedad civil. En lo que se refiere a la calidad democrática, es lo que podemos definir como la vinculación ciudadana en los asuntos públicos, aspecto que toma nuestro interés, ya que existe una reinterpretación de la libertad del individuo dentro de la sociedad, esto como resultado de los procesos de globalización, en conjunto con una cultura cívica de participación y responsabilidad ciudadana.

Dentro del análisis teórico de este capítulo se establecerán las interacciones de ambos conceptos a través de dos dimensiones: la política y la socioeconómica. Dentro de la dimensión política, la cohesión se interpreta como cohesión ciudadana, ya que el componente que conforma las actitudes o elementos subjetivos debe estar compuesto por indicadores, como la confianza en figuras públicas, junto con la confianza en las principales instituciones políticas, sociales y aquellas de otra índole. Por lo tanto, el estado y la sociedad son los actores principales tanto en la generación de los procesos de cohesión como los democráticos (Dickes et al 2010; Browne, 2013; Jensen, 1998). La forma en que se producen estas relaciones es objeto de esta evaluación.

Estas interacciones, dentro de la dimensión política, serán evaluadas a partir de tres ejes conceptuales. En primer lugar, aquel vinculado a la legitimidad, aspecto constituido como una de las bases de la estabilidad de los sistemas democráticos, por medio de la promoción de la estabilidad de las relaciones de autoridad en la sociedad y de poder en el espacio político, por eso su relevancia. En segundo lugar el principio de igualdad, el cual debe ser interpretado como un consenso universal sin el cual no se generan procesos de cohesión, por lo cual, la búsqueda al acceso a los derechos humanos, el bienestar material, la participación en el espacio público y el acceso a la información, son elementos fundamentales para el desarrollo adecuado y la participación de los individuos dentro de la sociedad. En tercer, y último lugar, tenemos al principio de ciudadanía como último eje de análisis, vinculado a la idea de participación del individuo en la definición de las reglas propias de su entorno, principalmente, en términos de la estructuración del estado en sus diversas dimensiones y el establecimiento de un sentido de pertenencia con su comunidad (CEPAL, 2007)

La dimensión socioeconómica de las interacciones cohesión/democracia será evaluada tomando en consideración el contexto de desigualdades sociales, factor que dificulta la práctica de una verdadera ciudadanía capaz de accionar los mecanismos que conforman la democracia. Para su comprensión serán evaluados dos ejes, en primer lugar el desarrollo económico, ya que 
este ejerce una acción importante en la caracterización del tipo de régimen político y su capacidad de sustentabilidad en el tiempo, alterando la estructura de estratificación social, debido a que el crecimiento económico tiende a la generación de procesos inclusivos.

El segundo eje en el cual se evaluaran estas interacciones es la integración, debido a que aspectos como normas, creencias y valores constituyen una conciencia colectiva, o una manera común de entender y actuar en el mundo, esta conciencia colectiva de forma conjunta une a los individuos y se vincula a ideas de concertación, siendo necesaria para el buen funcionamiento de las democracias, por medio de la participación activa de la sociedad civil.

Con base en este contexto teórico se comprobará, a través de una evaluación cuantitativa, el modelo que busca interpretar el impacto de la cohesión en la calidad de la democracia, a partir de indicadores estadísticos desarrollados por Berthelsmann-Stiftung Institute a través del Transformation Index, representando de forma operativa la complejidad de la investigación. Esto será realizado a partir de la evaluación de 118 paises en vías de desarrollo. Tomando de forma epistemológica la teoría de la sociedad civil que establece que la cohesión de una sociedad produce confianza social y cooperación, resultando en un compromiso cívico, el cual se constituye en una base para la promoción de la democracia.

El segundo capítulo buscará evaluar las políticas de cohesión implementadas por los estados, a partir de un análisis de la región de Europa del Este, estableciendo la sub hipótesis de que países con políticas sociales multidimensionales vinculadas a la cohesión presentan mejoras en los indicadores de calidad democrática, definiendo la estructura de cohesión como política pública y como estas han sido implementadas dentro de los estados evaluados, observando si las características coyunturales tienen una influencia en la efectividad y alcance de las políticas de cohesión, así como del impacto de estas políticas en términos democráticos. Europa del Este se considera relevante debido a que se dio una transformación completa de su status quo con el fin de la Unión Soviética y posteriormente con el ingreso dentro de la Unión Europea, que trajo consigo un foco en asuntos sociales.

En el tercer capítulo se evalúan las políticas de cohesión implementadas en América del Sur, que se considera una región relevante en términos de cohesión debido a que presenta características de homogeneidad cultural y lingüística, en términos históricos se observa una ausencia de voluntad política para mejorar la implementación efectiva de políticas sociales inclusivas y se considera un objeto de estudio interesante para la interpretación de las dinámicas sociales, en este sentido se presentan sub hipótesis para su interpretación, en primer lugar que 
países con políticas sociales multidimensionales vinculadas a la cohesión presentan mejoras en los indicadores de calidad democrática. En segundo lugar que América del Sur presenta un sentido de pertenencia e identidad cultural robustos proporcionando ventajas a la hora de implementar políticas de cohesión social y finalmente que las brechas sociales son el principal obstáculo para alcanzar desarrollo de la cohesión dentro de una sociedad.

América del Sur y Europa del Este son regiones de análisis importantes en términos de cohesión social ya que sufrieron transformaciones económicas y políticas, así como reformas sociales profundas durante los años noventa, por medio de programas que buscaban la disminución de las brechas sociales. En este sentido, la revisión teórica realizada toma en consideración la evolución de los procesos de desarrollo, las disparidades regionales y la implementación de políticas sociales efectivas.

Para esto, serán evaluadas las particularidades específicas de cada país vinculadas al capital social, diversidad cultural y el contexto geográfico, elementos que afectan los niveles de la cohesión social. Generando, en algunos casos, efectos positivos que deben ser interpretados como ventajas comparativas, observando la forma en que se ven afectados los procesos de desarrollo por medio de estas transformaciones.

Este análisis pretende ser un aporte a la visión que privilegia el análisis de políticas inclusivas que generan desarrollo dentro de las sociedades. Finalmente, sera realizada una comparación para definir aquellos aspectos que crean ventajas de una región frente a otra en términos de estructuras, lo que permitirá una diferenciación del estado de la cohesión social en diferentes países y una descripción de las diferentes tendencias que se observan a lo largo del tiempo, en dimensiones específicas y por medio de una clasificación general a nivel regional.

Mediante el análisis comparativo de políticas de cohesión social se busca llegar a acuerdos en cuanto a las modalidades más adecuadas para su implementación, por medio de una evaluación de los estándares de efectividad, así como los efectos en términos estructurales. Al establecer comparaciones entre diferentes países, se puede lograr una clasificación de las experiencias exitosas y como estas pueden ser replicadas, ya que las regiones aun presentando características diferentes, se ven afectadas por problemas similares.

El tercer, y último, capítulo analiza un caso específico de dinámicas de cohesión, para lo cual se seleccionó el caso Venezolano, que presenta un contexto atípico, en donde prevalece la polarización política y en consecuencia procesos de exclusión, los cuales se han incrementado durante los últimos 15 años, por lo tanto se establece la hipótesis de que el entorno venezolano, 
caracterizado por el conflicto social, ha reforzado el papel activo de las organizaciones de la sociedad civil (OSC), generando un fortalecimiento de sus lazos, por medio de un aumento en el diálogo y articulación entre estas organizaciones, resultando en procesos cohesivos.

En este sentido, se parte del postulado que establece que, los procesos de cohesión, son el resultado de una responsabilidad compartida por los derechos y el bienestar de todos los actores que conforman una sociedad. En este escenario, las organizaciones de la sociedad civil se consideran como un objeto de análisis relevante, debido al papel que ejercen dentro de las sociedades, vistas como causa y efecto de cambios democráticos y sociales, ya que fomentan un desarrollo equitativo y contribuyen a la realización de políticas públicas más efectivas, plurales y eficientes.

El análisis implementado busca evaluar las organizaciones de la sociedad civil en el área de participación y derechos ciudadanos, con el objetivo de develar la estructura y la composición de esta red específica, en el contexto de polarización política venezolana, por medio de relaciones tanto de contenido como de forma, analizando la estructuración de los lazos de estas organizaciones a partir del diálogo y la articulación, resultando en procesos cohesivos dentro de la sociedad, teniendo un papel fundamental como catalizadoras de la participación ciudadana. Este tipo de investigación, de redes socio métricas, ha sido profundamente influenciada por el campo de la Sociología, por medio de la suposición de que la participación de los actores dentro de un sistema y las relaciones surgidas de estas interacciones presentan características relevantes (Waserman; Faust, 1994).

Es importante resaltar que esta investigación requirió de una estructuración compleja para poder interpretar los procesos de cohesión y la relevancia de las dinámicas sociales en el mundo contemporáneo, las cuales, deben ser vistas como un elemento relevante a la hora de formular políticas. Esta estructura se caracteriza en primer lugar por la comprobación de nuestra hipótesis central en el primer capítulo a partir de una evaluación mundial del impacto de la cohesión en la calidad de la democracia por medio de un modelo, lo que permite realizar la investigación desarrollada en el segundo y tercer capítulo por medio de la observación de la implementación de políticas de cohesión en dos macro regiones Europa del Este y América del Sur y finalmente realizar un Case Study en el cuarto capítulo evaluando el contexto de cohesión en el caso Venezuela, que presenta características relevantes y atípicas en lo que se refiere a procesos de inclusión/exclusión, la estructura implementada evalúa el nivel macro de forma prioritaria para posteriormente tomar estos resultados como base para el análisis meso y micro. 
En definitiva, el objetivo normativo de este trabajo será la búsqueda de un camino para consolidar una cultura cívica y democrática, a través del compromiso de redes cívicas e institucionales, a nivel individual, estatal e internacional, por medio de la interpretación de los procesos sociales establecidos a partir de lazos, fortaleciendo valores y desafíos, compartidos por medio de la reciprocidad entre los individuos, estableciendo que, tanto la cohesión social como la democracia, son aspectos sine qua non para el desarrollo y bienestar social, siendo un proceso que se encuentra en constante evolución. 


\section{COHESIÓN SOCIAL Y CALIDAD DEMOCRÁTICA: VÍNCULOS, INTERACCIONES E IMPACTO EN LA CONFIGURACIÓN DE UNA NUEVA VISIÓN DE SOCIEDAD}

La idea de cohesión social trata de cuestiones transversales y complejas, que poseen gran amplitud, lo que puede ser definido como el principal problema a la hora de establecer una definición específica, principalmente en lo que se refiere a su impacto en la democracia, el concepto se encuentra vinculado a la idea de "reducir las brechas en materia de exclusión y crear un sentido de pertenencia de los individuos a la sociedad, fundado en el goce efectivo de ciudadanía y en una ética democrática” (CEPAL, 2007a).

Pero más allá de fundarse en la ética democrática, la cohesión social debe ser vista como catalizador de la misma. Muchas veces un análisis de este tipo confronta lo que podemos denominar como trade-off entre la capacidad de producir generalizaciones y desarrollar descripciones, visión que se aplica a este tipo de concepto, con el objetivo de facilitar la evaluación que se desarrollara en este trabajo la cohesión será interpretada como el conjunto del interacciones verticales y horizontales entre los miembros de la sociedad, compuestas por una serie de actitudes y normas que incluyen confianza, sentido de pertenencia, así como sus manifestaciones comportamentales.

Tomando esta definición como base nuestro enfoque trata lo referente a las dinámicas que se establecen dentro de las sociedades y que buscan evitar el distanciamiento social entre los miembros que las componen, tanto individuos como instituciones, esto supone que tales miembros se involucren en las cuestiones públicas, tanto gubernamentales como aquellas referidas a otras áreas del espectro institucional y el impacto que estas dinámicas individuosociedad generan en los sistemas democráticos ${ }^{1}$.

Actualmente la desigualdad es una de las mayores amenazas a la legitimidad de la democracia (HARDY, 2014) ratifica que esto debido a que refleja "una muestra de la cundida desafección política de la ciudadanía y su mala evaluación de las instituciones democráticas, especialmente de partidos y parlamentos". Es con base en una ciudadanía, en la cual los individuos sean verdaderos poseedores de derechos, que se deben construir sociedades inclusivas, estableciéndose una igualdad en el acceso a los derechos, evitando de esta

\footnotetext{
${ }^{1}$ Siendo considerado este tipo de sistema dentro de una connotación positiva, es importante destacar que referirse en estos términos en lo que se refiere al concepto de democracia, genera polémica. "Cuando un término se torna tan universalmente santificado, como lo es la democracia actualmente, comienzo a indagar si lo mismo significa algo, al significar tantas cosas" (T.S ELIOT apud HUNGTINGTON, 1989, p. 12 )
} 
forma las segregaciones que segmentan nuestras sociedades, así como la falta de incentivos para la participación ciudadana. Dichos elementos se constituyen como una verdadera amenaza a la cohesión social.

La literatura relacionada al tema de Cohesión Social la identifica con diversas dimensiones en términos económicos, políticos, sociológicos, históricos e inclusive biológicos, que buscan explicar cómo este tipo de dinámicas generan un sentimiento de pertenencia dentro de las sociedades. Aspectos que se deben considerar a la hora de establecer una vinculación con la calidad democrática, ya que, aun cuando la base en la cual se desarrolla nuestro análisis es política, debe estar contextualizada dentro de este alcance.

Por medio de este capítulo se busca evaluar el impacto de la cohesión social en la calidad de la democracia, tanto a nivel cualitativo como cuantitativo, definiendo a la cohesión como un proceso interno de las sociedades caracterizado por a las interacciones verticales y horizontales entre los miembros de la sociedad, determinados por un conjunto de actitudes vinculadas a la idea del sentido de pertenencia, siendo interpretada como nuestra variable independiente. La calidad de la democracia por su parte, se refiere al resultado de una ordenación institucional a través de mecanismos estructurales que funcionan correctamente, un régimen ampliamente legitimado $\mathrm{y}$, por lo tanto, estable, del cual los ciudadanos están plenamente satisfechos (MORLINO, 2012), esta estructura se interpretara como la variable dependiente de nuestra hipótesis, la cual establece que sociedades cohesionadas ejercen un impacto positivo en la calidad de la democracia.

Con el objetivo de realizar esta evaluación que busca comprobar la hipótesis presentada, este capítulo estará definido a partir de una evaluación teórica y empírica en dos niveles, en primer lugar una revisión amplia de la literatura que vincula ambos conceptos a partir de la siguiente estructura: 1) Interpretación de la complejidad de las dimensiones del concepto de Cohesión Social a nivel mundial 2) Establecimiento de la cohesión en términos de contribución o implicaciones para el crecimiento, bienestar y desarrollo de la sociedad 3) Interpretación del concepto de democracia dentro de la visión sociopolítica y su vinculación con el desarrollo 4) Definición de la calidad de la democracia como objetivo a ser alcanzado por las sociedades contemporáneas y finalmente 5) Establecimiento de la estructura de dialogo entre estos dos conceptos a partir de la dimensión política y socioeconómico.

En segundo lugar se realizara una evaluación empírica para testar nuestra hipótesis tomando como base los debates teóricos presentados anteriormente, por medio de la 
implementación de un modelo que refleja la propuesta de investigación, estableciendo que la falta de cohesión social ejerce un impacto sobre la calidad de la democracia, con el objetivo de operacionalizar la propuesta teórica a través de resultados estadísticos, usando la base de datos desarrollada por el Bertelsmann Stiftung Institute, específicamente, los datos contenidos en el Transformation Index (BTI) para 118 países, por medio de la utilización de dos indicadores, Nivel de Dificultad, que mide la falta de cohesión dentro de los países y Calidad de la Democracia.

Esta investigación pretende ser una herramienta a los estudios vinculados a las dinámicas sociales, proporcionando un nuevo enfoque en la interpretación de los factores que ejercen un impacto en el establecimiento de democracias con calidad, ya que se parte de la idea de que para su constitución es necesario dar respuesta a los asuntos relacionados a la desigualdad con el objetivo de generar una sociedad inclusiva, que produce individuos con capacidad de participación ciudadana y tolerancia dentro de los procesos políticos. En este sentido la cohesión debe ser vista como un proceso que busca consolidar la ciudadanía de forma plural, reduciendo las desigualdades, siendo interpretada como el punto de encuentro de la democracia social y la democracia política" (CUELLAR, 2009), donde los seres humanos tienen la capacidad de influir en los procesos de decisión que afectan sus vidas, estableciendo un equilibrio en lo que se refiere al papel de los individuos dentro de la polis.

\subsection{Cohesión Social, un asunto radicalmente humano, paradigma de una nueva visión de sociedad a través del sentido de pertenencia}

Al presentar el término radical estamos haciendo mención a un asunto que alcanza la base, que afecta la esencia y los fundamentos de un asunto determinado, en este caso estamos refiriéndonos a los seres humanos. El enfoque humanista, establece que los individuos se constituyen como el elemento insustituible de todo proceso que involucra progreso. De acuerdo a lo colocado por (ORDUNA, 2012) son los que conectan, conviven y se relacionan para generar una comunidad cohesionada en la que es posible participar y, por fin, es a las personas que se deben dirigir las acciones que pretendan elevar las condiciones de vida de un territorio. 
El interés en la cohesión social es consecuencia de la crisis contemporánea que se presenta a nivel de los lazos sociales ${ }^{2}$ y las crisis de solidaridad, principalmente frente a una preocupante realidad económica y política, donde las viejas estructuras de protección social están en crisis o no son capaces de hacer frente a un marco social complejo, en el que nuevos conflictos étnicos y sociales se generan debido a la migración y los procesos globales. En este contexto, el uso del concepto de cohesión social es una respuesta a los cambios estructurales y sus consecuencias (GIARDIELLO, 2014)

Frente a este escenario la cohesión social se constituye como una definición compleja, compuesta por diversas facetas. A su vez siendo el atributo de grupos y no exclusivamente de individuos. De acuerdo con BERNARD (1999) este es un "cuasi-concepto", es decir, una construcción mental híbrida construida dentro del escenario político y, al mismo tiempo, basado en el análisis de datos establecidos dentro del contexto. Durante el desarrollo de nuestro trabajo será desarrollada la definición establecida por (CHAN; TO; CHAN, 2006) por medio de la cual la cohesión social es estructurada como:

"el estado de asuntos relacionados tanto a las interacciones verticales como horizontales entre los miembros de la sociedad, siendo caracterizadas por un conjunto de actitudes y normas que incluyen confianza, sentido de pertenencia, así como la voluntad de ayudar y participar, así como sus manifestaciones comportamentales"3 (Traducción propia)

En este concepto, la cohesión social es definida como un atributo, no siendo considerada como un proceso interno de la sociedad, el cual es implementado a través de diversas dimensiones, tanto verticales/ horizontales así como objetivas/subjetivas. Lo más relevante se refiere al hecho de que su unidad de análisis se refiere a una nación geográfica y políticamente definida en la cual el Estado es el nivel institucional más adecuado para que la cohesión social sea observada y estudiada (GIARDIELLO, 2014).

Por medio de la aplicación de este concepto se incluyen las políticas de inclusión y de acceso a derechos, a su vez se otorga primacía a los procesos que conducen a la creación de vínculos sociales y rescata la incidencia en la cohesión de los aspectos más profundos de la vida

\footnotetext{
2 "La crisis de la conceptualización del lazo social como sociabilidad tutelada abre un nuevo espacio de reconocimiento a los vínculos interpersonales que, insuficientes en sí mismos, permiten comprender empero cómo se diseña una geografía de ayuda mutua y de solidaridades de un nuevo tipo, que no se basa más solamente en lazos comunitarios o identidades colectivas fijas, sino lo hace también cada vez más sobre vínculos afectivos, electivos o tradicionales revisitados (familia, jóvenes, inmigrantes, etc.) en los cuales las nuevas tecnologías tienen una función importante" (SORJ; MARTUCCELLI, 2008)

3 "social cohesion is a state of affairs concerning both the vertical and horizontal interactions among members of a society, as characterized by a set of attitudes and norms that include trust, a sense of belonging, and the willingness to participate and help, as well as their behavioral manifestations" (Chan et al, 2006, pag 4)
} 
social (actitudes, valores), que se relacionan al sentimiento de pertenencia, fundamental a la hora de hablar en términos culturales e históricos de una sociedad, siendo estos los elementos esenciales en lo que se refiere al establecimiento de las bases del concepto .

El universo semántico de la cohesión social muestra los siguientes términos relacionados: i) el capital social, que remite al acervo de redes y lazos existentes entre los distintos actores sociales; ii) la integración social, que alude al acceso de los ciudadanos a niveles básicos de bienestar, la exclusión social; iii) que expresa los procesos y mecanismos de acumulación de desventajas que conducen a la desvinculación y la privación social, y iv) la ética social, que subraya la importancia de la comunidad de valores y la solidaridad (Ídem). Todos estos elementos reflejan características de las sociedades contemporáneas y la naturaleza de la cohesión.

Dentro del análisis de (BERNARD, 1999) la cohesión social presenta dos facetas, la primera se refiere a los dominios de la actividad humana (económica, política y sociocultural) y la segunda distingue las relaciones sociales de acuerdo a su naturaleza:

Tabla 1: Tipologías de la Cohesión Social

\begin{tabular}{|l|l|l|}
\hline \multirow{2}{*}{ Áreas } & \multicolumn{2}{|l|}{ Naturaleza de las relaciones } \\
\cline { 2 - 3 } & Formal/Actitudes & Substancial/Comportamental \\
\hline Económica & $\begin{array}{l}\text { Inserción/ Exclusión } \\
\text { Una capacidad compartida de } \\
\text { mercado, particularmente lo que } \\
\text { se refiere al mercado laboral }\end{array}$ & $\begin{array}{l}\text { Igualdad en las oportunidades e } \\
\text { igualdad de condiciones }\end{array}$ \\
\hline Política & $\begin{array}{l}\text { Legitimidad/Ilegitimidad } \\
\text { Manutención de instituciones } \\
\text { públicas y privadas que actúan } \\
\text { como mediadoras }\end{array}$ & $\begin{array}{l}\text { Participación en el manejo de los } \\
\text { asuntos públicos, tercer sector } \\
\text { (en oposición al desencanto } \\
\text { político) }\end{array}$ \\
\hline Socio-cultural & $\begin{array}{l}\text { Aceptación/ Rechazo } \\
\text { Pluralismo tanto en los hechos } \\
\text { como una virtud, por ejemplo la } \\
\text { tolerancia en las diferencias }\end{array}$ & $\begin{array}{l}\text { Compartir valores comunes, } \\
\text { sentido de pertenencia a una } \\
\text { misma comunidad. }\end{array}$ \\
\hline
\end{tabular}

Fuente: Bernard, 1999

Dentro de estas dos facetas presentadas por (BERNARD, 1999) vemos que los atributos mencionados anteriormente son específicamente colocados en las sociedades no en individuos, 
estableciendo que, el concepto de cohesión social, es multidimensional, por lo cual no debe ser evaluado a través de un indicador compuesto único, ya que el espectro que cubre es mucho más extenso, incluyendo normas y creencias, que evolucionan en el tiempo y varían de acuerdo al nivel de análisis que es aplicado. Todas estas características, por lo general, son evaluadas de forma igualitaria, ya que el impacto que ellas tienen es, generalmente, proporcional dentro de las sociedades.

Como fue presentado por (JENSON, 1998) estas dimensiones de la cohesión social, generalmente, reflejan un proceso más que una condición en sí misma. El autor en este respecto elaboró una serie de dimensiones para su evaluación: 1) Afiliación/Aislamiento, refiriéndose a los valores comunes y sentimiento de pertenencia; 2)Inserción/ Exclusión, oportunidad de participar en el mercado laboral; 3) Participación/ Pasividad, participación en los asuntos públicos y 5) Legitimidad/Ilegitimidad, como la diversidad de instituciones que representan a los individuos y sus intereses.

(RAWLS, 1999) la define de forma concisa, como una medida en la que los miembros de una sociedad o sistema social tienden a compartir valores, en los cuales se presenta un sentido de pertenencia o se observa la capacidad de trabajar en conjunto. Analizando esta definición de forma estructural, no responde a las preguntas que se refieren a la pluralidad de condiciones, intereses e identidades existentes en las sociedades que, a nuestro modo de ver, son fundamentales, principalmente, a la hora de analizar su aplicación.

Como fue mencionado anteriormente, la estructura en la que se dan estas relaciones en los diferentes ámbitos de la cohesión social, en las cuales existen relaciones pasivas (aptitudes), como activas (comportamiento), refiriéndose a las conductas por parte de los tomadores de decisión, interpretados como los estados a nivel macro, así como por parte de los individuos (micro), que conforman las sociedades. En el nivel individual, la cohesión social se genera a partir de la construcción y establecimiento de una estructura de derechos (humanos, económicos, políticos, sociales y culturales), fundamentada en las relaciones primarias (familia, comunidad ${ }^{4}$ ), generando a su vez el fomento de la participación ciudadana, potenciando su ejercicio dentro de los sistemas democráticos. Esta estructura está basada en el enfoque humanista, definiendo a tales sistemas como parte del proceso productivo y objetivo final de un proceso de desarrollo:

\footnotetext{
4 Comunidad hace referencia, aquí, al colectivo sociodemográfico formado por sujetos y grupos (primarios y secundarios) que establecen entre ellos relaciones sociales (individuo-individuo, individuo grupo y grupo-grupo) para conseguir el bien común (el bienestar, la mejora de la calidad de vida) (ORDUNA, 2012)
} 
"los seres humanos son el recurso principal de toda comunidad. Dentro del marco provisto de los recursos naturales, los ciudadanos de una comunidad producen la riqueza, organizan y mantienen las instituciones, prestan servicios, dan la pauta progresista o conservadora y engendran la fuerza moral y los anhelos de la comunidad." (WARE apud ORDUNA, 2012, p.24)

Por otro lado, el nivel macro se fundamenta, a partir de la teoría neofuncionalista ${ }^{5}$,en términos de integración, cuyas directrices principales colocan en las autoridades centrales un papel fundamental, determinando el camino a ser seguido por los Estados y criticando la división existente entre las cuestiones técnicas-sociológicas y políticas, ya que ambas componen un conjunto homogéneo (HAAS, 1964). Su enfoque se realiza a través del spillover, que se refiere, desde una visión más política, a “el mecanismo que permite incrementar tanto el alcance limitado a las decisiones que tienen como objetivo expandir a otros ámbitos las ventajas obtenidas en un sector determinado como el nivel de acción para el conjunto de los compromisos adquiridos" (SCHMITTER apud (RODRÍGUEZ MANZANO, 1996).

Tomando en consideración los conceptos y estructuras mencionados anteriormente (deben ser revisadas las vertientes de las cuales forman parte), podemos definir dos principales, la primera sociológica como establecido por (PAHL, 1991), (BERGER, 1998) y (GOUGH; OLOFSSON, 1999), entre otros y en segundo lugar la vertiente política/económica a nivel macro presentada por diversos organismos internacionales tales como CEPAL, BID, Banco Mundial y OECD.

La visión sociológica se vincula a las ideas presentadas por Emile (DURKHEIM, 1989) y Parsons (1967), los cuales establecen lo que podemos llamar como el origen del análisis de la cohesión social como concepto fundamental en la estructura social. Esta tradición sociológicaacadémica considera a la cohesión social en términos macro-estructurales, siendo ejecutada una evaluación dentro de los complejos y elevados procesos de división del trabajo, así como la diferenciación funcional. Posteriormente se incluyen asuntos más amplios en esta área de análisis, tales como, la integración social, estabilidad y desintegración, los vínculos existentes entre integración social y exclusión social, así como los enfoques centrados en la estructura en contraposición a aquellos centrados en los actores (CHAN; TO; CHAN, 2006)

En esta corriente sociológica, otra visión relevante se refiere al estado de las redes primarias sólidas presentado por (LOCKWOOD, 1999), el cual, analiza la cohesión social a través de un micro nivel y la integración cívica (macro nivel), como dos niveles diferentes que

\footnotetext{
${ }^{5}$ Basada en los análisis realizados por (MITRANY, 1994), (HAAS, 1964), (KEOHANE; NYE, 2012)
} 
presentan interdependencias. Las relaciones primarias las identificamos en términos de familia, conocidos y el vecindario, las secundarias son referentes a la asociación, mientras que la integración civil se refiere al orden institucional de una nación.

En lo que se refiere al enfoque político/económico a nivel macro, este surge como respuesta a los problemas que se producen en el ámbito social, cultural y político de las sociedades globales. Existen una serie de definiciones, que se encuadran dentro de una perspectiva, que se enfocan en el papel del estado, en la creación de un ambiente sociopolítico en el cual los ciudadanos puedan expresarse y recibir una mejor calidad de vida. Este concepto, en términos de política nacional e internacional, es enfatizado a través de agencias internacionales, entre ellas el Consejo de Europa (EUROPARAT, 2005) que define Cohesión Social como:

"la habilidad de una sociedad moderna para garantizar el bienestar a largo plazo de todos sus miembros, incluyendo el acceso equitativo a los recursos disponibles, respeto por la dignidad humana tomando en consideración la diversidad, personal y autonomía colectiva así como a participación responsable" (traducción nuestra) ${ }^{6}$

El Banco Interamericano de Desarrollo la define como un "concepto acumulativo societal", es el conjunto de externalidades positivas que genera el capital social más la suma de factores que fomentan el equilibrio en la distribución de oportunidades entre los individuos". Por medio de esta definición se establece que debe existir una serie de condiciones económicas, sociales, políticas y culturales, proporcionadas a nivel macro, que promuevan la inclusión entre el individuo y la sociedad.

Esta definición está íntimamente relacionada con la capacidad de una sociedad en generar niveles de confianza social por medio de políticas inclusivas, que a su vez se vincula con las teorías de capital social ${ }^{7}$ que se enfocan en las ventajas de la asociación, explicando el compromiso cívico de los ciudadanos con una idea de unidad social. Este tipo de capital, al cual nos referimos, surge de la sociedad civil, que es el resultado de las dinámicas de creación de vínculos entre la diversidad de elementos que conforman una sociedad, etnia, religión, historia, entre otros aspectos.

La CEPAL establece a la cohesión social como "la dialéctica entre los mecanismos instituidos de inclusión/exclusión sociales y las respuestas, percepciones y disposiciones de la

\footnotetext{
${ }^{6}$ Texto original: "as the ability of a modern society to ensure long-term well-being of all its members, including equitable access to available resources, respect for human dignity with reference to diversity, personal and collective autonomy and responsible participation". (EUROPARAT, 2005)

7 Existe una gran diversidad de teorías de Capital Social entre las que se encuentran aquellas desarrolladas por Coleman (1990), Bourdieu (1980) Granovetter (1974) y la teoría de Putnam (1993) se distingue por su punto de partida: su actor es un ciudadano y su unidad de observación es la sociedad (URTEAGA, 2013).
} 
ciudadanía frente al modo en que ellos operan" (OTTONE; SOJO, 2007, p.10). Esta definición de la cohesión posee una serie de ventajas con respecto a otros enfoques ya que, en primer lugar, evita los sesgos funcionalistas, permitiendo la incorporación de la dimensión del actor; en segundo lugar, facilita el relacionamiento de dimensiones de la realidad que, habitualmente, han sido definidas como aspectos independientes que, desde nuestra perspectiva, se constituye como el aspecto más relevante y, finalmente, permite visualizar la cohesión como fin (se trata de que todos participen y se beneficien del desarrollo) y como medio (Ídem).

La (OECD, 2014), por su parte, establece que la cohesión social es un objetivo en sí misma y contribuye a mantener el crecimiento económico a lo largo del tiempo. Los escenarios en los cuales las desigualdades son amplias y la exclusión es un hecho común, son poco sostenibles, el enfoque presentado por esta institución resalta la necesidad de coordinación en la elaboración de las políticas que se interrelacionan entre si tales como: la política fiscal, empleo, protección social, participación social, participación civil, educación, género y migraciones, entre todas ellas existen interacciones, por lo que deben ser diseñadas con esta visión. El fortalecimiento de la cohesión social se constituye como un objetivo de política crítico, ya que "no es suficiente implementar tecnocráticamente marcos de buenas políticas mientras no se tome en cuenta el deseo de la población por un proceso político inclusivo" (traducción propia, ídem, p.19) $)^{8}$.

Existen muchas otras definiciones, tanto dentro de las esfera académica, como de la esfera internacional. En este trabajo pretendemos contextualizar la complejidad del concepto, así como la necesidad de su implementación para el alcance de un desarrollo sostenido de las sociedades, vinculándolo a la capacidad de los individuos hacia la cooperación y el compromiso cívico, creando una sociedad consolidada, por medio de la "teoría de la sociedad civil" usada a su vez en las "teorías del capital social" (COLEMAN, 1998). Este tipo de identificación de los individuos con determinadas características (cultura, historia, etc.), puede generar aspectos positivos a través del sentido de pertenencia y, a su vez, existe la posibilidad de desarrollar aspectos negativos por medio de polarizaciones sociales entre diferentes sectores, estas polarizaciones pueden ser socio-económicas, políticas, religiosas y étnicas, que en definitiva son consideradas como procesos de exclusión que derivan en violencia ciudadana $\mathrm{y}$, en casos extremos, en conflictos armados.

\footnotetext{
${ }^{8}$ Texto original: "it is clearly not sufficient to apply technocratically good policy frameworks while disregarding people's desire for inclusive political processes"
} 


\subsection{Cohesión Social, relaciones causales, dilemas y propuestas en el contexto contemporáneo}

“Como muchas veces es el caso en las ciencias sociales, es mucho más fácil encontrar correlaciones que descubrir la dirección y la fuerza de esta causalidad” (HELLIWELL; PUTNAM, 1995)

Dentro de este análisis de la cohesión social se examinan diversos trabajos que interpretan a la cohesión social como un concepto que contribuye a la obtención de resultados positivos, enfocados en lo que "este concepto hace", por lo tanto, el enfoque abordado no se refiere más a la fragilidad del concepto como consecuencia de la complejidad de sus dimensiones sino, por el contrario, a su contribución o implicaciones para el crecimiento, bienestar y la participación de la sociedad (JEANNOTTE, 2000).

Existen una serie de debates al respecto, sobre cómo el uso del concepto de cohesión social genera relaciones de causalidad, de forma constante ha quedado demostrado que el concepto en sí posee un peso fundamental en el alcance de resultados. Principalmente, al enfocarnos en dos de sus elementos constitutivos, el capital social y redes sociales, entendidos como integración y participación ciudadana, principalmente.

Existen varios niveles en los cuales puede establecerse esta visión, en primer lugar en el nivel económico/político. De acuerdo con (PUTNAM, 1993), fuertes vínculos horizontales, en el norte de Italia, estaban asociados con una eficiencia mayor por parte del gobierno local y con niveles mayores de PIB per cápita. Existía un impacto del asociacionismo y la participación ciudadana en el desarrollo económico. Esta lógica, se origina desde la comunidad civil, para la cual, las raíces comunes y estables pueden remontarse a siglos anteriores, hasta el desempeño institucional, generando, en consecuencia, una mayor satisfacción ciudadana con el gobierno regional (HELLIWELL; PUTNAM, 1995)

En definitiva, la investigación de Putnam establece que un elevado stock de capital social se asocia a mejores resultados sociales, políticos y económicos, con base en una cultura cívica, que implica una sociedad en la cual los ciudadanos están dispuestos a la confianza, la solidaridad y manifiestan interés en los asuntos públicos, debido a que existen las condiciones apropiadas en términos de derechos básicos, para que se realicen estos procesos.

Diversos estudios presentan descubrimientos obtenidos por parte de los cientistas políticos, en los cuales, países y regiones con una mayor vida asociativa, confianza y cohesión intergrupal tienen a tener una mejor prestación de servicios públicos, responsabilidad financiera 
y una mayor adherencia a las normas democráticas (Putnam et al. 1993, Knack 2002, Coffe; Geys 2005 apud (FOA, 2011);

La relación del concepto de cohesión social con la calidad de la democracia no es simple, entre ambas variables existe un nivel de causalidad en lo que se refiere a la amplitud de sus definiciones, ya que el hecho de que ambas posean diversos niveles de análisis y dimensiones eleva su complejidad a la hora de ser evaluadas. De acuerdo con (RITZEN, 2000) "la cohesión social de un país, en lo que se refiere, por ejemplo, a la inclusión de sus comunidades y su capacidad de maniobra institucional, tienen un rol importante en el manejo de la efectividad de la respuesta política de un país a los vaivenes de la economía global”.

De acuerdo a las dinámicas mencionadas anteriormente, en las cuales se observa a la cohesión social como generadora de resultados, lo cual conlleva a una relación de causalidad con otras variables, interpretadas como dependientes, siendo éstas afectadas por los procesos generados a partir de la interacción de la cohesión social, el sentido en el cual se establecen estas relaciones es un desafío, ya que constituye las causas del fenómeno bajo estudio, para lo cual deberán descartarse a su vez relaciones espurias. En este sentido y de acuerdo a lo establecido por (JEANNOTTE, 2000), los impactos de las relaciones causales de la cohesión social puede ser interpretados de la siguiente forma:

Tabla 2. Patrones de Causalidad

Diversos Factores ----------------------------------------------> Cohesión Social

Factores como:

*Globalización y nuevas tecnologías

*Diversidad, migraciones internacionales

*Comunidad

Cohesión Social Diversos Resultados

Resultados como:

*Desempeño económico y bienestar

*Salud

*Porcentajes de participación

*Legitimidad de las instituciones democráticas

Fuente: Jeanotte (2000)

\footnotetext{
${ }^{9}$ Ex vice presidente de Políticas para el Desarrollo del Banco Mundial.
} 
Cómo quedo establecido en la Tabla 2, evaluar la cohesión social en el contexto contemporáneo implica, entonces, la incorporación de una serie de factores y componentes tales como la globalización y las nuevas tecnologías, que cambiaron la forma en que se estructuran las sociedades. Existen otros elementos que forman parte del escenario mundial contemporáneo, que aun cuando no son recientes, han sido incrementados con estos procesos globalizadores, tales como, la integración regional, dinámicas migratorias y urbanas, así como las transformaciones culturales que se dan a la par de este proceso, afectando a las sociedades y sus estructuras.

La globalización debe ser observada como un punto de quiebre en la forma en que se interrelacionan las sociedades, en este sentido, la cohesión social debe ser evaluada como un elemento base para la reinvención de los Estados nacionales dentro de estos procesos, en un escenario fragmentado producto de estas dinámicas globalizadoras. De acuerdo con (RODRIGUEZ LARRETA, 2008):

"Los impactos de la globalización, las modernizaciones contradictorias de nuestras sociedades y los cambios en los sistemas políticos han abierto un conjunto de nuevos desafíos a los Estados nacionales que implican, entre otras cosas, sustanciales transformaciones en sus modos de "integración" o "cohesión" social. La heterogeneidad de las sociedades contemporáneas aparece en tensión con proyectos nacionales que se han representado históricamente desde identidades idealmente homogéneas".

Los cambios tecnológicos, generan, entre otros aspectos, un impacto en el mercado y en consecuencia en la sociedad, modificando el escenario actual principalmente en términos económicos, lo que crea un estímulo en las dinámicas de individualización. Estos aspectos han sido estudiados en términos teóricos por (GIDDENS, 1994), Bauman (2008), (BECK; VAN DER MAESEN; WALKER, 1997) entre otros. Esta nueva era de consumo crea nuevos niveles de acumulación de capital e incrementa las frustraciones de los que quedan en los márgenes, como consecuencia del aumento de las distancias en términos de desigualdades. (BAUMAN apud (RODRIGUEZ LARRETA, 2008), esto debido a que el status quo, de la división del trabajo, ya no corresponde a las transformaciones de la industria y los servicios, ni a un sistema político cuyas decisiones económicas deben tomar en cuenta las conexiones cambiantes del contexto mundial (BECK, 2000), (SASSEN, 2007)

Otro elemento que se vio modificado como consecuencia de las nuevas dinámicas sociales, producto de la globalización, fue la cultura, entendida, de acuerdo con (RODRIGUEZ LARRETA, 2008) como la "producción de significados, ideas, y símbolos externalizados a través de ciertos medios (desde danzas a libros y vehículos de comunicación electrónica), que la 
distribuyen socialmente entre grupos e individuos situados en diversas posiciones de la estructura social".

Evaluando la cultura como este conjunto de elementos que forman parte de un grupo definido, esta ha sido afectada a través del impacto inmediato de influencias internacionales por medio del acceso inmediato a la información y las transformaciones tecnológicas. Estos cambios trajeron consigo aspectos positivos, ya que este tipo de influencias genera nuevas formas y tipos de creaciones culturales, pero al mismo tiempo, es innegable que, en algunos casos, saberes endógenos se ven influenciados en medio del proceso de cosmopolitización consecuencia de la globalización.

En esta línea de raciocinio se observa el riesgo de homogeneización en términos cultura $^{10}$. Varios elementos, tales como: la occidentalización, transculturización y la difusión de nuevas etnicidades, afectan los saberes y expresiones propias de las comunidades alrededor del mundo, esto sigue siendo una consecuencia sine qua non del capitalismo contemporáneo y su diversificación alrededor del mundo, en conjunto con la ampliación del acceso a la tecnología, lo que genera una distancia en lo que se refiere a ideas de "identidad" nacional y autenticidad cultural, que se basa en discutibles premisas teóricas (GARCIA CANCLINI, 2004)

Este proceso de transculturación, el cual se vincula a la idea de la influencia de una sociedad sobre otra, debe ser entendido, por un lado, como una base importante para la consolidación del capitalismo, a través del incremento de patrones comunes de consumo entre las sociedades, lo cual se observa principalmente en los centros urbanos. Este proceso afecta la identidad nacional, la cual ha sufrido transformaciones aceleradas por el fenómeno de transculturización. Esta construcción viene dada por individuos y diferentes grupos sociales que viven o nacen en un territorio bajo la influencia de un discurso ideológico homogeneizador y reproductor del imaginario nacional. En la actualidad existe una mayor interrelación entre los países, así como el establecimiento de nuevos movimientos sociales y movilidades culturales,

\footnotetext{
${ }^{10}$ APPADURAI(2001) apud (RODRIGUEZ LARRETA, 2008) señala que existen cinco dimensiones en los flujos culturales globales, para lo cual el autor emplea el sufijo scape (de landscape= paisaje), ethnoscape (paisaje étnico), mediascape (paisaje mediático), technoscape (paisaje tecnológico), financescape (paisaje financiero) e ideoscapes (paisaje de las ideas). Estos mismos 'paisajes', escribe A. Appadurai, "son pues los ladrillos de construcción de lo que me gustaría llamar, ampliando así el concepto de Benedict Anderson, los mundos imaginados, es decir, los múltiples mundos constituidos por los imaginarios históricamente situados de personas y de grupos dispersos en todo el planeta" (Appadurai, 2001:69). En cualquier caso, el antropólogo mencionado habla de desarticulación o de clara disyunción entre estos distintos scapes, en un nuevo mundo que se construye tomando en consideración la metáfora de G. Deleuze en forma de rizoma.
} 
siendo estos, ejemplos paradigmáticos de tensiones relacionadas con la construcción de la cohesión social y como expresiones de la redefinición de lo nacional (BAEZA, 2006).

Estos cambios estructurales contemporáneos han creado conflictos que, en muchos casos, surgen como consecuencia de dinámicas de exclusión y polarización, originadas por la vulnerabilidad de amplios sectores sociales, lo que genera el aumento de la posibilidad de convertirse en ejecutores de actividades fuera de los padrones sociales, establecidos como un mecanismo de sobrevivencia, socavando las bases de una sociedad en la cual prime el bienestar social. Este escenario refleja los procesos de exclusión social, que se relacionan con la falta de posibilidades, por parte del individuo, de interactuar con su entorno y la posibilidad de progreso a partir de este contexto. La desigualdad se convierte en uno de los factores fundamentales que afecta la cohesión, así como en la definición de la trayectoria que seguirá una sociedad entre niveles de fragmentación y cohesión.

Tomando en consideración este escenario complejo, en el cual la desigualdad extrema afecta profundamente a los individuos que forman parte de las sociedades y en el que la búsqueda de mejores condiciones de vida se constituye como un elemento central de los individuos, independiente de su localización geográfica, el incremento de los movimientos migratorios se observa como otro fenómeno importante que afecta a la cohesión, los cuales se caracterizan por tener efectos multidimensionales, representando la diversidad y complejidad de la realidad social contemporánea, que se caracteriza de acuerdo con (ARAUJO, 2008)por cuatro aspectos principales: 1) una falta de alternativas para alcanzar sus metas ocupacionales, 2) la existencia de incertidumbre social sobre el futuro económico, 3) una inseguridad social general en lo que se refiere al aumento de la violencia ${ }^{11}$ y 4) finalmente la falta de satisfacción de las necesidades básicas.

Las migraciones han alcanzado una escala mayor en la última década debido a una serie de causas: las elevadas brechas sociales, conflictos armados y la falta de acceso a oportunidades, entre otros aspectos. La evaluación de estos elementos dentro de las regiones geográficas/culturales, es fundamental a la hora de evaluar los niveles de cohesión, ya que se producen cambios estructurales en la identidad, tanto en los individuos como las sociedades a las cuales están accediendo, impactando la dimensión de la cohesión definida como sentido de pertenencia. En este sentido, se observa la relevancia del vínculo entre los procesos migratorios

\footnotetext{
${ }^{11}$ Que se vincula a su vez a los problemas en términos de conflicto armado.
} 
dinámicos y acelerados, y la búsqueda de integración, por parte de los individuos, dentro de las sociedades con la cohesión social:

"La interrelación entre el concepto tradicional de integración y el de cohesión social se plasma en los esfuerzos políticos de armonizar las dimensión cultural y redistributiva. (...) Para alcanzar cohesión social es tan necesario acordar, respetar y compartir determinados valores, normas (e incluso elementos culturales como la lengua), cómo desarrollar eficientes políticas sociales de redistribución." (SOLÉ PUIG et al., 2011)

Esser (1993) apud Sole et al (2011) establecen que existen diferencias marcantes entre los conceptos de aculturación y asimilación con integración, que afectan los niveles de cohesión, en primer lugar, porque aculturación se vincula a la idea de aprendizaje de la cultura receptora por parte de los inmigrantes, asimilación por su parte se refiere a la fusión de elementos culturales de dos grupos, finalmente la integración es la interacción, en términos igualitarios, de los grupos sociales, manteniendo sus características propias. Tomando en consideración estos elementos, la idea de cohesión permite sentar las bases para que se den estos procesos, principalmente, a través de la promoción de un sentido de pertenencia enmarcado dentro de la pluralidad, superando al denominado "nacionalismo metodológico" (SOLÉ PUIG, 2010)

La propuesta que trae consigo la cohesión social es que, para su desarrollo positivo, es necesaria una estructura en la cual se priorice la disminución de las desigualdades y donde se den las condiciones para la promoción de un sentido de pertenencia. Históricamente un mecanismo que ha tenido resultados positivos, en el desarrollo de la cohesión, es, en primer lugar, la noción e implementación del Estado de Bienestar ${ }^{12}$, definido por (ESPING-ANDERSEN, 1990)como "los modos en que se reparte la producción de bienestar entre el estado, el mercado y las familias" y, en segundo lugar, la redistribución de recursos, dando una nueva interpretación del escenario económico, para alcanzar el desarrollo a través de políticas públicas asertivas e inclusivas. De acuerdo con Sole et al (2011) existen tres relaciones causales entre la cohesión social interpretada como el equilibrio entre la dimensión cultural y redistributiva:

"Primero a mayor grado de cohesión social, más apoyos recibirán aquellas políticas públicas destinadas a educación, sanidad o redistribución de ingresos. Políticas que, por su carácter universal tienen resultados sociales positivos. Segundo, cuanto más cohesionada sea una sociedad, más aceptabilidad de las normas de conducta y valores

\footnotetext{
12 "Concibe la relación entre desarrollo económico y política social desde la perspectiva de los derechos humanos, según principios y tratamientos cercanos a los de la agenda de Naciones Unidas, pero especialmente impulsada por los imperativos democráticos y de equidad social, bastante extendidos en tiempos recientes. Güendell y Barahona lo resumen bien, señalando que alí se integran "... tres cosas que normalmente se han visto separadas: el acceso a la riqueza, es decir el problema de las necesidades; el acceso a la libertad como autonomía, esto es, el problema del ejercicio de las capacidades y el acceso al poder, lo que alude al problema de la participación social y política" (Güendell y Barahona, 2005).
} 
compartidos de las instituciones sociales, y mayor confianza respecto a las leyes y a la justicia (...). Tercero, mayores niveles de cohesión social conllevan a más participación en la sociedad civil y refuerzan el capital social.” (SOLÉ PUIG et al., 2011)

En definitiva, la cohesión social se vincula al hecho inherente del ser humano, constituirse como un ser social, y la prioridad que tienen las dinámicas sociales en la consecución de un escenario propicio para el desarrollo, en un contexto en el cual no puede mantenerse aislado de los otros miembros que forman parte de su entorno. Por esta razón se encuentra en la búsqueda constante de unidad y acciones gregarias ${ }^{13}$, entre individuos, cómo fue establecido por Sorj y Martucelli (2008) "Como enseña la teoría social, todas las sociedades generan alguna forma de cohesión. Caso contrario ellas no existirían", la cohesión de esta forma se constituye como la respuesta a las transformaciones que socavan el tejido social.

En el escenario contemporáneo, en el cual se desarrolla la globalización, la cohesión social no puede estar disociada de lo que implican los cambios y el conflicto social como fue establecido anteriormente, esto, debido a que las sociedades se encuentran en procesos de constante mutación, generando como resultado desintegración, inviabilidad en la capacidad de legitimar las instituciones democráticas por medio de la confianza (idem), pero al mismo tiempo se observa un escenario positivo, en donde el individuo es visto en términos de su papel fundamental en la participación y las demandas s como ciudadanos.

Tomando en consideración estos aspectos que reflejan elementos que afectan las dinámicas sociales, nuestro foco serán los aspectos referidos a la creación de vínculos básicos entre los individuos en diversas instancias asociativas, entre ellas, la llamada cuestión nacional referida al nacionalismo o identidad nacional que puede presentarse a su vez como regional y étnica, aspecto fundamental a la hora de referirnos a la consolidación democrática y participación, reforzando el papel de los individuos como ciudadanos miembros de un conjunto.

\subsection{La calidad democrática y su trascendencia como estructura social}

1.3.1 Concepto de democracia como framework de desarrollo dentro de la visión sociopolítica

"El "artefacto" de la democracia tiene que ser concebido y construido antes de ser observado" (SARTORI, 1996)

\footnotetext{
${ }^{13}$ Como el concepto abarca la relación entre los individuos, la comunidad y la sociedad, es importante captar las valoraciones y percepciones de las personas acerca del grado de solidaridad que la sociedad les brinda y, a su vez, de cómo ellas definen su solidaridad hacia los demás. Ambas valoraciones forman parte de la dimensión intersubjetiva de esta relación entre individuo y sociedad, moldean y enriquecen su contenido, y contribuyen a definir predisposiciones y comportamientos. (OTTONE; SOJO, 2007, P. 76)
} 
Esta investigación se enfoca en la interpretación positiva de la democracia, la cual ha sido generalizada en el mundo contemporáneo, como aquella estructura política que presenta características deseables para los individuos ${ }^{14}$. Se observa que, históricamente, las democracias se han definido como estructuras capaces de viabilizar las exigencias ciudadanas, por medio de una serie de dinámicas que involucran a la población y el estado a través de una serie de derechos.

La globalización económica y cultural, la modernización de las sociedades, los enormes avances en comunicación y transporte han creado las condiciones para una nueva ola de experiencias democráticas en el mundo, entendiendo la democracia en los términos de Alexis de Tocqueville (ARANGO, 2010) como un tipo de sociedad y no solamente un conjunto de reglas formales de actividad política. La estructura democrática tiene una dimensión sociológica y antropológica en la cual el individuo, así como los procesos institucionalizados de individualización ocupan un lugar central.

Establecer una definición de democracia constituye un proceso complejo, ya que resulta en la revisión de una extensa literatura que la conceptualiza desde diferentes visiones, pasando desde su mantenimiento, medición, hasta la implementación dentro de las sociedades contemporáneas. Entre muchas otras, en este sentido, es importante resaltar:

\footnotetext{
“...los conceptos abarcan, ciertamente, contenidos sociales y políticos, pero que su función semántica, su capacidad de dirección, no es reducible solamente de los hechos sociales y políticos a los que se refieren. Un concepto no es sólo indicador de los contextos que engloba, también es un factor suyo". (KOSSELLECK, 1993)
}

Continuando con la problematización del concepto de democracia, (GOERTZ, 2011) apunta que la democracia fue definida comúnmente a través de la exposición de los elementos que le serían útiles, por medio de la afirmación categórica de sus dimensiones y de la relación de necesidad, como se observa a continuación:

"La parte relativa a la condición suficiente de estas estructuras está casi siempre ausente. En este caso se tienen que inferir los aspectos de suficiencia del constructo teórico [...]. Mientras que, una estructura conceptual sin suficiencia está incompleta. Esto significa consecuencias directas para la mensuración: clasificar a un país como democracia necesita de un criterio de suficiencia; por consiguiente, deben ser dadas las condiciones suficientes. Los elementos esenciales de forma individual no bastan para que se realice una clasificación positiva definitiva" (GOERTZ, 2011)

\footnotetext{
14 "Evita la tiranía, Derechos Esenciales, Libertad en líneas generales, Autodeterminación, Autonomía Moral, Desarrollo Humano, Protección de los intereses personales esenciales, Igualdad Política, búsqueda por la paz y la prosperidad" (DAHL, 2001)
} 
Por lo tanto, nuestro análisis se enfoca en la forma en que la democracia se constituye, de acuerdo con (DAHL, 2001), en una estructura que va más allá del acto de gobernar, esta se relaciona con la garantía de una serie de derechos fundamentales, que las "no-democracias" no estarían dispuestas a garantizar en el mundo contemporáneo como parte de las dinámicas sociales. De acuerdo con (CIPRUT, 2008) la democracia involucra aspectos éticos, ya que dentro de la dimensión política al hacer referencia a sistemas políticos democráticos estamos vinculando aspectos como igualdad y libertad, variando en su grado de efectividad dependiendo del objeto del análisis, ya que cada país posee características diferentes.

En este sentido, la democracia ha sido defendida y justificada bajo la idea de que se acerca al alcance de una serie de valores vistos como positivos, de acuerdo con (HELD, 1996) estos serían "igualdad política, libertad, desarrollo moral propio, el interés común, un compromiso moral justo, decisiones vinculantes que toman el interés común en consideración, utilidad social, la satisfacción de las necesidades y decisiones eficientes" (traducción propia) ${ }^{15}$. Toqueville (1992) resaltó el hecho que la democracia iba más allá de un conjunto de instituciones, ya que esta debería ser considerada una forma de sociedad.

(SEN, 2001) por su parte, la define como un valor universal y menciona las interrelaciones existentes entre las libertades políticas y la comprensión y satisfacción de las necesidades económicas, siendo que esta "implica exigencias complejas, que incluyen el voto y el respeto hacia los resultados de las elecciones, pero también implica la protección de las libertades, el respeto a los derechos legales y la garantía de la libre expresión y distribución de información y critica", tomando esto en consideración el autor establecio que una democracia, aun siendo una fuente importante de oportunidad social, existe con la misma una necesidad de "examinar los caminos y los medios para hacerla funcionar bien, para realizar sus potenciales" (Sen, 2010), definiendo tres aspectos que sustentan la relevancia de un sistema democrático: 1) su importancia directa asociada a capacidades básicas (como la participación política y social), 2) su papel instrumental al incrementar la capacidad de expresión al defender sus reivindicaciones y 3) finalmente, su papel constructivo en la conceptualización de las necesidades.

\footnotetext{
${ }^{15}$ Texto original "political equality, liberty, moral self-development, the common interest, a fair moral compromise, binding decisions that take everyone' interest into account, social utility, the satisfaction of wants, efficient decision's." (HELD, 1996)
} 
Las estructuras, por medio de las cuales se formula el concepto de democracia, en muchos casos se confunde con los procesos de democratización, siendo que no hay como explicar la manera, a través de la cual, las sociedades se convierten en más democráticas, sin que se haya interpretado, previamente, lo que se entiende por democracia (PETERLEVITZ, 2011) por eso la importancia de este abordaje teórico, que da énfasis a las transformaciones del concepto, ya que se caracteriza como un objeto de múltiples dimensiones, el cual no se mantiene estático y en el que debe ser considerada su evolución histórica.

Existen dos visiones a través de las cuales la democracia ha tomado un papel central en el mundo moderno, de acuerdo con (SARTORI, 1996) las podemos clasificar en "democracias realistas" y "democracias de razón". Las primeras de acuerdo con (GONZALEZ LOPEZ, 2010)están fundamentadas en una definición procedimental "que establece los arreglos institucionales que definen el modus operandi de la democracia, tales como el sufragio y el sistema representativo de partidos. La democracia se entiende como un objeto de hecho". Este tipo de matriz democrática sentó las bases institucionales de las democracias europeas y norteamericana (Estados Unidos).

En el caso de las democracias de razón, estas tienen su origen en la Revolución Francesa y los ideales establecidos en la misma: libertad, igualdad y fraternidad. El último aspecto constituye un aspecto fundamental dentro de nuestro foco de estudio. Para Fauchet e Lamourette (FAUCHET; LAMOURETTE APUD (FURET, 1989), la misma, constituía el elemento que inculca en los seres humanos "el sentimiento más vivo y más diferente de su identidad con los otros hombres, porque comprende la idea de una pátria o sociedad en la cual todos los hombres podrían ser hermanos", estableciendo vínculos de colaboración entre los miembros de la sociedad, impulsando la idea de una comunidad o grupo en común.

Una vez definidas las dos visiones principales, el establecimiento del concepto de democracia requiere de tres elementos básicos como fue establecido por (GONZALEZ LOPEZ, 2010). En primer lugar, esta se vincula, esencialmente, a un principio de legitimidad "en el cual la noción de participación viene a denominar una fuente de autoridad cuya connotación reconocida es la del "gobierno del pueblo", en segundo lugar, se establece como un sistema político, poseedor de procedimientos institucionales, transmitiendo el poder por medio de la representación y, en tercer lugar, deber ser interpretada como la aspiración hacia un ideal, lo cual permite su proyección. Con base en estos elementos buscaremos las aproximaciones teóricas del significado de democracia, que nos permitan sentar las bases para el 
desarrollo de nuestra hipótesis, por medio de la cual existe un impacto de cohesión social en la calidad democrática.

De acuerdo con (FRAZER; MARLIER, 2010)si algunos sectores de la sociedad perciben el sistema político como remoto o irrelevante, de acuerdo a sus necesidades, o si se sienten excluidos e impotentes, así como carentes de habilidades y conocimiento que les permitan participar de las decisiones que afectan sus vidas, entonces, el compromiso democrático se ve disminuido, la cohesión social socavada y los derechos fundamentales de las personas reducidos.

Por otra parte, existen dos clasificaciones amplias de los modelos de democracia, de acuerdo con (HELD, 1996) tenemos, en primer lugar, a la democracia participativa que se establece como un sistema de toma de decisiones, al respecto de asuntos públicos, en los cuales los ciudadanos están involucrados directamente $\mathrm{y}$, en segundo lugar, la democracia representativa o liberal, que se establece a partir del comprometimiento de funcionarios a representar los intereses de los ciudadanos, dentro del marco del "estado de derecho". Ambas clasificaciones abarcan una amplia gama de definiciones y tipologías, reflejadas alrededor del mundo, que han moldeado la vida política y social en el mundo contemporáneo.

En lo que se refiere a la democracia representativa, el concepto presentado por Schumpeter, la coloca como un procedimiento para lidiar con el problema del poder estatal, para esto coloca a las elecciones como el medio para realizar la competencia entre distintas élites políticas. De acuerdo con (DE LA ROSA, 2010), es un enfoque realista ya que "reduce las expectativas y la habilidad de la ciudadanía para influir en los resultados del gobierno democrático", ya que esta capacidad se limita exclusivamente al acto de votar. En el caso de la democracia participativa, esta se encuentra definida como:

"un proceso de toma de decisiones colectivas, que combina elementos de la democracia, tanto directa como de la representativa: Los ciudadanos tienen el poder de decidir sobre las propuestas referentes a políticas y los políticos asumen el papel de implementar las políticas. (...) Como resultado, la discreción de los políticos está muy limitada. En este sistema, el grado en que los ciudadanos pueden influir en la política y determinar las prioridades sociales se alinea directamente con el grado en que deciden 
involucrarse en el proceso." (ARAGONES; SANCHEZ-PAGES, 2008, traducción propia $^{16}$

Macpherson (1997) apud (PUERTA, 2010) establece que el modelo que cabe calificar correctamente de democracia participativa tendría una estructura piramidal, con la democracia directa en las bases y la democracia delegada en todos los niveles por encima de ella. El autor reconoce que el problema de esta estructura se encuentra en su alcance, "para que esta sea efectiva es necesario un concepto de ciudadanía que trascienda su naturaleza pasiva" (ídem). La consolidación de la Democracia Participativa, tiene como elementos imprescindibles la reducción de las brechas sociales/económicas, así como un sentimiento de comunidad sólido, reflejando el dilema participación/desigualdad social vinculado a la contradicción libertad/igualdad.

Tanto la visión histórica como las clasificaciones, dentro de las que se encuadra el concepto de democracia, comprenden un amplio rango de debates y consideraciones teóricas, estableciendo las bases para la construcción de la visión democrática vinculada a la idea de cohesión, esta idea de democracia no solamente establece valores considerados como correctos y positivos, sino adicionalmente debe ser interpretada como:

"una guía orientadora que puede ayudar a generar las bases para especificar las relaciones entre diferentes conceptos normativos. La democracia no presupone un acuerdo entre diversos factores; al contrario sugiere una forma de relacionar valores entre sí mismos y de dejar la resolución de conflictos de valores a los participantes en el proceso público sujetos solamente a ciertas provisiones la forma y el tipo de proceso en sí mismo" (HELD, 1996)

Tomando como base lo anterior, el concepto de democracia de mayor relevancia para los asuntos que atañen nuestra investigación, es aquel establecido por Lipset (WRONG, 1960), que define a la democracia como un sistema político que proporciona oportunidades, de forma continua, por medio de la estructura constitucional para realizar el cambio de los gobernantes, generando una solución al problema de intereses contrapuestos dentro de los grupos que deben elaborar soluciones conjuntas. El autor establece, a su vez, que la democracia no es,

\footnotetext{
${ }^{16}$ Texto original: "Participatory democracy is a process of collective decision making that combines elements from both direct and representative democracy: Citizens have the power to decide on policy proposals and politicians assume the role of policy implementation. The electorate can monitor politicians' performance simply by comparing citizens' proposals with the policies actually implemented. As a result, the discretion of politicians is severely constrained. In this system, the extent to which citizens can affect policy and determine social priorities is directly aligned with the degree to which they choose to involve themselves in the process" (ARAGONĖ; SÁNCHEZ-PAGÉS, 2009)
} 
simplemente, el medio a través del cual diferentes grupos buscan alcanzar una "buena sociedad", es, en verdad, la buena sociedad, en sí misma, en operación, vinculada a la visión planteada por medio de la cohesión social. Una sociedad unificada tiene la capacidad de operacionalizar derechos y condiciones que promuevan la calidad de las democracias.

Este proceso multidimensional definido como democracia en el escenario contemporáneo posee dos caras, en donde se debe observar por un lado la reforma del poder del estado y por otro la reestructuración de la sociedad civil (HELD; KEANE, 1984), siendo interpretada como una transformación interdependiente, de esta forma "la democracia podrá ser considerada como completamente válida si los ciudadanos pueden disfrutar de un conjunto de derechos que les permitan demandar participación democrática y considerarlo como un derecho" (SEN, 2001).

Podemos concluir que existen varias interpretaciones de la idea de democracia y en la actualidad, de acuerdo con O'Donnell (SORJ, 2007), la idea de una llamada "democracia consolidada" debe superar una serie de desafíos para poder referirnos a ella en términos de una consolidación real. Por lo tanto, es necesario comprender, realmente, cómo funcionan las dinámicas entre los países y la evolución de sus democracias, entre ellas se encuentran los cambios políticos, económicos y sociales, que, en muchos casos, están vinculados a la prolongación de legados de pobreza y desigualdad. Tomando estos aspectos en consideración nos encontramos frente a una "paradoja democrática" como establecido por Sorj (2007) vinculada al "incremento de las expectativas de igualdad acompañadas de una profundización de las desigualdades sociales".

Por medio de la estructura conceptual establecida se busca un comprensión interdisciplinaria de la democracia, tomando en consideración su evolución en relación a diversas dinámicas y afectada por procesos de individualización en el mundo contemporáneo, siendo interpretada como un mecanismo de aprendizaje social en constante transformación conformada por una diversidad de actores los cuales requieren de un nivel elevado de negociación y tolerancia mutua para su funcionamiento adecuado.

\subsubsection{Democracia con calidad, objetivo de las sociedades contemporáneas}

En lo que se refiere a la visión aplicada de la calidad democrática y su importancia dentro de una sociedad, daremos énfasis a los temas conceptuales. Vemos en primer lugar que la calidad se refiere al resultado, reflejado en esa ordenación institucional a través de mecanismos 
estructurales que funcionan correctamente, un régimen ampliamente legitimado y, por lo tanto, estable, del cual los ciudadanos están plenamente satisfechos (MORLINO, 2012). En algunos casos ha sido estudiada en términos de la connotación del concepto, enfatizando la calidad del desempeño del sistema democrático (ABENTE, 2007), otros autores aplican el grado de satisfacción de los ciudadanos e indicadores vinculados al buen gobierno o "gobernanza" (KAUFFMANN; KRAAY; MASTRUZZI, 2010)

Tomando en consideración estos aspectos, la calidad de la democracia es el mecanismo de evaluación del desempeño de un régimen democrático en un determinado país. De acuerdo con lo establecido por (VARGAS-CULELL, 2012) el objetivo de la misma es evaluar el estado de democratización, en lo que se refiere a unas determinadas características, en un punto concreto del tiempo. Esta definición se refiere a la calidad democrática como la captura temporal de una serie de elementos de los países, tomando en consideración que cada uno, de forma particular, posee construcciones tanto en su dimensión histórica como social. Siendo así, la sociedad debe ser considerada como el actor central dentro de un sistema denominado como democrático.

Para alcanzar una democracia con calidad es necesaria una consolidación de la pluralidad de la ciudadanía, así como la disminución de desigualdades y fracturas socioeconómicas en la sociedad. Standing (2011) sustenta esta hipótesis al colocar que las innovaciones y mejoras, en términos democráticos, solo pueden darse dentro de una sociedad que tome en consideración a los grupos vulnerables, así como las estructuras de clase emergentes y las dinámicas de estas por medio de la solidaridad. (LIJPHART, 2012) en sus investigaciones referentes a la calidad democrática llega a la conclusión de que las democracias consensuales gozan de una mayor calidad democrática que las mayoritarias, pero para que estas sean efectivas deben promover el consenso y la inclusión, porque de lo contrario se inclinaron hacia lo denominado como una "dictadura de las mayorías".

De acuerdo con la investigación del NUPP (USP) del "Significado de la Democracia para los brasileros" la calidad de la democracia es vista como "expresión de procedimientos institucionales (...) pero al mismo tiempo como una construcción referida a principios y valores del régimen, como las libertades, que distinguen claramente el proceso democrático de las alternativas autoritarias", esta implica procesos controlados por métodos y tiempos precisos, capaces de asignar características específicas, en este sentido y de acuerdo con (MOISES, 2009) un régimen será capaz de satisfacer las expectativas de los ciudadanos en lo que se refiere a la 
misión que le atribuyen a los gobiernos (la calidad de los resultados), garantizando de esta forma a los ciudadanos y a sus asociaciones el goce de amplias libertades y de igualdad política necesaria para que puedan alcanzar sus aspiraciones o intereses (calidad del contenido).

De acuerdo con esta investigación realizada por el NUPP en términos de calidad de la democracia se demostró que el crecimiento de la adhesión normativa de la población de forma masiva a la democracia se da en paralelo con una paradoja caracterizada por proporciones muy altas de desconfianza en las instituciones democráticas (MOISES, 2008). Esta adhesión debe vincularse con ciertos postulados como el desarrollo de medios de comunicación por medio de procesos de globalización, generando una influencia en esta aceptación que puede ser interpretado como "el deseo de las personas comunes de conquistar los niveles de renta y de consumo usualmente asociados con la realidad de las democracias occidentales"(MOISES, 2009).

La calidad de la democracia presenta una complejidad que se encuentra a la par del mismo concepto de democracia, debido a sus diversas implicaciones teóricas y a la vez empíricas, no existiendo un consenso por parte de la literatura especializada. Esta materializa la dinámica existente entre la democracia ideal y la real, ya que permite el establecimiento de una estructura comparativa de clasificación y catalogación en términos procedimentales, de forma vertical o valorativa, que busca el alcance de forma horizontal dentro de la sociedad ${ }^{17}$.

En este sentido, el conocimiento de las dimensiones y de los factores que influyen en la calidad democrática tiene una justificación sustantiva, porque solo de esta forma serán obtenidos los conocimientos para tener una democracia consolidada (DIAMOND; MORLINO, 2004) y su análisis no puede estar basado en un solo indicador, ya que este presenta las características de un concepto poliédrico (MAINWARING; PEREZ-LIÑAN, 2008)

Aun con la amplitud del concepto, en lo que se refiere a las formas en que puede ser mensurada la calidad, la mayoría de los autores, que estudian esta área de conocimiento, coinciden en que sólo se puede hacer análisis de calidad a los países que cumplen las condiciones esenciales de una democracia, de esta forma los regímenes híbridos o los no democráticos no pueden incluirse en los estudios de la calidad democrática, entre los que se encuentran los realizados por (ALTMAN; PEREZ-LIÑAN, 2002), (VARGAS-MACHUCA,

\footnotetext{
${ }^{17}$ En lo que se refiere a los objetivos vinculados a las ideas de libertad e igualdad que se esperan alcanzar por medio de la misma.
} 
2006) y (MORLINO, 2012) entre otros. La evidencia empírica es contundente a la hora de demostrar que ningún sistema democrático corresponde a una sola definición

De acuerdo con (TUSSEL, 2015) existen tres enfoques dentro de los cuales se coloca la calidad de la democracia. En el primero, se tiene como objetivo evaluar los procesos e instituciones que sirven para ejecutar los procesos electorales, en los cuales la ciudadanía tiene el papel protagónico, tomando como base el concepto de poliarquía ${ }^{18}$, en este sentido, la calidad de la democracia es "la capacidad de aprovechar el potencial que ofrece el régimen político democrático" (Altman y Pérez-Liñán, 2002 apud Tussel, 2015).

El segundo enfoque, tiene como aspecto de mayor relevancia el control del poder político, por medio de instituciones, el cual está vinculado a la premisa de que el ejercicio del control ciudadano es inherente a la calidad de la democracia, principalmente en lo que se refiere al poder político. Este control debe ser ejecutado por medio de un marco jurídico apropiado, en el sentido de garantizar los derechos, esto se define como accountability que de acuerdo con O'Donnell (2004) puede ser clasificada como "electoral y societal", la primera ejecutada a través del voto y la segunda durante los gobiernos electos, por medio de acciones implementadas por medio de grupos sociales para "hacer públicos los errores gubernamentales, introducir temas en la agenda pública y activar las agencias de accountability horizontal"(Smulovitz y Peruzzotti, 2000 apud Tussel, 2015).

El tercer enfoque prioriza los objetivos y resultados de la democracia, objetivos como libertad $^{19}$, igualdad cívica y política, por medio de la visión de (DIAMOND; MORLINO, 2004) definidos como "el control de las políticas públicas, la igualdad política y el buen gobierno", en términos de resultados, los mismos están vinculados a la disminución en las brechas sociales y

\footnotetext{
18 "De acuerdo con Dahl este es el término que mejor describe a las sociedades democráticas realmente existentes. Esto significa que es necesario reconocer que la democracia es un orden utópico e ideal al que no puede aspirar la sociedad, pues su realización no está al alcance de la humanidad. Dahl señala que existen una serie de características que deben cumplirse para la existencia de un orden plenamente democrático: 1) Que cada miembro exprese su preferencia, o sea, que vote; 2) Que influya por igual cada preferencia, cada voto; 3) Que triunfe la opción con mayor número de votos; 4) Que los individuos puedan insertar y elegir la opción preferida; 5) Que todos los individuos posean la misma información sobre todas y cada una de las alternativas propuestas; 6) Que 1 as alternativas con mayor votación desplacen a las otras; 7) Que se ejecuten las órdenes de los representantes designados o se lleven a cabo las acciones elegidas; y 8) Que todas las elecciones que se realicen cumplan con estas siete condiciones o que estén subordinadas a ellas. Dahl apunta que algunas de estas condiciones son posibles, pero otras son poco menos que inalcanzables. Es decir, un orden social democrático pleno, como se concibe mediante estas condiciones, es irrealizable. (GARCIA JURADO, 1997)

19 "Democracia, definida como la totalidad de instituciones, organizaciones, métodos y técnicas, está establecida con base en la libertad que está concebida como un valor en el sentido de autonomía" (Selçuk, 1999, traducción propia). Texto original: "Democracy, which is the totality of institutions, organizations, methods, and techniques, is established upon freedom which is conceived as a value in the sense of autonomy"
} 
de un incremento en la justicia social ${ }^{20}$, la cual debe ser evaluada a partir de tres procesos que la constituyen, en primer lugar como distribución de bienes, recursos materiales y culturales ${ }^{21}$, reconocimiento de las individualidades y culturas, buscando relaciones justas ${ }^{22}$ y la participación cívica de forma activa y equilibrada (MURILLO; HERNANDEZ, 2011)

El concepto de calidad de la democracia debe ser interpretado como un indicador del desempeño en términos de valores, que puede alcanzarse por medio de la evaluación de los elementos que la conforman y sus resultados estarán vinculados a la satisfacción de las expectativas ciudadanas frente a un gobierno específico en un periodo de tiempo definido. De acuerdo con la definición establecida por el Pnud (2000) "la democracia no solo es un valor en sí mismo sino un medio necesario para el desarrollo".

Para definir los elementos por los cuales será analizada la calidad de la democracia, el trabajo realizado por Diamond y Morlino (2004) se considera central para el desarrollo de nuestra investigación, que expone niveles de análisis y las interrelaciones entre los mismos. Las dimensiones propuestas por los autores y en las cuales estará orientado este trabajo son: 1)Estado de Derecho, que se refiere a la defensa de derechos políticos y procedimientos democráticos. 2)Participación, entendida como la ejecución de derechos e influencia en los procesos de toma de decisiones, 3)Competencia, entendida como la existencia de una diversidad de actores políticos durante los procesos electorales, 4)Rendición de Cuentas (accountability) horizontal, vinculada a la respuesta de los gobernantes a las instituciones del estado y burócratas, en lo que se refiere a su desempeño, 5) Rendición de cuentas (accountability) vertical, referida a la respuesta de los gobernantes a los electores e instituciones del estado, 6)Reciprocidad, en lo que se refiere a las expectativas de los ciudadanos frente a la ejecución de políticas, 7)libertad, vinculada a la ejecución de los derechos civiles, socioeconómicos y políticos por parte de los ciudadanos y por último, 8) igualdad, en lo que se refiere a la visión en la cual todos los ciudadanos y grupos poseen los mismos derechos y protecciones legales, también se vincula a la idea de solidaridad.

\footnotetext{
${ }^{20}$ Tres grandes concepciones de Justicia social conviven en la actualidad: Justicia Social como Distribución (Rawls, 1971; Nussbaum, 2006; Sen 2010), Reconocimiento (Collins, 1991; Fraser y Honneth, 2003; Fraser, 2008) y Participación (Young, 1990; Miller, 1999; Fraser y Honneth, 2003; Fraser, 2008). El primero está centrado en la distribución de bienes, recursos materiales y culturales, capacidades; el segundo en el reconocimiento y el respeto cultural de todas y cada una de las personas, en la existencia de unas relaciones justas dentro de la sociedad; y el tercero está referido a la participación en decisiones que afectan a sus propias vidas, es decir, asegurar que las personas son capaces de tener una activa y equitativa participación en la sociedad.

${ }^{21}$ Ver Rawls, 1971; Nussbaum, 2006; Sen 2010

${ }^{22}$ Collins, 1991; Fraser y Honneth, 2003; Fraser, 2008
} 
Estas dimensiones se encuentran profundamente interrelacionadas y se ven afectadas por diversos aspectos sociales, de acuerdo con (BEETHAM, 2003)se genera una combinación virtuosa en la mezcla de medidas cualitativas y cuantitativas, en el análisis empírico del fenómeno de la calidad de la democracia. (MORLINO, 2002) establece que la interconectividad de las dimensiones propuestas anteriormente provienen de la tradición liberal con base en dos planteamientos. El primero establece que si los ciudadanos tienen la posibilidad genuina de evaluar la responsabilidad del gobierno, en términos de la satisfacción de sus necesidades, lo harán de forma precisa. El segundo establece que los ciudadanos, de forma individual o integrando un grupo, son los únicos capaces de juzgar sus necesidades. De esta propuesta se establece la base de este trabajo. Sociedades con los elementos que conforman la cohesión poseen capacidad para establecer y mantener democracias con calidad.

En este trabajo se evalúa la calidad de la democracia por medio del "Indicador Estatus de la Democracia" (Transformation Index-BTI), que implementa la interpretación dada por Diamond y Morlino (2004), a través de las dimensiones de la calidad de la democracia, por medio de los siguientes aspectos: la capacidad para gobernar (stateness), participación política, el respeto a la ley (rule of law) con énfasis a lo que se refiere a la separación de poderes, estabilidad de las instituciones democráticas por medio de una evaluación de cuán profunda es la aceptación por parte de la población y la integración política, donde se presenta la capacidad de representar una amplia gama de intereses. Indicador que será desarrollado dentro de la operalización de nuestra investigación.

En este sentido, se toma en consideración el análisis en donde se afirma que la forma en que se estructura la sociedad y la forma en que son establecidas las relaciones entre los ciudadanos afecta la calidad de la democracia y, en este caso, el peso que tiene la cohesión social en estas dinámicas. Existen diversos estudios donde se establece que un mayor nivel de desigualdad social/económica y la fragmentación etnolingüística tienen efectos negativos en las dimensiones de la calidad de la democracia. Una menor fragmentación etnolingüística está asociada con una mayor calidad de la democracia (LA PORTA et al., 1999); Mainwaring y Pérez-Liñán, 2008).

En lo que se refiere a la desigualdad, existen estudios importantes en lo que se refiere a su impacto en los niveles de la calidad democrática, (BARREDA, 2011)establece que un contexto de gran polarización, en términos económicos, tiene un impacto negativo en la calidad de las instituciones democráticas, el autor establece que uno de los motivos que generan estos 
procesos se relaciona al hecho de que "las élites de sociedades desigualitarias son muy reticentes a medidas e instituciones que puedan hacer peligrar su situación privilegiada". En muchos países, principalmente en la región suramericana la desigualdad presenta características históricas.

La ciudadanía, que presenta características activas y participativas dentro de las dinámicas gubernamentales o públicas, genera un impacto positivo en la calidad democrática. Autores como Putnam (1993), Morlino (2008) y (LIPSET, 1994) dentro de sus estudios afirman que esta relación existe y debe ser considerada como un elemento importante, en conjunto con otro aspecto denominado como capital social, ampliamente vinculado con la cohesión, definido como "las características de la organización social, tales como las redes, las normas y la confianza, que facilitan la coordinación y la cooperación para un beneficio mutuo" (Putnam, 1993). El compromiso cívico caracteriza, según Putnam, una comunidad cívica, es decir una sociedad en la cual los ciudadanos están predispuestos a la confianza, a la solidaridad y manifiestan un interés por los asuntos públicos. Todo ello se encontrará en la participación asociativa, por una parte, y en la participación electoral, por otra parte. Para (BOIX; POSNER, 1998) el capital social fortalece la responsabilidad democrática porque permite a la ciudadanía informarse y debatir sobre asuntos colectivos.

Lo expuesto anteriormente es una simplificación estratégica de un debate teórico de gran extensión. Lo que se buscó por medio de esta revisión es una aproximación para evaluar cómo se estructura la calidad dentro de las democracias. En los capítulos posteriores, se establecerá una relación entre dos aspectos, cohesión social y calidad democrática, tanto de forma teórica como empírica. Varios estudios se han vinculado a la idea de mayor desigualdad/menor calidad democrática, nuestra visión se enfoca en la cohesión y sus diversas dimensiones como catalizador de una democracia con calidad.

El progreso en esta área debe estar basado en el establecimiento de un esfuerzo en términos colectivos, por parte de todos los segmentos que conforman la sociedad y la existencia más allá de un sentimiento nacionalista por parte de los ciudadanos, un verdadero incremento de ciudadanía con las instituciones políticas, en conjunto con políticas sociales más justas, por medio de una verdadera transformación social apuntando un proyecto colectivo que genere creencias y valores compartidos dando respuesta a los asuntos relacionados con la disparidad, la desigualdad y la discriminación. 


\subsection{Niveles de interacción entre la Cohesión Social y la Democracia, dimensiones y dinámicas}

\section{4. 1. Dimensión Política}

"La desigualdad puede ser atribuida a actos divinos; la igualdad sólo puede ser el resultado de actos humanos"

Giovanni Sartori

A la hora de referirnos a la dimensión política de las interacciones entre la cohesión social y la democracia, debemos tomar en consideración diversos aportes teóricos, (DUHAIME et al., 2004) incorpora como un aspecto fundamental: la confianza en las instituciones cívicas dentro de su mapeo de la cohesión social. Otra contribución importante es dada por Chan et al. (2006), quienes proponen que el componente que conforma las actitudes o elementos subjetivos de la cohesión ciudadana, en términos estatales, debe estar compuesto por indicadores como la confianza en figuras públicas, junto con la confianza en las principales instituciones políticas, sociales y aquellas de otra índole.

Bajo esta óptica, el estado y la sociedad son los actores principales tanto en la generación de los procesos de cohesión como los democráticos ${ }^{23}$, la forma en que se producen estas relaciones son objeto de este evaluación. En la actualidad se observa que la sociedad es un actor esencial, heterogéneo en su construcción y relevante a la par del estado, que a través de su organización es capaz de generar cambios, por lo tanto, desde la visión de una sociedad cohesionada, se establece la hipótesis de que a través de herramientas políticas, es posible consolidar una democracia de calidad.

En este sentido, la sociedad civil ejerce control ciudadano, requiriendo para su efectividad un compromiso por parte de los actores que la constituyen, generando una recomposición de los espacios públicos y la integración social. (ACKET et al., 2011) establece el concepto de "cohesión cívica", compuesta por cuatro componentes principales, entre ellos tenemos: la confianza en los sistemas de distribución nacionales (vinculados a la educación, la seguridad social, la salud, la justicia), la confianza en las organizaciones nacionales (vinculada a la prensa, los sindicatos, la policía, el parlamento, administración pública), la confianza en las instituciones de autoridad (vinculada a las iglesias, las fuerzas armadas) y la satisfacción con la democracia y el gobierno (incluyendo la satisfacción con la forma en que la democracia se

\footnotetext{
${ }^{23}$ Ver Dickes et al 2010; Browne, 2013; Jensen, 1998
} 
desarrolla, valoración subjetiva de los sistemas políticos). Estos aspectos son los que permiten un diálogo efectivo entre el estado y la sociedad.

Hay una fuerte literatura que sugiere que la falta de cohesión entre los grupos en la sociedad tiende a contribuir a la inseguridad, en lo que se refiere a la falta de confianza horizontal entre grupos y vertical con el Estado (Kaplan, 2008); (Jeanotte, 2003) ; ((EASTERLY; RITZEN; WOOLCOCK, 2006); ((JENSEN, 1998); (Norris, 1999);(CUELLAR, 2009), entre otros), lo cual resulta en un contexto de fragilidad de las instituciones estatales.

Tomando en consideración el escenario contemporáneo, las interacciones serán analizadas a partir de aspectos en los cuales se aproximan nuestros dos conceptos (cohesión social y democracia), estos son: la legitimidad, la igualdad y el principio de ciudadanía. Estos elementos pueden estar presentes en los sujetos y grupos sociales de manera independiente, pero al estar separados operan limitadamente, por lo que es necesario un vínculo entre ellos para potenciar una verdadera identidad social, capaz de impactar las estructuras institucionales y el escenario en el cual se desarrolla el estado.

\subsubsection{Legitimidad}

Durante el siglo pasado fueron establecidas una serie de clasificaciones en lo que se refiere a la cohesión social, estableciendo un vínculo con la democracia por medio de la dicotomía dada entre legitimidad/ilegitimidad, en este sentido, Jenson (1998) y Bernard (1999) establecieron que existe una dependencia entre las instituciones privadas y públicas, sirviendo como mediadores a la hora de resolver diferencias y conflictos de interés en diversas sociedades.

Esta visión encuentra un paralelismo con la propuesta por (NORRIS, 2011), que es, posiblemente, la representación que más abarca la legitimidad política hasta la fecha. Los indicadores de clusters desarrollados por Norris en lo que se refiere al apoyo político en un marco multidimensional, consisten en cinco componentes, que van desde lo más general a lo más específico, las dimensiones son: identidad nacional, aprobación de los principios y valores del régimen, evaluaciones del desempeño régimen y confianza en las instituciones del régimen

El primer componente, la identidad nacional ${ }^{24}$, representa el conjunto más general de las actitudes hacia la pertenencia o el apego al estado, con medidas basadas en estudios comunes e

\footnotetext{
${ }^{24}$ Este componente esta en gran medida ausente en la conceptualización de (ACKET et al., 2011) aunque lo hace en función de la actual serie de indicadores de desarrollo para la cohesión social, que se están utilizando para fines de supervisión de la Presidencia sudafricana.
} 
indicadores incluidos "orgullo nacional, patriotismo y sentimientos de identidad nacional". La segunda dimensión de apoyo, vinculada a la idea de aprobación de los principios y valores del régimen, siendo un apoyo a los principios y valores democráticos fundamentales. El tercer aspecto es la evaluación de desempeño de un régimen, y se concibe como la opinión de los ciudadanos hacia el desempeño democrático del gobierno, así como las evaluaciones de decisiones. Por último tenemos la confianza en las instituciones del régimen, que se refiere a la confianza en las instituciones del sector público, los niveles de apoyo público a la legislatura del gobierno, ejecutivo, el poder judicial y los tribunales, las fuerzas de seguridad, los diferentes niveles de gobierno (nacional, provincial y local), la administración pública, además de los partidos políticos (idem).

Este último aspecto vinculado a la confianza, de acuerdo con (ACKET et al., 2011), no debe estar enfocado exclusivamente en las instituciones del sector público, este debe tomar en consideración otras instituciones sociales importantes, tales como la prensa, el comercio, sindicatos e iglesias, que tienen un efecto importante en las dinámicas sociales. Debe ser enfatizado que la confianza institucional sigue siendo la prioridad en los intentos de identificar los indicadores de cohesión política o cívica de la toma de los procesos (idem).

Diversos autores, como Beetham (1991) y (BERGER; ZELDITCH, 1989) analizan las características individuales y el contexto en el cual estas se desarrollan, llegando a un consenso en el que la legitimidad es una de las bases de la estabilidad de los sistemas democráticos. La legitimidad se ve facilitada a través de una sociedad en la cual existan características de cohesión, promoviendo de esta forma la estabilidad de las relaciones de autoridad en la sociedad y de poder en el espacio político.

En el escenario contemporáneo existe un cambio importante en la forma en la cual se interpreta la ciudadanía, ya que esta no debe evaluarse bajo la óptica de la "crisis de legitimidad" que ha sido colocada por autores como (STRUWIG et al., 2012), definida como la "disminución de la participación electoral, la disminución de la confianza en el gobierno, una pérdida de capital social, el debilitamiento de la confianza interpersonal, y el creciente descontento público y la desafección", que se fundamenta en una ciudadanía basada en el deber (voto, obediencia a las leyes, etc.), por el contrario presenta características que reflejan un mayor comprometimiento $^{25}$ tales como la organización ciudadana, participación activa en la formulación de políticas, entre otros aspectos, esto como consecuencia de la evolución

\footnotetext{
${ }^{25}$ Ver Dalton, (2006), Zukin et al. (2006); McBeth et al. (2010)
} 
social/política y el progreso de la interpretación dentro de las sociedades, en lo que se refiere al peso del poder del ejercicio de ciudadanía y el sentido de solidaridad social (DALTON, 1996).

Aun con los avances ciudadanos la legitimidad continúa siendo un desafío y es esencial dentro de una sociedad cohesionada, la democracia por su parte debe ser caracterizada como un conjunto de canales legitimadores orientados a la tarea de institucionalizar todo conflicto social. De acuerdo con Sorj y Martuccelli (2010, p. 148), en este respecto, se establece que:

\begin{abstract}
"Una de las características fundamentales de un sistema social es la legitimidad de sus instituciones políticas, que se fundamenta en el respeto a los que poseen una autoridad delegada por la sociedad. Es esa legitimidad que permite que las autoridades públicas cumplan sus mandatos con mayor eficiencia y con el mínimo de coerción. Cuando no existe legitimidad, la autoridad solo podrá ser ejercida, ya sea por el uso del autoritarismo o por la violencia, sea por el uso de la corrupción, por medio de la cooptación de aliados y electores, más frecuentemente, por una combinación de las dos cosas"
\end{abstract}

Tomando en consideración lo evaluado anteriormente, para que exista una verdadera legitimidad del sistema democrático, debe existir una retribución estado-ciudadanía de las demandas de inclusión y participación expresadas desde los individuos hacia el sistema político, por lo tanto una sociedad estructurada por medio de la inclusión podrá estar en capacidad de exigir al establishment gubernamental el cumplimiento de sus derechos en todas las esferas.

\title{
1.4.1.2 Igualdad
}

La visión de igualdad dentro de las sociedades, principalmente para aquellas que se definen como democráticas, es un aspecto altamente complejo, ya que la disparidad se encuentra enraizada históricamente en nuestro entorno ${ }^{26}$ y al mismo tiempo estas inequidades no se producen con la misma intensidad en todos los ámbitos, cómo ha sido establecido por (SARTORI, 1996) "es en la búsqueda de dar respuesta a esta problemática del "cómo" debe ser realizado el ideal de igualdad, lo que muchas veces dificulta su implementación”.

La igualdad, interpretada como un valor, es un consenso universal, en lo que se refiere al acceso a los derechos humanos, el bienestar material, la participación en el espacio público y en el acceso a la información. Estos elementos son considerados como fundamentales para el desarrollo adecuado de los individuos dentro de la sociedad. En este sentido, la base material y simbólica de las democracias no se encuentra exclusivamente en una forma de institucionalidad

\footnotetext{
${ }^{26}$ Principalmente en regiones donde se dieron procesos de colonización, como es el caso de América del Sur, Africa, entre otras.
} 
política o un tipo de economía, sino, cada vez más, en "la aplicación del conocimiento como eje fundamental en conjunto con aspectos tales como la información y la comunicación" (CEPAL, 2010), ya que una sociedad informada de sus derechos y la forma de accederlos permite su desarrollo efectivo.

La cohesión social, dentro de las definiciones de la Comunidad Europea y de la (CEPAL, 2007b), considera a las sociedades como mecanismos eclécticos en su forma de desarrollo y características fundamentales, pero resalta el hecho de que para que el proceso de cohesión se realice o avance, sus miembros deben tener igualdad en el acceso a derechos básicos, no sólo aquellos constituidos por los derechos humanos, sino también los civiles, políticos, económicos, sociales y culturales.

La democracia moderna interpreta a los derechos humanos como el límite a la acción del Estado, a fin de garantizar la libertad de las personas en materias que son de la exclusiva soberanía de las mismas (HOPENHAYN, 2000). Esto puede definirse como uno de los mayores consensos en lo que se refiere al tema de igualdad a nivel mundial, consenso que se observa más en la teoría que en la práctica, debido a la continuación de prácticas autoritarias, excluyentes de nuevos actores sociales, con fallas profundas en la reivindicación de derechos, entre otros aspectos.

La relación entre igualdad y democracia, de acuerdo a lo establecido por (SARTORI, 1996), coincide en que el ideal igualitario puede ser elevado a la posición de símbolo del ideal democrático, queriendo decir con esto que la demanda en búsqueda de la igualdad alcanza su nivel más elevado dentro de un sistema democrático. Al establecer el vínculo con la cohesión social nos estamos refiriendo a la igualdad de oportunidades, que se encuentra tipificada entre los diversos "tipos de igualdad"27.

Actualmente, lo que consideramos como "democracia moderna" busca un tipo de igualdad que puede ser denominado como "justa” (ídem), los demócratas están dispuestos a intercambiar mayor igualdad por menos libertades, esto puede decirse que va más allá de la democracia liberal y de la democracia social, entrando en la esfera económica, que constituye un elemento que impacta fuertemente la relación entre los individuos con el sistema democrático,

\footnotetext{
${ }^{27}$ Dentro de los diversos tipos de igualdad establecidos por Sartori (1994) tenemos: 1) Igualdad jurídico-política, que se refiere a los mismos derechos legales y políticos para todos, esto es, el poder legalizado de resistir al poder político. 2) Igualdad Social, la misma importancia social para todos, esto es, el poder de resistir a la discriminación social. 3) Igualdad de oportunidades como acceso igual, las mismas oportunidades de ascensión para todos, esto es, el poder de hacer valer los propios méritos. 4) Igualdad de oportunidades como punto de partida igual, un poder inicial adecuado (condiciones materiales) para que todos adquieran la misma calificación y posición social de los demás. 5) Uniformidad económica, poder (económico) para nadie.
} 
esto se debe a que la igualdad no es un aspecto que puede ser satisfecho o que su indagación se realice simplemente por medio de un único criterio. Es necesaria la implementación de aspectos multidimensionales para proporcionar a los individuos con herramientas para una ciudadanía activa, herramientas compuestas por derechos sociales básicos, capaces de catalizar los procesos democráticos.

Evaluando el contexto contemporáneo, los derechos individuales y su vinculación con la igualdad, es importante resaltar que existen amplios debates dentro del área académica, Norberto (BOBBIO, 1994) establece que:

"la razón de ser de los derechos sociales como la educación, el derecho al trabajo, el derecho a la salud, es una razón igualitaria, los tres tienden a que la desigualdad sea menor entre quienes tienen y quienes no tienen, o a poner un número de individuos, siempre mayor, en condiciones de ser menos desiguales respecto a individuos más afortunados por nacimiento o condición social".

Si la institucionalización de la democracia se vincula, tanto de fondo como de forma, a la idea de derechos y de una concertación ampliada de la sociedad, esto contrasta con una realidad mundial que se caracteriza por la falta de presencia pública y de acceso a decisiones de una parte importante de la población, dichos sectores viven una realidad de exclusión, marginados del desarrollo económico y limitados, en consecuencia, a una participación política y social plena, debido a la falta de diálogo público, fundamental para el fortalecimiento del individuo como un ser político y de la democracia como un verdadero sistema político.

Esta realidad contemporánea, a la que hacemos mención, representa una crisis estructural, que refleja años en los que se le dio prioridad a los aspectos económicos, dejando de lado la complejidad de los aspectos que conforman el sistema en términos políticos y sociales:

"Para dar un salto en el reto de la igualdad, es condición buscar, al interior de los países, los acuerdos políticos y sociales que lo hagan posible. No habrá avances si no se pacta, social y políticamente, el modelo de solidaridad que los pueda sustentar. Sin duda esto tiene costos, pues redistribuir poder, conocimiento, información y recursos, significa desconcentrar y socializar. Ello sólo es factible con acuerdos y pactos, institucionalizados a través de normas obligatorias que terminan por construir, a partir de sus prácticas, nuevas relaciones en la sociedad y una cultura de mayor igualdad. Y ello requiere, a su vez, darle sostenibilidad fiscal." (HARDY, 2014)

De ahí derivan debates, en mayor o en menor grado, del concepto denominado como igualdad compleja, que es "el resultado de la diferenciación social en esferas de la justicia y la preservación de sus prácticas y las reglas internas de su autonomía institucional" (WALZER, 2008). El desafío de la igualdad debe ser abordado desde dos perspectivas: la primera, asumir 
que el problema de la desigualdad no está basado en las posesiones materiales, sino por el contrario este se fundamenta en "una relación compleja entre personas mediada por un conjunto de bienes" (Idem), y la segunda, entender que la desigualdad es un problema de estratificación y dominación donde esta búsqueda constante por la igualdad es la lucha contra la opresión por parte de los individuos.

(LUHMANN, 1984) refiriéndose a la igualdad compleja, establece la existencia de áreas en las que las desigualdades son menores, generando la capacidad de potencializar otras. Este principio no hace referencia a una naturaleza humana vista de forma igualitaria, sino a través de una relación abstracta que representa una exigencia estructural de los derechos modernos, garantizando una relativa autonomía del sistema (Ídem).

La fragmentación, como elemento constante de las sociedad, hace que la búsqueda por la igualdad sea una prioridad. En aquellas sociedades donde se observan elevados niveles de desigualdad se expresa escaso interés por los asuntos públicos, ya que se percibe un contexto en el cual unos se ven mayormente privilegiados a diferencia de otros. La reversión de este escenario tiene un impacto sistémico en el incremento de la participación de los individuos y mejora en la calidad de los sistemas democráticos (Brunetto Latini apud SARTORI, 1994).

Esta participación ciudadana depende del fortalecimiento de la cohesión social, en lo que se refiere a la igualdad en el acceso a las oportunidades de los miembros de nuestras sociedades, reforzando el sentido de pertenencia (CEPAL, 2007a) La tendencia es a generar una percepción como agentes y beneficiarios de los procesos de desarrollo, esto se realiza por medio del fortalecimiento de tres aspectos fundamentales:

a) Empleo, "visto como la inserción productiva que genera un aumento en los ingresos, seguridad y bienestar" (CEPAL, 2007), siendo estos aspectos interpretados como cohesión social objetiva $^{28}$ y en lo que se refiere a la cohesión subjetiva ${ }^{29}$, los aspectos referidos a sentido de pertenencia, reconocimiento del esfuerzo, internalización de normas y actitudes.

Debe considerarse que la inserción productiva se encuentra en un proceso de cambio constante, en la que influyen factores vinculados a la globalización. En este sentido, el objetivo debe ser la búsqueda de trabajos dignos por medio del aumento de oportunidades y la calidad del empleo. Por otro lado, tanto el desarrollo económico como cultural, requieren de la participación

\footnotetext{
${ }^{28}$ Se refiere a los mecanismos de inclusión y exclusión social (CEPAL, 2007)

${ }^{29}$ Se refiere a las percepciones de la ciudadanía frente a los mecanismos de inclusión y exclusión social, aspectos vinculados a confianza social, capacidad de empatía de los individuos, sentido de pertenencia y sentido de solidaridad (CEPAL, 2007)
} 
efectiva, en términos de fuerza laboral, por parte de los miembros que conforman la sociedad, esto implica, como fue establecido por la CEPAL, la inserción en "el esfuerzo colectivo de factores que refuerzan su identidad y comunión con los valores que la sociedad propugna" (CEPAL, 2010).

La integración acelerada de los países a nivel regional y mundial, los cambios en la economía mundial (en términos de mercado, intercambio comercial, acceso a bienes, entre otros), así como la evolución tecnológica, que puede considerarse como el factor principal, afectan la inserción productiva. Debe ser realizado un esfuerzo para ajustarse a esta realidad, fortaleciendo los intereses comunes y tomando en consideración la volatilidad del mercado, protegiendo a los más débiles.

b) Educación, es uno de los ejes centrales de la cohesión social. Establecemos que por medio de una visión sociopolítica, la educación puede, efectivamente, contribuir a fortalecer la democracia en el tejido social, por medio de las capacidades que se aspiran a ser desarrolladas en el individuo. Es un mecanismo que permite a los individuos "adaptarse a los cambios productivos a lo largo de su vida, dialogar activamente en espacios de decisión, ejercer su derecho de participar en lo público (...) a fin de participar activamente del intercambio simbólico en la sociedad (Hopenhayn;Ottone, 2000 apud OTTONE; SOJO, 2007).

La educación debe ser interpretada como un paradigma multicultural que corresponde a un incremento en el acceso de oportunidad y el reconocimiento de la diversidad, por medio del vínculo de los individuos y de los grupos con su historia, cultura e identidad. Las particularidades que se desprenden de estas dinámicas no pueden evitarse, ya que el objetivo a ser alcanzado es la convivencia entre las especificidades, la apertura entre las culturas y evitar la violencia para dirimir conflictos (CALDERON; HOPENHAYN; OTTONE, 1996)

El acceso a una educación de calidad debe ser visto como un activo simbólico ${ }^{30}$, este tipo de activos son aquellos que permiten alcanzar activos materiales ${ }^{31}$ a largo plazo, siendo considerados como mecanismos efectivos para revertir la pobreza ${ }^{32}$ y generar ciudadanos activos que busquen una democracia de calidad, siendo integrantes activos y con posibilidades de avanzar en términos de estratos sociales.

\footnotetext{
${ }^{30}$ Definidos como conocimientos y destrezas útiles (AGUERRONDO, 1993)

${ }^{31}$ Definidos como ingresos, bienes y servicios (idem)

32 Dentro de una amplia gama de reportes de los organismos de las Naciones Unidas (UNESCO, CEPAL, PNUD, etc.), se coloca a la Educación como el aspecto que más ejerce influencia en el desarrollo efectivo de los individuos, en consecuencia la educación debe ser vista como fundamental a la hora de establecer como un vínculo con el desarrollo de los individuos.
} 
Individuos que posean estas características definidas como activos simbólicos tienen la capacidad de ejercer una ciudadanía activa, ya que poseen las herramientas para participar y evaluar el desempeño de un sistema político, lo que genera a su vez un vínculo con la estructura institucional en términos de democracia, evaluando las diversas características que componen una calidad democrática efectiva.

c) Protección Social: cuando hacemos referencia a la protección social nos referimos a aquellas prestaciones que disminuyen el nivel de vulnerabilidad de la población y mejoran la calidad de vida de los individuos, miembros de una sociedad (CECCHINI et al., 2015) este tipo de asistencias permiten crear vínculos y sentimientos de pertenencia, ya que se genera una red de prevención y disminución de riesgos a los cuales se ven enfrentados los ciudadanos. Existen estratos sociales que sufren de una incidencia mayor en este sentido:

\footnotetext{
"Su distribución e intensidad a escala nacional y entre diferentes sectores y categorías sociales, están en función de la operación de los mercados, las familias y los Estados, vínculo respecto del cual las políticas sociales cumplen una función esencial, por lo que su intensidad y los mecanismos instituidos para paliar los riesgos varían de una sociedad a otra" (Huber y Stephens, 2004 apud CEPAL, 2007, p.199)
}

La protección social debe ser entendida como una disminución de los riesgos a los cuales se enfrentan los individuos, entre los cuales se encuentran el desempleo, la vejez, entre otros, obteniendo su financiamiento a través de los individuos que tienen una participación activa, en términos de ciudadanía, por medio de los impuestos (CEPAL, 2007a). Como fue establecido por (FILGUEIRA, 2013) la capacidad de integrar a los individuos en un marco normativo común depende, en buena medida, de que ellos perciban que, efectivamente, pertenecen a un "sistema conjunto de interacción, cooperación, y conflicto que, al menos parcialmente, los protege de ciertos riesgos fundamentales mediante sistemas de protección social".

Tomando en consideración los elementos, desarrollados anteriormente, que permiten a una sociedad ser entendida en términos de igualdad, vemos que la tesis que mejor se adecua en esta dinámica entre cohesión social y democracia, es aquella que establece que, para el alcance de una igualdad mayor dentro de las sociedades, debe existir una redistribución/equilibrio más amplia y completa de las desigualdades, esto se refiere a la obtención de un "sistema eficiente de compensaciones recíprocas entre las desigualdades" (Idem), donde un tipo de desigualdad tiende 
a contrabalancear otro, en definitiva, podemos decir que esta tesis se refiere al equilibrio de las disparidades, donde una desigualdad compensa otra.

Bajo este análisis, la igualdad es una forma de libertad, a su vez la libertad y las condiciones económicas se encuentran vinculadas entre sí, Sartori (1994) coloca que "en cuanto un estado de libertad abre de hecho el camino para el apetito por igualdad, el ideal de libertad se encuentra en desventaja, y el reclamo de la igualdad prueba ser más fuerte”, por estar vinculado a la concesión de beneficios tangibles. En este sentido, nos referimos a beneficios materiales, la libertad por su parte está vinculada a beneficios intangibles. Por estos motivos, la idea de igualdad juega un papel fundamental en el establecimiento de sociedades cohesionadas y el fortalecimiento de los sistemas democráticos, esta proporciona las bases para que los individuos tengan las mismas herramientas en el momento de formar parte activa de una sociedad.

\subsubsection{Principio de Ciudadanía}

El principio que define a la ciudadanía es el que está vinculado a la idea de participación del individuo en la definición de las reglas propias de su entorno, principalmente, en términos de la estructuración del estado en sus diversas dimensiones y el establecimiento de un sentido de pertenencia con su comunidad (CEPAL, 2007). La participación, tanto en la vida pública como en los procesos decisorios a nivel estatal, enlaza la ejecución de los derechos civiles y políticos, dando lugar a estas dinámicas ciudadanas, para lo cual el reconocimiento de dichos derechos es fundamental en términos de su aplicación.

Frente a este contexto vemos que los individuos, definidos como ciudadanos, se presentan como "los principales actores dentro de los procesos democráticos, que tienen como principal obligación la participación en la sociedad civil" (ARAYA, 2005) que como fue establecido por Glendon (1991, p. 109), es en este hecho donde "se forma el carácter, las competencias y la capacidad de la ciudadanía”. En las sociedades contemporáneas, que se denominan como democráticas, para que el principio de ciudadanía sea ejercido son necesarios un conjunto de elementos que le proporcionan las capacidades de acción, entre estos, tenemos que un ciudadano sea:

"titular de derechos civiles como el de libre expresión, propiedad privada, vida, educación, salud, etc.; titular de derechos políticos como: el de representación, elegir y ser elegido, el derecho al ejercicio del voto; y de derechos sociales como: el derecho que tiene el individuo a un ambiente sano, seguridad social, derecho a tener una familia, a la asociación, etc.; derechos todos que se encuentran en cabeza del Estado, el cual asume 
la responsabilidad de la promoción y la protección de los mismos" (PARADA BARRERA, 2009)

Como establece Pérez-Prat Durbán (2004 apud (PARADA BARRERA, 2009), el presupuesto fundamental en relación a la ciudadanía se encuentra en el pensamiento comunitario $^{33}$, donde aspectos tales como la civilidad y el autocontrol son condiciones para la implementación de un sistema democrático, en este sentido, cobran gran importancia los grupos civiles (iglesias, sindicatos, asociaciones, cooperativas, grupos de apoyo, etc.), ya que en ellos es donde el individuo, definido como ciudadano, entiende las implicaciones y beneficios del compromiso mutuo.

Desde esta perspectiva, al hacer referencia al vínculo del concepto de ciudadanía con la Cohesión Social, deben ser considerados un cierto conjunto de derechos. En términos teóricos resulta complejo establecer qué conjunto mínimo de derechos o capacidades pueden ser consideradas como suficientes para generar un acuerdo intersubjetivo, dentro de las sociedades esto sólo puede y debe ser decidido por la propia democracia, generando, como consecuencia, que estos derechos sean socialmente construidos y variables, dentro de ciertos límites (FAUNDEZ, 2006).

Siguiendo la línea de pensamiento, que vincula los derechos con la ciudadanía, existen tres aspectos importantes a ser considerados de acuerdo con Faundez (2006), en primer lugar, tenemos el aspecto individual/social de los derechos, al referirnos a ellos como un atributo a los individuos. En lo que se refiere a su asignación universal, en este sentido, (SEN, 2001) estableció que "la libertad individual es un producto quintaesencialmente social" . Sin embargo, a nivel macro, estos mismos derechos constituyen libertades que caracterizan y constituyen el contexto social en que los mismos individuos están incluidos (O’DONNELL, 2004). De acuerdo con Raz (1977) existe una razón para proteger constitucionalmente ciertos derechos fundamentales:

\footnotetext{
"Sin el bien público de un contexto social diverso, la efectividad de los derechos políticos estaría seriamente coartada. Cuando tal contexto existe, beneficia a todos, aun a los que no reconocen su valor: se trata de un bien público, derivado del carácter general de la sociedad de la que uno forma parte". (RAZ, 1977)
}

En segundo lugar, tenemos que referirnos al aspecto de implementación y funcionamiento de los derechos. Este punto se relaciona a la necesidad de una serie de

\footnotetext{
${ }^{33}$ La idea comunitaria de ciudadanía, está en contraposición con la visión liberal que se enfoca en el individuo, caracterizándose en el hecho de sentirse miembro de un grupo, en el cual son compartidas capacidades ciudadanas, como el respeto por los otros y el reconocimiento de la importancia del servicio público. Desde la perspectiva comunitaria, los derechos de los grupos pueden tener significados legales y políticos. (Idem)
} 
condiciones, en el entorno social, para que su ejercicio sea efectivo para todos los ciudadanos. El problema no está vinculado, en la mayoría de los casos, a la ausencia o limitación de las normas legales que definen los derechos, sino a "un déficit de enforcement, de ejercicio efectivo de derechos garantizados en la ley" (Tavares de Almeida apud (FAUNDEZ, 2006) .

En tercer lugar, debemos tomar en consideración lo que se refiere a la relevancia, en términos relativos, de los derechos civiles frente los derechos políticos y los de segunda generación (FAUNDEZ, 2006). Los derechos civiles ${ }^{34}$, constituyen un mecanismo generador de igualdad que permite el ejercicio de los derechos políticos, por un lado, y económicos, sociales y culturales, por el otro. Viendo estos derechos civiles como un aspecto esencial o, en otras palabras, como la base para el alcance de otro tipo de derechos y avances en términos de desarrollo humano, vemos que:

\begin{abstract}
"cualquier derecho civil que es conquistado puede convertirse en una importante palanca para avanzar en la democratización política y en la conquista de derechos sociales. Los derechos civiles no sólo protegen, también dan poder; ellos generan igualmente oportunidades de actuar para alcanzar más derechos. Los derechos civiles hacen así posible (pero insisto: sólo posible), para diversos actores individuales y colectivos, definir autónomamente su identidad y sus intereses" (O'DONNELL, 2004)
\end{abstract}

Para el establecimiento de la condición de ciudadanía, los derechos sociales son una condicion sine qua non, ya que estos son los que permiten el alcance de la equidad y la igualdad en nuestras sociedades. Estos vienen en conjunto con una serie de demandas específicas, planteadas al estado por parte de la sociedad, como mejoras en la educación, salud, entre otros aspectos, buscando el alcance de un mayor nivel de bienestar así como oportunidades en términos productivos para los ciudadanos.

Dentro del imaginario de nación, un incremento en la participación política dentro de los sistemas democráticos, genera un alcance mayor en lo que se refiere a la consolidación ciudadana. La concertación política entre los diversos actores que conforman la sociedad permiten el desarrollo de proyectos sustentables, el diálogo político, principalmente el diálogo ciudadano, se ejerce a través de diversos niveles, O’Donnell (2003) denomina esto como "intensidad ciudadana", el cual es entendido como "el libre y activo ejercicio de los derechos y el cumplimiento de los deberes genéricos propios del estatus de ciudadanía”, estableciendo el vínculo entre los individuos como agentes ejecutores de acciones políticas dentro de un sistema democrático.

\footnotetext{
${ }^{34}$ Siendo estos las libertades y garantías liberales clásicas (O’DONNELL, 2001)
} 
Con el objetivo de abordar este tema se usa la herramienta de tipología de perfiles de intensidad ciudadana, que clasifica a las personas de acuerdo con la manera como ejercitan su estatus de ciudadano, definidos como: Demócratas participativos (que poseen una orientación democrática y están dispuestos a involucrarse en el sistema democrático), Demócratas desmovilizados (poseen una orientación democrática, pero no están dispuestos a participar en el sistema democrático). Ambivalentes y no demócratas desmovilizados (presentan una ausencia de compromiso con la democracia y falta de participación política) y Ambivalentes y no demócratas participativos (tienen una ausencia de compromiso con la democracia y cierto nivel de participación política)(ídem).

Frente a estas caracterizaciones de la "intensidad ciudadana" y de acuerdo al informe "La Democracia en América Latina" (PNUD, 2004) esta es una herramienta que nos permite evaluar el nivel de vulnerabilidad de la misma, ya que el concepto o la idea de democracia requiere, para su aplicación, cierto nivel de participación política y esta división de los niveles de intensidad ciudadana permite el reconocimiento de los diversos grupos de ciudadanos que se presentan en este tipo de sistemas políticos.

La intensidad ciudadana, dentro de las democracias, depende de la ciudadanía inclusiva ${ }^{35}$ definida como el patrón a ser alcanzado. La distribución equitativa del ejercicio de la misma conlleva a una presencia mayor, en lo que se refiere a las decisiones políticas por parte de los individuos, generando mayor viabilidad en la ejecución de los derechos políticos, económicos y sociales (KABEER, 2005) . La cohesión social supone la participación amplia de los ciudadanos en las cuestiones públicas. Esta participación ciudadana debe ser vista como un propósito así como un mecanismo, ya que esta:

\begin{abstract}
"reconoce el derecho de todos los ciudadanos, produce conocimientos, nuevas modalidades de acción colectiva, y persigue fines igualitarios para la sociedad. Además, puede ser expresión y defensa de esa sociedad, al cumplir una función critica de la posible particularización de los asuntos públicos (concentración de la toma de decisiones en una elite). Finalmente, la participación permite establecer una identificación entre necesidades y soluciones a los problemas que se enfrentan (...) con lo que se favorece el desarrollo comunitario" (CEPAL, 2007, p. 91)
\end{abstract}

En definitiva, y tomando en consideración los aspectos mencionados anteriormente, la acción colectiva, vista como la participación activa por parte de los ciudadanos, en conjunto con la interacción de los diversos grupos que conforman una sociedad generan un fortalecimiento de

\footnotetext{
${ }^{35}$ La ciudadanía inclusiva se basa en el reconocimiento de las identidades de las personas y los pueblos, en el respeto a las diferencias y en el estímulo de una interacción y solidario (ROSALES LOPEZ, 2009)
} 
la cohesión social y, en consecuencia, un potenciamiento de la valoración de la democracia como sistema de representación, ya que se previene la erosión generada a partir del distanciamiento social. $^{36}$

\subsubsection{Dimensión Socioeconómica}

La fragmentación social, en conjunto con elevadas brechas socio económicas, implican una situación de fragilidad política que puede derivar en conflictos, este contexto de desigualdades sociales hace difícil la práctica de una verdadera ciudadanía capaz de accionar los mecanismos que conforman la democracia, debido a la debilidad de la legitimidad del Estado, impidiendo la formación de sistemas de gobernanza fuertes y compromiso democrático por parte de la sociedad civil.

El desarrollo socioeconómico se constituye como la estructura por medio de la cual se produce una estabilidad dentro de las sociedades y se les proporcionan las herramientas a los individuos para el alcance del progreso. En este sentido, evaluaremos las interacciones que se dan entre la cohesión y la democracia a partir de dos procesos: uno, el desarrollo económico de las sociedades vinculado a la idea de la disminución de brechas sociales y dos, la integración social dentro de una sociedad vista desde el enfoque del sentido de pertenencia y la integración a nivel macro entre estados. Y como todos estos elementos fortalecen los procesos de cohesión, sentando las bases para una democracia con calidad.

\subsubsection{Desarrollo Económico}

Dentro de la evaluación de las interacciones entre cohesión social y calidad democrática, existe la propuesta teórica que establece que el nivel de desarrollo económico de un estado ejerce una acción importante en la caracterización del tipo de régimen político y su capacidad de sustentabilidad en el tiempo, (LIPSET, 1994) defiende esta hipótesis y establece en su investigación que el nivel de desarrollo económico de un estado (tomando como base los aspectos sociales) interfiere en la probabilidad de consolidarse como un sistema democrático y a su vez tiene un efecto en su estabilidad ${ }^{37}$.

(DIAMOND, 1999) posteriormente, apoya la hipótesis de Lipset al afirmar la existencia de una relación causal entre el desarrollo socioeconómico y la democracia. Las razones de esta

\footnotetext{
${ }^{36}$ Procesos de desorganización social profundos, producidos por la falta de un contacto suficiente o suficientemente prolongado de los segmentos o grupos que conforman una sociedad (BOTELLO; CARMONA, 2004)

${ }^{37}$ En este aspecto es fundamental el efecto que tiene el desarrollo económico en la ampliación de la clase media.
} 
relación causal son resumidas en cinco propuestas establecidas por el autor: 1)En sistemas democráticos el desarrollo sostenido contribuye con la legitimidad y estabilidad y en donde no existe democracia el desarrollo sostenido conduce eventualmente a su instauración. 2)El desarrollo socioeconómico no tiene efectos legitimadores en los regímenes autoritarios a largo plazo. 3) No es el desarrollo económico de forma exclusiva lo que genera una consolidación de la democracia, sino aquellos cambios que generan mejoras sociales disminuyendo las brechas sociales. 4) El desarrollo económico conduce a la democracia si se logra modificar de forma positiva la "cultura política, estructura de clases, relaciones Estado-sociedad y la sociedad civil". 5) Es posible la existencia de un sistema democrático si las variables anteriores existen de forma adecuada aun en la ausencia de desarrollo económico.

De acuerdo con (DAHL, 1999) "hay una asociación indudablemente significativa entre el nivel socioeconómico y desarrollo político", la combinación de democratización y desarrollo contribuye a que ambos se establezcan de forma duradera, pues ni la democracia política puede consolidarse sin medidas económicas y sociales que propicien el desarrollo, ni una estrategia de desarrollo puede prosperar sin la legitimidad y el refuerzo que le confiere la participación democrática.

Tomando en consideración las visiones establecidas por Lipset (1994), Dahl (1999) y Diamond (1999) se puede concluir que el desarrollo económico es un concepto que supone profundas transformaciones estructurales, así como la necesidad de un programa social y político congruente con las necesidades sociales para alcanzar un verdadero impacto dentro de la sociedad. Es importante diferenciar desarrollo económico de crecimiento económico "que es una condición necesaria pero no suficiente, para el desarrollo propiamente dicho" (KUGELMAS, 2007) ya que para hacer referencia al desarrollo, ciertas características económicas deben ser consideradas a la par de su efecto en los indicadores sociales.

La democracia y el desarrollo económico son estructuras complementarias, y a su vez se ven reforzadas mutuamente, en este sentido el desarrollo económico altera la estructura de estratificación social, ya que se incrementa el número de individuos dentro de la clase media, lo que tiende a la generación de procesos inclusivos, como consecuencia de un incremento de la renta a nivel nacional y una mayor difusión de la educación superior, lo cual genera que las clases populares desarrollen expectativas de ascensión social de largo plazo.

Tomando en consideración estos aspectos, un sistema democrático no puede alcanzar un sistema de calidad elevado sin un compromiso social sólido, de esta forma los procesos 
inclusivos se encuentran estructurados en base a tres pilares, la redistribución, reconocimiento y la participación, por medio de la disminución de desigualdades y de una ciudadanía activa a través de la toma de decisiones colectivas (FRASER, 1996). Aun cuando en la mayoría de las instituciones políticas y económicas, a nivel mundial, se ha establecido el paradigma de la inclusión desde una visión básicamente economicista, no es un debate exclusivo de esta área, ya que posee una amplia vinculación con las políticas públicas y la capacidad del Estado como actor protagónico en la distribución de recursos.

El hecho de que la sociedad se haya vuelto más heterogénea y fragmentada afecta la formulación de pautas comunes, por lo tanto un orden social pluralista e inclusivo es esencial para la creación de democracias consolidadas, estos son los aspectos que generarán dinámicas en las cuales prime la negociación evitando la coerción, de acuerdo con (DAHL, 1999)

"Una economía avanzada y las estructuras sociales que la sustentan, distribuyen automáticamente los recursos políticos y habilidades políticas a una enorme variedad de individuos, grupos y organizaciones. Entre estas habilidades y recursos están: la renta, status y reconocimiento entre grupos especializados ; habilidad en la organización y la comunicación; y acceso a organizaciones, experts y elites"

Tomando en consideración la visión del autor se reafirma el hecho, de que el desarrollo económico en una sociedad mejora los indicadores disminuyendo las brechas sociales, elementos fundamentales dentro de la cohesión, creando, de acuerdo con Dahl (1999), sociedades "modernas, dinámicos y pluralistas". Este desarrollo debe estar profundamente vinculado con la equidad y la cohesión, siendo "un proceso de expansión de las libertades reales que goza el pueblo" (SEN, 2001). En este contexto, el principal obstáculo para la democracia es la pobreza, los individuos como miembros de una sociedad desigual, no poseen las herramientas para participar en la vida política y social, tanto en el ámbito local como nacional.

Una vez establecidas las diferentes visiones que sustentan estas dinámicas debemos tomar en consideración el escenario en el que se desarrollan estos procesos, por lo tanto, el capitalismo, como sistema económico, debe colocarse dentro de esta discusión. Dahl (1999) establece que existe una tensión permanente entre mercado y democracia, aun cuando afirma que la "democracia poliárquica" ${ }^{38}$ solo ha resistido en economías de mercado, siendo inexistente en estados socialistas, esto debido a que la economía de mercado coordina de forma más eficiente la producción nacional, aun cuando crea grandes desigualdades en la distribución de los recursos políticos.

\footnotetext{
${ }^{38}$ Poliarquía (el gobierno de muchos), democracia (el gobierno $-k r a t o s=$ poder- del demos=pueblo)
} 
El desarrollo económico es una herramienta que permite accionar políticas y acciones específicas para fortalecer la cohesión social y favorecer el surgimiento de una ciudadanía integral, resultando en una democracia efectiva que alcance las dimensiones de calidad. Una ciudadanía social, con el reconocimiento de derechos y promoción de la organización colectiva que permite sociedades inclusivas. El desarrollo económico permite el uso de herramientas por medio de las cuales serán implementadas políticas de inclusión productiva y de esta forma ampliados los procesos de participación ciudadana, generando dinámicas que involucran la confianza y concertación en todos los niveles.

\subsubsection{Integración}

Desde una perspectiva sociológica tenemos la propuesta teórica de Durkheim (apud (ANDERSEN; TAYLOR, 2000) que afirma que la sociedad ejerce una fuerza poderosa en los individuos, aspectos como normas, creencias y valores constituyen una conciencia colectiva, o una manera común de entender y actuar en el mundo, esta conciencia colectiva de forma conjunta une a los individuos y crea integración social. Siguiendo esta línea, la integración debe ser vinculada a las ideas de "concertación, coordinación, cooperación, integración económica, integración política, integración social, integración de hecho e interdependencia, entre otros" (Franco; Robles, 1995, pp. 18-22; De Lombaerde, 1996, pp.12-18 apud (TIRADO MEJÍA, 1997), que son desarrolladas en un escenario heterogéneo entre los actores que conforman una sociedad.

La interpretación de la integración se debe dar en dos niveles, el primero interno, en las sociedades que conforman los estados, definido como "un proceso dinámico y de principios donde todos los miembros participan en el diálogo para lograr y mantener relaciones sociales pacíficas" $^{39}$ (DESA, 2006), traducción propia) y en segundo lugar de forma externa, de acuerdo con (TIRADO MEJÍA, 1997) "es todo esfuerzo realizado en búsqueda del acercamiento por parte de los Estados, generador de vínculos económicos, políticos o sociales entre estados", que aun cuando no se constituye el foco de la investigación debe ser evaluada para la comprensión del escenario donde se realizan las interacciones a nivel internacional.

El primer nivel tiene como foco la forma de establecer patrones de relaciones humanas en una sociedad, los cuales tendrán un impacto en el sistema político (CAMOU, 2001). Esta

\footnotetext{
${ }^{39}$ Texto original: Social Integration can be seen as a dynamic and principled process where all members participate in dialogue to achieve and maintain peaceful social relations. (Department of Economic and Social Affairs, 2006)
} 
evaluación se realiza en términos sociológicos y busca la comprensión del funcionamiento de las sociedades, en este sentido, la integración se compone de un sistema de estratificación social ${ }^{40}$ basado en la interacción de las relaciones entre clases del sistema social en su conjunto, siguiendo la propuesta de (PARSONS, 1967) a partir del enfoque funcionalista ${ }^{41}$, en la cual esta estratificación social se constituye como el mecanismo base para la estabilidad de las sociedades, en la medida que posibilita que las relaciones sociales se ordenen en "referencia a valoraciones compartidas, fundamentadas en las motivaciones y al mismo tiempo se expresa normativamente en las instituciones"(idem).

En este sentido, la democracia es el mecanismo esencial para que los individuos, grupos sociales y países puedan participar libremente en un mismo proceso e integrarse dentro de este sistema. Por medio de esta afirmación nos referimos a las relaciones e interrelaciones que, todos los actores, van tejiendo entre sí, en función de visiones, acciones y proyectos en común, lo que en definitiva crea las estructuras para alcanzar el desarrollo de las sociedades de forma conjunta.

En el contexto contemporáneo se observan dos elementos que han afectado estos procesos de integración social. En primer lugar, el proceso globalizador, debido a la creación de nuevas estructuras y modalidades dentro de la economía mundial consecuencia del libre mercado/competencia, base del capitalismo, en donde "los trabajadores alrededor del mundo son colocados en competición por recursos escasos"42 (UNRISD, 1996), y en donde el lucro se establece como el objetivo principal. Por otro lado, existe un impacto generado como consecuencia del desarrollo de la ciencia y la tecnología, el cual ha sido ampliamente positivo en términos de avances, generando una aproximación social nunca antes vista en la historia ${ }^{43}$ pero, a

\footnotetext{
40 "Es la ordenación (ranking) diferencial de los individuos humanos que componen un sistema social dado y el orden de superioridad o inferioridad que guardan sobre ciertos respectos socialmente importantes" (PARSONS, 1967)

41 "Para Parsons, el mundo es una unidad y sus partes adquieren significación y sentido solo en relación con la totalidad. El vínculo que se establece entre las partes de la estructura tiene un carácter funcional que implica cierto tipo de ordenamiento o sistema. Los conceptos de sistema y función son básicos de la teoría parsoniana, según la cual todo sistema está constituido por variables independientes, cuyos valores no pueden determinarse de manera absoluta si no se conoce el valor de todas. En este sentido son interdependientes, y el sistema es integral (...) Parsons distingue cuatro sistemas de acción: Uno de ellos es el sistema social, cuya peculiaridad es la de cumplir con la función de integrar a los otros tres sistemas: el cultural, el de la personalidad y el sistema u organismo conductual". (PASTOR, 1992, p. 170)

42 Texto original: "workers and business people around the globe are thrown into competition for scarce resources"(UNRISID, 2007, p.3)

43 "La ampliación de las aplicaciones e impactos de la ciencia y la tecnología, el creciente protagonismo de las demandas sociales, la profundización en los procesos de dualidad social, tanto en los diferentes países como en el nivel global y los requerimientos de mayores cotas de eficacia y eficiencia en la administración de los recursos públicos, plantean múltiples oportunidades para el afianzamiento de las relaciones ciencia-tecnologíagobernabilidad. Probablemente este enfoque permite ampliar la dimensión política del desarrollo científico y
} 
su vez, ha traído elementos que implican cambios estructurales profundos en la forma en que se desarrollan las actividades humanas, principalmente, en términos laborales, generando incertidumbre económica.

En segundo lugar, tenemos el ámbito vinculado a las migraciones tanto locales como internacionales, en la búsqueda de una mejor la calidad de vida. Procesos de desigualdad y conflicto son los principales generadores, tanto en el nivel local (ejm.: de zonas rurales a urbanas), como en el nivel macro en las cuales se observan las migraciones de regiones caracterizadas por la pobreza y el conflicto a otras con mayor desarrollo. De acuerdo con el reporte desarrollado por el UNRISD (2007) “Aunque los procesos migratorios son positivos en muchos aspectos, la yuxtaposición de personas que a menudo no comparten un lenguaje, religión común, y costumbres comunes, requiere de demandas inusuales en la tolerancia y el entendimiento humano" ${ }^{\text {"44 }}$. Contexto que debe ser considerado al referirnos a integración social, principalmente, su impacto en la misma durante los últimos años en los cuales se han dado procesos de migración masiva.

En este sentido, Diamond (1994) establece que, en la búsqueda de la sustentabilidad de los procesos de integración, es necesaria la participación activa de la sociedad civil, siendo esta definida como "aquella parte de la sociedad que es autónoma del Estado y que se encuentra cohesionada por un orden legal o un grupo de normas". La sociedad civil actúa colectivamente en las esferas públicas para expresar sus intereses. $\mathrm{Y}$ demandar acciones específicas y responsabilidades del Estado. En las últimas décadas éstas han tenido un papel más activo como resultado de la insuficiente reducción de los niveles de pobreza y la prolongación de las inequidades, generando problemas de gobernabilidad, por lo cual estas organizaciones no gubernamentales "reivindican la creación de un espacio público para la participación ciudadana, a partir del cual construir una democracia más inclusiva y responsable” (Olvera, 2006).

Serbin (1994) hace énfasis en el papel protagónico de la sociedad civil, debido a que esta promueve iniciativas que toman en cuenta las demandas y las necesidades de amplios sectores de la población, afectados por las secuelas tanto de la globalización, como del impacto de las medidas que acompañan la profundización de la regionalización. En definitiva, las bases de la sociedad son las principales protagonistas de la integración y es desde estas mismas bases de

tecnológico, contribuyendo no solamente a fundamentar nuevos apoyos para este desarrollo, sino también para incrementar el rigor y la eficacia en la toma de decisiones y en la acción de gobierno" (SEBASTIAN, 2000, p. 8-23).

44 Texto original: "Although migratory processes are positive in many respects, the juxtaposition of people who often share neither a common language nor a common religion, and who have very different customs, makes unusual demands on human tolerance and understanding" (UNRISID, 2007, p. 4). 
donde deben salir las autoridades; es decir, los sectores o representantes que permitan aumentar, desarrollar, multiplicar la participación e incentivar la integración en todos los niveles.

En este sentido, es relevante hacer referencia a las Organizaciones no gubernamentales $(\mathrm{ONG} \text { 's })^{45}$ que se han establecido en los últimos años como actores importantes en los procesos de integración social a través de actividades en países y regiones a partir de la construcción de redes, "de la mano con sistemas estatales e internacionales conectando lo local con lo global, vinculando en sus actividades a organizaciones populares de base local, ONG nacionales y ONG internacionales" (Macdonald, p. 277 apud Serbin, 1997). Este tipo de dinámicas y actores, evaluados en términos de su diversidad, fomentan, por medio de su integración, la gobernabilidad dentro del sistema internacional al establecer vínculos con los gobiernos, desarrollando de esta forma "la capacidad de lograr que se hagan cosas sin la competencia legal de ordenar que sean hechas" (Czempiel, p. 250 apud Serbin, 1997).

El segundo nivel para interpretar la integración, es aquella que se realiza a nivel internacional, entre estados y entre regiones, pasando a ser un elemento clave para formar parte de las dinámicas en la búsqueda de niveles mayores de profundidad dentro de la comunidad internacional. La construcción de bloques y mecanismos de integración, a nivel subregional y regional, permite la convergencia de valores económicos, políticos y sociales fundamentales, De esta forma la integración como propósito colectivo sólo es viable en la medida en que las naciones que la proponen mantengan un compromiso con la democracia. El avance de la voluntad política de los gobiernos en la integración regional depende, en última instancia, de la voluntad política de sus pueblos (TIRADO, 1997).

La consolidación democrática se ve favorecida por procesos integradores, al generar nexos de solidaridad entre los gobiernos que llevan a cabo este tipo de procesos. Se ha comprobado que la implementación de políticas que buscan solamente el desarrollo económico tienden a fracasar, tanto en el corto como en el largo plazo. ${ }^{46}$, por lo tanto, estas relaciones deben ir más allá del comercio y hasta cierto punto de la economía (MACHINEA; UTHOFF, 2005) En este sentido, la redistribución de los beneficios del crecimiento y del desarrollo económico es necesaria, para dar las bases a la integración como un mecanismo efectivo.

\footnotetext{
45 "sus características definitorias refieren a su carácter de organizaciones formales, con continuidad institucional; que aspiran a autogobernarse con base en arreglos constitucionales o reglas de funcionamiento propias; que tienen carácter privado en el sentido de ser autónomas respecto de los gobiernos y carecen de conducción o dirección en la respectiva sociedad; que vinculan a organizaciones de varios países; que promueven una gama de temas sociales; que no tienen fines de lucro o que buscan beneficios pecuniarios; y que tienen, básicamente, objetivos, operaciones y conexiones trasnacionales" (Gordenker;Weiss, 1995, apud (SERBIN, 1997)

${ }^{46}$ Ver "Integración Regional y Cohesión Social" (MACHINEA; UTHOFF, 2004)
} 
Tomando como base este argumento, existe la hipótesis de que la inestabilidad política en un contexto de integración genera costos que pueden ser extremadamente altos para los gobernantes (NAIM; KING, 1996) esto no sólo en términos económicos. Hasta cierto punto se sugiere que la integración contribuye activamente al desarrollo democrático de los países que participan en ella. (VACCINO, 2002) establece que no existen posibilidades verdaderas de iniciar, y mucho menos profundizar, un proceso de integración cuando en él coexisten regímenes totalitarios y democráticos conjuntamente.

Evaluando objetivamente el escenario global vemos que existen numerosos ejemplos de gobiernos eficaces que están lejos de ser democráticos, así como gobiernos democráticos que no son eficientes ni estables (SHIFTER; NEILL, 1996), en este sentido la integración se observa como un elemento fortalecedor de las democracias, porque, en el contexto global en el que se desarrollan estos procesos, los costos en términos políticos y económicos de la presión internacional son un riesgo que pocos países están dispuestos a correr.

Para que las regiones más débiles y menos desarrolladas resulten beneficiadas con la integración, se debe implementar un modelo solidario o de cohesión, que aborde problemas que superen el ámbito del comercio internacional, no puede establecerse un proceso de "integración verdadera" sin que se fortalezca a su vez la democracia y la participación ciudadana tanto en términos nacionales como regionales (BRICEÑO RUÍZ, 2007).

Ambos niveles evaluados, uno en el sentido individual y otro en el sentido regional/internacional, presentan características que se relacionan profundamente con el desarrollo positivo de sistemas democráticos y dependen de contextos de inclusión para ser efectivos en su alcance. De acuerdo con la UNRISD (1994) "no es la forma de aumentar la integración en sí, sino la manera de promover un tipo de integración que favorece la creación de una sociedad más justa y equitativa.", esto solamente podrá ser alcanzado por medio de la implementación de políticas que desarrollen elementos económicos y sociales de forma conjunta.

\subsection{Impacto de la Cohesión Social en la Calidad Democrática, una evaluación cuantitativa}

En los anteriores subcapítulos se desarrollaron las bases conceptuales de los términos activos a través de los cuales interpretamos las relaciones y el impacto de la cohesión social en la calidad democrática, que nos permitirán realizar una evaluación cuantitativa a partir de estos elementos, tomando en consideración el comportamiento de una serie de países durante un 
periodo de tiempo definido, análisis que constituye un ámbito teórico-metodológico que debe proseguirse en nuestra disciplina.

Al desarrollar nuestra hipótesis ${ }^{47}$ buscamos presentar un enfoque nuevo en la forma de entender el proceso social en el mundo contemporáneo y la influencia que este ejerce en la consolidación del sistema político definido como democracia a nivel mundial. Con base en este escenario, concentraremos nuestra tarea en primer lugar, en la deducción de indicadores suficientemente significativos para que traduzcan de forma operativa toda la complejidad de relaciones existentes en la cohesión social y la calidad de la democracia para la concepción de un modelo teórico congruente en términos cuantitativos y cualitativos.

En consecuencia, el objetivo normativo será la búsqueda de un camino para consolidar una cultura cívica y democrática, estableciendo que tanto la cohesión social como la democracia son aspectos sine qua non para el desarrollo y bienestar social, formando parte de una proceso que se encuentra en constante evolución. Los resultados revelan que la calidad democrática de un país se ve afectada significativamente por el nivel de cohesión social en su población. Con base en estos hallazgos empíricos se sugiere un nuevo elemento a ser considerado en futuros análisis en esta área de investigación.

\subsubsection{Operacionalización}

Tomando en consideración la evaluación conceptual, vemos que existe una relación a nivel teórico y a través de diversas investigaciones se observa su relevancia, el impacto de la variable manifiesta como cohesión social sobre el constructo establecido como calidad de la democracia es fundamental a la hora de referirnos a un nuevo enfoque en la búsqueda de desarrollo dentro de las sociedades contemporáneas.

(BARRO, 1999) a través de su estudio denominado "Determinantes de la Democracia"48 especifica una serie de influencias en lo que se refiere a la consolidación de la democracia, que sustentan la relación entre nuestros conceptos. Entre ellos tenemos que existe un impacto significativo por parte de la educación superior, desigualdad de ingresos, fraccionamiento etnolingüística, historia colonial (refiriéndose a las herencias históricas), religión y libertades

\footnotetext{
${ }^{47}$ La cohesión social ejerce un impacto sobre la calidad de la democracia

${ }^{48}$ BARRO, Robert J. Determinants of democracy. Cambridge: Journal of Political Economy 107(S6): 158-183, 1999. Disponible en:

$<$ http://dash.harvard.edu/bitstream/handle/1/3451297/Barro_DeterminantsDemocracy.pdf?sequence=2>. Acceso en: $13 / 04 / 2014$
} 
civil. Todos estos son aspectos que juegan un rol fundamental dentro de la cohesión social, independientemente de la región en donde sean analizados. Barro demuestra que cada uno de estos aspectos de forma individual ejerce un impacto en la calidad de la democracia.

De acuerdo con (CUELLAR, 2009)una sociedad cohesionada debe ser un pre-requisito para la democracia política y la estabilidad social, siendo evidente que una sociedad con medios de vida bien distribuidos tiene una capacidad mayor en alcanzar niveles de productividad más altos y en consecuencia, generar mayor crecimiento económico sostenido a través del tiempo. Entre las conclusiones más relevantes de su trabajo vemos que la cohesión social contribuye a reducir las diferencias de clase mediante instituciones que funcionan y por medio de programas que fortalecen los controles sociales y políticos sobre la economía.

Otro aporte teórico en esta área es dado por (FRAZER; MARLIER, 2010) que establecen que "una situación de exclusión social limita la capacidad de los individuos de comprometerse en los procesos democráticos" específicamente en tres aspectos, primero, porque se socavan las habilidades y autoconfianza de los individuos en el comprometimiento con los actores políticos (policy makers), de expresar sus opiniones y de participar en la toma de decisiones. En segundo lugar, porque la vida puede convertirse en una lucha diaria para sobrevivir, un contexto complejo en donde a menudo hay poco tiempo, la energía o los recursos no son suficientes para participar en los procesos democráticos y, en tercer lugar, porque los procesos democráticos generalmente parecen muy remotos e irrelevantes, las personas no se involucran porque se crea un cierto nivel de apatía, hasta cierto punto se sienten desenganchados del proceso democrático y sin la capacidad ni los mecanismos de poder influir en él.

La llamada "Teoría de la sociedad civil" como fue establecido por (VALENZUELA et al., 2008)sustenta a su vez nuestra hipótesis, al establecer que la cohesión social se vincula a la capacidad de una determinada sociedad para producir confianza social, generando redes de cooperación efectiva entre extraños y comprometiendo el interés y respeto público, lo que genera, en definitiva, un compromiso cívico el cual sustenta la democracia. Esta proposición se apoya también en las teorías modernas de capital social propuestas por Coleman (1990) y Putnam (1993).

Por otro lado, vemos que la cohesión social vista desde un enfoque teórico equitativo como fue establecido por BERGER apud VALENZUELA (2008) remite a la capacidad de la sociedad de producir instituciones y disposiciones específicas hacia la mediación de conflictos que se identifican poderosamente con las instituciones democráticas. 
A su vez, el contexto externo, en el cual se evalúa esta relación, puede tener influencia en nuestros resultados, razón por la cual fueron adicionadas las variables de control "conflicto armado" y "Producto Interno Bruto (PIB)", así como una variable interactiva entre la cohesión social y el conflicto.

Debido a que los países con conflictos armados presentan un alto grado de fragmentación social, al igual que aquellos países que presentan altos índices de violencia ciudadana, aquí cabe cuestionar que tipo de calidad democrática está siendo implementada en nuestras sociedades contemporáneas. Existen muchos países denominados como democracias consolidadas, donde hay graves violaciones a los derechos humanos, elevadas tasas de homicidio, corrupción sistemática y recurrente en toda la estructura institucional, impunidad y un acceso limitado a los derechos civiles. Esta fragmentación social, a través del conflicto armado y la violencia ciudadana, demuestra la dificultad de definir un Estado democrático frente a una sociedad que mantiene trazos de exclusión que conllevan a violencia en diferentes niveles sociales e institucionales.

Tomando en consideración las reflexiones teóricas presentadas anteriormente, podemos afirmar que esta área de investigación requiere de una profundización tanto en términos cualitativos como cuantitativos, la mayoría de los enfoques presentados han sido por medio de un reflejo de la realidad local/regional, siendo limitado en términos amplios al no haber llevado a cabo un análisis global a la hora de evaluar la democracia por medio del prisma de la cohesión social y sus impactos a la hora de referirnos en términos de calidad.

\subsubsection{Hipótesis}

La hipótesis del trabajo es que el indicador definido como "Nivel de Dificultad", el cual representa la falta de cohesión social en los países seleccionados, ejerce un impacto sobre la calidad de la democracia. El aumento del Nivel de Dificultad, genera una disminución en la calidad de la democracia, por lo que se interpreta que a mayor cohesión social veremos mayor calidad democrática siendo una relación proporcional. Esta relación se establece tomando en cuenta las visiones provistas por la literatura en esta área y que ha sido poco estudiada en términos cuantitativos.

Por medio de esta investigación se pretende respaldar la propuesta teórica a través de resultados estadísticos, siendo realizada una evaluación a nivel mundial tomando en 
consideración un universo de 118 países, que serán el reflejo de las dinámicas que se establecen dentro de esta relación.

Tomando en consideración esta revisión teórica, nuestro modelo está definido de la siguiente forma:

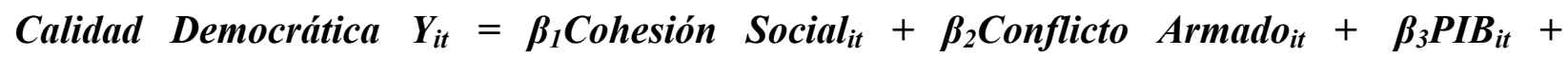
$\beta_{4}$ cohesion $\times$ conflicto $_{i t}+u_{i t}$

Los asuntos presentados por medio de nuestra hipótesis establecen que aspectos relacionados a disparidad, desigualdad, exclusión y discriminación de acuerdo a las teorías presentadas anteriormente, no permiten sociedades donde una democracia robusta y de calidad pueda ser aplicada, esta dinámica entre los dos conceptos, pretende vislumbrar como pueden ser aplicadas políticas para el desarrollo tomando en consideración un escenario donde la cohesión social ejerce un impacto en la calidad democrática. La interpretación que prevalece es que, de acuerdo a la literatura de Barro (1999), Cuellar (2005) así como Frazer y Marlier (2010), puede apreciarse una relación teórica entre estos conceptos, un vínculo cuya significancia será analizada estadísticamente por medio de regresiones para verificar la veracidad de la hipótesis, a través de las variables seleccionadas, las cuales poseen características societarias y se constituyen como fundamentales a la hora de aplicar el modelo.

\subsubsection{Datos y Metodología}

Para comprobar nuestra hipótesis, fue usada la base de datos desarrollada por el Bertelsmann Stiftung Institute, específicamente, los datos contenidos en el Transformation Index (BTI). La selección de este compendio de datos así como el tipo de análisis que realiza, se debe a la evaluación de cómo y en qué forma los países en vías de desarrollo y aquellos países en transición están direccionándose hacia la democracia y las economías de mercado. Para nuestro análisis serán usados 118 países por medio de un panel, cuya unidad temporal es de dos años, para los años 2006, 2008, 2010, 2012.

Los países seleccionados en este estudio pueden ser definidos como democracias y economías en desarrollo, excluyendo a aquellos países miembros de la Organización para la Cooperación Económica y el Desarrollo (OECD). Hemos dividido la muestra en siete grupos regionales: sur y este de África, Centro y Oeste de África, Asia y Oceanía, Medio Oriente y 
Norte de África, América Latina y el Caribe, Eurasia Post-Soviética y el Este-Central y Sureste Europeo

Para construir esta base de datos, BTI realiza un análisis estandarizado de las evaluaciones de expertos establecidos en los países seleccionados por medio de índices numéricos, en un proceso de revisión multinivel para hacerlos comparables a través de diferentes regiones, proporcionando datos transparentes y verificables a partir de las más de 6000 observaciones individuales.

La calidad democrática fue evaluada a través del indicador denominado como "Estatus de la Democracia" (Democracy Status) que se mide tomando como base 5 criterios: 1) Stateness, que es considerada una pre-condición para la transformación política; 2) Nivel de participación política; 3) Calidad del estado de derecho, o Rule of Law, teniendo como foco principalmente lo que se refiere a la separación de poderes y la investigación de abuso de cargos; 4) Estabilidad de las instituciones democráticas e 5) Integración política y social del sistema democrático, que se refiere a que tan aceptado es dicho sistema dentro de la población y la capacidad que dicho sistema posee para representar un amplio espectro de intereses domésticos.

De acuerdo con los parámetros establecidos por el BTI en la definición de democracias y autocracias, existen criterios mínimos: un país es clasificado como autocracia cuando uno de los aspectos que conforman el estatus de la democracia es menor que tres. En estos se incluyen también los llamados "estados fallidos" 49 .

El análisis de la cohesión social fue realizado por medio de un indicador denominado "Nivel de Dificultad", compuesto por las siguientes variables: 1) Restricciones estructurales; 2) Extensión de las tradiciones en la sociedad civil; 3) Indicadores de educación de las Naciones Unidas reajustados y; 4) La capacidad adquisitiva paritaria, que se interpreta como una característica fundamental dentro de la dimensión de brechas sociales.

En definitiva, para comprobar nuestra hipótesis, fue realizada una deducción de indicadores suficientemente significativos que representaron, de forma operativa, la complejidad de las relaciones en los conceptos que se implementaron en nuestro modelo teórico. Fueron agregados indicadores de control que están íntimamente vinculados con la calidad democrática en el corto plazo y que pueden afectar los datos. En primer lugar, tomamos como referencia la variable del crecimiento del PIB durante los últimos 3 años, asumiendo que cuando ese

\footnotetext{
${ }^{49}$ Países en los cuales el monopolio del estado carece del uso de la fuerza y de estructuras administrativas básicas a tal extremo que el gobierno está severamente limitado en su capacidad de actuación.
} 
crecimiento ha sido bajo hay mayores posibilidades que la calidad de la democracia se vea afectada. Para establecer esta relación tomamos en consideración la hipótesis de Lipset (apud Barros, 1999) que establece que la prosperidad deriva en un aumento en la propensión a experimentar libertad política. De acuerdo con Barros (1999) existe una regularidad empírica fuerte en esta relación. A su vez, debemos resaltar que la democracia es vista como un potenciador del crecimiento económico, y existe un debate al respecto del carácter endógeno de esta relación.

El segundo indicador de control es la existencia de conflicto armado durante los últimos 5 años. Existen hallazgos empíricos que comparan estados democráticos con bajo riesgo de conflicto armado con aquellos de alto riesgo, concluyendo que las democracias consolidadas poseen menos conflicto que las semi-democracias (HEGRE, 2014). Para esto se usó la base de datos del Peace Research Institute Oslo (PRIO) ${ }^{50}$, que fue diseñada para determinar la información cuantitativa y cualitativa sobre violencia organizada (Ej.: Estadísticas de fatalidad, actores armados y sus descripciones). Creamos una dummy, por lo que en nuestro modelo aquellos países clasificados con 1 son denominados países con conflicto armado.

Tomamos en consideración la tasa de muertes por cada 1000 habitantes como variable instrumental, usando el indicador elaborado por el Banco Mundial. Esta variable fue tomada en consideración asumiendo que será más elevada en países con mayor conflictividad.

Finalmente fue creada una variable interactiva entre el nivel de dificultad (Cohesión social) y existencia o no existencia de conflicto armado, a través de esta variable se asume que el nivel de dificultad será distinto en países con o sin conflicto armado.

\subsubsection{Test empírico: Resultados}

Para comprobar nuestra hipótesis se rodaron dos versiones del modelo, una con efectos fijos $^{51} \mathrm{y}$ otra con efectos aleatorios ${ }^{52}$. Esto se realiza debido a que dependiendo del tipo de datos, se presentan diferencias en términos de la variación a nivel temporal y las variaciones que se presentan entre los países, con el objetivo de definir cual se adecua de mejor forma a nuestro caso.

\footnotetext{
${ }^{50}$ Este compendio de datos es el resultado de un proyecto colaborativo entre el Departamento de Investigación de Paz y Conflicto en la Universidad de Uppsala y el Centro para el Estudio de las Guerras Civiles en PRIO. Los datos referentes a los conflicto iban desde 1989 a la actualidad.

${ }^{51}$ El modelo de efectos fijos crea una dummy para cada país.

${ }^{52} \mathrm{El}$ modelo de efectos aleatorios asume que el intercepto esta distribuido normalmente.
} 
Los datos usados en esta investigación presentan una variación temporal leve, debido a que son usadas cuatro unidades temporales (2002-2004-2006-2008) tanto en la variable independiente, Nivel de Dificultad, como en la dependiente, Calidad de la democracia. Al contrario, se observan variaciones importantes entre los 118 países de la muestra. Generalmente en este tipo de paneles con muchas unidades transversales y pocas unidades temporales es más apropiado el modelo de efectos aleatorios, debido a que no es necesario crear un intercepto para cada país, lo que "ahorra" grados de libertad, haciendo este modelo más eficiente que el de efectos fijos.

Con el propósito de definir el tipo de regresión que mejor se adecua a nuestro modelo se realizó el Test de Hausman, porque en ambos modelos se observa significancia estadística y, para ello, este test verificara nuestras suposiciones, examinando los parámetros estimados, permitiéndonos escoger uno de los dos. Al rechazar la hipótesis nula del test se establece que el modelo de Efectos Fijos se adecua mejor a nuestro modelo.

Una vez definido el modelo de Efectos Fijos como el más apropiado, se realiza un "lag" $" 53$ en la variable independiente principal definida como Nivel de Dificultad. Es decir, se le resta una unidad temporal para que el impacto en $Y_{t}$ sea de $X_{t-1}$, con el objetivo de comprobar que esta relación es unidireccional y con esto queremos decir, por ejemplo, que la calidad de la democracia del año 2006 es afectada por el nivel de dificultad del año 2004, controlando de esta forma los efectos de causalidad en el modelo, observándose de una forma simple e intuitiva.

Podemos observar en la Tabla 1 que el resultado obtenido es el esperado, se observa que el impacto del nivel de dificultad en la calidad de la democracia es significativo en ambos modelos, en el de efectos aleatorios el coeficiente es de -0.37 , mientras que en el modelo de efectos fijos es de -0,17. Razón por la cual podemos afirmar que la falta de cohesión social afecta la calidad de la democracia de manera inversamente proporcional, observándose un resultado intuitivo.

Podemos decir que en ambos modelos la variable independiente se comporta de la forma esperada, debido a que el nivel de dificultad tiene un efecto negativo sobre la calidad de la democracia, aun cuando se observa que en el modelo de efectos fijos es menor $(-0,179)$ y en el de efectos aleatorios la significancia estadística es más elevada con (-0,37). En lo que se refiere

\footnotetext{
${ }^{53}$ Es un modelo aplicado a datos en series temporales, en los cuales la ecuación de la regresión es usada para predecir valores actuales de una variable dependiente basada tanto en los valores actuales de la variable explicativa como y aquellos del período anterior (lagged) (BOLLEN; BRAND, 2010)
} 
al variable conflicto armado vemos que no posee significancia estadística, presentando 1,41 en el modelo de efectos fijos y 0,97 en el de efectos aleatorios. En lo que se refiere a nuestra variable interactiva (nivel de dificultad x conflicto armado) compuesta por dos variables independientes, esta tiene un impacto negativo con significancia estadística con un coeficiente de $-0,223$, para la utilización de esta variable es necesario que estén presentes en la base de datos las variables que la componen, su relevancia se encuentra en proporcionar suficiente flexibilidad para detectar diferencias entre los grupos y debe ser interpretada como dos líneas de regresión con el mismo intercepto pero diferentes pendientes.

Este tipo de variable se debe entender como la multiplicación entre las variables que la componen, en nuestro análisis esta variable interactiva nos permite saber para cada grupo, aquel que sufre de conflictos armados y aquel que no los tiene, si poseen un intercepto y una línea de función propia, creándose una línea de regresión para cada uno. Con esto se quiere decir que aquellos países con conflicto armado, de forma inherente poseen una predisposición distinta a como se relacionan con Nivel de Dificultad y Democracia, que aquellos que no presentan conflictos.

Para que la variable interactiva tenga efectividad, ambas variables que las componen deben estar dentro de nuestra base de datos, esto quiere decir que para la interpretación del coeficiente esta es una característica obligatoria. La significancia estadística observada en esta variable interactiva nos demuestra que hay dos líneas de regresión cada una con diferente inclinación, aquellos países que tienen conflicto armado tienen una inclinación más pronunciada porque el efecto negativo de $-0,22$ se agrega al efecto negativo de $-0,17$, generando un impacto mayor.

También vemos que el crecimiento del PIB está asociado positivamente a la calidad de la democracia, aun cuando no presenta significancia estadística en ambos modelos, en el modelo de efectos fijos posee un coeficiente de 0,0074 y en el de efectos aleatorios de 0,0085. 
TABlA 3: RESUltAdO DE LOS MODELOS DE REGRESIÓN

(1)

Panel com EF
(2)

\section{Panel com EA}

$-0.370 * * *$

$(-7.06)$

0.978 de Dificultad

$-0.223^{*}$

0.00857

Crecimiento del PIB

0.00749

$6.984 * * *$

$7.846^{* * *}$

$(16.83)$

\begin{tabular}{llc}
\hline $\mathrm{N}$ & 351 & 351 \\
\hline \hline
\end{tabular}

Nota: En paréntesis los valores del test $\mathrm{t} * \mathrm{p}<0.05, * * \mathrm{p}<0.01, * * * \mathrm{p}<0.001$. Dummies anuales fueron calculados para controlar por efectos fijos temporales, pero no están incluidos en la tabla.

A la luz de los hallazgos anteriores, se puede concluir que existe un impacto significativo de la cohesión social en la calidad de la democracia, la falta de ella genera una disminución en nuestro indicador de democracia lo que confirma nuestra hipótesis, reafirmando la importancia que tiene este aspecto cuando nos referirnos al fortalecimiento democrático ${ }^{54}$. Esto puede verse

\footnotetext{
${ }^{54}$ Ver nota metodológica.
} 
de manera resumida en los gráficos presentados a continuación para las diferentes regiones de los países analizados con base en los datos del Transformation Index ${ }^{55}$ :

\section{Grafico 1: Tendencia de la relación entre la cohesión social y la calidad de la democracia en América Latina}

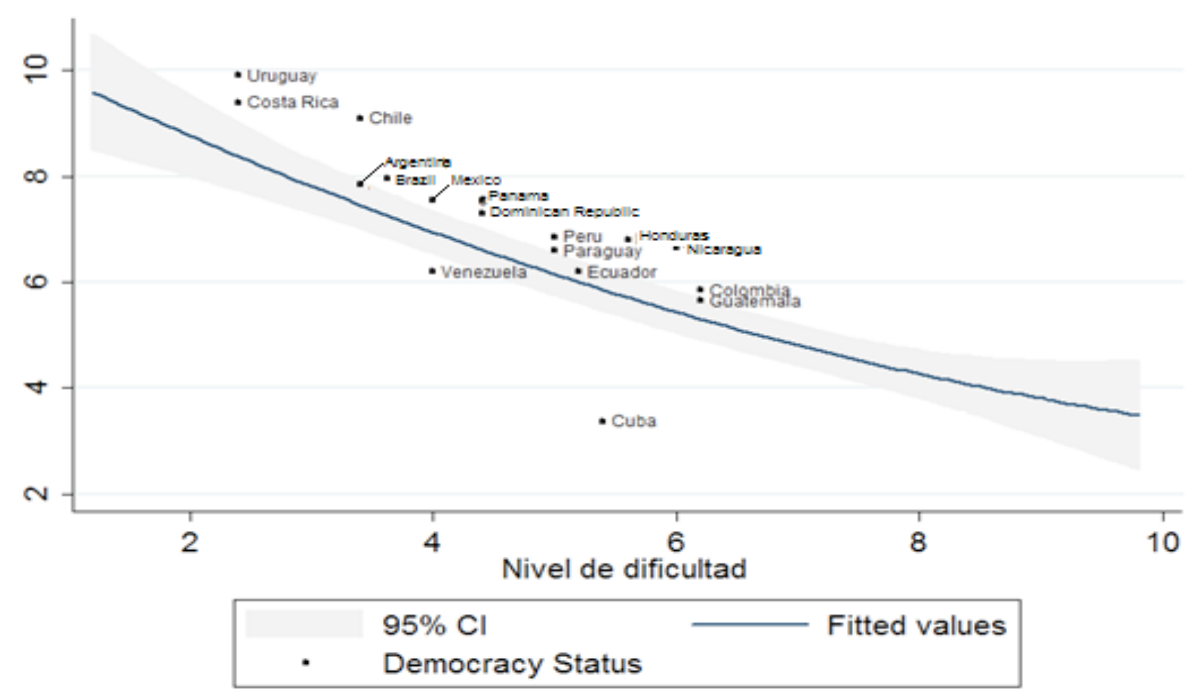

Fuente: Elaborado por la autora

\section{Grafico 2: Tendencia de la relación entre la cohesión social y la calidad de la democracia} en África Sub-sahariana

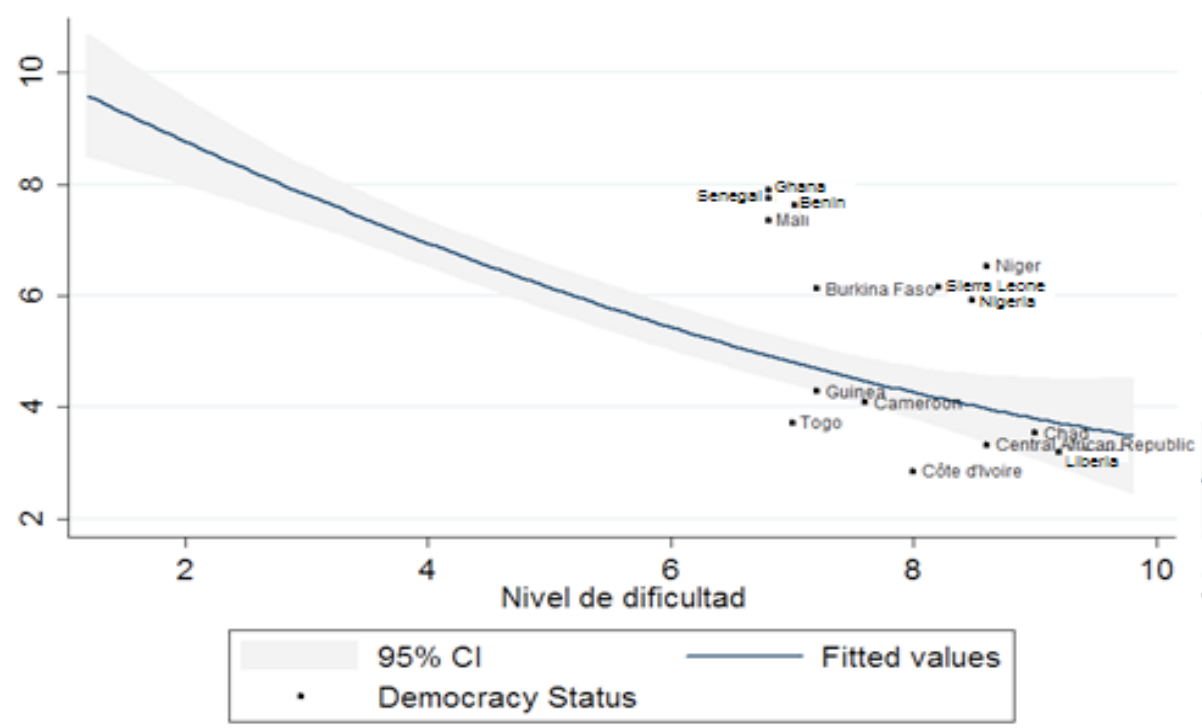

Fuente: Elaborado por la autora

\footnotetext{
${ }^{55}$ Bertelsmann Stiftung. Transformation Index Database, 2014. Disponible en: $<$ http://www.btiproject.org/index/status-index/>. Acceso en: 12/11/2014
} 
Grafico 3: Tendencia de la relación entre la cohesión social y la calidad de la democracia en Asia Central

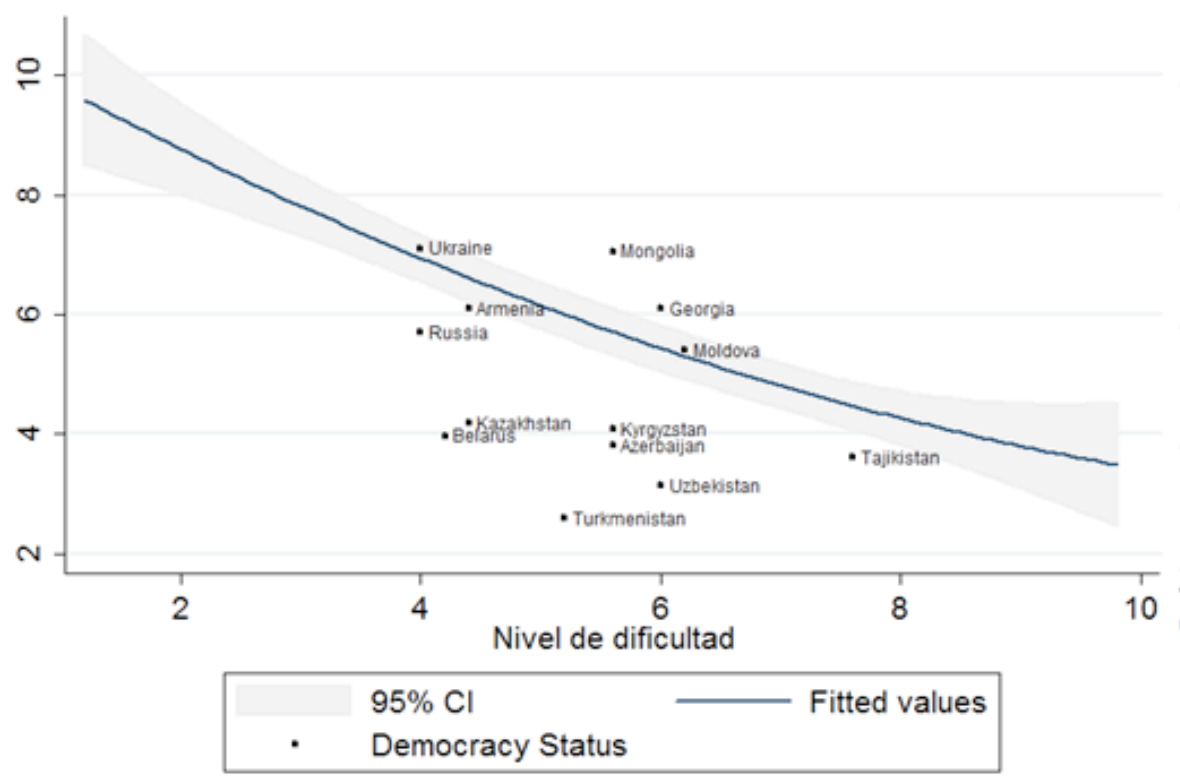

Fuente: Elaborado por la autora

Grafico 4: Tendencia de la relación entre la cohesión social y la calidad de la democracia en Europa del Este

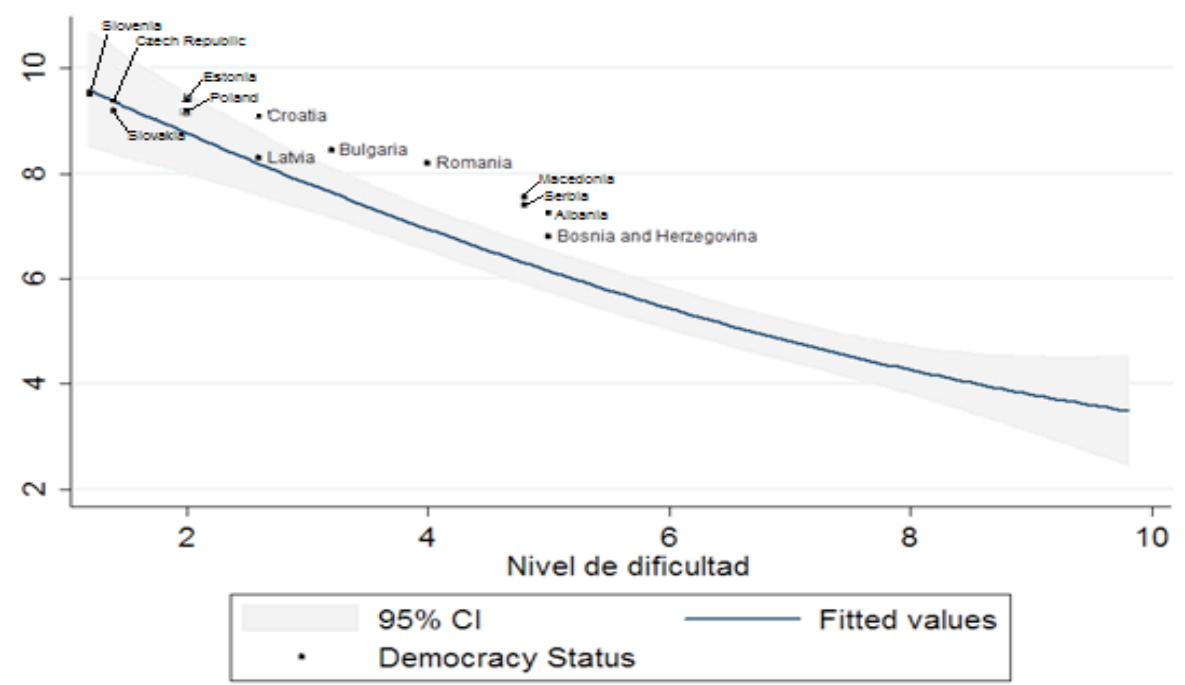

Fuente: Elaborado por la autora 
Grafico 5: Tendencia de la relación entre la cohesión social y la calidad de la democracia en Medio Oriente

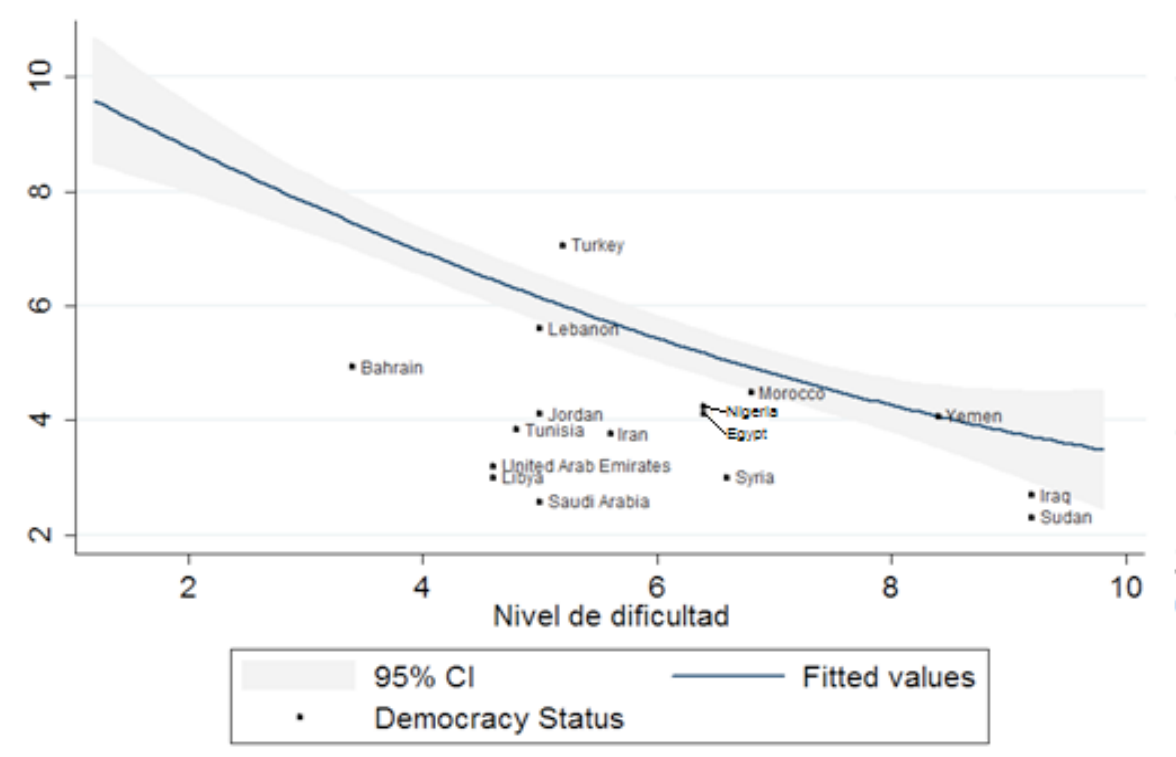

Fuente: Elaborado por la autora

Grafico 6: Tendencia de la relación entre la cohesión social y la calidad de la democracia en Sudeste Asiático

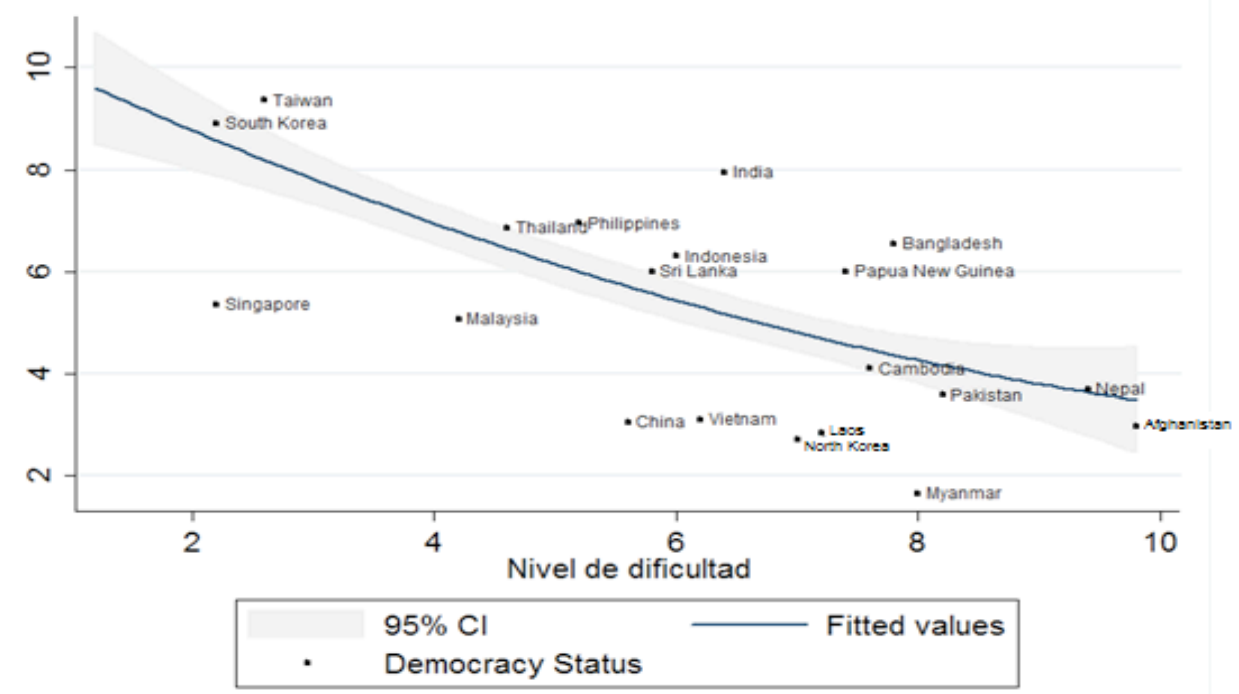

Fuente: Elaborado por la autora 
Grafico 7: Tendencia de la relación entre la cohesión social y la calidad de la democracia en África del Sur

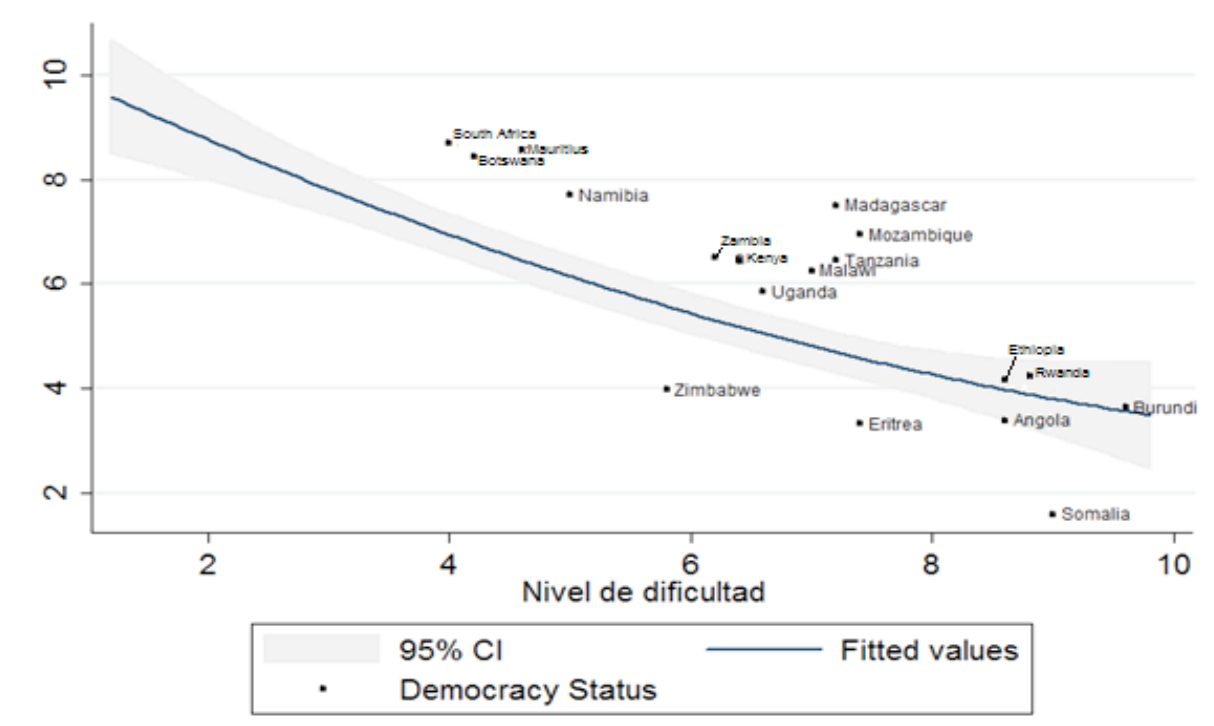

Fuente: Elaborado por la autora

\subsection{Conclusiones}

La evaluación realizada, tanto a nivel cualitativo como cuantitativo, confirma la hipótesis del importante impacto que la cohesión social ejerce sobre la calidad de la democracia, reafirmando la idea de la necesidad de una sociedad con características fuertes de inclusión para alcanzar sistemas democráticos sólidos. por medio de herramientas que les permitan accionar sus demandas de forma efectiva así como sus capacidades ciudadanas, empleos dignos, acceso a servicios básicos, acceso a la educación, sentido de pertenencia y mecanismos para el procesamiento de conflictos sociales. El ideal a ser alcanzado es un contexto de equidad en el cual sea posible establecer una gobernabilidad democrática de calidad.

El enfoque interdisciplinario, por medio de la cohesión social, refleja la realidad del escenario contemporáneo, siendo un mecanismo para la comprensión de la complejidad de la vida en sociedad, la cual está constituida por sistemas autonómicos y diversos, constituyéndose en la base para relaciones verdaderamente pluralistas y de estructuras institucionales efectivas, ya que los sistemas democráticos sólo podrán ser formados a partir del reconocimiento de subsistemas donde los individuos, vistos como ciudadanos, sean el foco de los procesos de desarrollo. 
El diagnóstico global, por medio de nuestra evaluación, presenta la existencia de un desfase entre las instituciones y la realidad social, denominado como déficit social, debido a la priorización de la dimensión económica en la implementación de las políticas, por parte de los estados. Una democracia de calidad no puede ser evaluada simplemente por su legitimidad y eficiencia, esta debe tomar en consideración su componente valorativo, en el que se incorporen las expectativas ciudadanas, creando una nueva lógica de relaciones entre el Estado, el mercado y la sociedad civil.

Muchas de las regiones a nivel mundial, principalmente aquellas con países en vías de desarrollo, presentan estados caracterizados por elevados niveles de burocracia, corrupción y falta de capacidad a la hora de ejecutar políticas, así como recursos reducidos en lo que se refiere al gasto social. El tema de la cohesión social representa una oportunidad para introducir en el debate público una visión renovada de los rumbos de las sociedades, enfatizando el papel de actores sociales y del espacio público, en donde se implemente el enfoque "desde abajo" de la estructura de toma de decisiones.

Los indicadores vinculados a esta área de investigación presentan grandes dificultades, principalmente en lo que se refiere a la falta de información en los países con mayores niveles de desigualdad, obstaculizando una evaluación cuantitativa efectiva. El indicador utilizado en esta investigación, Transformation Index (BTI), es uno de los más completos a nivel mundial, debido a su capacidad para ser comparado y su disponibilidad en más de 120 países, presentando datos tanto para el área de cohesión como para la calidad de la democracia de forma pertinente.

El modelo implementado busca ser una contribución al debate de cómo alcanzar e implementar sistemas democráticos de calidad y al papel que las sociedades deben jugar en este proceso, siendo imprescindibles, ya que una sociedad con características de inclusión es un catalizador de la democracia en términos positivos.

Una vez definido que existe un impacto real de la cohesión social en la calidad de la democracia, en el próximo capítulo haremos una revisión histórica de las políticas sociales vinculadas a la cohesión para evaluar aquellas que han tenido un impacto positivo en la calidad de la democracia en dos regiones: Europa del Este y América del Sur, con el objetivo de localizar y definir aquellas que se caractericen como políticas efectivas y guías para un desarrollo social y político sólido por parte de los actores gubernamentales.

\footnotetext{
${ }^{56}$ Refiriéndonos a los individuos como miembros activos de las sociedades.
} 


\section{2- TIPOLOGÍAS REGIONALES, POLÍTICAS DE COHESIÓN SOCIAL Y SU IMPACTO EN LA CALIDAD DEMOCRÁTICA: EUROPA DEL ESTE Y SU ENFOQUE SOCIAL}

\subsection{Introducción}

Las sociedades deben ser interpretadas como estructuras complejas con características específicas, que resultan de las dinámicas culturales, históricas, políticas y económicas de los individuos que la conforman. Frente a estas diversidades, la cohesión social se presenta como un elemento común a la hora de formular políticas capaces de generar cambios en las estructuras sociales a mediano y largo plazo, permitiendo la integración de distintas perspectivas provenientes de la ética social, la filosofía política y de las ciencias sociales, con consideraciones de orden práctico que facilitan el diseño e implementación de políticas factibles (CEPAL, 2007a).

Dentro de este contexto, debemos entender a la cohesión como un elemento de medición de ciertas características vinculadas a la idea de inclusión de una sociedad en particular. Estos elementos permiten la diferenciación de distintos niveles de desarrollo a la hora de comparar una sociedad con otra. El periodo de tiempo o momento histórico, en el que se desarrollan estos fenómenos, es esencial, ya que la coyuntura juega un papel relevante cuando se realizan las observaciones. Aquí es donde encontramos el gran desafío a la hora de establecer indicadores que busquen una ponderación en el grado de cohesión social que se encuentra en una sociedad en particular, como fue establecido por (SORJ; MARTUCCELLI, 2008):

"La comparación regional es decisiva para el conocimiento común de los problemas de nuestra sociedad y porque estamos convencidos de que en un mundo globalizado mostrar cómo en diversos países, a pesar de la diversidad nacional, se comparten procesos y tendencias comunes"

Tomando esta visión en consideración, debemos partir de la idea de que existen problemas que son comunes a todas las sociedades a nivel mundial, principalmente en lo que se refiere al tema de desigualdad económica, política y social, discriminación y acceso a derechos, aun teniendo conocimiento de este escenario se le ha dado poca relevancia a la implementación de políticas comunes que tomen en consideración el conjuntos de aspectos involucrados, así como las asimetrías existentes.

Evaluando estas aproximaciones teóricas, en este capítulo se realizará una evaluación de las políticas sociales implementadas a nivel nacional dentro de los países que conforman Europa del Este y se buscará determinar el impacto que tuvieron en la cohesión de las sociedades que 
conforman estos estados, logrando definir políticas efectivas y la existencia de similitudes en su implementación, con el objetivo de establecer un camino para alcanzar mejoras en la dimensión social al observar la forma en que esta ha sido implementada en el pasado, siendo interpretada la cohesión como un elemento catalizador del desarrollo y como el conjunto de interacciones verticales y horizontales de los miembros de una sociedad caracterizadas por un grupo de actitudes vinculadas al sentido de pertenencia.

Las políticas sociales efectivas por su parte, deben ser interpretadas como una variable interviniente en la evaluación de la cohesión social, definida como aquellas políticas caracterizadas por objetivos e instrumentos que buscan el desarrollo social a partir de la reducción de las vulnerabilidades y una mayor igualdad de oportunidades dentro de las sociedades, siendo consideradas como la herramienta más importante para modificar la distribución del bienestar dentro de las sociedades, de acuerdo con (ESPING-ANDERSEN, 1990) en las sociedades modernas hay tres instituciones principales que intervienen en la producción y distribución de los bienes y servicios: el mercado, la familia y la política social, nuestro enfoque estará en la evaluación de la efectividad del último aspecto.

Tomando en consideración estas definiciones, el caso de Europa del Este se considera relevante debido a que se dio una transformación completa de su status quo con el fin de la Unión Soviética y posteriormente con el ingreso dentro de la Unión Europea, que trajo consigo un foco en asuntos sociales. Por medio de esta evaluación se buscará definir fortalezas y debilidades de esta región en lo que se refiere a la implementación de políticas de cohesión, aun cuando los países presentan características diversas se ven afectados por problemas comunes debido a que estos tienen sus raíces en dinámicas humanas.

Este capítulo busca establecer una aproximación a la construcción teórica y empírica de las políticas que buscan el fortalecimiento de la cohesión, por medio de la evaluación de una sociedad que ha priorizado este elemento en su diseño de políticas, como lo es la sociedad europea, superando el énfasis exclusivo en la dimensión económica que ha caracterizado la investigación en términos de desarrollo. Definiendo la forma en que estas políticas han sido implementadas, evaluando los estándares de efectividad y estableciendo cuáles han sido los efectos de estos cambios estructurales, tanto de forma positiva como negativa a lo largo del tiempo. Al establecer comparaciones entre países diferentes, se puede lograr una clasificación de las experiencias exitosas y como estas deben ser implementadas en otras localizaciones 
geográficas, que aun, presentando características particulares a su contexto, se ven afectadas por problemas similares.

Debe ser acrecentado que la evaluación realizada en este capítulo servirá como base a la investigación comparativa que será implementada en el capítulo 3, buscando establecer la efectividad de las políticas de cohesión en términos regionales, tomando como objeto de estudio los países que conforman las regiones de Europa del Este y América del Sur.

\subsection{Metodología}

La revisión teórica realizada, en este sentido, toma en consideración la evolución de los procesos de desarrollo, las disparidades regionales y la implementación de políticas sociales efectivas. El enfoque para evaluar las transformaciones en el campo del desarrollo, en las últimas dos décadas, tuvo cambios profundos (ILIEVA, 2013), "tanto en el nivel nacional como subnacional" (BARCA; MCCANN; RODRIGUEZ-POSE, 2012), también se generó un impacto por medio de una serie de reportes de gran influencia acerca de las políticas de intervención para el desarrollo regional realizados por el (BANCO MUNDIAL, 2009), la Comisión Europea (BARCA, 2009), la OECD (OECD, 2009a) (OECD, 2011) y la Corporación Andina de Fomento (SANGUINETTI; ALVAREZ; CAF, 2012), los cuales modificaron la visión exclusivamente economicista, que fracasó en la mejora de los indicadores sociales.

En consecuencia se establece la hipótesis de que países con políticas sociales multidimensionales vinculadas a la cohesión presentan mejoras en los indicadores de calidad democrática. Con el objetivo de confirmar nuestra hipótesis será realizado un análisis en dos etapas. En primer lugar, la revisión de la cohesión social como política pública en búsqueda de desarrollo. En segundo lugar una evaluación, tanto de forma como de fondo, en la aplicación de políticas de cohesión, para cada uno de los estados que conforman la region estudiada y su impacto en los indicadores de calidad democrática.

Esta estructura de investigación permitirá una evaluación comparativa del estado de la cohesión social en diferentes países y una descripción de las diferentes tendencias que se observan a lo largo del tiempo, en dimensiones específicas y por medio de una clasificación general. Para la evaluación comparativa se utilizará el indicador del Transformation Index- BTI en conjunto con investigaciones para cada región desarrollados por la CEPAL, OECD, Banco Mundial, Comisión Europea y finalmente, entrevistas con especialistas de este campo de investigación. 
Este estudio pretende ser un aporte a la visión que privilegia el análisis de políticas inclusivas que generan desarrollo dentro de las sociedades. De esta forma, el papel de la cohesión social en la formulación de políticas no es un proceso que se puede examinar sin tomar en consideración los elementos como la identidad, fortalecimiento institucional, el desarrollo económico, la desigualdad y el conflicto. Por eso la relevancia de esta investigación en la búsqueda de una comprensión mayor de las dinámicas sociales. El alcance de logros sustanciales y efectivos se debe fundamentar en el fortalecimiento del capital humano, reduciendo la vulnerabilidad de los individuos y promoviendo sus capacidades ciudadanas para alcanzar democracias con calidad.

\subsection{La Cohesión Social vista como política y su impacto en la sociedad}

Con el objetivo de evaluar las políticas de cohesión social, el concepto implementado debe estar libre de atributos específicos, ya que su uso debe adecuarse a diferentes características sociales, económicos, geográficos, históricos y culturales, vinculado a las sociedades modernas, por lo tanto la interpretaremos como "la propiedad por la cual sociedades enteras, y los individuos dentro de ellas, se encuentran unidas internamente mediante la acción de actitudes, comportamientos, reglas e instituciones específicas, que se basan en el consenso más que en la coerción pura" (SOMMA; VALENZUELA, 2015), sustentados a partir de arreglos institucionales y configuraciones perdurables.

Los cambios estructurales generados como consecuencia de los procesos de globalización, han generado un desafío en la forma en que se interpreta el sistema de bienestar social $^{57}$ tradicional en los estados-nación y la forma en que se manejan los problemas que surgieron en consecuencia, tales como el desencanto con las políticas democráticas, el desempleo persistente como resultado de las reestructuraciones económicas, incremento en la movilidad de la población, así como en su diversidad, y las nuevas formas de información, en la era de la tecnología de la información y de las sociedades en red (JEANNOTTE, 2000).

En este sentido, es importante establecer algunas definiciones para entender el área de acción de las políticas públicas, (MULLER; SUREL, 1998) establecen que es "el proceso por el cual se elaboran y se implementan programas de acción pública, es decir dispositivos políticoadministrativos coordinados (...) alrededor de objetivos explícitos", también pueden ser consideradas en un sentido amplio como "una política pública es una acción gubernamental

\footnotetext{
${ }^{57}$ (KEYES, 1998) lo define como la valoración que hacemos de las circunstancias y el funcionamiento dentro de la sociedad»
} 
dirigida al logro de objetivos fuera de ella misma" (HECLO; WILDAVSKY, 1974), finalmente puede ser considerada como "el trabajo de las autoridades investidas de legitimidad pública gubernamental y que abarca múltiples aspectos, que van desde la definición y selección de prioridades de intervención hasta la toma de decisiones, su administración y evaluación" (THOENING, 1997)

Tomando en consideración estas definiciones, se afirma que todas las políticas públicas inciden en la cohesión social (PALMA IRARRÁZAVAL, 2009) sin embargo algunas de ellas lo hacen de forma directa, y generalmente son definidas como "políticas sociales", en tanto otras actúan de forma indirecta. Con el objetivo de promover la cohesión social, una política específica no tiene que estar basada en los aspectos y dimensiones definitorias que la componen, esta se debe enfocar en mejorar su conjunto. De esta forma, la selección de políticas depende de las prioridades de los estados, por medio de un diálogo constante con el gobierno, tomando en consideración la susceptibilidad de la que son objeto los indicadores.

En este sentido, una política que busca el fortalecimiento de la cohesión social implica la aceptación de algunos desafíos, Tassara (2014) los define como una serie de aspectos tales como: la progresiva universalización de la protección social; mejoramiento de la calidad y ampliación del acceso a los servicios públicos, y a la justicia, sobre todo para los sectores más pobres de la población; implementación de políticas activas de empleo y ampliación de los derechos de los trabajadores; generación de mecanismos sociales progresivos y solidarios.

Siguiendo esta línea de pensamiento, debe ser reforzada la idea de que el crecimiento económico, no puede ser interpretado como un factor exclusivo para el desarrollo, es necesario que a la par del crecimiento haya una mejora en todos los indicadores ${ }^{58}$ que buscan la disminución de las brechas sociales y el fortalecimiento del sentido de pertenencia. De esta forma, cabe cuestionar lo siguiente: ¿las políticas sociales son realmente efectivas a la hora de referirnos a la formación de cohesión social dentro de las sociedades? ¿Existen características propias de las sociedades que permiten un desarrollo en mejores términos de las dimensiones de la cohesión?

La coyuntura juega un rol fundamental al tratar de dar respuesta a estas interrogantes. Las políticas públicas que, de forma directa o indirecta, se orientan hacia la cohesión social deben enfrentar un escenario en el que existen múltiples comunidades nacionales, las cuales pasan por transformaciones dispares y complejas, siendo afectadas por la existencia de grados relativos de

\footnotetext{
${ }^{58}$ Que se vinculan a las dimensiones de distancia, institucionalidad y sentido de pertenencia.
} 
desarrollo económico, grados de inserción en el proceso de globalización, diferentes culturas (tomando en consideración a su vez las culturas originarias), la tradición política que las caracteriza y la solidez de sus sociedades civiles (MINISTERIO DE PLANIFICACIÓN DE CHILE, 2007).

Existen debates en los que se establece que existe un control exacerbado por parte de las elites en la elaboración de las políticas públicas, particularmente aquellas políticas que tienen un foco social, los decisores activos que intervienen de modo inmediato y próximo a la elaboración de políticas públicas, constituyen una pequeña proporción de la población que en un sentido amplio se rige principalmente por el interés económico (LINDBLOM; GOÑI, 1991).

Actualmente, están siendo reivindicadas categorías que proponen un crecimiento sostenible basado en la participación ciudadana y un fortalecimiento de los mecanismos que impulsan, y resguardan, los derechos que reflejan lo establecido por medio de la cohesión social. En este contexto cabe lo planteado por (KLIKSBERG, 2001), en lo que se refiere al aporte que las sociedades pueden dar a los procesos de construcción de política, cuando establece que es posible, mediante la acción pública, modificar el mismo capital social con el propósito de resolver problemas de desarrollo en todas las esferas.

De acuerdo con (DÁVILA; SOUTULLO, 2011) el estudio de políticas públicas se define por tres aspectos comunes, primero una vocación a resolver problemas concretos, el enfoque multidisciplinario, y la necesidad de establecer relaciones con lo mencionado anteriormente y el conocimiento para mejorar la democracia y la dignidad humana. Aquellas políticas que tienen un enfoque hacia la cohesión social buscan en primer lugar desarrollar una identidad común "establecen situaciones de igualdad de oportunidades y generan dentro de una comunidad relaciones basadas en la reciprocidad" (PALMA IRARRÁZAVAL, 2009). La promoción de políticas con este tipo de características es necesaria debido a que son vistas como un:

\footnotetext{
"proyecto destinado a crear las condiciones institucionales necesarias para promover la igualdad de derechos y oportunidades, particularmente de aquellas capas sociales de la población que, tradicionalmente, han sido reprimidas o impedidas de acceder a los recursos colectivos y que la literatura especializada denomina sectores excluidos" ((COTLER, 2006)
}

Tomando en consideración esta visión de las políticas públicas en la búsqueda de la cohesión social, se observa que debido a su complejidad, se generan problemas estructurales tales como la falta de coordinación de dichas políticas, lo que en muchos casos genera una duplicidad en el uso de los recursos, así como la falta de coordinación e integración de las 
políticas. Un ejemplo claro de esto son las políticas redistributivas. Los países desarrollados, que inicialmente tenían altas desigualdades en los ingresos, realizaron una redistribución a través de impuestos y transferencias, por el contrario, muchos de los países en vías de desarrollo, como es el caso de América Latina, tenían sistemas de impuestos y transferencias con un impacto mucho más limitado en la distribución de los ingresos (OECD, 2011).

Las políticas, en materia de cohesión social, necesitan tanto de una visión desarrollista multidimensional, como un compromiso a largo plazo, en conjunto con un escenario macroeconómico estable, con esto se establece que para que la inversión, en términos de políticas de cohesión, se vea reflejada, son necesarios periodos de tiempo prolongados que permitan obtener cambios profundos en la estructura.

En este sentido, existen áreas fundamentales para el desarrollo de este tipo de políticas, las cuales deben tomar en consideración las desigualdades en lo que se refiere al acceso de oportunidades por parte de los individuos que conforman una sociedad en una localidad geográfica específica, compuesta por una serie de características (género, identidad socioeconómica, tradiciones, etc.). La selección de las políticas por parte de un país depende de sus prioridades, a continuación se identifican las áreas más relevantes de acuerdo con la (OECD, 2011):

Tabla 4: Áreas relevantes para la implementación de políticas sociales

\begin{tabular}{|c|l|}
\hline $\begin{array}{c}\text { Empleo y } \\
\text { Protección } \\
\text { Social }\end{array}$ & $\begin{array}{l}\text {-Se refiere a la reducción de las desigualdades y la prevención de la exclusión social, } \\
\text { considerando a los sistemas de protección social y sus interacciones con el mercado } \\
\text { laboral principalmente en las estructuras familiares pobres/vulnerables, permitiendo } \\
\text { identificar las deficiencias en el diseño y mejoras de programas. }\end{array}$ \\
\hline Educación & $\begin{array}{l}\text {-Moldean y transmiten valores comunes que respaldan los conceptos de capital social } \\
\text { e inclusión. Construye el sentido de pertenencia de una sociedad, incrementando de } \\
\text { esta forma la participación de niños de grupos en desventaja, generando en } \\
\text { consecuencia una educación más inclusiva, promoviendo la diversidad y mejorando } \\
\text { las percepciones positivas de los otros dentro del sistema y la sociedad. }\end{array}$ \\
\hline Género & $\begin{array}{l}\text {-Consideran las dinámicas culturales y el hecho de que las instituciones sociales } \\
\text { están basadas en las relaciones de poder existentes, por lo cual desafiar a las } \\
\text { instituciones sociales discriminatorias es una tarea intimidante, los cambios en este }\end{array}$ \\
\hline
\end{tabular}




\begin{tabular}{|c|l|}
\hline \multirow{2}{*}{ Migraciones } & $\begin{array}{l}\text { tipo de políticas se deben dar en las áreas de empleo, educación y de } \\
\text { emprendimiento. }\end{array}$ \\
& $\begin{array}{l}\text {-Las políticas en esta área deben prevenir e invertir en la exclusión social de los } \\
\text { inmigrantes, promoviendo la creación de lazos positivos entre los inmigrantes y } \\
\text { residentes locales. A su vez deben permitir la movilidad en términos sociales de los } \\
\text { inmigrantes mejorando el acceso a los mercados laborales, facilitando el } \\
\text { emprendedorismo y promoviendo la educación }\end{array}$ \\
\hline Política Fiscal & $\begin{array}{l}\text { Aquellas que mantienen un financiamiento sustentable a largo plazo en los } \\
\text { programas sociales, un objetivo difícil de ser alcanzado en un contexto de ingresos } \\
\text { volátiles principalmente en los países en vías de desarrollo que dependen de la } \\
\text { fluctuación de los precios de los productos básicos (commodities) y el agotamiento } \\
\text { potencial de los recursos naturales no renovables. La existencia de bajos niveles de } \\
\text { confianza, en lo que se refiere a cómo los impuestos se obtienen y cómo son } \\
\text { gastados los ingresos, traduciéndose en menores ingresos. }\end{array}$ \\
\hline
\end{tabular}

Fuente: OECD, 2011

Podemos establecer que, en el escenario contemporáneo, la insuficiencia en la implementación de políticas apropiadas y congruentes con la realidad de las sociedades, en conjunto con una baja calidad institucional, pueden ser identificadas como las causas para la falta de crecimiento, la pobreza endémica y el conflicto civil, que derivan a su vez en una baja calidad democrática. Existen una serie de limitaciones para las reformas políticas desde una perspectiva social principalmente en los países en vías de desarrollo, podemos observar que se generan estructuras complejas:

Tabla 5: Dinámicas Cohesión/ Desarrollo

\begin{tabular}{|c|c|c|}
\hline $\begin{array}{l}\text { Estructuras Sociales } \\
\text { Sólidas } \\
\text { (Grado de Cohesión } \\
\text { Social) }\end{array}$ & $\begin{array}{l}\text { Instituciones Políticas } \\
\text { (Capacidad de } \\
\text { Implementar } \\
\text { políticas) }\end{array}$ & $\begin{array}{l}\text { Desarrollo Sostenido } \\
\text { (Dimensión } \\
\text { Social, Política y } \\
\text { Económica) }\end{array}$ \\
\hline
\end{tabular}

Fuente: Elaboración propia 
El sentido en que los vectores se encuentran establecidos tiene un motivo de fondo, países con estructuras sociales en donde se ve reflejada la exclusión, falta de confianza y poco sentido de pertenencia, tienden a sufrir de grandes limitaciones en la implementación de reformas políticas:

"La cohesión social determina la calidad de las instituciones que a su vez tiene un impacto importante sobre cómo y de qué forma las políticas que buscan el desarrollo son ideadas e implementadas (...) las políticas pro-desarrollo son comparativamente raras en los países en vías de desarrollo no solo en una escala menor por la falta de fibra moral de los políticos sino también como consecuencia de la insuficiencia de cohesión social que impide la construcción de instituciones efectivas". (EASTERLY; RITZEN; WOOLCOCK, 2006) $)^{59}$

El foco presentado en la caracterización de diversas regiones ${ }^{60}$, como polos de cohesión social, se establece en relación al conjunto de características demográficas, étnicas, lingüísticas (en algunos casos), culturales, etc. propias de estos territorios, donde se observa una área de vida en común, que aun existiendo una gran dificultad en establecer una visión común para países con características tan diversas, se aplica una clasificación a través de las regiones por medio de una visión humana/geográfica, en donde son consideradas las estructuras de relaciones humanas (económicas, políticas, etc.) y se puede evaluar la aplicación de políticas en términos estatales y regionales.

Tomando esta revisión conceptual como base, la búsqueda de mayores niveles de cohesión social, como un objetivo de las políticas públicas, necesita de la promoción de mecanismos de inclusión y de un fortalecimiento del sentido de pertenencia, permitiendo el alcance de derechos en todos los niveles por parte de todos los ciudadanos, en definitiva, los miembros de la sociedad deben buscar la ciudadanía plena y políticas que apunten a todos los miembros de la sociedad, para que puedan ser percibidos a sí mismos como parte activa de ella, como ciudadanos plenos. Esta visión proviene principalmente de una "tradición" reciente, de acuerdo a lo establecido por Chan (et al, 2005), por parte de los formuladores de políticas y los analistas de políticas sociales, que buscan definir y operacionalizar la Cohesión Social como un asunto clave.

\footnotetext{
${ }^{59}$ Texto original: "social cohesion determines the quality of institutions, which has important impacts on whether pro-growth policies are implemented or not (...)pro-growth policies are comparatively rare in developing countries not only on a smaller scale due to the lack of moral fiber of its politicians, also due to the failure of social cohesion which prevents building effective institutions"

60 "Las regiones humanas son definidas por los grupos humanos, ya que no son otra cosa que esos grupos humanos y sus modos de vida considerados desde un punto de vista espacial"' (CHOLLEY, 1951).
} 
El desafío que se observa en esta evaluación se refleja en dos aspectos principales: 1)La utilización de un indicador que tuvieses datos para las regiones que están siendo evaluadas tomando en consideración las tres dimensiones básicas en las cuales se interpreta la cohesión social: distancia, institucionalidad y sentido de pertenencia 2)Establecer un contexto específico en términos históricos e institucionales para la cohesión social de cada región, para establecer vínculos entre los datos obtenidos y el contexto específico en el cual se desarrollaron estos procesos.

\subsection{Europa del Este y el impacto de las políticas de cohesión social}

Con el objetivo de evaluar las dinámicas de cohesión social dentro de los países en vía de desarrollo es necesario establecer una comparación entre diversas regiones, buscando definir la efectividad de las políticas en términos sociales. Europa del Este o Europa Oriental es una región que atravesó diversos cambios estructurales a lo largo de su historia, cambios profundos que afectaron la estructura social, política, económica, institucional y cultural, por medio de procesos en los que las dinámicas políticas y de cambio, domésticas, han coexistido con la influencia de procesos/actores regionales y globales. Los países que conforman esta región y que serán evaluados a través de este estudio son Croacia, Bulgaria, República Checa, Estonia, Hungría, Letonia, Lituania, Polonia, Rumanía, Eslovaquia y Eslovenia.

Los países de Europa del Este son considerados como objeto de análisis a la hora de observar la evolución de la implementación de políticas de cohesión social. El desarrollo de los procesos en el ámbito social se dieron a un ritmo diferente del que se observa en Europa Central, en términos de recursos y el contexto histórico, principalmente al evaluar dos momentos específicos, que son establecidos como el fin de la Unión Soviética y la estructuración del proceso de integración europea. Estos países presentaban niveles de pobreza mucho más elevados que aquellos países miembros de la EU15 ${ }^{61}$ en el momento de acceso, esto debido a que habían sido desconectados de Europa Occidental por cuatro décadas, por causa de la incorporación en la Unión Soviética o por estar ocupados por los soviéticos.

\footnotetext{
${ }^{61}$ Austria, Belgica, Dinamarca, Finlandia, Francia, Alemania, Grecia, Irlanda, Italia, Luxemburgo, Holanda, Portugal, España, Suecia y el Reino Unido
} 
Grafico 8: Muestra del Nivel de Cohesión Social en Europa, período 1989-1995

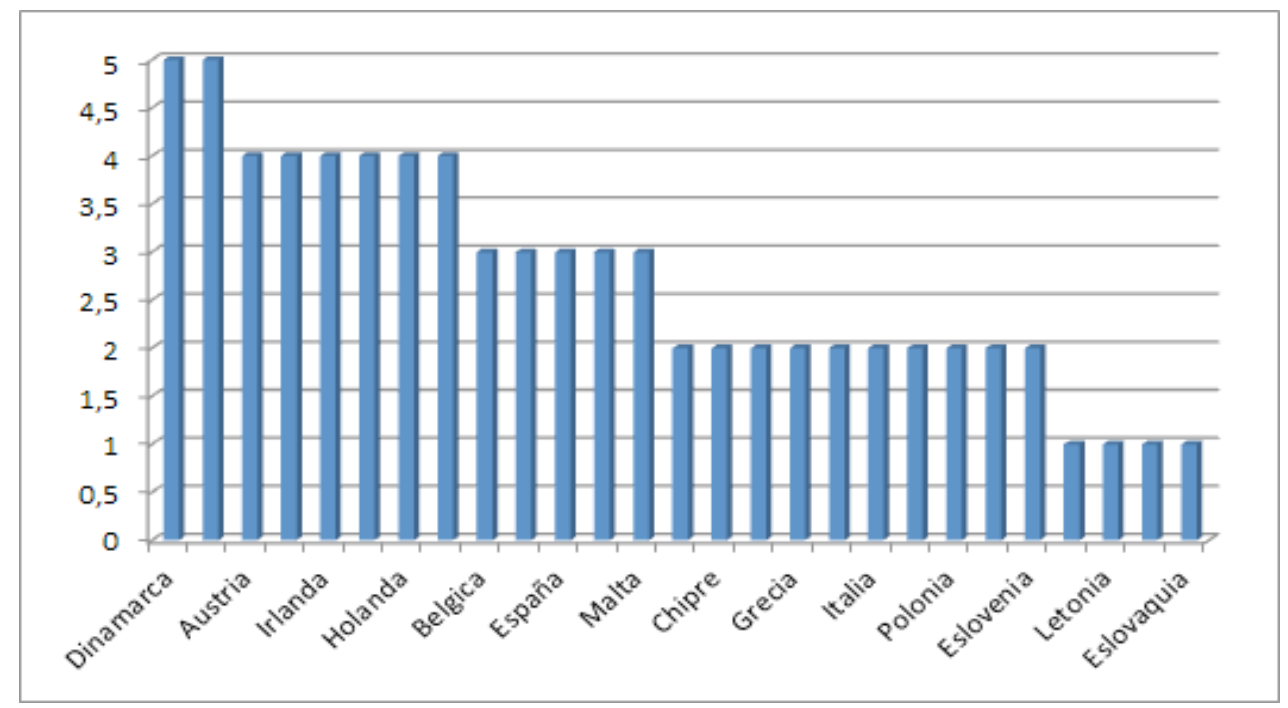

Fuente: (Bertelsmann Stiftung, 2013)

Grafico 9: Muestra del Nivel de Cohesión Social en Europa, período 2009-2012

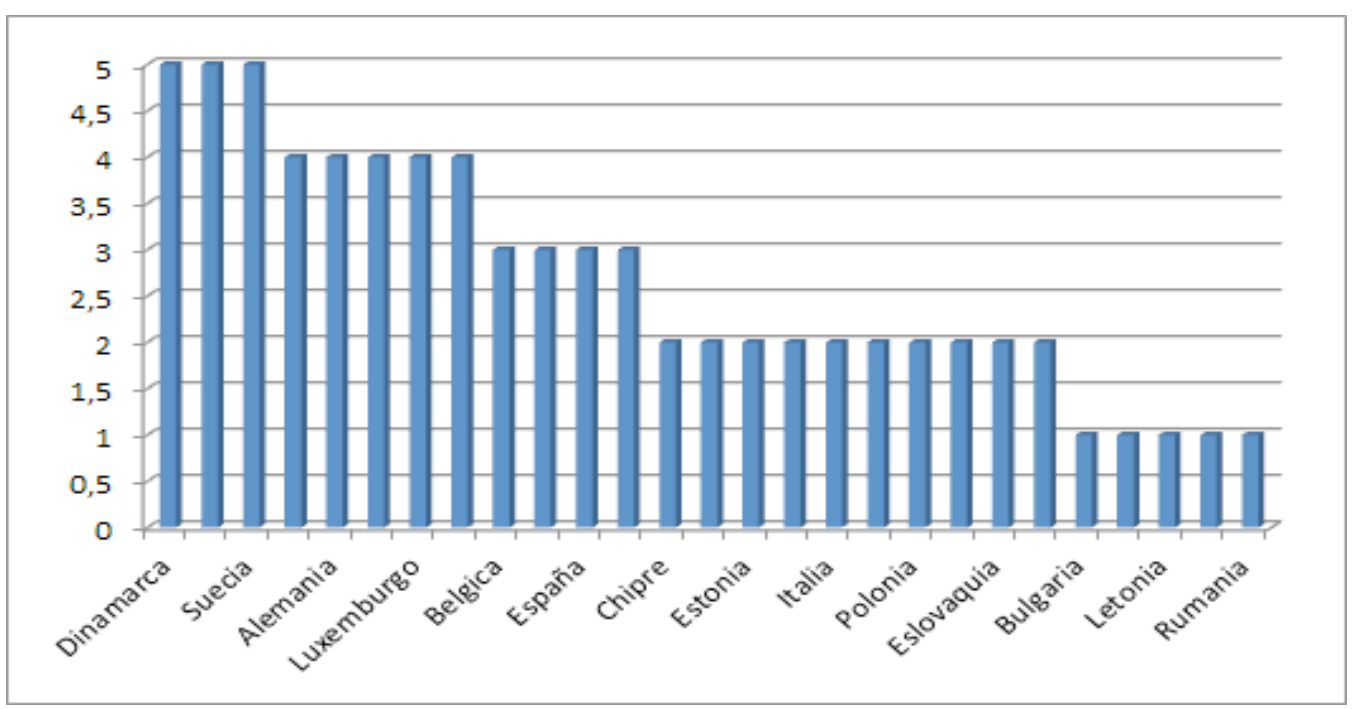

Fuente: Bertelsmann Stiftung, 2013

En términos políticos los individuos que forman parte de esta región desafiaron al contexto impuesto por el régimen comunista, lo que generó la implementación de estructuras políticas, sociales y económicas diferentes de acuerdo a sus diversidad histórica/cultural/social y al legado dejado por el comunismo en cada país. La difícil transición a una democracia multipartidaria y a una economía de libre mercado fue un proceso complejo, al cual se le suma la renovación de algunos conflictos interétnicos, especialmente en los estados de Croacia, Rumania y Eslovaquia (ROTHSCHILD; WINGFIELD, 1993). En definitiva los países de Europa del Este buscaban en la Unión Europea no sólo apoyo económico, acceso a mercados y asistencia técnica sino también 
el reconocimiento de su condición de "Europeos", es decir, de aquel sentido de pertenencia al continente (DINAN, 2010).

Actualmente se observa un escenario en el cual las políticas en pro del desarrollo son prioridad, implementadas sobre la suposición de una periferia pobre (Europa del Este) y un núcleo rico (Europa Central), dispuesto a financiar ciertas políticas que resultan en un crecimiento conjunto (ídem). Esto es una consecuencia del aumento de las desigualdades entre los países Europeos, lo que llevó a la inferencia de que la liberalización del mercado no iba ser el factor que reduciría estas brechas entre "ricos" y "pobres, por eso el papel relevante de las políticas de cohesión en este escenario.

En un periodo de 20 años se dieron cambios profundos en la región, la cual pasó de ser receptora de ayuda internacional a convertirse en un actor relevante, implementando programas de cooperación internacional y de asistencia pública. Estos países post comunistas, al contrario de algunos de sus homólogos occidentales, han sido objeto de políticas sociales ambiciosas y grandes reformas en lo que se refiere al mercado de trabajo durante las últimas décadas, así como una transformación de estados totalitarios en democracias a partir de un proceso endógeno, es decir, sin imposición exterior del nuevo marco político (González, 1992)

En términos históricos, de acuerdo con (HERNANDEZ, 2011) podemos establecer dos momentos claves en esta región después de la caída de la Unión Soviética, en primer lugar durante la década de los noventa se construyen las bases para los nuevos sistemas democráticos, donde se establece el realineamiento internacional y en segundo lugar, la inserción dentro del proceso de integración europeo, donde se observa un alineamiento de políticas públicas, a su vez se da inicio al desarrollo de capacidades políticas y administrativas.

Desde el punto de vista de la articulación del diálogo político y social, los procesos de transición en Europa Oriental se realizaron a través de un espacio de concertación entre las autoridades de los regímenes comunistas y los representantes de las fuerzas democratizadoras, siendo un espacio fundamental para articular los tiempos y los procesos de transición política que se desarrollaban (ídem). De esta forma se establece el marco básico para la estructura institucional de las nuevas democracias en algunos casos, como lo fue el Polonés, en donde se incluye el modelo social ${ }^{62}$.

62 El modelo de políticas sociales comunistas había sido denominado como "estado-colectivista", estado de bienestar "burocrático-colectivista" o un "estado antiliberal, con una mezcla de políticas jerárquicas socialista con elementos conservadores (KSIEZOPOLSKI, 1993). Polonia en conjunto con la Unión Europea y otros Estados Miembros ayudo en la promoción de una nueva estructura política con una mayor participación de los agentes 
Existen una serie de elementos que tuvieron un papel relevante en este cambio estructural, en primer lugar la liberalización económica, la implementación de una Reforma política, por medio de nuevas estructuras institucionales (separación de poderes) y la que se establece como nuestra área de análisis, la implementación de una política social. Estos elementos permitieron articular hasta cierto punto un modelo de diálogo social permanente y con un nivel mayor de efectividad en el contexto de las políticas de transformación económicas, post unión soviética.

Aun cuando se comienza a construir la institucionalidad en torno al diálogo social dentro de estos países, esto no significó, necesariamente, un incremento entre la interacción de la ciudadanía y los "policy makers", principalmente durante el comienzo de la década de los noventa, ya que en conjunto con estos cambios políticos se observa un proceso de desmovilización ciudadana, como consecuencia de reformas estructurales que no contaban con el apoyo de la población, ya que afectaron todos los ámbitos de la vida ciudadana, esto se ve reflejado en un cierto nivel de desconexión entre la ciudadanía y los actores sociales (JUBERIAS, 2002).

A finales de la década de los noventa se produce la revitalización de los espacios de diálogo social en el marco de las políticas públicas, se produce como consecuencia de varios aspectos de acuerdo con Hernández (2014), en primer lugar la incorporación paulatina de una cultura de gobernanza con el apoyo de la cooperación internacional, en segundo lugar la consolidación de los espacios de concertación social, en tercer lugar los mecanismos dedicados al diálogo y la participación de la sociedad civil para la implementación de políticas públicas (por ejemplo el establecimiento del Centro de ONGs en Letonia) y por último la implementación de mecanismos de concertación y participación de actores en el marco de la reforma de políticas sociales, (ejm.: la experiencia de la reforma en la República Checa de los sistemas de educación y formación profesional).

Desde finales de la década de los noventa se produce un proceso gradual en el cual se ve definido el papel de la sociedad civil en medio del escenario de incorporación de estos países dentro de la Unión Europea, siendo empoderadas tanto la ciudadanía como los actores institucionales, como aquellos capaces de definir las políticas públicas (JUBERIAS, 2012).

sociales. Las políticas sociales polonesas fueron afectadas principalmente por los principios operacionales del Fondo Social Europeo (procedimientos de implementación y los acuerdos institucionales necesarios) en el nivel operacional, el cual co-financió inversiones en Polonia que en otro escenario no habrían sido posibles, en los campos de inclusión social, empleo y salud pública (WISNIEWSKI, 2005). 
Debido a la complejidad de las sociedades en términos del funcionamiento político posterior a la Unión Soviética, se busca promover la diversificación del intercambio y dialogo social entre los actores, el cual se realiza a partir de mecanismos de incorporación vinculados a las políticas públicas por medio de la participación y coordinación de los mismos dentro de las instituciones gubernamentales. Esto se realiza de acuerdo con Hernández (2014) a partir de dos niveles, en primer lugar la construcción de grandes consensos políticos, definido como un momento transicional, y en segundo lugar lo que se refiere a la experiencia de modernización de los modelos de gobernanza, durante el inicio de la transición en esta región la dureza de las reformas estructurales se vio como limitante en lo que se refiere a la capacidad de los actores sociales y el papel ejecutado por los mecanismos de diálogo.

El segundo momento histórico esencial en Europa Oriental, es el proceso de adhesión a la Unión Europea en el marco de políticas públicas y el proceso de incorporación del acervo comunitario $^{63}$. Esta región construyó su fortaleza sobre la base del sentido de pertenencia y su tejido asociativo, lo que ha permitido avanzar hacia la constitución de modelos de interacción complejos.

\section{Gráfico 10: Periodos de Ingreso en la Unión Europea}

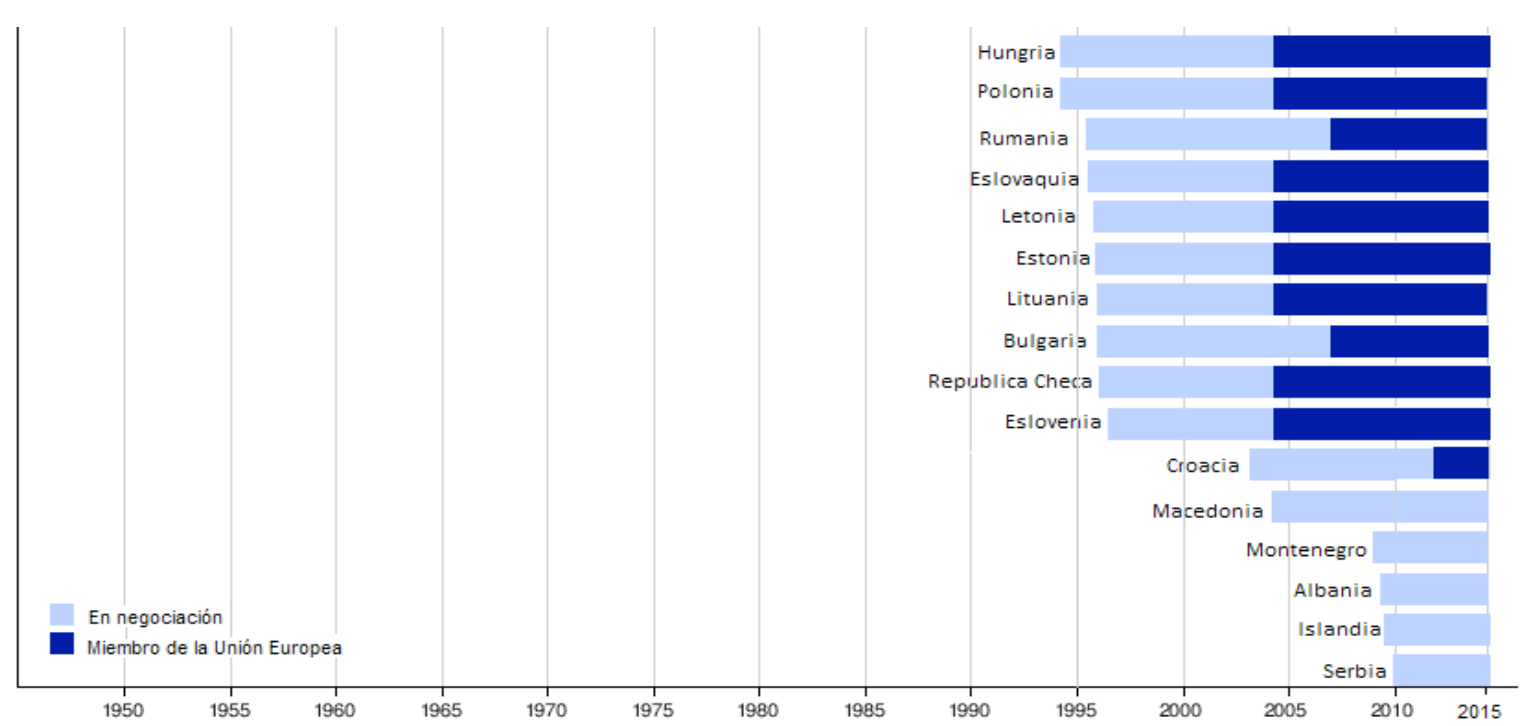

Fuente: (FELDMAN, 2011)/ (UE, 1995-2015)

${ }^{63}$ El acervo comunitario comprende la base común de derechos y obligaciones que vincula al conjunto de los Estados miembros de la Unión Europea (Unión Europea, 1995-2015) 
Para alcanzar la incorporación dentro de la Unión Europea, se implementaron diversos programas, entre ellos uno de los más importantes fue el programa PHARE ${ }^{64}$, creado en 1989 con el objetivo de ejecutar reformas y permitir la transición política, económica y social, por medio de una evaluación inicial de los principales problemas. En un primer momento fue aplicado en Polonia y Hungría, posteriormente se extendió a los otros países candidatos al ingreso (LÓPEZ-MANTEROLA, 2000).

Este programa tuvo como objetivo la ayuda comunitaria a los países de Europa Central y Oriental, implementado desde 1994 posterior a la invitación propuesta durante el Consejo Europeo de Copenhague en 1993, el PHARE tuvo como foco ayudar a los países a alcanzar los niveles requeridos para entrar en la Unión Europea, con tres objetivos principales, en primer lugar el fortalecimiento de la Instituciones y Administración pública dentro de los países, la promoción de la convergencia con las leyes europeas y finalmente la promoción de la cohesión económica y social (WALLACE; POLLACK; YOUNG, 2015), en el cual nos enfocaremos.

\subsection{Especificidades de las políticas de cohesión dentro de los países de Europa del Este}

El análisis del contexto europeo de políticas sociales, proporciona las bases para comprender el proceso de transformación económica, política y social, así como el refuerzo de la estructura democrática en estos países durante las dos últimas décadas. Con el objetivo de profundizar aún más en la evaluación del desarrollo de la cohesión social, se realizara una decantación de las principales políticas sociales que afectaron de forma directa a los países de esta región con el objetivo de definir aquellas que impactaron de forma positiva a la cohesión, observando el comportamiento dentro del período evaluado 2003- 2014 tomando en consideración el indicador Nivel de Dificultad y la Calidad de la democracia en este período.

\subsubsection{Croacia}

Croacia a diferencia de otros países de Europa del Este, presentó un contexto de mayor complejidad en el establecimiento de la cohesión social y el desarrollo, por causa de la Guerra Croata de independencia (1991-1995), pero aun así, logró alcanzar niveles de estabilidad elevados después de un proceso grande de transformación que se enfrentó a diversos obstáculos en términos de estructuración:

\footnotetext{
${ }^{64}$ Programa de ajuda comunitária aos países da Europa Central e Oriental
} 


\begin{abstract}
"la política de desarrollo no abordo la distribución geográfica de la pobreza y la exclusión, y como consecuencia las disparidades regionales se han profundizado desde que Croacia se convirtió en un país independiente. Este problema de desigualdad regional y la pobreza es especialmente grave en las zonas afectadas por la guerra de Eslavonia Oriental, que no se habían recuperado económicamente de los efectos de la guerra en la década de 1990”.(BONKER; PETAK; BARTLET, 2015)
\end{abstract}

En este sentido los principales problemas se vinculaban a la exclusión social y la pobreza, durante los años 90 las transferencias sociales no contaban con una estructura apropiada para alcanzar un impacto significativo en la disminución de estos problemas, aun cuando la educación era considerada como la mejor vía para avanzar en esta dimensión, presentaba problemas estructurales ya que segmentos vulnerables de la población eran transferidos a la rama técnica de la educación secundaria, no permitiendo el acceso a la educación superior (STUBBS; SINIŠA, 2005). Este contexto hizo que el acceso general a la educación en Croacia estuviese por detrás de la media de la Unión Europea, razón por la cual se implementaron reformas profundas debido a que rápidamente las industrias estarían basadas en el conocimiento y la innovación impulsada por el crecimiento económico, al convertirse en países miembros (MIROŠEVIĆ, 2007).

Un elemento importante a ser considerado es el "Acuerdo de Estabilización y Asociación" (AEA) firmado entre Croacia y la UE en el 2001, considerándose como el primer paso de un proceso de transformación a largo plazo en términos políticos, económicos y sociales, enfocados en siete aspectos:

"las mejoras en la protección de la salud y la seguridad de los trabajadores, los ajustes del sistema legal en materia de condiciones de trabajo y la igualdad de oportunidades para mujeres y hombres, ajustes a los sistemas de seguridad social de acuerdo con los nuevos requisitos económicos y sociales, así como las mejoras en los servicios de desempleo, promoción del desarrollo local y ayuda en la reestructuración del mercado industrial y el laboral" (STUBBS; SINIŠA, 2005, p. 172, traducción propia) ${ }^{65}$.

En 2002, el Gobierno aprobó un "Programa de Lucha contra la Pobreza y la Exclusión Social" (STUBBS; SINIŠA, 2005), siendo la primera vez que un documento oficial que abordaba estas cuestiones esbozó el papel y las tareas de las diferentes agencias estatales en la reducción de la tasa de pobreza, fue totalmente elaborado y aprobado por los representantes del Estado con el apoyo de expertos y profesionales en políticas sociales.

\footnotetext{
${ }^{65}$ Texto original: "Improvements in services of unemployment, promotion of local development and help in restructuring the industrial market and the labor market; adjustments of social security systems to new economic and social requirements; adjustments of the legal system in respect of work conditions and equal opportunities for women and men; improvements in the protection of health and security of workers".
} 
En el 2007 Croacia firmó el Memorándum Conjunto de Integración (MCI ${ }^{66}$ con la Unión Europea, el cual presto apoyo en la evaluación y el diseño de políticas y estrategias prácticas para la inclusión de sus poblaciones más vulnerables, dándole prioridad a las diferencias regionales y de género, así como las evaluaciones de la población en riesgo de exclusión social, para evitar una mayor marginación de estos grupos y recibir la atención adecuada a través de la planificación estratégica para su inclusión (BONKER; PETAK; BARTLET, 2015).

Otros dos acuerdos que presentan relevancia para el análisis de cohesión son el "Programa de Cooperación entre el Gobierno de la República de Croacia y las organizaciones no gubernamentales" (2001), estableciéndose como un marco para mediar la cooperación entre el sector público y civil, así como la promoción de la sociedad civil y en segundo lugar la "Estrategia Nacional para la creación de un ambiente favorable para el desarrollo de la sociedad civil 2006-2011”, por medio de un plan operacional, basado en los principios de pluralismo, transparencia e independencia del sector civil (MATEI; VAŠIČEK; KAŠTELAN-MRAK, 2011).

Las políticas implementadas desde el ingreso como miembro de la Unión Europea trajeron consigo una reconstrucción del Estado, así como el fortalecimiento de identidades nacionales y la redefinición de la influencia ciudadana en lo referente a los derechos de asistencia social y la aparición de nuevas modalidades de asistencia social. El desarrollo de las políticas de cohesión en conjunto con el fortalecimiento de la sociedad civil trajo consigo trajo una mejora generalizada en los indicadores sociales así como de la estabilidad gubernamental lo que se ve reflejado en el Transformation Index como vemos a continuación:

Tabla 6: Croacia: Relación Cohesión Social/ Calidad de la Democracia

\begin{tabular}{|l|c|c|c|c|c|c|}
\hline Años & 2003 & 2006 & 2008 & 2010 & 2012 & 2014 \\
\hline Nivel de Dificultad & 4,0 & 2,6 & 2,6 & 2,4 & 2,4 & 2,0 \\
\hline Calidad de la Democracia & 8,40 & 9,10 & 8,85 & 8,50 & 8,40 & 8,45 \\
\hline
\end{tabular}

Fuente: Transformation Index, 2015

Observando los indicadores vemos que Croacia se ha caracterizado por una mejora sostenida de nuestro indicador de Cohesión Social durante el período estudiado y en el caso de la calidad de la democracia se ha mantenido una estabilidad del indicador de la calidad de la

\footnotetext{
${ }^{66}$ Joint Integration Memorandum
} 
democracia, en el año 2006 se observa un cambio radical en los dos indicadores producto del inicio del proceso de adhesión y el impacto de las políticas y programas sociales, políticos y económicos implementados en dicho proceso.

\subsubsection{Bulgaria}

El contexto en el cual se dio la transformación estructural Búlgara tuvo como base el Acuerdo Europeo de 1995, que posteriormente se transformó en una asociación para la adhesión en 1997 y abrió las negociaciones con la UE en el año 2000, derivando en el Tratado de Adhesión en el año 2005, convirtiendo a Bulgaria en un miembro de la UE en 2007. La intensificación del proceso de asociación europea, el continuo flujo de fondos de la UE y la ayuda internacional ayudó profundamente a la recuperación de la economía (MONASTIRIOTIS, 2008).

De acuerdo con (FALKNER; NENTWICH, 2000), (PICKLES; SMITH, 1998) у (LAVIGNE, 1999) de forma general los principales problemas que presentaba Bulgaria era ser una burocracia estatal muy centralizada, con una organización ineficiente de su producción, falta de capital privado y financiero, así como grandes desigualdades sociales, por otra parte se observaban problemas a nivel de la justicia, la corrupción, los desequilibrios en el funcionamiento de la economía de mercado, la capacidad de hacer frente a grupos de presión y de mercados competitivos a la hora de ingresar a la UE.

En este sentido fueron adoptadas una serie de reformas, estructuradas en 5 áreas prioritarias: 1) el poder judicial fue reformado para eliminar los mecanismos ilegales y para equilibrar el emprendimiento empresarial competitivo de forma legítima, 2) se hicieron reformas en el área de la educación a fin de limitar la exclusión de diversos grupos principalmente los minoritarios, se priorizó la alfabetización básica, y la generación de capital humano. 3) los sistemas de atención de salud y de pensiones, 4) se invirtió en la infraestructura y 5) se le dio un mayor apoyo para fomentar una fuerza de trabajo altamente calificada y la flexibilidad en términos de movilidad (GANEV; POPOVA; BONKER, 2015).

Bulgaria se comprometió a invertir más de la mitad de la asignación de los Fondos Estructurales provenientes de la UE, en las prioridades directamente vinculadas al Programa Nacional de Reformas de Bulgaria en el reconocimiento de la importancia de la política de cohesión, buscando alcanzar los objetivos de la Agenda de Lisboa (ídem). En consecuencia, el programa nacional de reformas refleja las metas del Fondo Nacional Estructural y los respectivos 
"elementos de crecimiento y empleo, sobre todo el espíritu empresarial, la investigación, desarrollo e innovación, el desarrollo sostenible, la educación y la formación" (EUROPEAN UNION, 2013).

Bulgaria se caracteriza por tener, en su período posterior a la adhesión, un marco de políticas para el desarrollo con una estructura sólida y coherente vinculada al acervo de la UE (GANEV; POPOVA; BONKER, 2015). La financiación obtenida trajo consigo un incremento en la entrada de recursos necesarios para la inversión en políticas sociales principalmente en áreas con problemas de exclusión, buscando la difusión del crecimiento de la periferia, considerada como un objetivo focal.

La estrategia de cohesión social búlgara reconoció la importancia crucial de la inversión en la investigación y la innovación como un área clave para el desarrollo sostenible a largo plazo del país, la mejora de la adaptabilidad de los trabajadores a través de la inversión en la formación continua y el lugar de trabajo, así como diversas medidas para promover la inversión en capital humano. Durante el proceso de pre-adhesión se buscó dar a los trabajadores, los empleadores, las mujeres, los jóvenes, los grupos desfavorecidos desempleados, entre otros las herramientas para alcanzar empleos dignos a partir del "Programa Operativo de Recursos Humanos Desarrollo" (EUROPEAN UNION, 2013).

Después de un período de desarrollo dinámico de la economía búlgara (2005-2008), la crisis económica mundial tuvo un impacto negativo y trajo consecuencias negativas, afectando la implementación de políticas, principalmente aquellas vinculadas al área social, aun así se puede decir que tuvo un proceso exitoso de pre y pos adhesión, el financiamiento de las políticas de cohesión en este sentido ha sido un motor importante para reformas profundas, trayendo mejoras consistentes en los indicadores sociales, aun cuando este país continua en la posición de ser uno con las mayores tasas de pobreza de la UE y con un sistema político con características complejas (DAWSON, 2014).

La sociedad civil en este sentido ha sido un actor relevante para que estas reformas tuviesen efecto y se vieran reflejadas en la estructuración de un sistema político estable, convirtiéndose en un actor bien regulado y libre para la ejecución de sus actividades, tanto en comunicación con el estado como con los medios (ORENSTEIN, 1995). Evaluando de forma amplia el papel de la Unión Europea en este proceso de reformas políticas cabe resaltar lo establecido por Ekiert et al, 2007 apud Dawson, (2014, p. 10):

"La Unión Europea puede estar presidiendo el programa más exitoso de promoción de la democracia nunca antes implementado por un actor internacional. La 
trayectoria hasta ahora es excelente: cada uno de los estados democratizadores se ha convertido en un creíble futuro miembro de la Unión Europea (...)”. (traducción propia) ${ }^{67}$

Tomando en consideración el proceso de implementación de políticas por parte de Bulgaria nuestros indicadores de cohesión social y calidad democrática reflejan estas dinámicas, así como demuestran que Bulgaria ha alcanzado un avance considerable a través de la implementación de reformas que buscan solventar los problemas de exclusión como se observa a continuación:

Tabla 7: Bulgaria: Relación Cohesión Social/ Calidad de la Democracia

\begin{tabular}{|l|c|c|c|c|c|c|}
\hline Años & 2003 & 2006 & 2008 & 2010 & 2012 & 2014 \\
\hline Nivel de Dificultad & 4,0 & 3,2 & 3,2 & 3,0 & 2,8 & 2,8 \\
\hline Calidad de la Democracia & 8,00 & 8,45 & 8,70 & 8,75 & 8,65 & 8,35 \\
\hline
\end{tabular}

Fuente: Transformation Index, 2015

En nuestra evaluación se observa una mejora consistente en la Cohesión, producto de las reformas e inversiones sociales implementadas en el proceso pre-adhesión, la calidad de la democracia alcanza su valor más elevado entre 2006-2008, esto puede ser interpretado desde varias visiones, en primer lugar desde el 2001 se venían implementando en Bulgaria reformas a nivel económico, político y social para alcanzar los niveles de desarrollo de la Unión Europea, por lo cual en el 2007 se observa un avance proporcional en estos indicadores, producto del ingreso en la Unión Europea, también de observa una disminución importante en la falta de cohesión entre 2003-2006 como resultado del inicio en la implementación de las políticas multidimensionales con fuerte financiamiento de la UE.

\subsubsection{República Checa}

La Republica Checa ha tenido históricamente un vínculo fuerte con la dimensión social, su transición del modelo comunista trajo consigo transformaciones profundas en las políticas sociales que contribuyeron de forma directa al proceso de transición a una economía de mercado. El modelo social-liberal de la transformación económica de la República Checa trató de llevar a

\footnotetext{
67 Texto original: The European Union may be presiding over the most successful democracy promotion program ever implemented by an international actor. The track record so far is excellent: every democratizing state has become a credible future member of the European Union
} 
cabo una transformación en la esfera social con reformas radicales en términos macroeconómicos (ORENSTEIN, 1995)

Las nuevas instituciones de política social (ejm.: Fondo del Seguro General de Salud), así como los nuevos sistemas de financiación, se desarrollaron simultáneamente con las instituciones de promoción de mercado, priorizando de esta forma soluciones a largo plazo. Debido a la implementación temprana, en lo que se refiere a reformas sociales y económicas, la República Checa es el único país de Europa del Este, que ha creado una red de seguridad social efectiva (SVATOŠOVÁ; SMOLÍK, 2015).

De acuerdo con la encuesta microcenso de 2002, el 8\% de la población en la República Checa era pobre ${ }^{68}$, índice que vio mejoras considerables durante la década pasada, el país se encuentra con el nivel más bajo de la pobreza, en comparación con la media europea del 16\% (SIROVÁTKA; RÁKOCZYOVÁ, 2007).

Un aspecto importante a ser considerado es que desde el inicio de la transformación de la economía, los representantes políticos consideraron que la protección de la población era un aspecto esencial para evitar el impacto negativo de estas reformas para lo cual le dieron un fuerte énfasis en la prevención de la pobreza con medidas a largo plazo fundamentadas en la redistribución hacia grupos de bajos ingresos (TOMEŠ, 1991). Esta protección se dio a partir de una fuerte inclusión de la población en el mercado laboral y el fortalecimiento de los servicios sociales básicos, con el objetivo de atender las necesidades específicas de grupos en riesgo, reforzando la coordinación, así como la interconexión a nivel nacional, regional y local.

La política social estaba orientada a la compensación de ingresos insuficientes para la población en riesgo de pobreza como resultado de los cambios económicos implementados. La reforma de la política social Checa se basó en tres componentes básicos: el empleo activo; la liberalización y pluralización del bienestar social basado en el Sistema de seguridad propuesto por Bismarck, que estuvo profundamente arraigado en la historia del país desde el final del siglo y por último el desarrollo de una red de seguridad social para las personas en necesidad (SIROVÁTKA; RÁKOCZYOVÁ, 2007).

El estado de apoyo social se introdujo en 1995 y con la ayuda de los fondos ${ }^{69}$ de la UE en conjunto con un fondo nacional, se aseguraron las plazas dentro de las escuelas primarias y

\footnotetext{
${ }^{68}$ Oficina Estadística Checa - Encuesta de las condiciones sociales de los hogares, datos de $2001(\mathrm{n}=27000)$

${ }^{69} \mathrm{La}$ contribución en términos económicos por parte de los Fondos Estructurales Europeos y el Fondo Social Europeo (FSE) en la primera fase de la adhesión fue de unos 400 millones de euros se asignarán a la República Checa a través de los proyectos del Fondo Social Estructural.
} 
guarderías para cubrir la necesidad de la población. Dentro del campo de inclusión social y reducción de la pobreza se implementaron programas para que el trabajo de campo en localidades excluidas fuese fortalecido, se implementó una ley referente a viviendas sociales para personas de bajos recursos (UE, 2009), siendo medidas altamente redistributivas en favor de los grupos en situación de exclusión.

Estas políticas redistributivas estaban dirigidas a grupos de bajos ingresos por medio del sistema de apoyo social del Estado, dirigido principalmente a las familias con niños, representando una estructura de beneficios interconectados por medio del efecto combinado del subsidio familiar, el beneficio social complementario y el subsidio de vivienda, cuyo papel en la compensación de ingresos es fundamental sobre todo para las familias con niveles cercanos al mínimo de subsistencia (ORENSTEIN, 1995).

Las propuestas para la inclusión social vista como una estrategia dentro de la política social se introdujo por medio de la CE, como uno de los programas que eran obligatorios para los nuevos Estados miembros (POTUCEK, 2004). En 2003, la República Checa aprobó el "Memorando Conjunto sobre la inclusión social" y elaboró el "Plan Nacional de Acción para la Inclusión Social" para el período 2004-2006, implementando una estrategia compleja, movilizando actores y recursos para combatir los procesos de exclusión social, de esta forma los recursos disponibles a través de los fondos estructurales europeos se canalizan a un espectro más amplio de actores en situación de exclusión, las comunidades políticas pasan a tener una participación importante en el proceso de formulación de políticas de abajo hacia arriba (SIROVÁTKA; RÁKOCZYOVÁ, 2007).

De acuerdo con Orenstein (1995) el éxito de la política social dentro de la República Checa se debe a la implementación de una mayor centralización y eficiencia de su estado. Este proceso de transformación que trajo consigo la implementación de estas políticas impactando la sociedad checa se ve reflejada en nuestros indicadores de cohesión social y calidad de la democracia, como se observa a continuación:

Tabla 8: República Checa: Relación Cohesión Social/ Calidad de la Democracia

\begin{tabular}{|l|c|c|c|c|c|c|}
\hline Años & $\mathbf{2 0 0 3}$ & $\mathbf{2 0 0 6}$ & $\mathbf{2 0 0 8}$ & $\mathbf{2 0 1 0}$ & $\mathbf{2 0 1 2}$ & $\mathbf{2 0 1 4}$ \\
\hline Nivel de Dificultad & 1,0 & 1,2 & 1,2 & 1,2 & 1,2 & 1,2 \\
\hline Calidad de la Democracia & 10,00 & 9,45 & 9,55 & 9,80 & 9,65 & 9,60 \\
\hline
\end{tabular}

Fuente: Transformation Index, 2015 
Se observa que durante el 2003 la República Checa presento los mejores niveles tanto en términos de cohesión social como en su nivel de calidad democrática, esto se debe a las sólidas políticas implementadas durante su proceso pre-adhesión, las cuales fueron materializadas en la fecha de su ingreso. Este país presenta los mejores indicadores en términos de cohesión, manteniéndose constante en el periodo evaluado, su calidad democrática se mantiene fluctuando de forma positiva, producto de este contexto de desarrollo en términos sociales, económicos y políticos.

\subsubsection{Estonia}

Desde su salida de la Unión Soviética, Estonia ha pasado por cambios radicales en términos de su estructura política y económica, afectando profundamente el área social tanto de forma subjetiva como objetiva en lo que se refiere al bienestar de la población, contexto que se ve reflejado en los elevados niveles de pobreza a la hora de comparar este país con otros miembros de la UE (BÖHNKE, 2004).

Después de retomar su independencia en 1991 se dio un amplio proceso de privatización, Estonia alcanzo una transición rápida a la economía de mercado, en un proceso en el cual sus políticas eran implementadas por medio de consultas entre el gobierno, sindicatos y asociaciones empresariales, estas políticas se caracterizaron por un comprometimiento fuerte en lo que se refiere a la "prudencia fiscal, acceso a mercados flexibles y en políticas enfocadas más en los incentivos que en la redistribución de los ingresos, por medio de transferencias en especie a la población" (OECD, 2009b). Durante la década de los años 2000, el riesgo de pobreza relativa se mantuvo constante o se vio disminuido solo en algunos segmentos poblacionales específicos (ídem).

El sistema de protección social, herencia del régimen socialista, fue financiado principalmente por contribuciones de los empleadores a los presupuestos del Estado, este sistema se basaba en el pleno empleo, y servicios sociales específicos, no siendo lo suficientemente amplio para alcanzar a toda la población en situación de exclusión (KALLASTE et al., 2003). Hubo un énfasis limitado en las transferencias por medio de programas de redistribución y tuvieron mayor relevancia los servicios de la salud y la educación. Algunas políticas implementados durante el procesos de pre-adhesión formaban parte del sistema anterior, por ejemplo, la prevalencia de las contribuciones de los empleadores en la financiación de la política social son característicos para el sistema de protección social de la Estonia miembro de la Unión Soviética (ídem). 
Otras políticas se enfocaron en el sistema de protección social, que consiste en la seguridad social y el bienestar social. La seguridad social en Estonia se encuentra constituida por elementos como el seguro de salud, el seguro de desempleo, el seguro de pensiones, las prestaciones de desempleo del Estado, beneficios familiares del Estado ${ }^{70}$, las prestaciones sociales para las personas con discapacidad, y otros beneficios financiados por el estado (TRUMM, 2006).

Las directrices de las políticas provenientes de la UE formaban un conjunto de principios que diseñaron el sistema de políticas sociales de la Estonia contemporánea. Las cuestiones de desarrollo social han recibido más atención durante el proceso de adhesión a la UE que en ningún otro momento histórico, por otra parte la Estrategia de Empleo de la Unión y el Memorando conjunto de integración formaron un marco fuerte para el desarrollo de la política social de Estonia en la actualidad (MATEI; VAŠIČEK; KAŠTELAN-MRAK, 2011).

En el año 2003, se firmó en Bruselas el "Memorándum Conjunto de integración" de Estonia, describiendo los principales desafíos en materia de la lucha contra la pobreza y la exclusión social, este documento presento a su vez las principales medidas para empezar a traducir los objetivos comunes de la UE en las políticas nacionales, identificando las cuestiones políticas clave para el seguimiento y la política futura, en este sentido se definieron como los principales desafíos:

"1) desarrollo de un mercado de trabajo inclusivo, 2) abordaje de las desventajas educativas, 3) garantizar ingresos suficientes a través del empleo o de la seguridad social, 4) mejorar el acceso a servicios de salud y la situación de salud de los grupos desfavorecidos, 5) la mejora de las condiciones de vivienda y la prevención de la falta de vivienda, y 6) la promoción de un enfoque integrado para combatir la pobreza y la exclusión social (Memorando Inclusión Común, 2003 apud Trumm, 2006, p. 14, traducción libre del autor $)^{72}$.

\footnotetext{
${ }^{70}$ El sistema de prestaciones familiares en Estonia incluye once tipos diferentes de beneficios: 1) asignación por hijos, 2) Cargo por cuidado de niños, 3) asignación única de los padres, 4) la asignación por hijo de recluta, 5) Subsidio de cuidado de crianza, 6) asignación por nacimiento, 7) subvención adaptación, 8) subvención escolar, 9) se inicia en ejercicio subsidio-vida independiente, 10) la prestación complementaria por tres o más hijos o con subsidio de custodia, 6) asignación por nacimiento, 7) subvención adaptación, 8) subvención escolar, 9) la puesta en in- subsidio-vida independiente, 10) la prestación complementaria por tres o más hijos o con los triples, y 11) el subsidio parental (introducido en 2004)(TRUMM, 2006)

71 "Joint Integration Memorandum"

${ }^{72}$ Texto original: "1) developing an inclusive labour market, 2) tackling educational disadvantage, 3) guaranteeing adequate income through employment or social security, 4) improving access to health care and health situation of disadvantaged groups, 5) improving housing conditions and preventing homelessness, and 6) promoting an integrated approach to tackle poverty and social exclusion"
} 
El memorándum proponía que la ayuda integral estuviese basada en los planes de acción individuales (el plan de rehabilitación y plan de acción individual para el trabajo) interpretados como enfoques más eficaces para promover la integración social de los grupos más vulnerables, buscando la creación de un contexto de mayor inclusión en los sectores más pobres. (KALLASTE et al., 2003). El país durante el proceso de adhesión presentaba cifras preocupantes, basado en datos de la Encuesta del Eurobarómetro de la Comisión Europea (2002), el nivel de exclusión social percibido en Estonia era del 18\% de la población, lo que significaba 1,5 veces superior a la media de la UE.

El Plan de Desarrollo Nacional de Estonia para 2004-2006, priorizó el desarrollo económico y social, destinando los fondos asignados para cuatro áreas prioritarias "el desarrollo de los recursos humanos; la competitividad de las empresas; la agricultura, la pesca y el desarrollo rural; infraestructura y desarrollo local" (Ministerio de Finanzas de Estonia 2004, p. 13). El énfasis principal de la inversión en infraestructura era en el desarrollo de los centros regionales de formación profesional, la modernización de la red de hospitales y ampliar el desarrollo y uso de las TIC's.

De acuerdo con Trumm (2006) se dio un gran progreso por medio de la elaboración e implementación de políticas sostenibles en términos económicos y sociales para la promoción de la inclusión social y el desarrollo, la situación de los excluidos y pobres continuó siendo un problema en Estonia pero ha mejorado de forma considerable con el transcurso de los años, demostrando una mejora en su capital humano y social.

El problema principal en términos de cohesión, es que prevalecieron a lo largo del tiempo las políticas de libre mercado sobre políticas sociales efectivas, como establece el ex primer ministro de Estonia Kallas (1996) "La política económica da los parámetros, y los otros ámbitos de la política deben adaptarse a estos" (TRUMM, 2006), esta visión afecto profundamente el desarrollo efectivo de las políticas sociales, ya que se priorizaron medidas macroeconómicas de alto impacto dentro de la sociedad.

Evaluando de forma cuantitativa vemos que nuestro indicador refleja la realidad presentada anteriormente:

Tabla 9: Estonia: Relación Cohesión Social/ Calidad de la Democracia

\begin{tabular}{|l|c|c|c|c|c|c|}
\hline Años & 2003 & 2006 & 2008 & 2010 & 2012 & 2014 \\
\hline Nivel de Dificultad & 3,0 & 2,0 & 2,4 & 1,8 & 2,0 & 1,8 \\
\hline Calidad de la Democracia & 9,60 & 9,40 & 9,55 & 9,60 & 9,55 & 9,70 \\
\hline
\end{tabular}


Se observa que nuestros indicadores son consecuentes con la hipótesis, ya que la mejora en el indicador Nivel de Dificultad ha generado un impacto positivo en la Calidad de la Democracia, que alcanzo su puntaje más elevado en la última fecha evaluado, demostrando la necesidad de políticas multidimensionales que busquen inclusión social.

\subsubsection{Hungría}

Durante su proceso de transformación, se dieron una serie de reformas económicas, políticas y sociales que impactaron a la sociedad Húngara, de acuerdo con (GONZALEZ, 2001) entre estas medidas se encontraban "la privatización de la actividad económica, la liberalización de los precios, de los salarios y de las ayudas sociales" por una parte recuperando la economía pero por otra trayendo efectos sociales negativos, esto debido a que se dieron tres procesos graves, la disminución de los ingresos, el deterioro de las clases medias y el establecimiento de estructura sociales polarizadas (De Cueto apud (CARRETERO; GARCES; RÓDENAS, 2002)

En 1999 se fueron eliminando estas medidas y se dio inicio a otra fase que involucraba a la UE, la cual implemento una estrategia para mejorar el diálogo social en los países ingresantes, como lo fue el caso de Hungría, estrategia basada en cuatro pilares: 1) comunicación con sus pares regionales (Europa del Este) a nivel sectorial, 2) presión en los gobiernos de los países ingresantes para involucrar a los interlocutores sociales a participar en el foro Europeo de dialogo social, 3) Invitar a los interlocutores sociales de la región de Europa del Este a participar del Foro Europeo de dialogo civil y 4) Diseño de programas de ayuda financiera para el desarrollo de este dialogo entre los diversos actores de la región (FERGE; JUHÁSZ, 2004).

Durante la década de los noventa, Hungría en comparación con otros países de la UE invirtió una porción pequeña de su presupuesto nacional a los sistemas de protección social (DEACON, 1992) aun cuando la reducción de las desigualdades fue una de las cuestiones más difíciles de ser abordadas en la transformación del sistema. Este proceso de transición del socialismo de Estado a economías de mercado reflejan percepciones modificadas sobre la necesidad y la redistribución, estas reformas fueron el resultado de un compromiso basado en "el legado institucional del antiguo régimen, el asesoramiento de los organismos internacionales, la necesidad de legitimidad y el apoyo de la clase media" (DEACON, 1992). 
En la Cumbre de Lisboa (2000) se formularon los objetivos para alcanzar un crecimiento económico sostenido, pleno empleo, cohesión social y desarrollo sostenible, Hungría encontraba dificultades para alcanzar estos objetivos, debido a dos áreas complejas, el mercado laboral y la forma en que eran redistribuidos los ingresos (FERGE; JUHÁSZ, 2004). Las características del mercado laboral no eran favorables, presentando un bajo nivel de empleo, en comparación con otros estados miembros de la Unión Europea, este se caracteriza en general por una baja tasa de empleo, así como la alta inactividad (FAZEKAS; KOLLO, 2005). La redistribución se vincula a la idea de disminución de la pobreza y la desigualdad, en Hungría la tasa era de 9,9\% para el año 2003 (HBS, 2003 apud FERGE; JUHÁSZ, 2004).

En el año 2000 se elaboró la Agenda de política social que confrontaba a las políticas de competitividad económica, debido a la necesidad de ampliación de la oferta laboral así como una mayor cohesión social, siendo evaluados por medio de un seguimiento anual a través de indicadores elaborados por la CE, para evaluar la aplicación del acervo social y laboral de los países candidatos, dando apoyo al diálogo social, para contribuir al desarrollo de las ONG y para asegurar la participación en los programas de acción comunitarios en el área social (SOCIAL POLICY AGENDA, 2000).

Los informes periódicos sobre los progresos de los aspectos mencionados anteriormente por parte de Hungría hacia la adhesión, eran el Evaluación Conjunta de la política del empleo ${ }^{73}$ (2001), y el MCI ${ }^{74}$ (2003) abordando diferentes aspectos de estas cuestiones.

Tomando como base estas premisas, la UE hizo disponibles recursos para mejorar el diálogo social en este proceso, (AVDAVIG, 2001) indica que Hungría fue el beneficiario de dos programas PHARE, que buscaban alentar el desarrollo del diálogo social, el Programa de Empleo y el de Desarrollo Social, posteriormente en el año 2002 se puso en marcha otra iniciativa para apoyar la mejora del diálogo social sectorial con 2,5 millones de euros. Es importante resaltar que en el año 2001, el gasto total en protección social de Hungría, ascendió a 19.8\% del PIB, para el año 2003 la proporción se incrementó en 1,5 puntos porcentuales y así ascendió a 21,4\%, cifras que se vieron impulsadas por estas ayudas por parte de la Unión Europea (FERGE; JUHÁSZ, 2004)

Otro aspecto importante era el riesgo de pobreza entre los niños, que pasó a ser prioridad en el año 2000, este aspecto está vinculado al sistema de prestaciones familiares de gran

\footnotetext{
${ }^{73}$ Joint Assessment of Employment Policies

${ }^{74}$ Joint Integration Memorandum
} 
complejidad, a mediados de 2005, este sistema fragmentado estaba compuesto de los siguientes tipos de beneficios "Subsidio de maternidad, Subsidio para el cuidado de niños, Apoyo para el desarrollo infantil y el subsidio familiar"(ídem).

El apoyo sustancial en el dialogo social se enfocó en el desarrollo de las organizaciones y asociaciones civiles, el programa PHARE ayudó a su creación con 5,5 millones de euros, contribuyendo a fortalecer el desarrollo de la asociación civil en Hungría, el contexto de garantía de derechos de asociación entre ellos, crearon un clima favorable para la proliferación de organizaciones civiles. Los posteriores gobiernos húngaros percibieron el potencial de los actores civiles, el Estado pasó a ser el mayor donante de las organizaciones civiles (ídem).

Los cambios en términos de políticas sociales en Hungría buscaron traer una garantía para el estado de derecho, las instituciones democráticas y los derechos humanos. Desde el ingreso en la Unión Europea se colocó al tema de la pobreza y la exclusión social en la agenda política, aun así las políticas sociales no han abordado de forma multidimensional los problemas, priorizando desde su salida de la Unión Soviética la dimensión económica, lo que ha impactado la evolución de nuestros indicadores:

Tabla 10: Hungría: Relación Cohesión Social/ Calidad de la Democracia

\begin{tabular}{|l|c|c|c|c|c|c|}
\hline Años & 2003 & 2006 & 2008 & 2010 & 2012 & 2014 \\
\hline Nivel de Dificultad & 1,0 & 1,4 & 1,4 & 1,4 & 1,6 & 1,6 \\
\hline Calidad de la Democracia & 10 & 9,40 & 9,35 & 9,25 & 8,35 & 7,95 \\
\hline
\end{tabular}

Fuente: Transformation Index, 2015

Se observa que el indicador Nivel de Dificultad en el año 2003 alcanzó su mejor puntuación posteriormente se observa un incremento progresivo hasta el año 2014, lo cual afecta la calidad democrática en el período evaluado de un máximo de 10 en el año 2003 a 7,95 en el 2014. Hungría alcanzo sus mejores puntuaciones durante su período de adhesión ya que se hizo un esfuerzo en las reformas económicas, políticas y sociales, que no se mantuvo debido a la prioridad de los gobiernos húngaros al desarrollo del acceso a mercados y no a la disminución de desigualdades.

\subsubsection{Letonia}

La transición pos-comunista coincide con los procesos de globalización y a su vez con una crisis del estado de bienestar Europeo, creando un contexto complejo a nivel nacional e 
internacional para Letonia que tuvo que reinventarse en este escenario. Es importante resaltar que estos cambios se realizaron en un contexto de "transferencias de políticas" dentro de la formulación de las mismas, ya que las políticas sociales tuvieron que ser reconstruidas tomando como base un contexto en el cual habían amplias dinámicas de desigualdad, esto hizo que se buscase un modelo externo que se adaptase a sus necesidades tales como los "EEUU, Canadá, Australia, Nueva Zelanda, Alemania, Reino Unido y Suecia” (RAJEVSKA, 2005) que trajo consigo un enfoque liberal a las reformas sociales.

De acuerdo con (BARR, 2005) las reformas implementadas, tenían dos objetivos principales, en primer lugar aumentar los estándares de vida al estilo occidental por medio de una economía de mercado y segundo aumentar la libertad individual, esto a través de dos acciones: la consolidación fiscal y las reformas estructurales. En 1995 el parlamento letones firma la Declaración apoyando el ingreso a la Unión Europea y se establece la reforma de la seguridad social, para el año 2001 varios de los problemas existentes de este sistema en términos de financiamiento fueron resueltos (RAJEVSKA, 2005).

En este período se implementaron una serie de herramientas, como parte de la participación de Letonia en el proceso de inclusión social de la UE, el "Plan de Acción Nacional para la Reducción de la Pobreza y la Exclusión Social"75 que fue lanzado en 2004 en conjunto con la "Estrategia Nacional Económica" (2004-06), el "Memorándum conjunto para la Inclusión Social" (2003) y el "Plan Nacional de Empleo" (2004), con elementos que dialogaban entre si y otros que priorizaban exclusivamente el desarrollo del mercado, en este sentido vemos que:

\footnotetext{
"Estas tendencias contradictorias en el desarrollo socio-económico del sistema se reflejan en el desarrollo del proceso legislativo. Este proceso tenía por objeto proporcionar una red de seguridad para el futuro y también afectó el marco del concepto de la política social" (CUNSKA; MURAVSKA, 2009)
}

En lo que se refiere al marco legislativo en la dimensión social vemos que en el 2003 entran en vigor dos leyes importantes, la Ley en Servicios Sociales y la Ley Estatal de beneficios y Asistencia Social y el beneficio del ingreso Mínimo Garantizado ${ }^{76}$, que era una precondición necesaria para ingresar a la UE (RAJEVSKA, 2005), aun así este beneficio no alcanzo a toda la población en situación de exclusión, debido a las grandes desigualdades de ingreso en diferentes regiones.

\footnotetext{
${ }^{75}$ Aplica al conjunto de indicadores del Consejo Europeo de Laeken de ingresos para supervisar el progreso en la reducción de la pobreza y la exclusión social.

${ }^{76}$ Guaranteed Minimum Income (GMI)
} 
Tomando en consideración estas estructuras, vemos que el gasto en protección social representó el 12,2\% del PIB en 2006, la proporción de los gastos de protección social ha ido disminuyendo en los últimos años (CUNSKA; MURAVSKA, 2009). Por otra parte el crecimiento económico positivo durante el período evaluado tuvo un impacto positivo en el mercado laboral en Letonia, principalmente durante el 2003-2007, ya que se vio un incremento en $6,5 \%$ en el empleo y se disminuyó el desempleo en 4,5\% (ídem). Otro aspecto relevante es que Letonia posee el financiamiento más bajo del sistema de salud dentro de los países de la Unión Europea, de acuerdo con Rajevska (2005) representaba el 4\% del PIB total del país. El sistema de protección social no se ha beneficiado de crecimiento económico. ${ }^{77}$

El salario mínimo definido por el estado fue aumentado de forma regular entre el 20022004, principalmente en el periodo posterior a estos años, debido a la fuerte inflación que afecto el país en el 2004 (aproximadamente de un 7,5\%) (Ídem), aun así Letonia continuo con los mayores indicadores de pobreza dentro de la UE con el salario mínimo más bajo. Por otra parte existe una débil estructura de empleo (CUNSKA; MURAVSKA, 2009), aspecto que se vio afectado con el ingreso de Letonia en la UE, trayendo un desafío a la hora de competir con las sociedades de otros países miembros, debido al incremento en la movilidad de la mano de obra calificada.

De acuerdo con el Reporte del BTI (2014) sobre Letonia, un aspecto importante a ser considerado es el problema estructural referente a la existencia de "dos sociedades paralelas", presentándose una segregación de los letones y las comunidades rusas dificultando la integración social y afectando de esta forma la cohesión. Este contexto afecta la democracia y los procesos de inclusión, por lo tanto una condición sine qua non para una democracia sostenible en Letonia sigue siendo la plena integración de la minoría ruso hablante.

La integración total de la sociedad debe ser una prioridad estratégica a medio plazo para el gobierno letón, en este sentido se han implementado varias medidas, incluida la aplicación de los principios de política étnicos que consideran los intereses de la sociedad letona, así como de otras nacionalidades, entre ellas se encuentra "la mejora de las normas de la política étnica; y la mejora del prestigio de la ciudadanía letona, creando así una actitud más positiva hacia la adquisición de la ciudadanía” (BTI, 2014). ${ }^{77}$ Ver el "Latvian National Action Plan for Reduction of poverty and Social Exclusion (2004-2006)
http://www.lm.gov.lv 
Es importante resaltar que Letonia se mantuvo en el camino democrático, en medio de la transformación de su orden político y teniendo a la integración en la Unión Europea como un proceso simultaneo, aun así se presentan algunas deficiencias en los “ámbitos de la estatalidad (la ciudadanía para la minoría rusa) y el cumplimiento del Estado de Derecho (corrupción política)" (BTI, 2014). Estas características se observan en nuestros indicadores:

Tabla 11: Letonia: Relación Cohesión Social/ Calidad de la Democracia

\begin{tabular}{|l|c|c|c|c|c|c|}
\hline Años & 2003 & 2006 & 2008 & 2010 & 2012 & 2014 \\
\hline Nivel de Dificultad & 3,0 & 2,6 & 2,2 & 2,2 & 2,2 & 2,4 \\
\hline Calidad de la Democracia & 8,80 & 8,70 & 8,70 & 8,85 & 8,80 & 8,75 \\
\hline
\end{tabular}

Fuente: Transformation Index, 2015

Nuevamente se refleja el impacto positivo del acceso en la UE que tuvo lugar en el 2004 en ambos indicadores, con una caída de 3 a 2.6 en el nivel de dificultad y con una Calidad Democrática que se mantiene de forma amplia como constante, presentando una ligera disminución en el 2014 con el incremento del nivel de dificultad.

\subsubsection{Lituania}

Lituania al igual que los otros países de Europa, tuvo que enfrentar grandes desafíos e implementar transformaciones profundas con su salida de la Unión Soviética, creando de esta forma nuevas políticas sociales que buscaban establecer un paralelo con aquellas implementadas por sus pares regionales, motivo por el cual desde el inicio de las reformas en 1990-1991, las tendencias liberales prevalecieron, hasta cierto punto con el fin de rechazar el legado soviético y establecer un sistema económico de libre mercado y un sistema político democrático, de acuerdo con (GUOGIS; BERNOTAS, 2008)

"En Lituania la élite política, de medios de comunicación y académica entendieron el papel del Estado como un "protector pasivo", es decir, prevaleciendo de esta forma la actitud hacia un estado débil y el libre mercado. Tal actitud no proporcionó un ambiente favorable para el desarrollo de un estado de bienestar socialdemócrata, para el cual sería necesario un reconocimiento de un Estado fuerte y un alto grado de intervención estatal." (traducción libre del autor) ${ }^{78}$

\footnotetext{
78 Texto original: "in Lithuania most political, media and academic elite understood the role of the state just as a "passive keeper", i.e. an attitude toward a weak state and free market prevailed. Such an attitude did not provide for a favourable environment for the development of a social democratic welfare state, which would need an acknowledgement of a strong state role and a high degree of state intervention".(GUOGIS; BERNOTAS, 2008, p. 15)
} 
Tomando estos aspectos en consideración, el nuevo sistema de protección social en Lituania se proyectó con base en el principio de beneficios relacionados con el mercado de trabajo, siguiendo la ideología liberal, el marco jurídico de la legislación pertinente estaba orientado con base en las normas generales de la UE en diversos ámbitos (empleo, protección social, entre otros), aun así, debido a los limitados recursos financieros y el bajo nivel de cooperación entre los actores sociales, se obtuvo poca eficiencia de las medidas en lo que se refiere a la protección social de los ciudadanos (GRUZEVSKIS; BLAZIENE, 2013).

De acuerdo con (NAKROSIS, 2008) los preparativos de Lituania para implementar la política social y económica de la UE, comenzaron a finales de 1996, el proceso de preparación se puede dividir en tres etapas principales: 96-98, 99-00 y 01-03. La integración dentro de la Unión Europea tuvo inicio en el 2004, encuadrada dentro de los objetivos de la estrategia de Lisboa, durante el periodo del 2004 hasta el 2006 Lituania recibió alrededor de 1380 mill de euros a partir de los fondos estructurales y de cohesión (ídem).

Los ingresos recibidos en este período fueron casi el doble del tamaño del Programa de Inversiones del Estado de Lituania , obteniendo de acuerdo con la Unión Europea (2009) 54,6\% de inversión por parte de los fondos estructurales, principalmente orientados hacia el programa de "Recursos Humanos" cuyo objetivo era la creación de empleos eficientes, asegurando igualdad de oportunidades, el apoyo de los fondos estructurales es considerado uno de los principales beneficios de la membresía de Lituania en la UE.

En el curso de las reformas, diversas organizaciones internacionales como el FMI, BM y la $\mathrm{OMC}$ ejercieron presión para la construcción de un Estado de bienestar liberal en el que el mercado fuese la prioridad, sin embargo, el apoyo político interno para el desarrollo de un estado de bienestar en el país no era suficiente y la oposición era fuerte (NAKROSIS, 2008). Los lituanos aun demandaban que el Estado que asumiera la responsabilidad por el desempleo, la inflación y la pobreza, a pesar de esto la mayoría de los partidos políticos lituanos aceptaron la ideología del fundamentalismo de mercado (GUOGIS; BERNOTAS, 2008).

El papel del Estado se redujo y la sociedad civil presentaba características de fragilidad, sin fuertes poderes sociales o movimientos sociales interesados en la regulación estatal, generando un escenario de mayor complejidad. Por medio del proceso de reformas el papel de las ONG comenzó a tomar relevancia en el aumento de la inclusión social, participando tanto del diseño como de la implementación de políticas para reducir la pobreza y la exclusión social en Lituania: 
"Las actividades de las ONG en Lituania difieren mucho en cuanto a su eficacia y el alcance, pero la mayoría de ellas contribuyen (alrededor del 63\%) a la reducción de la pobreza en el país, implementando proyectos relacionados principalmente a las actividades de educación, formación profesional y ayuda a las personas con discapacidad y jóvenes en conseguir integrarse en el mercado laboral" (ídem, p. 16).

Desde hace varios años, el coeficiente de Gini de Lituania ha superado considerablemente al resto de la UE en términos negativos (BANCO MUNDIAL, 2009). La amplia desigualdad económica combinada con un bajo nivel de vida, han generado un elevado número de personas que viven en la pobreza y la exclusión social. Según datos de Eurostat (2011) la tasa de pobreza y exclusión social en Lituania estaba por encima de 33\%, también una de las cifras más altas de la Unión Europea (GRUZEVSKIS; BLAZIENE, 2013)

El Estado destinaba muy pocos recursos para cubrir los gastos sociales en el periodo posterior a la salida de la Unión Soviética, los derechos sociales garantizados no eran suficientes y no llegaban a la totalidad de población en situación de exclusión. De acuerdo con GRUZEVSKIS; BLAZIENE (2013) en el 2000 Lituania desarrolló su primera estrategia para lidiar con el contexto de desigualdad, aprobando la "Estrategia de Reducción de la Pobreza para el período 2002-2004", haciendo hincapié en "la prevención de la exclusión social, mejora de las actividades de las instituciones pertinentes, promoción de la participación de los individuos en el mercado laboral, la eliminación de la pobreza infantil, y el aumento del apoyo a las familias" (ídem).

La evaluación posterior encontró que la asistencia de la UE por medio del Fondo Social Europeo durante el 2003 contribuyó al crecimiento económico y la modernización de la economía de Lituania (NAKROSIS, 2008), por lo que se observa un impacto efectivo de estas inversiones en el desarrollo del país, en función de su uso eficiente, principalmente en la creación de igualdad de oportunidades y a la implementación del desarrollo sostenible.

De acuerdo con GRUZEVSKIS; BLAZIENE, 2013) se observa que los principales obstáculos para la implementación de la política de cohesión en Lituania son de carácter nacional en términos de burocracia, por otra parte el gran volumen de ayuda de la UE básicamente agrava muchos problemas existentes a nivel nacional, esto debido a una administración pequeña y en segundo lugar porque algunos beneficiarios de los proyectos no eran capaces de hacer frente a los requisitos burocráticos de la ayuda de la UE. 
Viendo en perspectiva la implementación de la política de cohesión estructurada por parte de la UE en el país, esta ha ayudado a mejorar la calidad de la gobernabilidad en Lituania, siendo especialmente evidente en la gestión de programas y proyectos del sector público vinculados a la dimensión social, logrando desarrollar suficientes proyectos para absorber toda la ayuda de la UE, generando una mayor estabilidad en el sistema administrativo y político después de la adhesión al mecanismo de integración (NAKROSIS, 2008).

Evaluando estas informaciones, se observa que los procesos de transformación con la salida de la Unión Soviética y entrada en un sistema liberal han sido positivos aun dentro de un proceso complejo en lo que se refiere al acceso a derechos sociales, esto se ve reflejado en los indicadores Nivel de Dificultad y Calidad de la Democracia:

Tabla 12: Lituania: Relación Cohesión Social/ Calidad de la Democracia

\begin{tabular}{|l|c|c|c|c|c|c|}
\hline Años & 2003 & 2006 & 2008 & 2010 & 2012 & 2014 \\
\hline Nivel de Dificultad & 1,0 & 2,0 & 1,6 & 1,6 & 1,6 & 1,8 \\
\hline Calidad de la Democracia & 10 & 9,25 & 9,35 & 9,35 & 9,35 & 9,25 \\
\hline
\end{tabular}

Fuente: Transformation Index, 2015

Durante el proceso de adhesión e ingreso en la Unión Europea se observa un avance amplio en las puntuaciones de ambos indicadores, en el año 2006 empeora en Nivel de Cohesión y se observa una caída en el indicador Calidad de la Democracia de 10 a 9,25, esto es un reflejo de las dificultades para implementar las medidas y los programas vinculadas a la cohesión, en los años comprendidos entre el 2008 al 2012 se mantiene estable es indicador Nivel de Dificultad, así como de la Calidad de la Democracia, en 2008 aumenta levemente el indicador Nivel de Dificultad afectando a la Calidad de la Democracia en 0,5 puntos. Ratificando de esta forma nuestra hipótesis que establece que la Cohesión de una sociedad tiene un impacto en la Calidad de la Democracia.

\subsubsection{Polonia}

A diferencia de otros países de Europa del Este, Polonia no tenía una visión estructurada de la política social de transición, de acuerdo con (KSIEZOPOLSKI, 1993) "la política social polaca ha reaccionado a la crisis fiscal del Estado más de lo que se ha ajustado a cualquier 
estrategia particular a corto o largo plazo" (traducción libre del autor) ${ }^{79}$. La mala planificación y administración gubernamental, por medio de políticas de emergencia y una estrategia que priorizó la rápida transformación económica, ignorando la dimensión social, afecto la evolución positiva del desarrollo social sin alcanzar resultados a largo plazo, un ejemplo claro, es la prioridad a las ayudas por desempleo y la reforma de pensiones, desplazando a las inversiones en salud y educación que son la base para el crecimiento futuro (ORENSTEIN, 1995).

De acuerdo con (STARĘGA-PIASEK; MATELA, 2006) el modelo social polaco es una mezcla donde los elementos de la tradición conservadora se mezclan con los elementos del modelo liberal, dominado por el seguro social, parcialmente privatizado, que ofrece beneficios relacionados con el empleo, complementada con lo universal, prestaciones supeditadas, por otro lado el sector de los servicios sociales está poco desarrollado.

Durante el proceso de adhesión Polonia adopto el discurso de políticas sociales de la UE, con controversias dentro de las elites conservadoras y socialistas en la forma de abordar este asunto, que resulto en el fortalecimiento parcial del discurso neoliberal, así como la implementación de las orientaciones políticas de la Unión Europea (BÉLAND; PETERSEN, 2015). Después de la caída del comunismo el término de política social era entendido como política "socialista" trayendo connotaciones negativas, ya que se vincula a "políticas pobres" o asistencia social, por medio del Fondo Social Europeo la idea de igualdad de oportunidades e igualdad de género ganaron terreno (ídem).

Las reformas políticas y económicas fueron los principales motores de la transformación del modelo social en Polonia, incluyendo cambios políticos para crear las bases de un sistema democrático, como los derechos individuales, las libertades civiles y políticas, los cambios en la administración del Estado, por medio de la descentralización de la administración pública y cambios en el sistema económico dirigido a una economía de mercado (STARĘGA-PIASEK; MATELA, 2006). En este sentido Polonia descentralizó la mayoría de funciones de bienestar social, colocándolas bajo la autoridad de los gobiernos autónomos locales, si bien esto puede haber sido bueno para la democracia polaca, tuvo resultados trágicos para la prestación de servicios sociales en algunas regiones (ídem).

De acuerdo con Orenstein (1995) una de las primeras medidas aplicadas durante el proceso de transformación fue la red de protección social, con el objetivo de proteger a las

\footnotetext{
${ }^{79}$ Texto original: Polish social policy has reacted to the fiscal crisis of the state more than it has conformed to any particular short or long-term strategy.
} 
personas por debajo de la línea de la pobreza. Después de su implementación surgieron problemas con su financiación y administración, no actuando como una herramienta eficaz en contra de la pobreza:

\begin{abstract}
"Atrapados entre los generosos beneficios oficiales, pagos reales poco generosos, y un sistema de administración ineficiente, la red de protección social polaca tuvo problemas graves durante todo el período de transformación, llevando a un descontento con la reforma, tanto entre los pobres y los ciudadanos entre que vivían próximos a las familias pobres y simpatizaban con una situación compleja causada generalmente por la falta de empleo" (Grootaert 1995 apud Orenstein, 1995, p. 192, traducción libre ${ }^{80}$ )
\end{abstract}

Este contexto de transformación sistémica resultó en una desmonopolización parcial del estado de bienestar"(STARĘGA-PIASEK; MATELA, 2006), ya que históricamente los sindicatos cumplían el rol de interlocutores sociales con el gobierno; teniendo una influencia directa en la política. Con el tiempo, junto con la privatización de la economía y la descentralización de la administración pública, su papel se hizo considerablemente más débil y se equilibra con las organizaciones de empleadores. El movimiento de las iniciativas civiles, tuvieron lugar en los primeros años del período de transformación, por medio de la implementación de las principales libertades civiles, como lo son el derecho de demostración y asociación (ídem).

Cuando el país se unió a la UE en el 2004, todas las regiones polacas estaban por debajo de la media de los países de la Unión en lo que se refiere al indicador del PIB per cápita, Polonia recibió €435 millones para la financiación estructural, en el 2007 la cifra fue de más de 3,1 mil millones. Se estima que con el apoyo de los fondos de la UE, la tasa de crecimiento del PIB en el año 2007 aumentó en 0,6-0,9\%, así como la tasa de empleo también aumentó de un promedio de $51 \%$ en 2003 a 57\% en 2007 (European Union, 2009).

Otra área importante de la política social europea es el diálogo social, el gobierno polaco expresó su apoyo a la idea del diálogo social y declaro su disposición a tener como participantes a los representantes polacos en todos los foros de discusión entre empresarios y trabajadores. Siguiendo las disposiciones del Acuerdo Europeo, Polonia desarrolló aún más las instituciones de diálogo social (ídem).

De acuerdo con STARĘGA-PIASEK; MATELA, (2006), se adoptaron medidas concretas en el tema de la exclusión social a través de la aproximación a las personas con bajos niveles de

\footnotetext{
80 Texto original: "Caught between generous official benefits, rather less generous actual payments, and an inefficient delivery system, the Polish social safety net had serious holes during the entire transformation period, undoubtedly leading to discontent with reform, both among the poor and among others who lived in proximity to poor families and sympathized with a plight that was often caused by unemployment"
} 
educación, los discapacitados, las mujeres y las minorías étnicas, buscando crear una estructura más eficiente. En este sentido el Sistema de Asistencia Social fue reformado en el 2004 cuando se introdujeron los "contratos sociales", es decir, los acuerdos entre los agentes sociales y los beneficiarios de la asistencia que estableciendo las obligaciones de ambas partes.

En el área laboral el gobierno polaco implemento un enfoque denominado como "bienestar laboral"(ídem), que buscaba hacer efectiva una estructura eficiente para traer a personas sin empleo de la asistencia social en trabajos dignos, por medio del cual se ofrecían programas de formación profesional y responsabilidad en la búsqueda activa de trabajo, otra medida efectiva fue que el sistema de jubilación anticipada se redujo con el fin de disminuir la cantidad de profesionales en desactivación, buscando mejoras de la estructura laboral.

Polonia al igual que el resto de los países de Europa del este, vio grandes transformaciones en su dimensión social afectando la forma en que participa la sociedad dentro del sistema político y afectando la democracia, en líneas generales el estado polonés busco la promoción de la cohesión y por medio de la promoción de una sociedad civil activa y participativa, lo que se observa en nuestros indicadores:

Tabla 13: Polonia: Relación Cohesión Social/ Calidad de la Democracia

\begin{tabular}{|l|c|c|c|c|c|c|}
\hline Años & 2003 & 2006 & 2008 & 2010 & 2012 & 2014 \\
\hline Nivel de Dificultad & 2,0 & 2,0 & 1,8 & 1,6 & 1,6 & 1,6 \\
\hline Calidad de la Democracia & 10 & 9,20 & 8,80 & 9,00 & 9,20 & 9,35 \\
\hline
\end{tabular}

Fuente: Transformation Index, 2015

En los años posteriores al ingreso se observa una mejora continua del indicador Nivel de Dificultad, que se ve reflejado en las mejoras continuas en la calidad democrática, la puntuación más elevada del indicador Calidad de la Democracia se observa en el año en que se firma el tratado de adhesión con la Unión Europea, debido a que el sistema político implemento una restructuración y la sociedad civil aprobó todo el proceso como un mecanismo positivo para avance económico, político y social, aun cuando el Nivel de Dificultad aparece elevado en el 2003 en comparación con las otras puntuaciones, este sin duda presenta una mejora considerable de los años previos para los que no se tiene registro, siendo implementada un reforma del sistema de seguridad social así como los beneficios para la población. 


\subsubsection{Rumania}

En los primeros años de la transición, el país sufrió de una fuerte contracción económica, como resultado de los cambios económicos y estructurales necesarios para lograr un crecimiento sostenible y choco con el sistema de planificación centralizado establecido durante el período anterior, generando un aumento de la pobreza durante la transición y en las décadas que le siguieron, el motivo principal fue la fuerte caída de la producción económica, por descenso en el consumo y una mala distribución de ingresos (BANCO MUNDIAL, 1997).

El gobierno adoptó una serie de programas de estabilización fuertes, una "política fiscal restrictiva y una estricta política monetaria así como la liberalización del régimen de tipo de cambio" (ídem). Estas políticas casi tuvieron resultados inmediatos afectando el área social, priorizando el desarrollo de una economía de mercado. Buscando aliviar este contexto convulsionado el gobierno adopto una transformación de la dimensión social que se dio a partir de tres fases:

"una fase reparadora (de medidas injusticia o falta de otras medidas sociales específicas), la fase de construcción de un marco legal e institucional de política social con los elementos esenciales pero implementados dentro de una emergencia y la fase de transición con una política social más reactivo con fuertes tendencias minimalistas" (STANESCU, 2014, p. 7, traducción libre del autor). ${ }^{81}$

En el transcurso de estas tres fases se implementaron diversas políticas, durante la fase de transición, de acuerdo con lo establecido por el Banco Mundial (1997), el objetivo principal de la dimensión social fue el gasto público en transferencias monetarias (subsidios por hijos y la asistencia social discrecional) y las transferencias en especie, buscando mejorar la equidad y reducir la pobreza. El gasto público total en los tres principales programas de transferencia de monetarias, las pensiones, los subsidios familiares ${ }^{82}$ y la asistencia social ${ }^{83}$, disminuyo de casi el 10\% del PIB en 1990 a un 8\% del PIB en los años posteriores (ídem), aun así los costos sociales de la transición fueron representados por:

"El aumento de la tasa de desempleo; la disminución de número de trabajos remunerados; nivel de ingresos medianos; explosión de la economía informal como

\footnotetext{
${ }^{81}$ Texto original: "reparatory stage (of injustice measures or lack of specific other social measures), the stage on building a legal and institutional social policy framework with crucial elements but done in an emergency and transition with a social policy rather reactive with strong minimalist tendencies"

${ }^{82}$ El Programa de Subsidio Infantil (junto con las prestaciones por desempleo) es el programa de beneficios más progresista en Rumania, pero una mirada más de cerca el programa de asignación por hijo revela que estas transferencias no llegan a todas las familias elegibles y algunos 'fugas' a los hogares no elegibles

${ }^{83}$ La ausencia de incentivos laborales en el programa de asistencia social es un problema potencial muy grave y podría crear un grupo permanente de pobres.
} 
alternativa; disminución del valor de los beneficios sociales; aumento de la polarización social y la segregación social" (STANESCU, 2014, p. 7, traducción libre del autor ${ }^{84}$ )

Durante la década de los noventa, dos elementos fueron prioritarios en el alcance de la equidad social, la educación y la salud, en este sentido el Gobierno gastó casi 3.4\% del PIB en educación (BANCO MUNDIAL, 1997), en el caso de la salud, Rumania tiene un sistema público que afirma tener cobertura universal, sin embargo, la calidad y la equidad del sistema de salud pública de Rumanía ha sido socavado por una financiación inadecuada, en la actualidad tiene la asignación más baja salud-presupuesto de cualquier estado miembro de la UE (BONKER; WAGNER; POP-ELECHES, 2015).

En términos de exclusión se observa que históricamente el Nordeste es la región más pobre de Rumania, Bucarest por el contrario emerge como el área más rica del país. Esto es un reflejo a su vez del vínculo entre la educación y la pobreza observada en la población nacional, distritos con una menor incidencia de la pobreza tienden a tener una menor proporción de jefes de hogar con sólo el primario la escolarización (ídem).

Rumanía se convirtió en un Estado miembro de la UE desde 2007 y ha necesitado tiempo para adaptarse a la aplicación de las inversiones de la política de cohesión de la UE (EUROPEAN COMISSION, 2014), aun así es importante resaltar que la financiación de las política de cohesión ha sido un motor importante para las reformas en Rumania, ya que existían disparidades sin precedentes en términos económicos y sociales entre Rumania y el resto de los países miembros, por lo cual era vital una política social común (PHINNEMORE, 2006).

Durante el período 2007-2009, Rumania se benefició de subvenciones, cuatro veces mayores que en el período de preadhesión, aproximadamente de 5973 millones de euros (CHINDRIŞ-VĂSIOIU; UNGUREANU; OTHERS, 2011), siendo la base para el desarrollo de la gestión de los instrumentos estructurales. La política de desarrollo regional de Rumania es una política nacional que tiene como objetivo reducir las diferencias de desarrollo entre las regiones y diferentes partes del país y evitar la aparición de nuevos desequilibrios, reduciendo así las disparidades de desarrollo entre Rumania y todos los demás países.

El Plan Nacional de Desarrollo, es la herramienta de recuperación de las disparidades socioeconómicas de Rumania con respecto a las prioridades de la UE, para que estas estuviesen orientadas a los objetivos definidos en los instrumentos estructurales. Los objetivos del Plan

\footnotetext{
${ }^{84}$ Texto original: "Social costs of transition were represented by: the increased rate of unemployment; decreasing number of paid jobs; decreased level of medium incomes, especially small incomes; explosion of the informal economy as an alternative; decreased value of social benefits; increased social polarization and social segregation"
} 
Nacional de Desarrollo se enfocaron en la competitividad, la economía basada en el conocimiento, el desarrollo y la modernización de la infraestructura, logrados a través de los instrumentos estructurales y correlacionados con los objetivos de Lisboa, (CHINDRIŞVĂSIOIU; UNGUREANU, 2011).

Los avances en términos de políticas sociales y la gran inversión realizada durante el proceso de pre-adhesión y una vez consolidado como país miembro de la Unión Europea, trajo consigo mejoras en los indicadores. El avance en términos de cohesión social es evidente, ya que Rumania es uno de los países que presentó mayores índices de pobreza y exclusión en términos históricos y continua siendo uno de los países dentro de la Unión con un desarrollo social bajo:

Tabla 14: Rumania: Relación Cohesión Social/ Calidad de la Democracia

\begin{tabular}{|l|c|c|c|c|c|c|}
\hline Años & $\mathbf{2 0 0 3}$ & $\mathbf{2 0 0 6}$ & $\mathbf{2 0 0 8}$ & $\mathbf{2 0 1 0}$ & $\mathbf{2 0 1 2}$ & $\mathbf{2 0 1 4}$ \\
\hline Nivel de Dificultad & 4,0 & 4,0 & 3,6 & 3,2 & 2,8 & 2,8 \\
\hline Calidad de la Democracia & 8,00 & 8,20 & 8,55 & 8,50 & 8,55 & 7,90 \\
\hline
\end{tabular}

Fuente: Transformation Index, 2015

Entre los años 2003-2006 Rumania presentaba un elevada puntuación en el indicador Nivel de Dificultad y una Calidad de la Democracia que se vio mejorada por las transformaciones políticas implementadas durante el proceso de pre-adhesión así como reformas a nivel nacional, entre el 2008 y el 2014 se observa una mejora constante del indicador nivel de dificultad que es acompañada por la calidad de la democracia, cabe hacer un llamado al hecho de que durante el año 2014 se observa una disminución de la calidad de la democracia aun con un Nivel de Dificultad positivo, esta puntuación refleja el contexto político complejo de luchas políticas entre la mayoría parlamentaria y el presidente Traian Basescu por medio de un referéndum revocatorio que afecto el status quo democrático durante este período (BTI, 2015).

\subsubsection{Eslovenia}

Las primeras elecciones libres celebradas se dieron a inicios de la década de los noventa y los dos primeros gobiernos que le siguieron lograron con éxito alcanzar la independencia del país y dieron forma a la reforma del sistema político, económico y social. Entre ellas se puede observar la tendencia a la centralización de las funciones del Estado muchos de los cuales solían ser delegada a las comunidades locales, estos cambios aumentaron el control del Estado sobre la 
prestación de servicios básicos de bienestar como la educación, la salud, el cuidado de niños y servicios similares (SVETLIK, 1993).

En la transición del socialismo a la sociedad post-socialista, el sistema de bienestar esloveno se constituyó como un modelo dual, con elementos del sistema de bienestar conservador-corporativo (un sistema de seguro social obligatorio, basado en la cooperación social) y el sistema de bienestar social-demócrata, donde el sector público/estatal sigue siendo el principal proveedor de servicios, en el que todos los ciudadanos tienen el mismo derecho (Kolaric et al. 2009 apud (FILIPOVIČ HRAST; IGNJATOVIĆ, 2013)

En términos económicos Eslovenia ha mantenido tradicionalmente estrechas relaciones económicas con economías occidentales y muchas de sus empresas tuvieron la capacidad de mantener los vínculos establecidos sin cambios radicales, "sus niveles de desarrollo económico se puede comparar con el de los países menos desarrollados de la UE, como Portugal, Grecia e Irlanda" (ídem)..

Durante los primeros años de la transición no se prestó demasiada atención por parte de los gobiernos y la sociedad civil al problema de las desigualdades, posteriormente las organizaciones internacionales y nacionales vinculadas a esta área se dedicaron entre otros objetivos, a la lucha contra la pobreza, la promoción de la integración social y la inclusión, siendo consideradas como un activo desde el inicio de la transición, convirtiendose finalmente en parte de la agenda de políticas públicas (EUROPEAN COMISSION, 2013).

En este sentido Eslovenia ha experimentado cambios políticos significativos con la transición a la democracia, reflejados en las actitudes políticas y la sociedad civil en general también. El número de organizaciones de la sociedad civil se ha duplicado entre 1990 y 2008 , aunque los datos sobre la participación en las organizaciones o asociaciones que no sean los partidos o grupos de acción política siguen indicando que Eslovenia se está quedando detrás de los países de Europa occidental (FILIPOVIČ HRAST; IGNJATOVIĆ, 2013)

En la segunda mitad de la década de 1990, el proceso de los preparativos de adhesión a la UE hizo que fuese implementado el "Método de Coordinación Abierto de la Unión Europea" referente a la pobreza y la exclusión social generando en consecuencia un enfoque más consistente de estas cuestiones (EUROPEAN COMISSION, 2013). Los diversos aspectos de la situación de cada país fueron objeto de un análisis profundo, se identificaron objetivos y prioridades en las distintas áreas de política relacionadas con la inclusión social, entre los 
problemas de mayor relevancia estaba el tema de la desigualdad y la exclusión de minorías (ídem).

Durante la transición, se introdujeron cambios en todos los ámbitos de la sociedad, en la esfera política, sistema económico y el sistema de bienestar, todo lo cual influyo en los niveles de desigualdad, entre las políticas más relevantes en este sentido implementadas por el gobierno esloveno se encuentran:

"políticas activas del mercado de trabajo, el establecimiento de un salario mínimo (introducido en 1995); El sistema de impuesto de renta de persona física. Hasta el año 2004, la renta activa se grava a tasas progresivas con cinco niveles de ingresos, más tarde reducido a tres, beneficios de asistencia social y los niños, prestaciones de desempleo; y el sistema de pensiones (con el sistema de seguro de invalidez)" (FILIPOVIČ HRAST; IGNJATOVIĆ, 2013)

Después de más de una década de procesos de transición y preparación para la adhesión, Eslovenia en el año 2004, se convirtió en un nuevo Estado miembro de la UE (EUROPEAN COMISSION, 2013). A diferencia de los otros países opto por la implementación de reformas estructurales de forma gradual, esto debido a que económicamente era el país más desarrollado de la región, este proceso ha sido considerado como una superposición con el proceso de transición, considerándose como una tarea difícil diferenciar los efectos de ambos procesos ya que algunos de los costos de la adaptación a la UE eran al mismo tiempo parte de la adaptación transitoria, es decir, las reformas estructurales que tendrían que llevarse a cabo de todos modos.

Otro elemento importante a ser considerado es que en el año 2000, se aprobó el "Programa de Lucha contra la Pobreza y la Exclusión Social", con la adopción del programa, la política de inclusión social se definió como una prioridad política del gobierno (EUROPEAN COMISSION, 2013). La desigualdad en Eslovenia se mantuvo relativamente estable y baja durante el período de la independencia en 1991 hasta el final del 2008, consecuencia de diversas políticas, entre ellas este programa.

En Eslovenia, de acuerdo con FILIPOVIČ HRAST; IGNJATOVIĆ (2013) los indicadores de privación material, la tasa de riesgo de pobreza y la exclusión social retratan una sociedad relativamente estable, reflejando un escenario positivo. De acuerdo con la investigación realizada en el reporte Impacto de las Desigualdades en el Desarrollo (ídem) la proporción de personas que sufren de privación material grave ha sido de alrededor del 5\% (5,1\% en 2005 y $5,9 \%$ en 2010), mientras que la proporción de personas que sufren de pobreza o exclusión social ha sido de alrededor del $18 \%$ (18,5\% en 2005 y 18,3\% en 2010), por otra parte los indicadores vinculados a cohesión social muestran que Eslovenia es una sociedad con inclusión y fuertes 
lazos familiares, los indicadores sobre la felicidad y la satisfacción con la vida muestran una tendencia relativamente estable desde 2000 hasta 2009.

El desarrollo de la sociedad eslovena y sus instituciones permitieron su convergencia a la hora de compararla con los países europeos más desarrollados, supo implementar reformas multidimensionales de forma gradual teniendo como prioridad el bienestar de la población y manteniendo a lo largo del tiempo ideales de igualdad, en términos de cohesión y democracia debe ser visto como un caso ejemplar, lo que se ve reflejado en los indicadores:

Tabla 15: Eslovenia: Relación Cohesión Social/ Calidad de la Democracia

\begin{tabular}{|l|c|c|c|c|c|c|}
\hline Años & $\mathbf{2 0 0 3}$ & $\mathbf{2 0 0 6}$ & $\mathbf{2 0 0 8}$ & $\mathbf{2 0 1 0}$ & $\mathbf{2 0 1 2}$ & $\mathbf{2 0 1 4}$ \\
\hline Nivel de Dificultad & 1,0 & 1,2 & 1,0 & 1,0 & 1,0 & 1,2 \\
\hline Calidad de la Democracia & 10 & 9,55 & 9,70 & 9,75 & 9,65 & 9,30 \\
\hline
\end{tabular}

Fuente: Transformation Index, 2015

Eslovenia es el país del este europeo que presenta las mejores puntuaciones de nuestros indicadores, esto debido a su nivel de desarrollo económico y social que acompaño al político, consolidando su democracia, el nivel de dificultad presenta un leve aumento en el año 2006 y en el 2014 lo que se refleja en la disminución de la calidad de la democracia en ambos períodos. Entre el 2008 y el 2012 el nivel de dificultad se mantiene constante y la calidad de la democracia mantiene un promedio de 9,70 durante estos años.

\subsubsection{Eslovaquia}

La política social en Eslovaquia ha andado un largo camino de transformación desde 1989, alcanzando efectos positivos significativos del proceso de reestructuración política y social. Para la sociedad civil de Eslovaquia, los años noventa pueden ser considerados como un período de aprendizaje, en términos de capacidad de acción y la obtención de financiación extranjera, dirigida principalmente a la construcción de la sociedad civil en Eslovaquia (Brezani, 2013 apud (BOTEK, 2014)

El año de 1996 el país se aleja del período de "solución de crisis" a un proceso de transformación real (BOTEK, 2014), esto debido a que se dejaron de implementar políticas de emergencia y se comenzaron a estructurar políticas a largo plazo dentro de la dimensión social, por lo cual se establecen una serie de concepciones complejas como la "Concepción de Estado 
de Política Familiar, Concepción de la política del empleo, la introducción de un seguro de pensiones complementario, etc.” (ídem).

La reforma eslovaca del Estado de bienestar inicialmente incorporó elementos del régimen socialdemócrata, el gobierno enfatizó el hecho de mantener una estructura centralizada de la asistencia, además de incluir las políticas universales gratuitas como la educación y cuidado de los niños (Cerami, 2008 apud GOULD; HARRIS, 2012). Este énfasis puede haber impedido inicialmente la plena liberalización de la política de bienestar dentro del país, que aun presentaba características del periodo anterior.

Entre 1998 y 2004 la situación política interna había mejorado significativamente debido al cambio de gobierno, desarrollándose el proceso de ingreso a la UE, en este sentido el desarrollo de la política social puede caracterizarse como un esfuerzo para adaptarse y utilizar las posibilidades ofrecidas por las regulaciones e instituciones de la CE, eso significaba cambiar de enfoque universalista al sistema social residual dominado por consideraciones de gasto público (KUSA; GERBERY, 2007).

La República Eslovaca, siendo un país candidato a la adhesión a la UE en el año 2000, participó del Consejo Europeo de Lisboa y recibió la orientación de implementar políticas económicas que promoverían la inclusión de los grupos desfavorecidos para alcanzar los niveles requeridos por la UE en términos de indicadores, en este sentido, Eslovaquia desarrollo un conjunto de políticas y directrices abordando la pobreza mediante la promoción del empleo, llamado el "Plan de acción Nacional para la Inclusión Social 2004-2006" (GOULD; HARRIS, 2012).

Eslovaquia se convirtió en miembro de la Unión Europea en el 2004 y en consecuencia receptor de apoyo a través de los Fondos Estructurales, desde entonces el principal objetivo de la estrategia de desarrollo era hacer frente a las principales fuentes de las disparidades regionales que fueron identificados en diferentes áreas entre ellas infraestructura, recursos humanos, la pobreza, exclusión de minorías, entre otros, la asignación total de la financiación de la política de cohesión para el período 2007-2013 era de 11,6 mil millones de euros (EUROPEAN COMISSION, 2009).

De acuerdo con Tomeš (2010) apud BOTEK (2014, p. 2) se definen diez principios fundamentales en el proceso de transformación de la dimensión social:

85 2004-2006 National Action Plan on Social Inclusion (NAPS) 


\begin{abstract}
"Desmonopolización, garantizando la pluralidad de los sujetos, la abolición de la función exclusiva del Estado. Descentralización de la esfera pública, buscando acercar la protección social. Democratización, independencia jurídica de las instituciones. Modificación del objeto, ver al receptor no como un miembro del grupo, sino como un individuo con necesidades particulares. Pluralización de las fuentes, dejar de tener el presupuesto del Estado como la única fuente de financiamiento de la política social. Pluralización de tipos y formas, remplazar a los sistemas no alternativos por sistemas plurales de protección social. Humanización. Reconfiguración de necesidades. Personificación, aproximación del proveedor de la asistencia y el receptor. Profesionalización, implementar profesionales en la protección social" (traducción libre de la autora) ${ }^{86}$.
\end{abstract}

Una característica que puede ser una herencia positiva del periodo comunista, es el establecimiento dentro de la constitución Eslovaca del principio de solidaridad y la persistencia de diversos esquemas que colocaban a el estado como el proveedor de necesidades básicas, los cuales no impidieron la innovación dentro de las reformas que estaban basadas en tres pilares, seguro social, el estado social de apoyo y la asistencia social (CERAMI, 2006).

De acuerdo con Cerami (2006), los eslovacos prefieren una mayor responsabilidad del Estado y medidas redistributivas organizadas centralmente, lo que en líneas generales se ha implementado a lo largo de la última década. Eslovaquia presenta características positivas en términos de implementación de políticas sociales y de la reestructuración de su sistema político lo que se refleja en los indicadores:

Tabla 16: Eslovaquia: Relación Cohesión Social/ Calidad de la Democracia

\begin{tabular}{|l|c|c|c|c|c|c|}
\hline Años & 2003 & 2006 & 2008 & 2010 & 2012 & 2014 \\
\hline Nivel de Dificultad & 2,0 & 1,4 & 1,8 & 1,8 & 1,8 & 1,8 \\
\hline Calidad de la Democracia & 10,00 & 9,20 & 9,20 & 9,35 & 9,00 & 9,05 \\
\hline
\end{tabular}

Fuente: Transformation Index, 2015

Durante su período de adhesión se presentan las mejores puntuaciones en términos de su calidad democrática, así como en su nivel de dificultad ${ }^{87}$, en el 2006 se observa una mejora en el

\footnotetext{
${ }^{86}$ Texto original: "Demonopolization - to ensure plurality of subjects. Decentralization of public sphere - to move social protection as close as possible to people. Democratization - legal independence of institutions, inclusion, Modification of object - see client not as a member of the group but as an individual with particular needs. Pluralisation of sources - leave the state budget as the only one source of financing of social policy. Pluralisation of types and forms. Reconfiguration to needs - make social protection adequate in terms of time, extent, intensity of problem, etc. Personification approximate provider of assistance and the client, Professionalization - implement professionals in social protection,".

${ }^{87}$ Debido a la falta de datos para los períodos anteriores resulta un desafío realizar una evaluación complete, pero los datos obtenidos por medio del Banco Mundial (2014) y la Unión Europea (2009) se observa que la situación previa a la adhesión era de mayor complejidad para la sociedad eslovaca.
} 
Nivel de Dificultad y comienza un periodo de relativa estabilización en su calidad democrática con una media de 9,2, también se presenta una estabilidad de la falta de cohesión social en 1,8.

\subsection{Conclusiones}

La revisión de la implementación de políticas sociales en los países que conforman Europa del Este tuvo como objetivo principal la definición de aquellas que han tenido un efecto positivo en lo que se refiere a la mejora del contexto de cohesión dentro de las sociedades y su relación con el comportamiento de la calidad de la democracia bajo este prisma de evaluación.

Debe ser resaltado que aun siendo un conglomerado de poblaciones con antecedentes históricos, religiones e idiomas diferentes, sufrieron procesos de reformas políticas, económicas y sociales en el mismo momento histórico por lo cual se considera relevante su evaluación en la búsqueda de una comprensión más amplia de las dinámicas de cohesión, en donde se observan similitudes de implementación de políticas.

De acuerdo con (DERLIEN; SZABLOWSKI, 1993) y (LEWIS, 2000) este conjunto de países no reaccionaron a la disolución del comunismo en la misma forma, lo que resulta en una variedad de transiciones políticas, económicas y sociales, cuya interrelación merece ser evaluada debido al progreso acelerado observado en poco más de una década en la mayoría de los países. Lewis (1997) ha resaltado que la modernización y la democratización se han convertido en dos términos cercanos vinculados profundamente a la forma en que se transforman y relacionan los miembros de una sociedad, dependiendo por un lado de los resultados económicos de los países y de la consolidación de las instituciones.

El enfoque implementado en los países de Europa del Este es ampliamente consistente con el debate científico en lo que se refiere a inversión social, ya que buscaba al mismo tiempo confrontar los problemas estructurales y aumentar la eficiencia y efectividad de las políticas sociales, tomando en consideración los cambios claves en términos demográficos y sociales.

Es imposible referirse a un análisis de políticas sociales en Europa del Este sin tomar en consideración la actuación de la UE en ellas. La intensidad de la inversión de la ayuda en términos per cápita es una de las mayores en el conjunto de la UE (Barca, 2009). Aun cuando los países que conforman Europa del Este representan aproximadamente un octavo del total de la población de Europa, más de un tercio de la totalidad de la asignación de los Fondos de la política de Cohesión Social va dirigida a estos países (POTLUKA, 2010).

La efectividad de las políticas en este ámbito se dio por medio de la definición de tres 
aspectos comunes dentro de los países de esta región, primero una vocación a resolver problemas concretos, implementación de un enfoque multidisciplinario, y la necesidad de establecer relaciones con lo mencionado anteriormente y el conocimiento para para mejorar la democracia y la dignidad humana, estos procesos se dieron en niveles diferentes en cada una de las regiones evaluados.

Se confirma que los países con políticas sociales multidimensionales presentan mejoras en los indicadores de cohesión, al observar el comportamiento de nuestros indicadores Nivel de Dificultad y Calidad de la democracia dentro de los países de Europa del Este, en donde fueron implementadas una serie de políticas que buscaban el establecimiento de estructuras sociales sólidas para alcanzar una ciudadanía activa y participativa, con capacidades de exigir derechos y ejercer control social para el funcionamiento de democracias con calidad, en algunos casos siendo efectivas y en otras manteniendo las estructuras de exclusión.

En el caso de Europa del Este, se implementaron reformas sociales solidas a la par de las reformas económicas por medio de un modelo con elementos del sistema de bienestar, características de redistribución sólidas y la garantía de derechos sociales universales. El enfoque de políticas sociales que se implementó en estos países es consistente con el debate científico en lo que se refiere a inversión social, confrontando los problemas estructurales y aumentando la eficiencia y efectividad de las políticas sociales.

Por medio de nuestro análisis encontramos políticas sociales exitosas que han tenido efectos positivos en términos de cohesión en los países evaluados, a su vez se observan similitudes en la forma en que las políticas se estructuraron y una reacción semejante en el efecto de las sociedades, constituyéndose en referencias a la hora de formular políticas en otras regiones, entre ellas tenemos:

- Los países con mejores puntuaciones implementaron reformas sociales solidas a la par de las reformas económicas por medio de un modelo dual con elementos del sistema de bienestar conservador-corporativo (un sistema de seguro social obligatorio, basado en la cooperación social) y el sistema de bienestar social-demócrata (en el cual un fuerte sector público/estatal sigue siendo el principal proveedor de servicios de todo tipo (Caso de Eslovenia, Eslovaquia y República Checa)

- Fortalecimiento y fomento de la capacidad de acción de las ONG y de la sociedad civil, facilidades para la obtención de financiación extranjera, la cual estaba dirigida principalmente a la construcción de la sociedad civil (Caso Lituania, Eslovenia, Eslovaquia y República Checa). 
- Estrategia multidimensional contra la pobreza y la exclusión, a través del refuerzo de la seguridad social, fomento de la participación activa de los individuos en el mercado laboral, la eliminación de la pobreza infantil, y el aumento del apoyo a las familias, dándole prioridad a las diferencias regionales y de género (Caso Eslovaquia, Republica Checa, Lituania).

- Descentralizó la mayoría de funciones de bienestar social, colocándolas bajo la autoridad de los gobiernos autónomos locales (Caso Polonia y Eslovenia)

- Principio de solidaridad como eje de las políticas por medio de un fomento a nivel constitucional (Caso Eslovaquia)

- Prioridad al desarrollo de las necesidades culturales de los grupos sociales minoritarios, por medio de la creación de las condiciones para facilitar el acceso a valores culturales definiendo las categorías de las necesidades culturales y determinando las posibilidades de desarrollo percibiendo a la cultura como un mecanismo integrador (Caso Eslovaquia y Eslovenia)

- Reformas profundas en la educación basadas en el conocimiento y la innovación con el intuito de acompañar los procesos globalizadores, priorizando la generación de capital humano (Caso Bulgaria y Croacia).

De acuerdo con nuestro indicador y tomando en consideración la revisión de la implementación de políticas sociales en los países de esta región, podemos definir estas políticas como aquellas que impactaron de forma directa el desarrollo de la cohesión social. Se observa que los países con mejores indicadores en términos del comportamiento de Cohesión Social son Eslovenia, Eslovaquia y República Checa, ya que implementaron políticas sociales de forma similar en términos estructurales.

De forma general podemos afirmar que la región avanzo en términos de cohesión durante la última década, todos los países reflejaron avances significativos, como podemos observar en la comparación regiona 


\section{Gráfico 11: Comportamiento del Nivel de Dificultad en Europa del Este}

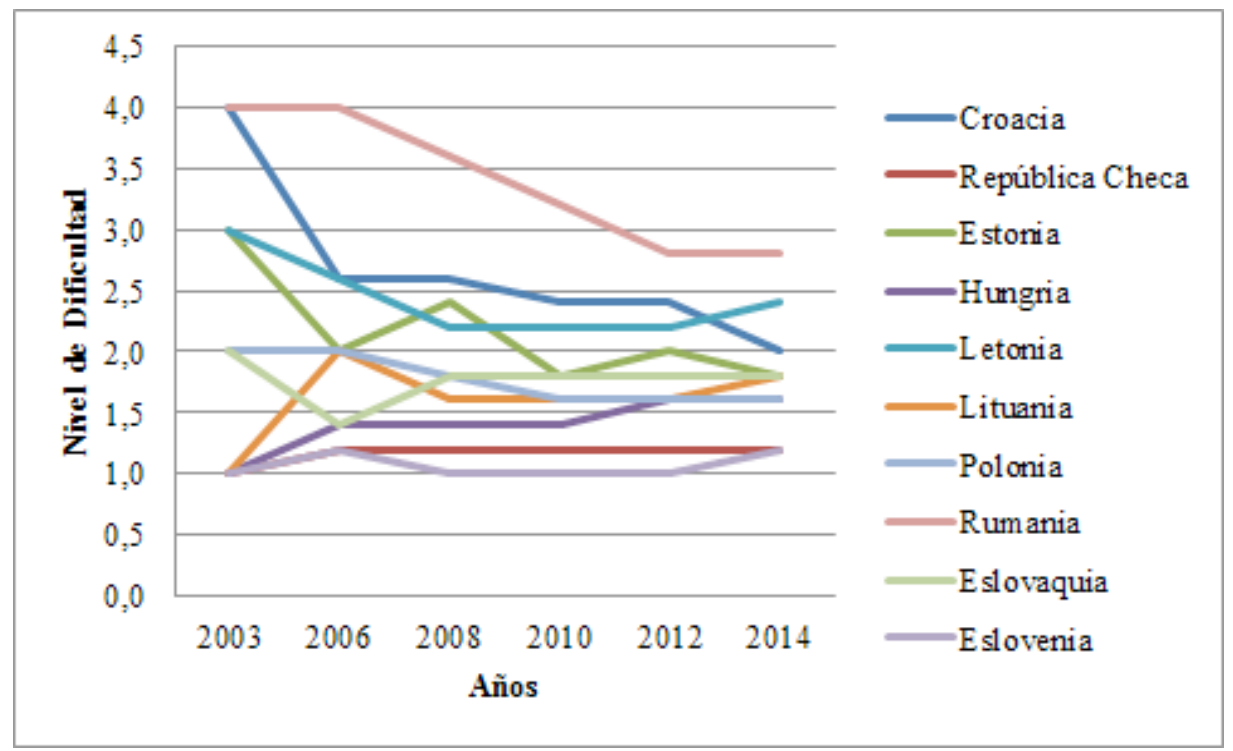

Fuente: Elaboración propia

Por medio de la evaluación de este indicador podemos observar que todos los países de la región presentaron mejoras en sus valores o se mantuvieron estables a los largo de la década, como lo fue el caso de la República Checa. El país en donde se observa una mejora considerable a través del período 2006-2014 en una comparación con los otros países de Europa del Este es Croacia pasando de 4 a 2 en su nivel de dificultad. Hungría es el único país que no presentó una evolución positiva de su indicador, incrementando su nivel de dificultad de 1 a 1,6 en un período de 11 años. Ninguno de los 10 países que conforman la región presenta un nivel de dificultad mayor de 3 para el año 2014. El país con una mejor situación en términos de Cohesión Social es Eslovenia y el que presenta una situación más deficiente es Rumania, ambos países mantienen esta posición desde el año 2003, considerado como el año inicial de observación. Debe hacerse un énfasis en el hecho de que las brechas entre todos los países fueron disminuidas considerablemente.

En términos de la democracia, Huntington (1991) ha enfatizado correctamente que ningún factor puede ser suficiente para explicar el desarrollo de las sociedades en un país determinado principalmente en términos democráticos, aun así el proceso de democratización de acuerdo con nuestra revisión es el resultado de una combinación de causas y acontecimientos, por medio de esta revisión histórica de la implementación de las políticas sociales posterior al fin 
de la Unión Soviética, buscamos tener una mayor comprensión del período evaluado en términos del comportamiento de la cohesión y su relación con la democracia.

Diversos autores apoyan esta afirmación tales como (DIAMOND; LINZ; LIPSET, 1988), (GASTIL RAYMOND D, 1985), y Pinkney (1993) apud Cerami (2000), resaltando la importancia de una explicación multicausal para alcanzar sistemas de calidad. Para estos autores, antecedentes históricos y culturales de una nación son cruciales para el éxito de las sociedades en la transición hacia democracia. Aspectos que se ven reflejados en los resultados de nuestro modelo presentado en el capítulo 1 de esta investigación, en donde se observa que todos los países evaluados expresan la hipótesis, como se puede observar en el gráfico XX:

Grafico 12: Tendencia de la relación entre la cohesión social y la calidad de la democracia en Europa del Este

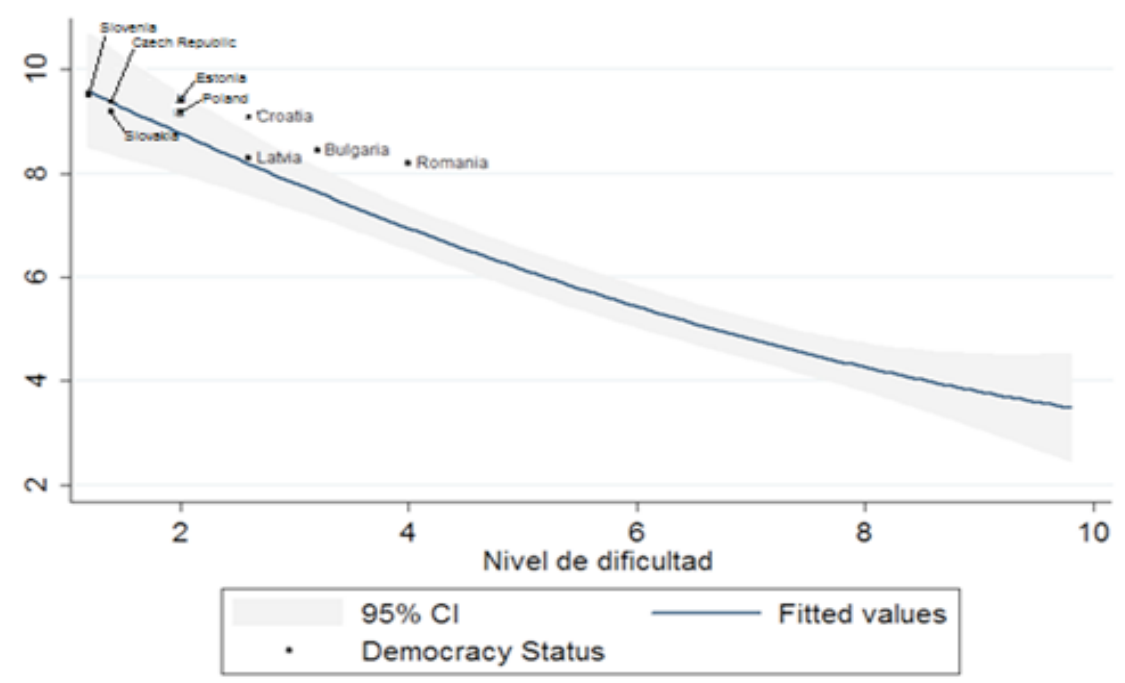

Cualquier intento de lograr y mantener reformas significativas y permanentes en términos de políticas sociales, trae consigo problemas prácticos y teóricos en todos los ámbitos, aun así debe considerarse al caso de Europa del Este como exitoso en términos de desarrollo social. Esta región sufrió las dificultades de la transición hacia economías de mercado, aspectos como la pobreza continúan siendo un problema aun cuando se observa una disminución de las mismas. Como establece Arat (1991, p.152 apud Cerami, 2006) "mientras persistan las desigualdades sociales y económicas, los países en desarrollo experimentando un proceso de democratización en la actualidad están condenados a volver a algún tipo de autoritarismo" (traducción libre del autor $)^{88}$.

\footnotetext{
${ }^{88}$ Texto original: "as long as social and economic inequalities persist, developing countries that go to a process of democratization today are doomed to return to some form of authoritarianism"
} 


\section{TIPOLOGÍAS REGIONALES, POLÍTICAS DE COHESIÓN SOCIAL Y SU IMPACTO EN LA CALIDAD DEMOCRÁTICA: AMÉRICA DEL SUR Y SU ENFOQUE SOCIAL}

\subsection{Introducción}

Las sociedades suramericanas han experimentado grandes transformaciones, principalmente en lo que se refiere a las relaciones sociales tradicionales en las que se desarrolló la cohesión. En este sentido la utilización del concepto de cohesión social surge como consecuencia de la necesidad de encarar problemas persistentes a lo largo de la historia suramericana, presentes en todos los países que la conforman, independiente de su nivel de desarrollo, entre los que se encuentran los altos índices de pobreza, la extrema desigualdad, diversas formas de discriminación y de exclusión, elementos que forman parte de la historia suramericana (CEPAL, 2007a).

América del Sur se caracteriza por una falta de comprometimiento por parte de los gobiernos en lo que se refiere a la implementación de políticas, principalmente aquellas ligadas a la solución de problemas estructurales por medio de la inversión en el capital humano, tomando en consideración las dimensiones que conforman la Cohesión Social (Brechas Sociales, Institucionalidad y Sentido de Pertenencia). Durante las últimas dos décadas, se construyó una visión más social en un contexto establecido dentro del mundo globalizado con avances acelerados en conjunto con desigualdades profundas, lo que contribuye al surgimiento de respuestas populistas en diferentes países de América del Sur (Sorj, 2008).

Aun en este escenario y a pesar de todas las dificultades, desde una perspectiva amplia, es una región con una sociedad cohesionada en términos de identidad ${ }^{89}$, de acuerdo con Salazar apud Santana (1997) alrededor de esta idea de unidad suramericana se construyó una ideología social con una larga trayectoria histórica la cual ha sido al mismo tiempo paralizadora y movilizadora de la acción y unidad social, se presenta un constructo simbólico común y rasgos de sentido de pertenencia fuertes, que la diferencian de otras regiones, de acuerdo con Alain

\footnotetext{
89 "La identidad tiene, en primer lugar, una dimensión locativa en el sentido de que a través de ella el individuo se sitúa dentro de un campo (simbólico) o, en sentido más amplio, define el campo donde situarse. Es decir, el individuo asume un sistema dc relevancia, define la situación en que se encuentra y traza las fronteras (más o menos móviles) que delimitan el territorio de su mismidad. La identidad tiene también una dimensión selectiva en el sentido de que el individuo, una vez que haya definido sus propios límites y asumido un sistema de relevancia, está en condiciones de ordenar sus preferencias y de optar por algunas alternativas descartando o difiriendo otras. Por último, la identidad tiene una dimensión integrativa en el sentido de que a traves de ella "el individuo dispone de un marco interpretativo que le permite entrelazar las experiencias pasadas, presentes y futuras en la unidad de una biografía.(SCIOLLA, Loredana, Identita, op. cit., 1983 p. 22 apud (GIMÉNEZ, 1996)
} 
(TOURAINE, 1983) existe una dimensión importante de la lucha entre los incluidos y los excluidos compuesta por características culturales y simbólicas que se mantiene a lo largo del tiempo.

A diferencia de Europa, en América del Sur las políticas de cohesión social no surgen como un esfuerzo consolidado entre todos los países por medio de un mecanismo de integración, tampoco hubo un modelo social ${ }^{90}$ como el implementado en Europa, basado principalmente en la cultura de los derechos ciudadanos, históricamente estos aspectos sólo comenzaron a tener un papel relevante en América del Sur a mediados del siglo pasado, por lo cual la estructura en términos de cohesión debió implementar una visión propia, sin tomar en consideración una configuración previa.

Estas estructuras se desarrollan principalmente en centros urbanos ${ }^{91}$, con un crecimiento que no ha seguido un orden específico, en los cuales se observa dos realidades en conflicto, una sociedad "cosmopolita, instruida y de clase media, y otra marginalizada, empobrecida y desencantada." (TIRONI; SORJ, 2007), produciendo sociedades altamente fragmentadas propensas al conflicto. En el aspecto político, fue solo hasta los años 80 que se observan transformaciones democráticas en la región, pasando a regímenes políticos civiles, con un papel protagónico por parte de los ciudadanos, aún con este proceso la región se ha establecido en un estructura caracterizada por la democracia, pobreza y desigualdad (PNUD, 2004).

Este mapa durante muchos años tuvo como actores principales a los partidos y organizaciones políticas, que fueron piezas fundamentales en el proceso de democratización de América del Sur, que se vieron debilitados por la falta de capacidad de representación de las sociedades en las cuales se vieron exacerbadas las brechas sociales. En consecuencia, surgen otros actores, que han tomado fuerza progresivamente, tales como las ONG y los movimientos sociales, que se posicionaron como formas emergentes de representación en conjunto con los partidos políticos, formando parte de las interacciones entre el Estado (HOPENHAYN, 2005).

\footnotetext{
${ }^{90}$ El principio básico del Modelo Social Europeo es que la sociedad debe proporcionar a cada uno de sus miembros ciertos bienes básicos (tales como educación y salud), debe garantizar la protección frente a ciertos riesgos (enfermedades, desempleo, vejez), efectuando una redistribución equitativa buscando el beneficio de ciertas categorías de la población (familias, deficientes), proporcionando a cada uno de los miembros lo medios para ganar su vida a través de una actividad remuneradora, en condiciones laborales satisfactorias (MATHIEU; STERDYNIAK, 2008)

91 De acuerdo con el "Relatorio de las Ciudades de América Latina y el Caribe" (2012) en nuestra región se encuentran cuatro de las ciudades más pobladas Ciudad de México (México), Sao Paulo (Brasil), Buenos Aires (Argentina) y Río de Janeiro (Brasil), para el año 2020 la tasa de urbanización en Brasil y el resto de los países del cono sur llegará a 90\%. En México y en los países de la región Andino-Ecuatorial, el número actual no pasa de $85 \%$. (ONU-HABITAT, 2012)
} 
Esta singular configuración de la región latinoamericana demuestra que los conflictos se profundizan como consecuencia de la falta de un sistema político fuerte, es decir de la existencia de instituciones eficaces que permitan resolver conflictos de toda índole. De acuerdo con GRYNSPAN; LOPEZ-CALVA, (2007) "la relación entre polarización o fragmentación y conflicto no es monotónica, y la intensidad del conflicto depende positivamente del grado de polarización".

Tomando como base estos aspectos en este capítulo se buscara analizar de forma específica la implementación de las políticas sociales dentro de los países que conforman la región, las cuales que se han visto influenciadas por el crecimiento económico caracterizado por condiciones externas favorables y la diversificación de la estructura que las compone con el objetivo de eliminar los procesos de exclusión social, afectando los niveles de cohesión en la región suramericana y a su vez ejerciendo un impacto en la consolidación de las democracias y la participación ciudadana, lo cual pretende ser evaluado a partir de la observación de los indicadores Nivel de Dificultad (Transformation Index-BTI), que refleja la falta de cohesión, y Calidad de la Democracia (Transformation Index-BTI) en la región, evaluando el impacto que han tenido las políticas en estas estructuras.

América del Sur resulta un caso de estudio importante debido a que no conto con un mecanismo de integración sólido para la implementación de este tipo de políticas, así como tampoco de una estrategia consensuada entre todos los países que la conforman. Aun con estas características se observan avances importantes en términos de cohesión, que resultan de procesos sociales, económicos culturales e históricos, que serán evaluados, los cuales forman parte de un proceso de construcción nacional de Estados complejos, en términos territoriales y poblacionales, con aspectos culturales compartidos producto por las raíces ibéricas, entre otras características:

\footnotetext{
"nuestra identidad latinoamericana es el primer y único caso de construcción de una identidad supranacional continental basada en una historia y civilización comunes que, más allá de las diferencias, se nutrió de luchas y paradigmas compartidos y se reconfigura con los desafíos presentes" (RAMOS, 2003)
}

Estas características diferencian a América del Sur de otras regiones (caso Europeo), ya que posee ventajas en los que se refiere a la homogeneidad lingüística, religiosa y la poca 
cantidad de conflictos étnicos ${ }^{92}$ y armados durante el siglo pasado ${ }^{93}$, siempre buscando la resolución por medios pacíficos. De acuerdo a lo establecido por Sorj y Tironi (2007, p. 113):

“(...) no ha tenido revoluciones políticas (salvo quizás la revolución mexicana), ni un radicalismo político de larga duración con sustento popular. Lo que ha tenido son guerrillas armadas, que se asocian a la debilidad del Estado para integrar a las poblaciones rurales a los beneficios del desarrollo y para ejercer su dominio sobre el territorio, y violación a los derechos humanos por parte de los propios Estados contra sus ciudadanos -lo cual no contribuyó a legitimar el orden institucional, sino todo lo contrario."

En este sentido, un segundo nivel de investigación que se desarrollará en este capítulo, es un estudio comparativo de las estructuras de cohesión entre América del Sur y Europa del Este, ya que ambas regiones sufrieron transformaciones profundas durante la década de los 90 que afectaron la dimensión social y la forma en que eran interpretadas e implementadas las políticas en esta área. Con este objetivo se tomara en consideración la evaluación realizada en el capítulo 2 para Europa del Este, logrando detectar similitudes y diferencias, definiendo de esta forma cuales políticas deben ser consideradas como efectivas en términos de cohesión.

A partir del contexto anterior, la estructura para la evaluación de América del Sur en este capítulo, se dividirá en tres partes, 1) Revisión general de la implementación y financiamiento de las políticas públicas vinculadas a la cohesión social en América del Sur, 2)Definición de las Especificidades de las políticas de Cohesión Social en los países, suramericanos, por medio de una evaluación individual para cada país, con el objetivo de tener una mayor comprensión de los niveles de cohesión de las sociedades y a su vez definir los elementos efectivos de estas políticas, 3)Síntesis de la evaluación de la región suramericana con base en los indicadores (Transformations Index) para posteriormente concluir con una comparación entre ambas regiones evaluadas.

\footnotetext{
${ }^{92}$ La fragmentación étnica de acuerdo a análisis econométricos inspirados por el estudio de la desigualdad y el crecimiento, arrojan resultados ambiguos, por ejemplo respecto de que sea un determinante del conflicto. Según los autores, es muy probable que aquella evidencia esté reflejando la inexistencia de mecanismos institucionales efectivos de solución de conflicto, variable que es difícil de incorporar empíricamente (GRYNSPAN; LOPEZCALVA, 2007)

93 "De 1825 hasta hoy hubo en América Latina diez disputas interestatales que pueden caracterizarse como guerras importantes: cinco sucedieron en el siglo diecinueve y otras tantas en el siglo veinte, de las cuales tres antes de terminar la Segunda Guerra y dos en períodos subsecuentes. Los cinco enfrentamientos armados en el siglo XIX fueron suscitados por la definición de fronteras: las dos Guerras Cisplatinas, la Guerra de la Confederación, de la Triple Alianza y del Pacífico. En el siglo XX, hasta el final de la Segunda Guerra, se produjeron tres conflictos bélicos interestatales: la Guerra del Chaco, entre Bolivia y Paraguay, el enfrentamiento de Perú y Colombia en Leticia (1932-1933), y la disputa entre Perú y Ecuador por el territorio adyacente a la parte navegable del río Marañón (1941-1942), en la región amazónica.” (SORJ; FAUSTO, 2010)
} 
El análisis de las políticas de cohesión resulta fundamental, principalmente en una región como América del Sur, ya que por medio de la investigación en esta área se pretende ampliar los conocimientos sobre la situación social en los países que conforman la región y comprender el porqué de su transformación en el tiempo, para tener una noción amplia de como deberán ser enfrentados en el futuro problemas vinculados a la exclusión y la desigualdad.

\subsection{Metodología}

Cada región presenta particularidades específicas que afectan el crecimiento y los procesos de desarrollo, tales como aquellas "físicas, tecnológicas y características fundamentales como capital social, diversidad cultural, industrial así como geográficas” (MARROCU; PACI, 2013), estando constituidas por elementos propios que se ven modificados con el tiempo y afectan los niveles de la cohesión social, generando en algunos casos efectos positivos y en consecuencia, ventajas comparativas ${ }^{94}$. En este sentido América del Sur se considera una región relevante en términos de cohesión debido a que presenta características de homogeneidad cultural y lingüística, por otro lado en términos históricos se observa una ausencia de voluntad política para mejorar la implementación efectiva de políticas sociales inclusivas, que se traducirían en ventajas en términos de la capacidad de gobernabilidad y sentido de pertenencia de la sociedad (CEPAL, 2007a)

La revisión teórica realizada, en este sentido, toma en consideración la evolución de los procesos de desarrollo, las disparidades regionales y la implementación de políticas sociales efectivas, así como el cambio en la interpretación de las estructuras de las políticas sociales CEPAL, (2007); (BANCO MUNDIAL, 2009); OECD (2009a), (OECD, 2011) y la Corporación Andina de Fomento (SANGUINETTI; ALVAREZ; CAF, 2012), entre otros, los cuales modificaron la visión exclusivamente economicista, que fracasó en la mejora de los indicadores sociales de la región.

En consecuencia se establecen las siguientes hipótesis: H(1) países con políticas sociales multidimensionales vinculadas a la cohesión presentan mejoras en los indicadores de calidad democrática. H(2) América del Sur presenta un sentido de pertenencia e identidad cultural

\footnotetext{
${ }^{94}$ Ventajas comparativa es un término que se asocia al economista David Ricardo, el cual considera que los bienes y servicios que un país produce, deben ser especializados, colocando sus recursos escasos en la producción de bienes y servicios para los cuales poseen ventajas en los costos comparativos. En este caso el uso de este término está vinculado a una visión amplia y no específicamente económica, que se refiere a un conjunto de aspectos estructurales de una sociedad que le generan ventajas frente a otras.
} 
robustos proporcionando ventajas a la hora de implementar políticas de cohesión social. H(3) Las brechas sociales son el principal obstáculo para alcanzar desarrollo de la cohesión dentro de una sociedad

Con el objetivo de confirmar nuestras hipótesis será realizado un análisis tanto de forma como de fondo, en la aplicación de políticas de cohesión, para cada uno de los estados que conforman la región estudiada y su impacto en los indicadores de calidad democrática. Esta estructura de investigación permitirá una evaluación comparativa del estado de la cohesión social en diferentes países y una descripción de las diferentes tendencias que se observan a lo largo del tiempo, en dimensiones específicas y por medio de una clasificación general. Para la evaluación comparativa se utilizará el indicador del Transformation Index- BTI en conjunto con investigaciones para desarrollados por la CEPAL, OECD, Banco Mundial, así como entrevistas.

La revisión realizada en este capítulo tiene como objetivo principal convertirse en una herramienta relevante para la comparación a nivel nacional entre países y a nivel regional en términos globales, definiendo debilidades y fortalezas, para de esta forma poder elaborar estrategias efectivas que tengan un verdadero impacto en sociedades con desigualdades extrema, las cuales juegan un rol fundamental en la consolidación democrática, siendo este trabajo un aporte a la visión que privilegia el análisis de políticas inclusivas que generan desarrollo dentro de las sociedades.

\subsection{Políticas de Cohesión Social en la Región Suramericana}

Las políticas públicas en términos de cohesión social en América del Sur se caracterizan por poseer un vínculo directo con las políticas sociales, la agenda implementada en los años noventa consideraba la ampliación de las oportunidades, la promoción del desarrollo de las capacidades y la conformación de redes más inclusivas de protección en las sociedades, siendo considerados los ciudadanos como actores vulnerables y foco de este tipo de políticas.

Frente a este escenario, se formularon una serie de premisas a la hora de implementar políticas que buscaban ampliar el bienestar social, estableciéndose como aspectos característicos en este contexto de cambio suramericano:

“1) el crecimiento económico es el mecanismo central de la política social de reducción de la pobreza; 2) el gasto social debe concentrarse en los "muy pobres"; 3) se debe fomentar la prestación de servicios de educación, de salud y de pago de pensiones por proveedores del sector privado, y 4) se necesitan programas de protección social de 
emergencia para enfrentar crisis macroeconómicas y desastres naturales"(SOLIMANO, 2005)

Debe entenderse que América Latina está compuesta por países con diferentes niveles de desarrollo y características económicas particulares, aun así existe cierto consenso en el diagnóstico de la problemática de la región, ocurre lo contrario en lo que se refiere a la implementación un consenso general de cómo deben ser aplicadas las políticas, principalmente aquellas vinculadas al concepto de cohesión. En la coyuntura regional actual, hay dos aspectos que diferencian el reto de la cohesión social, los bajos niveles de desarrollo y nuestros altos niveles de desigualdad y bajas cargas tributarias (MACHINEA; UTHOFF, 2005).

En consecuencia se implementó un proceso de reforma durante los años noventa por medio de la evaluación de las políticas públicas tanto a nivel gubernamental como en los organismos internacionales, con el objetivo de alcanzar sociedades más solidarias e inclusivas, considerando la estructura de los países en términos de recursos y en segundo lugar la voluntad por parte de los actores principales/policy makers.

En el transcurso de las últimas tres décadas es importante destacar los importantes procesos de democratización y descentralización hacia los gobiernos sub-nacionales, implementados en todos los países suramericanos, en paralelo, fueron diversificados los presupuestos estatales, que anteriormente se encontraban centralizados, observándose un esfuerzo progresivo para incrementar el gasto social, la expansión de este tipo de gastos estuvo ligada a los ritmos de crecimiento de cada país, como se observa a continuación:

\section{Gráfico 13: Gasto público social como porcentaje (\%) del producto interno bruto} (PIB) (América del Sur)

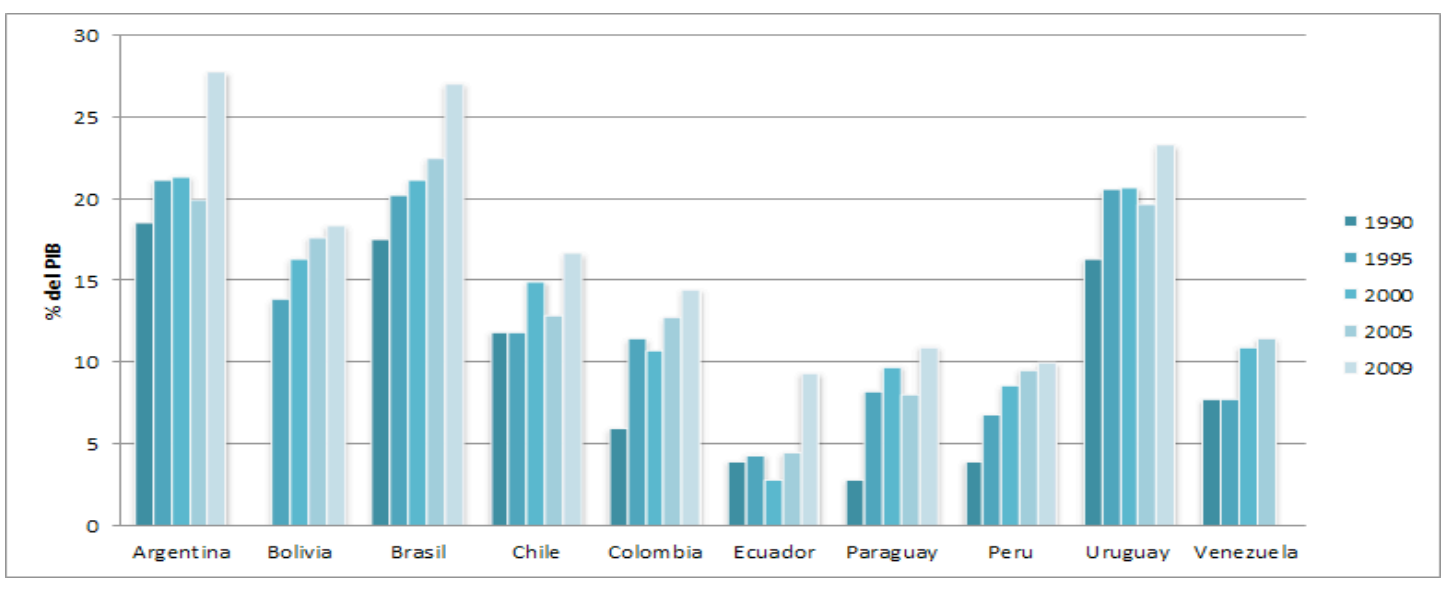

Fuente: Elaboración propia, datos (CEPALSTAT) 
Durante este periodo de tiempo la región invirtió de forma general menos del $20 \%$ en gastos sociales en la mayoría de los países exceptuando a Argentina, Brasil e Uruguay, aun cuando se observa que el impacto en la disminución de la desigualdad no fue alto, se ven leves mejoras en la mayoría de los países de acuerdo al Coeficiente de Gini para la región

\section{Gráfico 14: Î́ndice de concentración de Gini para América del Sur}

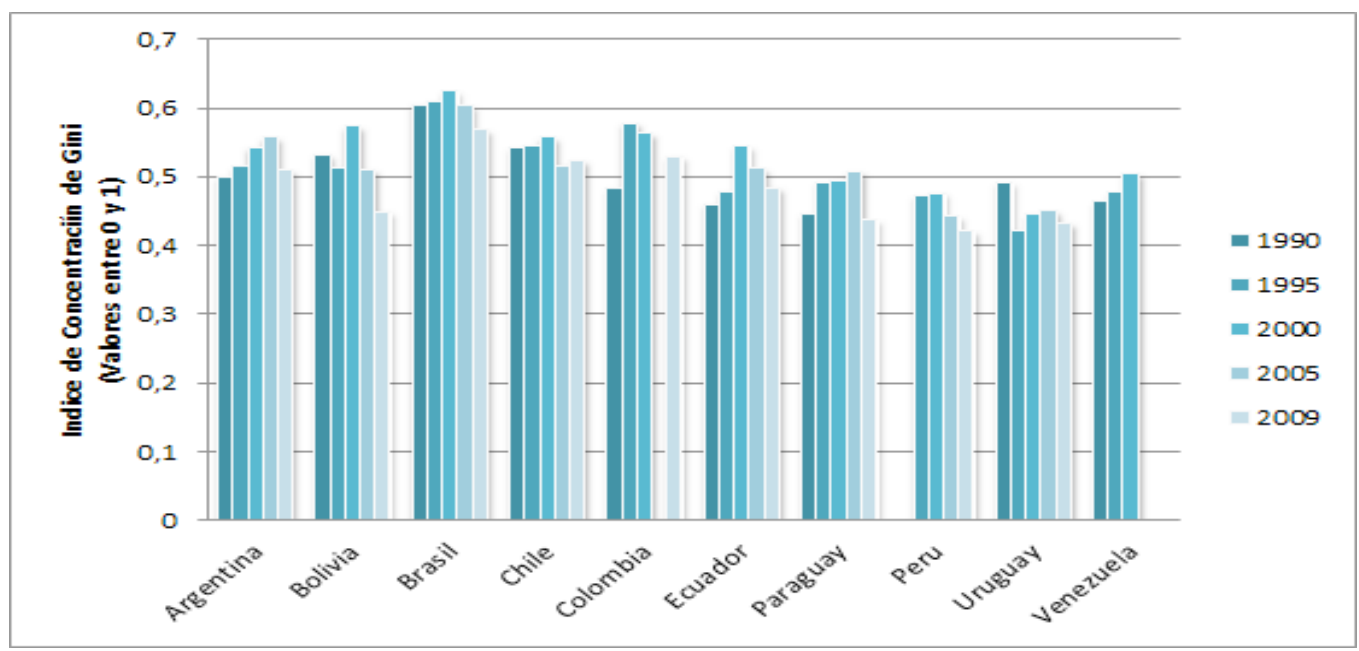

Fuente: Elaboración propia, datos (CEPALSTAT)

A través de este indicador podemos observar que la desigualdad en la distribución de los ingresos mantiene niveles elevados, aun con el incremento del gasto social en todos los países de la región, lo que nos hace cuestionar su efectividad y la existencia de una verdadera articulación de las políticas sectoriales, en materia de educación, salud, empleo, infraestructura, entre otros, ya que persiste dentro de las sociedades suramericanas un elevado nivel de insatisfacción social y pobreza crónica.

Un paradigma que se ha visto reflejado dentro de las sociedades suramericanas, es la relevancia de la protección social ciudadana como un mecanismo fundamental para alcanzar la inclusión (CEPAL, 2007), el cual se mantuvo hasta comienzo de la década de los noventa, cuando se expuso que esta estructura no había logrado atender las necesidades de las sociedades en su totalidad. En medio de estas dinámicas, la región busca un nuevo paradigma para la implementación de políticas sociales efectivas:

"Las mejoras distributivas no solo son el resultado del incremento del gasto sino dependen también de la capacidad para incorporar y mejorar los mecanismos de transferencia solidaria como parte de las prestaciones. Se trata, ciertamente, del desafío de integrar la lógica de los incentivos con los de la construcción de mecanismos de solidaridad. De manera específica, deben considerarse: el agotamiento de la seguridad 
social como mecanismo de inclusión y el papel de la nueva protección social en la mejora de la cohesión; la necesidad de modernización en las políticas públicas que mejoren calidad y equidad; la revisión de la descentralización como receta universal y la cohesión territorial, $\mathrm{y}$, muy especialmente, la búsqueda de solvencia y equidad a través de la tributación" (CENTRANGOLO; GOMEZ, 2007)

El riesgo en la implementación de políticas sociales, es que en muchos casos se han adoptado en el nombre de esta causa, políticas populistas ${ }^{95}$, las cuales poseen pocas posibilidades de mantenerse sustentables a través del tiempo. Este fenómeno ha surgido de acuerdo con WEFFORT, (1989) como consecuencia de la masificación de las camadas de la sociedad, desvinculando a los individuos de sus estructuras sociales de origen, estando relacionados por una sociabilidad periférica y mecánica, en segundo lugar cuando se da una pérdida de la representación efectiva de la clase dirigente y finalmente cuando existe la presencia de un líder carismático que atrae a las masas. Las políticas populistas se han visto implementadas en varios países de la región como una forma de acercamiento con las sociedades, desencantadas con los gobiernos tradicionales.

Los recursos para el financiamiento de este tipo de políticas, tanto las populistas como las sociales, tienen orígenes diversos, muchos países se caracterizan por obtener los recursos de la explotación los recursos naturales, principalmente por medio de la explotación de hidrocarburos y la minería que se encuentran, en su mayoría, en manos del sector público como es el caso de Venezuela, Bolivia, Ecuador y Chile, trayendo ingresos fiscales de tal importancia que han relevado a sus gobiernos de la necesidad de afianzar la recaudación tributaria, (CENTRANGOLO; SABAINI, 2007).

Los gobiernos suramericanos han implementado una serie de mecanismos para movilizar recursos y a su vez promover la institucionalidad, una de las herramientas relevantes en este sentido es la política fiscal en busca de la estabilización macroeconómica por medio de la obtención de recursos, en segundo lugar por medio de la creación de mecanismos que garanticen la transparencia en la implementación de las políticas sociales evitando esquemas de corrupción, que poseen raíces profundas en las instituciones gubernamentales, el desarrollo regional a través del comercio internacional y la infraestructura competitiva por medio servicios públicos de calidad ha sido también un área que ha tomado relevancia en términos de cohesión social, principalmente dentro de los mecanismos de integración.

\footnotetext{
95 "Que pueden ser interpretadas como un fenómeno de origen social, una forma de gobierno o una ideología (WORSLEY, 1973)
} 
El enfoque de políticas de cohesión social en la región no ha sido implementado de forma firme y consolidada, una hipótesis es que se ha dado por sentado las estructuras ventajosas en términos de sentido de pertenencia y raíces culturales con elementos como la comunidad y el mestizaje, así como un modelo de autoridad que sigue la tradición paternalista dificultando la acción de actores estructuras diversificadas de implementación. Tomando en consideración las estructuras sociales que caracterizan la región, el análisis será enfocado desde dos visiones una nacional por medio de una evaluación de las políticas sociales implementadas por cada país que conforma la región y en segundo lugar evaluando la forma en que se implementaron las políticas de cohesión dentro de los mecanismos de integración.

\subsection{Especificidades de las políticas de Cohesión Social en los países suramericanos}

El análisis del contexto suramericano de políticas sociales, proporciona las bases para comprender el proceso de transformación económica, política y social, así como el refuerzo de la estructura democrática en estos países durante las dos últimas décadas. Con el objetivo de profundizar aún más en la evaluación del desarrollo de la cohesión social, se realizara una decantación de las principales políticas sociales que afectaron de forma directa a los países de esta región con el objetivo de definir aquellas que impactaron de forma positiva a la cohesión, observando el comportamiento dentro del período evaluado 2003- 2014 tomando en consideración el indicador Nivel de Dificultad y la Calidad de la democracia en este período.

\subsubsection{Argentina}

Argentina es un país que presenta concentración de pobreza, así como la exclusión en los sectores con baja renta, produciendo este fenómeno de forma intergeneracional. Durante los años 90, las causas generadoras de pobreza tenían un vínculo directo con el mercado laboral como generador de exclusión y desigualdad “entre 1992 y 1995 la pobreza aumentó del 21,9\% al $28,8 \%$ y finalmente a partir de 1998, cuando la economía entra en recesión y luego explota en la crisis, la pobreza pasa del 30\% a más del 57\% de la población” (AMADEO, 2008).

Pueden ser definidos tres momentos que determinaron procesos fuertes de exclusión en la Argentina contemporánea, en la llamada "década perdida" ${ }^{96}$. En primer lugar el proceso de privatización de empresas públicas y ajuste del aparato estatal que producen una salida masiva de empleados (150.000 personas en 3 años), generando una contracción del empleo

\footnotetext{
${ }^{96}$ Es un término empleado para describir las crisis económicas sufridas en América Latina (CEPAL, 2007)
} 
principalmente en el sector industrial. En segundo lugar la crisis macroeconómica que tuvo su momento más álgido en 1994, en donde el ingreso real promedio cayó 7\%, pero el del primer quintil lo hizo en un $35 \%$ y el del 2 do en un $20 \%$ y por último el tercer momento que fue definido como "corralito", en el cual se limitaron los saques en efectivo dejando sin dinero a la mayoría de la población, principalmente a los que forman parte de las clases más bajas (ídem).

Esto se da en un proceso de fragilidad democrática, es importante resaltar que Argentina es una democracia consolidada de tiempos recientes, ya que desde su formación como nación independiente, nunca se había atravesado un período democrático tan prolongado como el actual. Uno de los principales problemas del realpolitik argentino se vincula al escaso compromiso ciudadano para las cuestiones públicas, en lo que se refiere a la participación ciudadana, debido a que existe una falta de entendimiento acerca de la importancia del ejercicio responsable de las obligaciones cívicas, junto a un bajo nivel de interés en las cuestiones vinculadas a la política, afectando negativamente el desarrollo de la democracia (SARIENGA, 2014).

Otro aspecto importante a ser considerado es que Argentina es un país con una "población trasplantada" (LARRETA, 2008) de inmigrantes, con poca presencia de pueblos originarios durante el periodo de construcción nacional, por lo tanto las minorías permanecieron casi invisibles, en este sentido cabe resaltar:

\footnotetext{
"La inmigración, combinada con la afirmación cultural nacional republicana fue el camino. La unificación se consiguió a través de los símbolos y la pedagogía educativa de la Republica, la movilización de la comunidad nacional ante el extranjero, el antiimperialismo y la reivindicación de símbolos nacionales durante el periodo de nacionalismo popular y luego mediante las audiencias nacionales de la industria cultural de masas" (RODRIGUEZ LARRETA, 2008)
}

Vemos que la pobreza tiene varios orígenes entre ellos tenemos las vulnerabilidades de la protección social y un aumento de la violencia ciudadana, en un contexto de deterioro del sistema educativo así como una falla en la cobertura de las pensiones. El gobierno en vista al escenario de desigualdad implementó una fuerte inversión pública en campos fundamentales como lo son la educación y la salud, desarrollando programas con foco en la protección social, dirigidos a la población excluida planteando de esta forma estructuras de cobertura masiva (AMADEO, 2008).

En términos nacionales fueron implementados un conjunto de programas que en su mayoría se priorizan el rol de las mujeres como encargadas de la distribución del subsidio monetario: "Programa jefas y jefes de hogar desocupados" que se caracterizó por la magnitud del 
gasto $^{97}$ (AMADEO, 2008) "Programa familias por la inclusión social" con el objetivo fundamental de promover la protección e integración de familias en situación de vulnerabilidad os (MDS, 2005), "Plan nacional de seguridad alimentaria" que se extiende a todas las prestaciones con componentes alimentarios que se desarrollan a nivel nacional (comedores, huertas, granjas, etc.) (CEPAL, 2008), Plan nacional de desarrollo local y economía social Manos a la obra" tiene por objetivo generar puestos de trabajo (MDS, 2006) y en el campo de la salud "Remediar", que tuvo como objetivo el proporcionar a la ciudadanía de medicamentos (REMEDIAR, 2015) y “Nacer" aumentando la cobertura de salud de las embarazadas.

Aun cuando los programas implementados tuvieron un impacto significativo directo en la reducción de la exclusión en el corto, presentan problemas en lo que se refiere a su estructura general e implementación. Como establecido por Amadeo (2008) en el caso Argentino la política social se reduce a programas coyunturales, que pueden ser desbordados por las crisis macroeconómicas:

"En el caso de Argentina, que hemos visto en detalle, el problema no fue originado solamente en la adopción de políticas de ajuste fiscal y apertura de los años 90. Es el resultado de un proceso asincrónico entre exigencias y capacidades productivas, acelerado por la sucesión de violentos ciclos generados por algunos aspectos idiosincrásicos de la sociedad argentina.” (AMADEO, 2008, p.25)

Por otro lado, también es cierto que existe una desconfianza importante en términos institucionales, de acuerdo con (LEPORE; MORENO, 2007) las mejoras económicas y sociales de los últimos años generaron un incremento relativo de la confianza en las instituciones políticas, por lo tanto para su sustentabilidad a través del tiempo debe generarse un refuerzo de los mecanismos de participación democrática tales como el voto popular, el uso efectivo de herramientas de participación directa, el fomento de las Ong y las asociaciones cívicas.

Tomando en consideración este contexto se observa una redefinición de la prioridad de las políticas sociales principalmente a través de nuevas modalidades de asistencia social. El desarrollo de las políticas sociales en conjunto con el fortalecimiento de la sociedad civil trajo consigo trajo una mejora generalizada en los indicadores sociales así como de la estabilidad gubernamental lo que se ve reflejado en el Transformation Index como vemos a continuación:

\footnotetext{
${ }^{97}$ El total de recursos empleados en 2003 (momento de mayor cobertura del programa) fue de ARS \$3.709 millones, equivalentes a 1\% del PIB (Golbert, 2007 apud CEPAL, 2006).
} 
Tabla 17: Argentina: Relación Cohesión Social/ Calidad de la Democracia

\begin{tabular}{|l|l|l|l|l|l|l|}
\hline Años & 2003 & 2006 & 2008 & 2010 & 2012 & 2014 \\
\hline $\begin{array}{l}\text { Nivel de } \\
\text { Dificultad }\end{array}$ & 4,0 & 3,4 & 2,6 & 2,8 & 2,8 & 2,8 \\
\hline $\begin{array}{l}\text { Calidad de la } \\
\text { Democracia }\end{array}$ & 7,60 & 7,85 & 7,85 & 7,90 & 7,55 & 7,55 \\
\hline
\end{tabular}

Fuente: Transformation Index, 2015

Observando los indicadores vemos que Argentina se ha caracterizado por una mejora del indicador de Cohesión Social durante el período estudiado 2003-2014, esto se vincula a la implementación de diversos programas y reformas dentro de las políticas sociales buscando la disminución de la desigualdad, en el caso de la calidad de la democracia se observa una mejora proporcional a la mejora de la cohesión social del 2003 al 2008. Durante el 2010 se observa una disminución del indicador Calidad de la Democracia aun cuando el Nivel de Dificultad se encuentra estabilizado, en este sentido debe tomarse en consideración el contexto de polarización política y el inicio de las protestas del $8 \mathrm{~N}$ ( 8 de noviembre) por parte del sector opositor al kirshnerismo generando un contexto de inestabilidad ciudadana lo cual afecto la puntuación del indicador.

\subsubsection{Bolivia}

El Estado Boliviano debe ser considerado como un caso de estudio particular en lo que se refiere cohesión social, ya que se han aplicado reformas en todas las dimensiones estatales. Los años noventa siguieron los procesos de profunda crisis económica vivida en los años 80, caracterizada por una "caída sostenible del producto interno bruto e hiperinflación, la cual se vio agudizada por la deuda externa, factores climáticos, crisis política y social, así como un manejo macroeconómico ineficiente" (MORALES; SACHS, 1989)

Es importante resaltar que Bolivia fue uno de los primeros países en implementar reformas de corte ortodoxo para generar estabilización, estas se iniciaron durante el gobierno de Víctor Paz (1985-1989) compuestas por una devaluación del tipo de cambio (93\%), reducción generalizada de aranceles, liberalización de las tasas de interés, libre negociación de contratos de trabajos en el sector privado, y ajuste fiscal (JEMIO, 1999). Estas medidas fueron continuadas 
durante los gobiernos sucedáneos aun cuando resultaron en un costo elevado para la sociedad boliviana.

En conjunto con estas medidas, durante el gobierno de Sánchez de Lozada, el estado boliviano comenzó la institucionalización de una Bolivia "pluriétnica y multicultural", de acuerdo con Larson et al (2008) estas acciones estuvieron enmarcadas dentro de una fachada política para establecer un régimen neoliberal "cruel” afectando a los sectores más vulnerables de la sociedad boliviana, aun cuando se dieron importantes reformas políticas sustantivas de la "Ley de Participación Popular", lo que generó un impulso a los líderes indígenas, que posteriormente alcanzaron posiciones de poder (MCNEISH, 2006).

Debido a la estabilización económica producto de las reformas, en 1991, se planteó la Estrategia Social Boliviana (ESB) ${ }^{98}$ en la que se establecen las bases para modificar el enfoque de la política social con una visión estratégica sobre el capital humano en la lucha contra la pobreza, en paralelo fue definida una estrategia específica para luchar contra la desigualdad, por medio de una administración eficiente de los recursos destinados al sector social en consecuencia, entre 1990 y 1997 fueron invertidos por parte del gobierno boliviano en el gasto social un 6\% con respecto al PIB (JEMIO, 1999).

Así como se ve reflejado en otros países de América del Sur, el gasto social ha pasado a tener un papel fundamental durante las últimas dos décadas, entre 1996 a 2006 se vio triplicado el gasto público social ${ }^{99}$, esto fue una consecuencia, a su vez, de un contexto fiscal favorable en el que se incrementaron los precios internacionales de las materias primas (CONAPSO, 1991).

En lo que se refiere al aumento gasto social en la década de los 90 de acuerdo con (LOAYZA, 1999), estuvo vinculado con un desempeño más estable de las finanzas públicas, en este sentido la prioridad de las inversiones se dieron en los programas y proyectos a nivel nacional que buscaban una disminución de la pobreza y teniendo como objetivo estratégico la mejora de los indicadores sociales apoyado por organismos internacionales. Otro aspecto importante a ser considerado fue la implementación del "Plan Operativo de Acción", que presentó los cuatro ejes de acción del Estado Boliviano “Oportunidad, Equidad, Dignidad e Institucionalidad” (ídem).

\footnotetext{
98 "la Estrategia Social Boliviana se constituye en un marco de referencia para que; por un lado las distintas instituciones del sector público vinculadas al tema social, diseñen políticas y programas específicos consistentes con los lineamientos y objetivos planteados, y por otro, para que el sector privado y organismos internacionales, relacionados con la problemática social, orienten sus acciones según las prioridades definidas en la estrategia" (CONAPSO, 1991)

${ }^{99}$ Se pasó de 5.220 a 15.466 millones de bolivianos (CONAPSO,1991),
} 
Aun cuando se incrementaron los niveles de gasto social, estos no fueron suficientes para generar cambios sustanciales en las condiciones de vida de la población, tampoco generaron una consolidación de las coberturas universales de los servicios sociales básicos (PNUD, 1998), $70 \%$ de la población boliviana vivía en condiciones de pobreza (LOAYZA et al, 1999). En este contexto y aun con la implementación de diversos proyectos se vio un incremento en el porcentaje de habitantes en áreas urbanas como consecuencia de la migración campo-ciudad, debido a los niveles de pobreza y falta de oportunidades en las áreas rurales.

En el año 2001 se implementó el "Plan Nacional de Empleo de Emergencia"(PLANE) que fue continuado por medio del PLANE-II y PLANE III (culminando en febrero de 2006) con el propósito de generar empleos de carácter temporal y disminuir la falta de ingresos en los hogares pobres. En ese mismo año se inició la implementación del "Programa de Lucha contra la Pobreza y Apoyo a la Inversión Social" (PROPAIS), con intervenciones orientadas a la inversión en pequeñas obras de infraestructura social, formación de la mano de obra y facilitar la reinserción en el mercado de trabajo (CANAVIRE-BACARREZA; AYAVIRI, 2010).

La estructura de inversión social mencionada anteriormente se mantuvo hasta la llegada de Evo Morales, durante su gobierno se implementaron cambios profundos, enfocados principalmente en el fortalecimiento del Estado Central, así como en la aplicación de reformas estructurales en una dirección distinta los modelos tradicionales. Para esto se aplicó un nuevo modelo de desarrollo denominado como el "Plan Nacional de Desarrollo Bolivia Digna, Soberana, Productiva y Democrática para Vivir Bien” (GOBIERNO DE BOLIVIA, 2006) colocando a las comunidades como el actor central y promoviendo la intervención del estado en el mercado, así como la implementación de un Impuesto Directo a los Hidrocarburos ${ }^{100}$. Este plan se estructuró con la idea de darle prioridad a la redistribución de ingresos por encima del crecimiento económico, protagonismo a la acción comunitaria y cultural (MORALES; SACHS, 1989).

En términos políticos se realizaron reformas institucionales profundas por medio de la Asamblea Constituyente (Julio 2006) que modificó la estructura social, a través del nuevo texto constitucional aprobado en el año 2009, definiendo al Estado Boliviano como un "Estado

\footnotetext{
100 "equivalente al $32 \%$ de la producción bruta de hidrocarburos en boca de pozo. Este impuesto, asociado a las regalías y participaciones del 18\%, ocasiona que el Estado, independientemente de los costos de operación y capital, participe del $50 \%$ de las ventas brutas en boca de pozo. Por otra parte, el artículo 57 de la nueva Ley de Hidrocarburos establece los porcentajes de coparticipación en la recaudación de este impuesto, de la siguiente manera: a) 4\% para cada uno de los departamentos productores; b) 2\% para cada departamento no productor; c) el Tesoro General de la Nación (TGN), pueblos indígenas y originarios, comunidades campesinas, municipios, universidades, fuerzas armadas, policía nacional y otros" (MEDINACELI, 2015)
} 
Unitario Social de Derecho Comunitario Plurinacional" y reconociendo la "justicia comunitaria" impartida por autoridades indígenas, se determinó a su vez el "control social" de las instituciones públicas por medio de una sociedad civil organizada, se dictamina a la educación como “descolonizada, liberal y revolucionaria", entre otras reformas (HERNANI-LIMARINO; FUNDACIÓN, 2010).

El sistema político boliviano transitó, de una democracia estrictamente representativa a otra con énfasis en la participación ciudadana, en donde se observa una priorización de las identidades culturales, las naciones, pueblos y comunidades, así como en la preservación de la diversidad étnica. De acuerdo con Cordero (2010) esta nueva estructura es incluyente de forma superficial, ya que se observa que el énfasis principal del estado es hacia a las identidades indígenas, pero se colocan de lado a importantes sectores sociales definidos como clases medias y mestizos, de pequeñas, medianas y grandes ciudades donde se concentra más del $70 \%$ de la población del país.

En paralelo debe considerarse contexto económico, ya que se dio un aumento en los precios de las materias primas, generando tasas positivas de crecimiento, convirtiendo a Bolivia de un país de ingresos bajos a uno de ingresos medios (LOAYZA, 1999) ${ }^{101}$, con mayores recursos para la promoción de la dimensión social.

Los actores al nivel central del Estado, que participaron en la implementación de los diversos programas sociales, son el Consejo Nacional de Política Económica y Social $(\text { CONAPES })^{102}$, CONALCAM y los Ministerios sectoriales, en conjunto con los niveles departamentales, municipales y comunitarios. En este contexto se debe resaltar un organismo que ha ejecutado un papel protagónico, esta sería la Red de Protección Social, la cual había sido creada en 2004 durante el gobierno de Carlos Mesa, a la cual se le adiciono el Desarrollo Integral Comunitario (RPS-DIC), convirtiéndose en uno de los principales pilares de la política social ${ }^{103}$.

\footnotetext{
101 Según datos del Programa de Naciones Unidas para el Desarrollo (PNUD), la pobreza extrema ha bajado en Bolivia de 41,2\% en 1996 a 32,7\% en 2008. Sin embargo, los mismos datos indican que este índice está por debajo de la media latinoamericana y que las desigualdades en la distribución del ingreso persisten en Bolivia (PNUD UNICEF - CEPAL, 1999)

102 Coordina políticas nacionales de desarrollo social y económico, con capacidad de concertar acciones y proponer políticas enmarcadas en el Programa Nacional de Desarrollo

${ }^{103}$ Este programa "propone una estrategia de largo plazo basada en tres componentes: (i) Comunidades en Acción, que se implementaría en municipios rurales con extrema pobreza, (ii) Comunidades Recíprocas que propone intervenciones orientadas a mejorar las capacidades económicas, físicas, naturales, humanas y socio-comunitarias, y (iii) Comunidades Solidarias, orientado al potenciamiento de capacidades, oportunidades, proyecciones y derechos de la población más vulnerable" (CANAVIRE-BACARREZA; AYAVIRI, 2010).
} 
Por medio de estas instituciones se implementaron los principales programas sociales entre los cuales pueden ser clasificados en cuatro grandes áreas: Programas para la infancia, Programas para la Edad Escolar; Programas de Empleo; y Programas de desarrollo comunitario. Entre los programas de transferencias monetarias, los más significativos son el Bono Juancito Pinto y el Programa de Incentivos Monetarios a la mujer gestante, en lactancia y con niños menores de dos años (Bono Juana Azurduy de Padilla) (MORALES; SACHS, 1989).

El programa "Juancito Pinto", fue definido como un programa de transferencia monetaria esto con el objetivo de promover la matrícula y la permanencia escolar de forma universal. En términos operativos, el programa es relativamente barato teniendo un costo operativo de $2.5 \%$ del total del presupuesto del Ministerio de Educación y Cultura (MEC apud (MORALES; SACHS, 1989). El segundo programa importante en términos de bonos fue el "Madre-Niño-Niña Juana Azurduy" teniendo como objetivo principal el acceso a los servicios de salud y desarrollo integral por parte de la población para disminuir la mortalidad materna e infantil.

Aún cuando se observa que las estrategias nacionales reconocieron los severos problemas de exclusión, desigualdad y pobreza extrema, así como la vulnerabilidad social existente en la sociedad boliviana, de acuerdo con Canavire-Bacareza y Ayaviri, (2010) tales acciones para la protección social en las dos últimas décadas carecieron de articulación, no tuvieron mecanismos de focalización para atender realmente a poblaciones en extrema pobreza ni protegieron a los sectores más vulnerables.

La continuación de las amplias brechas sociales, es resultado de la falta de un enfoque adecuado de los programas sociales, siendo en su mayoría asistenciales y de corto plazo, lo que genera un contexto en el cual se ha dado continuidad de los problemas que originan las brechas sociales y en consecuencia exclusión social. Desde la década pasada se ha dado una reorientación promoviendo la lucha contra la desigualdad y el énfasis en las culturas propias e indígenas, que se constituyen como elementos fundamentales para la cohesión social, lo cual se observa reflejado en nuestro indicador.

En términos de la evolución de la cohesión social interpretada por medio del indicador "Nivel de Dificultad" (BTI) y su relación con la Calidad de la Democracia, se observa una evolución positiva 
Tabla 18: Bolivia: Relación Cohesión Social/ Calidad de la Democracia

\begin{tabular}{|l|l|l|l|l|l|l|}
\hline Años & 2003 & 2006 & 2008 & 2010 & 2012 & 2014 \\
\hline $\begin{array}{l}\text { Nivel de } \\
\text { Dificultad }\end{array}$ & 6,0 & 5,8 & 5,8 & 5,6 & 5,6 & 5,8 \\
\hline $\begin{array}{l}\text { Calidad de la } \\
\text { Democracia }\end{array}$ & 7,20 & 6,75 & 6,40 & 6,50 & 6,85 & 7,10 \\
\hline
\end{tabular}

Fuente: Transformation Index, 2015

Observando nuestros indicadores vemos una mejora en el Nivel de Dificultad desde el 2006 hasta el 2012, esto como resultado de las profundas reformas sociales implementadas en Bolivia, aun cuando se presenta como una mejora modesta se debe resaltar su relevancia debido la situación histórica de exclusión dentro de la sociedad boliviana. Cabe resaltar que en el año 2003 se presenta un relación atípica entre nuestros indicadores, ya que la falta de cohesión social presenta su puntuación más elevada al igual que la Calidad Democrática, esto se debe a que la sociedad boliviana hace efectiva la renuncia del presidente Sánchez de Lozada y se busca alcanzar la reconciliación nacional por medio de un referéndum, lo cual proporciono confianza en la democracia por parte de la sociedad boliviana. Bolivia debido a su complejidad debe ser evaluada cuidadosamente, tomando en consideración el contexto en el que sedan estos cambios.

\subsubsection{Brasil}

El caso brasileño es esencial a la hora de referirnos a la implementación de políticas sociales en la región, posee la mayor extensión demográfica y territorial, aspectos que no pueden compararse con ningún otro país suramericano. Dentro de las principales tendencias en los gobiernos que siguieron al proceso de democratización están la gran inestabilidad de los programas sociales, falta de mecanismos de control eficientes, desvío de recursos, prácticas populistas tales como el "clientelismo"104, así como la falta de un diálogo directo entre los formuladores de política y los receptores.

Durante los años noventa se dieron una serie de reformas consecuencia de la nueva constitución, entre ellas la descentralización y la reformulación en la prestación de servicios

\footnotetext{
104 toda relación clientelar "es personalizada porque (...) los patrones y los clientes no están interesados en la igualdad y las reglas universales sino en personas (...) promueven (...) situaciones de favoritismo mediante el desvío de recursos públicos" (FARINETTI, 2000)
} 
sociales, esto se da en paralelo con un escenario en el cual se mantienen/amplían las brechas sociales ${ }^{105}$, de esta forma:

"Puede afirmarse, entonces, que en el país predomina un patrón de políticas sociales que, a pesar del carácter masivo de sus programas', excluyó dc sus beneficios a una parte significativa de la población, principalmente los trabajadores rurales y las poblaciones urbanas pobres, o sea casi la mitad de la población económicamente activa, vinculada en forma precaria al mercado de trabajo." (DRAIBE; ARRETCHE, 1995, p. 100-101)

A inicios de los noventas el gobierno de Collor se caracterizó por la falta de estructura en la implementación de políticas sociales así como la extinción de varios programas, presentando elevados niveles de corrupción. Durante el gobierno de Itamar Franco se buscó ejecutar algunos de los programas abandonados, lo cual fue realizado "en el ámbito del nuevo plan de estabilización, el Fondo Social de Emergencia, posiblemente con objetivos de equilibrio fiscal más que propiamente sociales" (idem).

De acuerdo con Almeida Tavares (2005) existen dos factores principales que crean este contexto favorable al regreso de políticas sociales, en primer lugar la estabilidad monetaria como consecuencia del Plano Real, lo cual generó mayores recursos para la diversas áreas entre ellas la social y en segundo lugar un "aprendizaje institucional" que promueve los procesos de descentralización y el diálogo entre los diversos niveles de gobierno para proporcionar bienestar social.

El gobierno de Henrique Cardoso se caracterizó por una serie de cambios estructurales en la dimensión social, las características principales de su política social fueron definidas en un documento denominado "Una estrategia de Desarrollo Social" (1996) ${ }^{106}$, que reflejaba las propuestas y sus límites, entre ellos alcanzar niveles sustentables de crecimiento y la mejora de la distribución de renta, entre otros factores, de acuerdo con Draibe (2003) la política social a la cual se refiere el documento buscaba garantizar una serie de aspectos tales como el derecho social, la promoción de la igualdad y la protección de los grupos vulnerables, como colocado en el documento estas estaban dirigidas:

"más directamente para políticas de bienestar y promoción social que son - de acuerdo con la tradición internacional- las áreas de educación, salud y nutrición, seguridad social y seguro-desempleo, trabajo, viviendas y saneamiento (....) La Inspiración, se puede afirmar que es social-demócrata y el horizonte, más que el Estado, es de una sociedad de bienestar, para la cual se pretende caminar, plan donde se

\footnotetext{
${ }^{105}$ IDH se reduce de 0,784 (1990) a 0,730 (1993)

${ }^{106}$ Ver: Uma estratégia de desenvolvimento social. Brasília. Disponível en: http://www.planalto.gov.br/publica.htm.
} 
articulan los objetivos de la política social y de la consolidación democrática" (Presidencia de la República de Brasil apud (DRAIBE, 2003)

Se definieron tres grupos de políticas sociales aquellas que comprendían los Servicios Sociales básicos universales y de responsabilidad pública, para el cual se buscaba una restructuración mejorando su efíciencia y calidad, en segundo lugar los programas básicos, dentro de los cuales se encuentran la Reforma Agraria, la educación básica, entre otros, fueron definidos 45 programas "seleccionados por su carácter prioritario, seleccionados por su carácter estratégico frente a la pobreza” (Ídem) y por último los Programas para enfrentar la pobreza, para esto se reforzó la idea de descentralización por medio de la cooperación entre el gobierno central, los estados, municipios y la sociedad civil por medio del programa "Comunidad Solidaria" como guía principal.

Tabla 19: Gobierno FHC, estrategia de Desarrollo Social

\begin{tabular}{|l|l|l|}
\hline Objetivos & Condiciones Necesarias & Desafíos \\
\hline -Garantia de los Derechos & -Estabilidad Macroeconómica & -Crecimiento económico \\
Sociales & -Reforma del Estado & -Generación de empleo \\
-Igualdad de Oportunidades & -Reanudación del Crecimiento & -Mejora en la distribución de \\
-Protección a los grupos & Económico & renta \\
vulnerables & -Reestructuración de los & \\
& programas sociales universales & \\
\hline
\end{tabular}

Fuente: (DRAIBE, 2003)

Es importante resaltar que se ejecutó una reforma del sistema de seguridad social, se amplió y reforzó la red de protección social por medio de la creación de una serie de programas dirigidos a la población más pobre usando la transferencia de renta con retorno a través de contrapartidas por parte de los beneficiarios como el mecanismo de ejecución, entre los principales tenemos:

"Beca-escuela, Erradicación del Trabajo Infantil (PETI), Beca-Alimentación, Auxilio Gas, Agente Joven, Programa de Salud de la Familia, Programa de Apoyo a la Agricultura Familiar y el Proyecto Alvorada para los 2361 municipios donde era mayor la proporción de brasileros situados abajo de la linea de pobreza" (ALMEIDA TAVARES, 2005, p. 4, traducción libre del autor ${ }^{107}$ )

\footnotetext{
107 Texto original: "Bolsa-Escola, Erradicação do Trabalho Infantil (PETI), Bolsa-Alimentação, Auxilio-Gás, Agente Jovem, Programa de Saúde da Família, Programa de Apoio à Agricultura Familiar, além do Projeto Alvorada para os 2.361 municípios onde era maior a proporção de brasileiros situados abaixo da linha da pobreza"
} 
A su vez se realizó una reforma de la seguridad social que buscaba corregir las distorsiones identificando al gobierno con los socialmente excluidos, siendo bien recibida por los actores internacionales. Con la finalización del gobierno Cardoso, de acuerdo con (VARGAS FAULBAUM, 2014) se observó que desde la década de los 80 hasta ese momento, se había ejecutado la reproducción de las experiencias exitosas en América del Sur por medio de los Fondos de Inversión Social ${ }^{108}$, proceso que culminó, con el lanzamiento del programa "Comunidad Solidaria"109.

Dentro de los grandes avances encontramos el refuerzo de las políticas universales, tanto dentro del área de la salud como de la educación, buscando la igualdad en el acceso de los ciudadanos. En ambos gobiernos de Cardoso, aun con las reformas estructurales y el esfuerzo gubernamental, se observa la continuación de procesos con rasgos ineficientes, resultando en mejoras de los indicadores sociales pero continuando con profundas brechas sociales.

En el año 2003, comienza el gobierno Lula que da continuación a la visión social de Cardoso pero cambia su forma de ejecución reforzando programas asistenciales, dirigidos a los más pobres, como el FUNDEB y PROUNI en términos de educación, el SUS en la área de la salud, "Bolsa-Familia" y el "Fome-zero" considerados como los más importantes de esta administración, los cuales fueron reconocidos por actores internacionales como marcos de referencia en términos de política social.

El programa "Fome-zero", era coordinado por el Ministerio Especial de Seguridad Alimentar (MESA) que posteriormente entró a formar parte del Ministerio de Asistencia Social, fue mucho más centralizado que otros programas, estaba compuesto por varios ejes de acción transferencias monetarias a través de la Tarjeta-Alimentación (que posteriormente entró en el programa Bolsa-Familia). Es una estrategia que busca garantizar el derecho humano a una alimentación apropiada, disminuyendo la pobreza extrema y generando inclusión social (GRAZIANO DA SILVA; DEL GROSSI; GALVÃO, 2010).

El programa Bolsa-familia fue implementado para auxiliar a las familias en situación de pobreza extrema, coordinando políticas intersectoriales, tres programas implementados durante el gobierno de FHC se unificaron el Bolsa-Escola, Bolsa-Alimentação e Auxílio-Gás, este

\footnotetext{
108 "Los fondos de inversión social han sido concebidos como intermediarios financieros cuyo objetivo primordial es evaluar y supervisar los proyectos. El diseño y la ejecución de éstos se entrega al sector privado y a los ministerios pertinentes. La cartera de proyectos se determina de acuerdo con las solicitudes de las comunidades y de las organizaciones no gubernamentales o, en algunos casos, por los organismos estatales" (SIRI, 1996)

109 "Propuesta del gobierno federal en colaboración con tres niveles de gobierno- federal, estatal y municipal- y la sociedad en sus diversas formas de organización y expresión. Pretende ser una estrategia de articulación y coordinación de acciones de gobierno en la lucha contra el hambre y la pobreza" (DRAIBE; ARRETCHE, 1995)
} 
programa se dirige a familias con perfiles caracterizados por la vulnerabilidad/pobreza extrema, es importante resaltar que además del impacto dentro de los núcleos familiares este tipo de programa genera un movimiento de la economía en la región en la cual se implementa.

Este programa sufrió reformas posteriores a su implementación estableciendo las transferencias condicionadas, así como una mayor transparencia por medio de nuevos mecanismos de gestión y la ampliación de su extensión de forma evolutiva, de acuerdo con el IBGE las familias beneficiarias superan los 11,2 millones (CARVALHO LOPES, 2005).

Los Programas implementados durante el gobierno Lula impactaron los indicadores sociales, aún cuando se observa una continuación de los bolsones de pobreza y las grandes brechas sociales, hubo una reducción considerable, como colocado por Neri et al (2012):

"Como consecuencia del mantenimiento de crecimiento con reducción de desigualdad, la pobreza también continúa su tendencia decreciente, que se produce desde 2003, cuando el número de pobres, según la línea de la FGV de R\$ 151 mensuales era de 49 millones de personas (....) .En la totalidad de la era Fernando Henrique Cardoso, se produjo una caída del 31\%, incluyendo los efectos de la estabilización monetaria. Desde el advenimiento del Real hasta el final de la década pasada, marcó del fin de la Era Lula, el índice de pobreza cayó 67\%." (NERI et al., 2012)

Evaluando las políticas implementadas desde la década de los años noventa, en la dimensión social, se observa que Brasil tuvo avances importantes principalmente a través de los programas que usaban como mecanismo las transferencias condicionadas, el impacto de las mismas es innegable. A diferencia de otros países de la región suramericana desde Cardoso hasta Lula se trató de dar "continuidad de las políticas sociales y macroeconómicas" (idem), lo que ha tenido un impacto positivo en el desarrollo de la dimensión social.

La cohesión social interpretada por medio del indicador "Nivel de Dificultad" (BTI), tuvo una amplia mejora dentro del período evaluado, lo cual se refleja de forma proporcional en el indicador Calidad de la Democracia, como puede ser observado a continuación:

Tabla 20: Brasil: Relación Cohesión Social/ Calidad de la Democracia

\begin{tabular}{|l|l|l|l|l|l|l|}
\hline Años & 2003 & 2006 & 2008 & 2010 & 2012 & 2014 \\
\hline $\begin{array}{l}\text { Nivel de } \\
\text { Dificultad }\end{array}$ & 5,0 & 3,6 & 3,6 & 3,4 & 3,6 & 3,4 \\
\hline $\begin{array}{l}\text { Calidad de la } \\
\text { Democracia }\end{array}$ & 7,20 & 7,90 & 7,95 & 8,20 & 8,15 & 8,15 \\
\hline
\end{tabular}


Fuente: Transformation Index, 2015

La evolución presentada por Brasil refleja el impacto que tienen las políticas sociales implementadas de forma sólida y continua en términos de cohesión, se observa la puntuación más elevada en el 2003 con 5,0 y al finalizar el período evaluado vemos una mejora hasta 3,4, lo que se ve acompañado por una mejora de la calidad de la democracia de 7,20 en el 2003 hasta 8,15 en el 2014, teniendo su mejor puntuación en el 2010 con 8,20 en paralelo con la mejor puntuación en el nivel de dificultad con 3,4. El caso brasilero refleja de forma palpable nuestra hipótesis de que existe un impacto de la cohesión social en la calidad democrática.

\subsubsection{Chile}

Chile es un país que ha pasado por grandes transformaciones en términos sociales, de acuerdo con (TIRONI, 2007) históricamente mantuvo un modelo de cohesión social de corte marcadamente "europeo-continental", por medio de un estado que permea todas las esferas públicas, con instituciones democráticas y partidos políticos fuertes, así como una política de industrialización y de protección de la industria nacional. El golpe militar trajo con Pinochet la implantación de un "modelo autoritario liberal excluyente""110 (CASTELLS, 2005) caracterizado por la reversión del intervencionismo del Estado "al costo de una desigualdad social galopante, la economía se internacionaliza y desarrolla, la sociedad se estabiliza y el ingreso y el consumo comienzan a crecer sostenidamente" (TIRONI, 2007).

Después del Régimen Militar, se establece un nueva fase tanto en términos políticos, económicos y sociales "la Concertación ha reintroducido algunos principios del Estado benefactor, como la igualdad, la protección social, la cultura pública y la ciudad democrática, pero sin alterar la naturaleza del modelo imperante"(idem). Durante el primer gobierno democrático del Presidente Patricio Aylwin (1990-1994), se buscó compatibilizar una economía capitalista de libre mercado, en conjunto con un equilibrio macroeconómico, buscando las mejoras de las condiciones distributivas y el combate a la pobreza, cambiando las prioridades y los contenidos (FARÍAS, 2013).

El gasto social se subdivide en tres grandes categorías como colocado por (TOMEI, 1997), la "red asistencial" que fue denominada de esta forma ya que está estructurada en ayuda monetaria canalizada a los grupos que se encuentran en situación de extrema pobreza, en

110 "Prioriza los mecanismos de mercado sobre los valores de la solidaridad social, sin aplicar políticas públicas correctoras de las desigualdades y de los privilegios de las élites sociales y económicas" (CASTELLS, 2005, p. 10) 
segundo lugar los "subsidios laborales" para complementar los salarios básicos de los trabajadores, y finalmente la "red social" que se refiere a los gastos realizados por los Ministerios de Salud, Educación y Vivienda.

De acuerdo con (RACZYNSKI, 1994), las prioridades por parte del Estado Chileno recayeron sobre la inversión del capital humano, apoyando las actividades productivas de pequeña escala, así como la mejora de la situación laboral de los trabajadores, principalmente en las regiones más pobres del país. En lo que se refiere a la asistencia social individual, por medio de programas de transferencia se estableció que este tipo de ayuda solo sería otorgada a hogares extremadamente pobres.

La política social en esta nueva fase adquiere un perfil más complejo expandiendo en un $20 \%$ el gasto fiscal social, siendo abordados nuevos temas de la agenda social tales como la calidad de la educación, capacitación laboral y el apoyo productivo, a su vez se ampliaron los grupos destinatarios, creando nuevas instituciones entre las que se encuentran el Servicio Nacional de la Mujer (SERNAM), el Instituto Nacional de la Juventud (INJ) y la Corporación Nacional de Desarrollo Indígena (CONADI) (Idem).

La implementación de programas sociales surge como una consecuencia de la deuda social, buscando de esta forma eliminar las desigualdades sociales que resultaron en procesos de exclusión, en este sentido, se reivindica la acción del Estado como ente regulador y se introduce el concepto de vulnerabilidad como principal criterio orientador de las políticas sociales (MIDEPLAN apud TOMEI, 1996).

Los principales programas implementados por parte del gobierno chileno durante los años noventa buscaban, combatir los procesos que reproducen la pobreza, entre los principales estaban el Programa de Mejoramiento de la Calidad y Equidad de la Educación Básica el cual contó con el apoyo del Banco Mundial, siendo la prioridad por su implicación en el alcance del desarrollo, así como el Programa de Capacitación Laboral de Jóvenes "Chile Joven”, y finalmente el Programa "Entre Todos", del Fondo de Solidaridad e Inversión Social (DRAKE; JAKSIC, 1999)

Otros programas relevantes dentro de la dimensión social fueron Chile Barrio ${ }^{111}$, implementado en 1997 durante el gobierno de Eduardo Frei (1994-2000), que tenía como

\footnotetext{
${ }^{111}$ Su objetivo fundamental es "contribuir a la superación de la pobreza de los habitantes de asentamientos precarios identificados en el Catastro Nacional de Asentamientos Precarios, poniendo a su disposición alternativas para un mejoramiento sustancial de su situación residencial, de la calidad de su hábitat y de sus oportunidades de inserción social y laboral" (D.S. N²0. MINVU /1998).
} 
objetivo enfrentar los problemas de marginalidad social y económica (SABORIDO, 2005) (FARÍAS, 2013). Los programas implementados durante el gobierno de Ricardo Lagos (20002006), tales como el programa Orígenes que "tenía el propósito de mejorar las condiciones de vida y promover el desarrollo con identidad de los pueblos aymara, atacameño y mapuche en el área rural, en los ámbitos económico, social, cultural y ambiental” (BID, 2014) y Chile Solidario que tuvo como objetivo modificar las condiciones de vida de familias viviendo en pobreza extrema por medio de un bono de carácter transitorio. ${ }^{112}$

Un gran avance de los programas sociales durante los años noventa, es que establecieron las bases de colaboración entre organismos públicos e instituciones privadas y organizaciones no gubernamentales, podemos decir que tanto los programas implementados como la nueva estructura dio paso a un papel protagónico de la política social mejorando en consecuencia la calidad de vida en las regiones más pobres.

Chile ha sido uno de los pocos países que colocó énfasis en una estrategia de crecimiento con equidad por medio de la inversión en programas sociales y durante los 90 , de acuerdo con (FARÍAS, 2013) el gasto social prácticamente se triplicó, pero fue poco efectivo en el alcance de "la superación de la pobreza, la reducción de la vulnerabilidad, la mayor igualdad de oportunidades y la reducción de la desigualdad del ingreso" (Idem).

De acuerdo con la Encuesta $\mathrm{CASEN}^{113}$ entre 1990 y 2003 el empleo acumuló un crecimiento de $33 \%$, mientras que los salarios reales se reajustaron en alrededor 17 de un 50\%, en paralelo con un crecimiento del PIB, por otro lado el porcentaje de personas en pobreza disminuyó considerablemente en el país, desde un nivel de $45 \%$ en 1987 a un $18,8 \%$ en el año 2003 (LARRAÑAGA, 2007), datos fundamentales a la hora de evaluar la cohesión social por medio de la efectividad de las políticas a través de programas específicos.

La actual política social Chilena surge como consecuencia de las complejas dinámicas políticas, los gobiernos de Concertación como se puede observar en este análisis han incrementado gasto social por medio de diversos programas de desarrollo social con un enfoque en lo que se refiere a grupos vulnerables. De acuerdo con Larrañaga (2007) la desigualdad se mantiene por tres características "una desigual distribución de los ingresos del mercado a nivel de

\footnotetext{
112 "Chile Solidario incluye un componente de apoyo psico-social que acompaña por un período de dos años a las familias participantes, facilita el acceso de los usuarios a la oferta tradicional de programas asistenciales y sectoriales, modificando las condiciones de vida de las 225.000 familias más pobres del país" (año 2005) (FARIAS, 2013)

${ }^{113}$ Ver: http://observatorio.ministeriodesarrollosocial.gob.cl/casen/casen_usuarios.php
} 
perceptores individuales; un patrón de conformación de los hogares que exacerba la desigualdad de los ingresos individuales; y la escasa acción redistributiva por parte del Estado”.

La reducción de la pobreza ha sido impactada profundamente por la formación de capital social esto puede interpretarse a través de tres ejes de políticas sociales, en primer lugar programas que tienen la promoción de la educación como foco, en segundo lugar el acceso de servicios sociales a grupos mayoritarios de la población que históricamente estuvieron excluidos y por último la promoción de las culturas originarias, en este sentido vemos que la cohesión social chilena por medio del indicador Nivel de Dificultad (BTI) refleja estos avances:

Tabla 21: Chile: Relación Cohesión Social/ Calidad de la Democracia

\begin{tabular}{|l|l|l|l|l|l|l|}
\hline Años & 2003 & 2006 & 2008 & 2010 & 2012 & 2014 \\
\hline $\begin{array}{l}\text { Nivel de } \\
\text { Dificultad }\end{array}$ & 4,0 & 3,4 & 2,4 & 2,2 & 2,0 & 2,2 \\
\hline $\begin{array}{l}\text { Calidad de la } \\
\text { Democracia }\end{array}$ & 9,60 & 9,10 & 9,30 & 9,30 & 9,30 & 9,10 \\
\hline
\end{tabular}

Fuente: Transformation Index, 2015

En términos de cohesión se observa un desarrollo positivo durante el período evaluado reduciéndose el Nivel de Dificultad de 4 en el 2003 a 2,2 en el 2014, alcanzando su menor puntuación en el 2012. La calidad democrática también presenta características positivas reflejando un indicador superior a 9,10 durante todo el período evaluado, presentando una estabilidad entre el 2008 y el 2012 en 9,30.

Chile cuenta con una estrategia social coherente en términos estructurales, aspectos que se observan en la disminución progresiva y continua del Nivel de Dificultad. A partir de los años 90 se respaldaron programas sociales necesarios para la disminución de la exclusión, enfrentando los desafíos que implican una mejora en la calidad de vida de la población. En términos regionales, Chile se caracteriza como un país que se expande progresivamente a la promoción de la inclusión avanzando en las dimensiones que conforman la cohesión social.

\subsubsection{Colombia}

La situación colombiana es compleja, a diferencia de los otros países de la región suramericana, se desarrolla un conflicto armado desde los años sesenta afectando todas las 
dimensiones vinculadas a la sociedad, tanto la política, económica como social, presentando momentos de mayor y menor intensidad. Este escenario afecta a los sectores más excluidos en todo el país, pero principalmente en las regiones donde continúa la violencia armada, generando limitaciones en lo que se refiere al avance de la política social y el sentido de cohesión de la ciudadanía.

La década de los noventa, se caracterizó por la implementación de transformaciones estructurales, este tipo de reformas reflejaban los cambios que se realizaron en paralelo en diversos países suramericanos, fundamentados en políticas destinadas a aliviar la pobreza por medio de tres componentes básicos, eliminar el desempleo a través de la industrialización sustitutiva de importaciones, la promoción de las migraciones del campo a las ciudades buscando el aumento de la fuerza de trabajo y la redistribución de la tierra no utilizada, así como el aumento de los créditos y recursos para los pequeños propietarios de tierras ((OECD, 2013) .

Durante el gobierno de César Gaviria (1990-1994) se realiza la Asamblea Nacional Constituyente en 1991, la Constitución aprobada de acuerdo con (VILLAR, 2001) definió cambios en todas las esferas de la vida pública, elevando a rango constitucional un amplio conjunto de derechos civiles, económicos, sociales y culturales, y amplió los mecanismos de participación,. Durante el gobierno de Ernesto Samper (1994-1998), se genera una crisis de gobernabilidad originada por acusaciones de vínculos financieros con el narcotráfico, contexto que desvió el esfuerzo por parte del gobierno en la dimensión social. A finales de los años noventa Colombia experimentó su mayor crisis económica en setenta años, el PIB cayó 4,3\% y se dio un aumento en la intensidad del conflicto armado (RAMÍREZ, 2002).

En este contexto de crisis, las reformas para mejorar las condiciones sociales tuvieron retos importantes, se priorizó la descentralización, enfocándose en áreas tales como salud, educación, vivienda y servicios públicos. Se implementaron un conjunto de leyes para modificar los mecanismos para ejercer los derechos sociales, la Ley 60 en términos de educación que establece el proceso de descentralización y ejecución de esta área, la ley 115 de 1994 en donde se consagró el derecho de las personas a acceder a la educación y el Estado asumió la responsabilidad de garantizar la calidad y la prestación del servicio, la Ley 100 de 1993 reformó el sistema de seguridad social (ídem).

En el año 2000 se establece la Red de Apoyo Social (RAS), que tenía como objetivo disminuir el impacto de la crisis en los grupos más pobres y vulnerables, por medio de tres programas el 1) Jóvenes en Acción, que proporcionaba capacitación para el trabajo, 2)Empleo en 
Acción, constituido como un programa de empleo temporal y 3) Familias en Acción, que se enfoca en dar un apoyo a las familias en condiciones de pobreza a mantener condiciones dignas de vida (MÉNDEZ; CUESTA, 2002).

Es importante resaltar que el programa "Familias en Acción", en sus inicios fue concebido como una medida de choque a la crisis de 1999, posteriormente fue interpretado como una estrategia a largo plazo, para reducir la pobreza e incrementar el capital humano, convirtiéndose en una política gubernamental central y ampliando su extensión debido a los resultados positivos que fueron alcanzados.

Es importante establecer dos consideraciones al respecto de este programa, en primer lugar no se adoptaron medidas para que este programa tuviese una interacción con otros programas sociales, demostrando la falta de articulación y en segundo lugar este programa representó una nueva comprensión del papel del estado en el proceso de desarrollo, pasando de un gasto estatal desde un enfoque top-down, en su lugar se implementaron órdenes maleables (OECD, 2013).

El estado colombiano contemporáneo se ha caracterizado por el cambio en su estrategia de desarrollo, por medio de reformas constitucionales, cambios dentro de sus instituciones gubernamentales así como la aplicación de programas sociales de transferencia, que buscaron la disminución de las brechas sociales. Esto se realizó por medio de un incremento en el gasto social, la descentralización y cumplimiento de una serie de derechos económicos, sociales y culturales dirigidos a la población históricamente excluida a través de la transferencia directa de dinero.

En este sentido, Colombia tuvo avances incuestionables en lo que se refiere a el acceso a la educación, con un foco en la educación básica, el área de la salud y el acceso a los servicios básicos, los programas que implementan las transferencias monetarias condicionadas han tenido un papel prioritario, como la forma más efectiva de canalizar los servicios a los sectores en donde se presentan las mayores desigualdades. En definitiva la revisión histórica de la implementación de políticas sociales en Colombia durante las últimas dos décadas, nos permite evaluar el impacto que estas tuvieron en los niveles de cohesión:

Tabla 22: Colombia: Relación Cohesión Social/ Calidad de la Democracia

\begin{tabular}{|l|l|l|l|l|l|l|}
\hline Años & 2003 & 2006 & 2008 & 2010 & 2012 & 2014 \\
\hline Nivel de & 8,0 & 6,2 & 5,4 & 5,6 & 5,6 & 5,4 \\
\hline
\end{tabular}




\begin{tabular}{|l|l|l|l|l|l|l|}
\hline Dificultad & & & & & & \\
\hline $\begin{array}{l}\text { Calidad de la } \\
\text { Democracia }\end{array}$ & 5,20 & 5,85 & 5,75 & 5,95 & 6,05 & 6,55 \\
\hline
\end{tabular}

Fuente: Transformation Index, 2015

Como podemos observar en nuestra evaluación del indicador, Colombia es el país que presenta la mayor caída en términos estadísticos del Nivel de Dificultad, demostrando el efecto profundo que tuvieron las inversiones en términos sociales dentro del territorio colombiano, aun con estas mejoras sustanciales es el segundo país con los niveles mas elevados de Nivel de Dificultad (después de Paraguay) para el año final de nuestra evaluación, demostrando que las políticas sociales estructuradas tienen un efecto profundo en los niveles de cohesión, aun dentro de un contexto de conflicto. Lo cual también se ve reflejado en el indicador Calidad de la Democracia que tuvo un incremento de 5,20 en el 2003 a 6,55 en el 2014, de forma progresiva.

\subsubsection{Ecuador}

Evaluar la dimensión social ecuatoriana implica considerar distintos momentos que afectaron la articulación política y económica. Ecuador posee una gran diversidad étnica en paralelo con profundas desigualdades históricas. Es un país en el cual el gasto social no ha sido un área prioritaria, la implementación de políticas redistributivas siempre estuvo en un segundo plano posterior a la aplicación y estructuración de los ajustes económicos (VOS, 2002). En este sentido se observa que con el paso de distintos gobiernos, se trataron de implementar diversas reformas para el desarrollo de la sociedad pero no se dio una concretización de políticas macroeconómicas necesarias a largo plazo para generar estabilidad.

Durante las últimas décadas Ecuador paso por momentos graves de crisis económica, política y social, el primero de 1989 a 1992 cuando son implementados ajustes macroeconómicos direccionados bajo la influencia de organismos financieros internacionales de gran impacto, bajo la idea de un Estado de Bienestar y del 1998 al año 2000 cuando se observó un incremento en los indicadores de desempleo, inflación, afectando de forma más profunda a la sociedad ecuatoriana (CORNEJO et al., 2003).

En este contexto de gran discontinuidad de las políticas públicas sociales, falta de consolidación de un sistema congruente con la realidad del país y de fuertes momentos de crisis, se ve profundamente afectada la capacidad de desarrollo del Estado. Las condiciones sociales de 
la población ecuatoriana fueron deteriorándose de forma acelerada a finales de los años noventa, los indicadores de pobreza reflejan la situación crítica de la sociedad ${ }^{114}$.

Durante la década de los noventa los actores internacionales tuvieron un papel relevante en la implementación de programas sociales, por medio de préstamos que de acuerdo con Vásconez et al (2005) buscaban responder a tres objetivos:

\begin{abstract}
"el de cohesión social o mejor dicho amortiguamiento de probables conflictos sociales, el de cumplimiento con algunas condicionalidades/recomendaciones de la cooperación internacional; y el de mantenimiento de índices mínimos de bienestar frente al ajuste económico (el gasto social ha tenido un carácter pro cíclico -mayor cuando hay mejores condiciones fiscales- suavizado en los últimos años gracias a movilización y procesos de abogacía por parte de ciertos grupos de la sociedad civil, las ONG y la cooperación)" (VÁSCONEZ; CÓRDOBA; MUÑOZ, 2005)
\end{abstract}

El gobierno de Luis Felipe Borja del 89 al 92, se caracterizó por modelo neoliberal con un contexto económico positivo expandiendo el gasto social como consecuencia del incremento en el gasto público, aun no siendo un objetivo directo de su gobierno, su sucesor Sixto Duran Ballen (92-96) se enfocó en la privatización, implementó una apertura en el diálogo con los pueblos indígenas aspecto que los gobiernos que le antecedieron no habían visto como un área relevante, aun cuando existen más de 200 grupos indígenas reconocidos por el gobierno de acuerdo con la CONAIE.

A su vez se creó el "Fondo Social de Emergencia", que buscaba mejorar la situación de pobreza a nivel nacional por medio de infraestructura física y social ${ }^{115}$, también se estableció una “Agenda para el Desarrollo", la cual tenía entre sus objetivos el desarrollo del bienestar social por medio de medidas asistencialistas pero sin una definición específica, a la par de una visión neoliberal de las políticas dentro de las cuales la privatización era el eje en conjunto con procesos de descentralización de la gestión social, de cierta forma las políticas sociales son delegadas, de acuerdo con Vasconez et al (2005, p. 45):

"Es a partir de este gobierno que se hace más evidente la injerencia o transferencia de políticas desde la banca de desarrollo. A la hora de los pronunciamientos a favor o en contra de la Agenda, se visualizan posicionamientos como el del Banco Mundial y el BID, quienes además de proporcionar apoyo técnico, "premian al gobierno", como la AID que otorga 12 millones de dólares para el fondo social".

\footnotetext{
114 Base de datos del Banco Mundial ver http://data.worldbank.org/country/ecuador

115 "Durante la Fase 1 (1994-1998), 1926 del total de 4797 proyectos (con 777.354 o $23 \%$ del total de beneficiarios. Durante la segunda y actual fase, 229 de los 530 proyectos (esto es $43 \%$ ) se ejecutaron a la fecha en los cantones mas pobres; esto representa 154.321 beneficiarios o $22 \%$ del total de beneficiarios" (VOS et al, 2000)
} 
Durante el gobierno de Abdala Bucaram, se incrementa la política clientelista, se caracteriza por ser un gobierno populista y sin una política de estado concreta en términos sociales, "no se esboza una política de Estado para resolver los problemas de la pobreza. Su plan tiene un eje exclusivamente coyuntural que ni de lejos resuelve el problema de la pobreza, solo arregla el momento, no es de largo plazo, ni da garantías de continuidad" (Archivo de prensa, El Comercio, 1996-1997 apud Vasconez et al, 2005, p. 47).

El estilo político de Bucarán, así como la implementación de un modelo neoliberal, respondía a una estructura regional dejando de lado la realidad del país, esto generó una situación de inestabilidad dentro de la sociedad, la cual posteriormente llevó a su salida del gobierno. La dialéctica de su discurso iba en contra de las elites y de la estructura capitalista, además se abstiene de tomar una posición en lo que se refiere a los temas indígenas "continuando la posición racista de muchos otros políticos ecuatorianos" (De la torre, 1997)

El gobierno de Jamil Mahuad continuó las políticas neoliberales eliminando subsidios en la canasta básica de los ecuatorianos, lo que generó un rechazo por parte de la población, razón por la cual fue implementado un mecanismo de transferencia directa de recursos, a través del Bono Solidario creado como una herramienta de compensación por la pérdida de poder adquisitivo de sus salarios y por el alto nivel de desempleo imperante en este período (DOVROSKY; MONCAYO, 2007).

Para el año de 1999, Ecuador tenía una de las mayores concentraciones de riqueza en la región latinoamericana, el 10\% más rico de la población percibía casi 49 veces más ingresos que el 10\% más pobre (RIVIERA VELEZ, 2003). La profunda crisis económica y política del país resultó en la renuncia de Mahuad y la posesión de Noboa como presidente, el cual implemento un programa de protección social a través de 3 ejes principales el crédito productivo, la continuación del bono solidario y la beca escolar (ídem).

De acuerdo con Vasconez et al (2005, p. 51) el plan para estabilizar el escenario de crisis, estaba compusto por un conjunto de programas:

"Los pilares básicos de este programa fueron 1) Nutrición básica para todos los niños y mujeres embarazadas (...) 2) Atención materno infantil para todos los niños, madres y mujeres embarazadas, a través del MSP, MIDUVI, FISE y gobiernos locales, reorientando los recursos actualmente invertidos hacia las poblaciones más pobres. 3) Asistencia y permanencia en las escuelas, a través del MEC y el INNFA, con el apoyo de una Beca Escolar (...). 4) Participación de todos los sectores de la sociedad, a través de la creación del Fondo Nacional de Participación Social en el que se financiarían programas de capacitación y fortalecimiento de organizaciones comunitarias y Fondo Indígena. 5) Empleo emergente, a través de la provisión de empleo en inversiones y 
proyectos públicos, además de un programa de microcrédito para apoyar la economía popular".

Por medio de estas evaluaciones se observa que las políticas sociales implementadas durante este periodo no tenían una estructura de planificación, eran mas políticas de emergencia que respondían a un escenario específico, , generando una ampliación profunda de la desigualdad "los niveles de desempleo se elevaron entre 1997 y 1999 de 10\% a 16\%, y el subempleo llegó a cerca del $60 \%$ en este año, dado el cierre y el recorte presupuestario de muchas empresas" (Ídem)

Los gobiernos que precedieron a Noboa implementaron programas para enfrentar la pobreza, entre ellos el el Plan Social de mediano plazo 2001-2005, que establecían de acuerdo con (RIVERA VELEZ, 2003) varias áreas de acción:1) Programas de cuidado y nutrición infantil: Operación Rescate Infantil; Programa Nacional de Educación Preescolar Alternativa; Programa Nacional de Alimentación Escolar y el Programa de Alimentación Complementaria Materno-Infantil, 2) Educación: Proyecto de Desarrollo, Eficiencia y Calidad, Programa Redes Amigas y el Programa Niño Trabajador, 3)Salud: Proyecto de Fortalecimiento y Ampliación de los Servicios Básicos de Salud; el Programa de Inmunizaciones del Ministerio y el Programa de Maternidad Gratuita 4) Infraestructura social: Fondo de Inversión Social de Emergencia y 5) Transferencias monetarias a los hogares: se le dio continuación al bono solidario implementado desde 1998.

Las políticas públicas para combatir la exclusión y la pobreza de los grupos étnicos en el país han sido canalizadas a través de dos iniciativas estatales importantes, por una parte se encuentra el Proyecto de Desarrollo de los Pueblos Indígenas y Negros del Ecuador (PRODEPINE), financiado con un crédito del Banco Mundial, este fortalecimiento del tejido social contribuyó a sentar las bases para un desarrollo participativo a nivel nacional, hubo una consolidación de las organizaciones negras e indígenas (FIDA, 2008). En segundo lugar se implementó el Fondo de Desarrollo Indígena con el objetivo de canalizar recursos destinados a combatir las privaciones de los grupos indígenas; estructurado a partir de la representación directa de las organizaciones indígenas.

Un programa importante de acuerdo con Rivera Vélez (2003) fue el "Plan Social 20012005 para la Reducción de la Pobreza", que fue una referencia dentro de la dimensión social, articulando la política económica y la política social, por medio de la disminución en los niveles de desempleo, la calidad de la educación, entre otros aspectos, buscando ampliar el impacto de la 
inversión social en el desarrollo humano, pero su efectividad se vio afectada por los problemas presentados en la coyuntura política y económica.

Durante el gobierno de Correa, se establece mediante una serie de documentos gubernamentales la política social como un mecanismo orientado a crear "ciudadanía" por medio de un enfoque de derechos, siendo tanto sujetos como ejecutores (RAMIREZ GALLEGOS; MINTEGUIAGA, 2007), los principales programas implementados fueron la continuación del Bono de Desarrollo Humano (BDH), la reformulación del Programa Socio País incorporando subprogramas que plantean una conexión entre componentes sociales y económicos: "Hilando el Desarrollo" y "Nutriendo el Desarrollo" y finalmente el "Programa de Microcrédito Juvenil" a través del Banco Nacional de Fomento, se buscó la articulación entre lo económico y lo social por medio de tres programas: "Negocios Sociales Inclusivos", el "Plan de Intervención Territorial Integral" y el "5-5-5", que busca beneficiar a pequeños productores que no han podido acceder al crédito de la banca privada (ídem, p. 91) .

Es necesario establecer una serie de elementos estructurales que han dificultado el desarrollo exitoso de las políticas sociales en Ecuador, principalmente durante el gobierno de Correa, las leyes que establecen los marcos para ejecución del gasto público en alrededor del 90\% del presupuesto, corresponde a proyectos establecidos previamente, dándole continuidad a una burocracia estatal caracterizada por una política que favorece conservadurismo del cargo, presentando una ausencia de meritocracia así como de programas de capacitación profesional y en tercer lugar las grandes dificultades para abandonar la política social como una herramienta de clientelismo político (ALBORNOZ; OLEAS, 2007)

Por medio de esta revisión podemos decir el Estado como promotor de Bienestar ha enfrentado grandes dificultades consecuencia de la falta de reformas que se planteen la necesidad de continuación a través del tiempo y de acuerdo con Ramírez Gallegos y Minteguiaga (2007) al hecho de que fueron asumidos una serie de compromisos financieros con organismos internacionales que afectaron la forma en que se distribuyó el gasto. El gasto social solo se vio incrementado a finales de los años 2000 como consecuencia de los recursos provenientes del aumento del petróleo (ídem). ${ }^{116}$

\footnotetext{
${ }^{116}$ Mientras en el 2006 el gasto social como porcentaje del presupuesto del Estado era de 25,2\%, en el 2007 fue de $27,6 \%$ y en la proforma presupuestaria enviada al Congreso para el 2008 es de 30,7\% (Datos tomados del presupuesto publicado en el Registro Oficial y del Ministerio de Economía y Finanzas, proforma 2008 apud MINTEGUIAGA, 2007).
} 
Los indicadores de cohesión social reflejan el impacto que tuvo la coyuntura económica y política en su desarrollo, posterior a la llegada de Rafael Correa en el gobierno se observa una mejora consistente producto del incremento del gasto social, aspectos que se vieron continuados hasta el último periodo de análisis como se observa a continuación:

Tabla 23: Ecuador: Relación Cohesión Social/ Calidad de la Democracia

\begin{tabular}{|l|l|l|l|l|l|l|}
\hline Años & 2003 & 2006 & 2008 & 2010 & 2012 & 2014 \\
\hline $\begin{array}{l}\text { Nivel de } \\
\text { Dificultad }\end{array}$ & 5,0 & 5,2 & 5,2 & 4,8 & 4,8 & 4,6 \\
\hline $\begin{array}{l}\text { Calidad de la } \\
\text { Democracia }\end{array}$ & 6,80 & 6,20 & 6,15 & 5,90 & 5,70 & 5,70 \\
\hline
\end{tabular}

Fuente: Transformation Index, 2015

Vemos que la disminución se dio de 5,0 en el 2003 a 4,6 en el 2014, esto es un reflejo de la importante inversión social realizada en el país en conjunto con la disminución de la exclusión y la prioridad dada a las minorías étnicas. El caso de la calidad democrática es atípico, ya que presento una disminución progresiva de 6,80 en el 2003 a 5,70 en el 2014, esto es un reflejo de los profundos niveles de polarización social dentro de la sociedad en términos políticos.

\subsubsection{Paraguay}

El Paraguay es un país con una gran deuda social en lo que se refiere a la cobertura de servicios básicos, principalmente a la población que se encuentra en estado de pobreza. Este contexto requirió de nuevas respuestas a la cuestión social en lo que se refiere a los programas y el número de beneficiarios que acceden a los mismos, así como la prioridad que alcanza la participación ciudadana en el control y la formulación programas vinculados al área social.

La pobreza y la desigualdad en el Paraguay tienen múltiples causas, de acuerdo con (IMAS, 2007) los elementos que explican esta situación se vinculan a factores territoriales por medio de la concentración rural de la pobreza, aspectos socioeconómicos, subjetivos y/o culturales (procesos de exclusión de la niñez, mujer y los guaraní hablantes); ineficiencia e ineficacia institucional por la implementación de políticas sectoriales fragmentadas, un modelo de Estado económico excluyente, de baja presión tributaria, capacidad regulatoria y un contexto político con características clientelistas. 
El escenario paraguayo durante los años noventa se caracterizó por momentos de cambios profundos en las estructuras económicas, se realizaron una serie de acciones de oposición a las políticas neoliberales por parte de la sociedad, principalmente el sector agrario vinculado a la producción de soya, buscando en definitiva una reforma justa en el principal sector productivo del país (GARCÍA-LÓPEZ; ARIZPE, 2010).

Los movimientos sociales tuvieron un papel importante durante este periodo, lo que generó una respuesta por parte del estado como la creación de instituciones como la DIBEN, esta organismo en conjunto con otros surgen como respuestas estatales al escenario de desigualdad social, con metodologías de corte participativo y visión asistencialista, la cual se sumaba a otras instituciones ya existentes, enfrentando problemas de desarticulación por parte de los organismos responsables de accionar las medidas sociales (idem).

A mediados de los años 90 se crea la Secretaría de la Mujer, la Secretaria Nacional de Niños y Adolescentes y Secretaria de Acción Social, esta última institución fue creada siguiendo la línea estructural de los modelos de asistencia e intervención producidos por los organismos internacionales, buscando articular institucionalmente las acciones del Estado, los Partidos Políticos y la Sociedad Civil, en torno a una Política Social que buscaba promover una mayor equidad social, esto "por medio del desarrollo sostenido del capital social, un orden económico más justo y un sistema de protección y promoción social" (SECRETARIA DE ASUNTOS SOCIALES DEL PARAGUAY, 2015).

La reforma educativa que se implementó desde 1994 , asigno un mínimo de $20 \%$ del presupuesto estatal para esta área generando un avance importante en los indicadores de acceso a la educación, sin embargo, no acompañado en igual medida por otras políticas como la atención a la salud, de reforma agraria, y de mercado laboral (IMAS, 2007).

Paraguay hasta finales de esta década atravesó una fuerte crisis económica que afectó el financiamiento de muchos de los programas de cuño social, el abordaje desde el Estado hacia la problemática social continuo siendo insuficiente y disperso, consecuencia de la desarticulación entre entes institucionales "cerca de 2 millones 557 mil paraguayos se encuentran en condiciones de pobreza, entre 1999 y 2003 la pobreza en Paraguay aumentó de 33,7 \% a 41,4 \% y la extrema pobreza de 15,5\% a 20,1\%" (DGEEC, 2013).

Siguiendo esta lógica diversos indicadores muestran una redefinición impuesta como consecuencia de la lógica neoliberal:

"se implementaron programas de lucha contra la pobreza focalizadas en los sectores vulnerables y la intervención estatal se retrae a través de estrategias básicas 
como por ejemplo la asistencia selectiva a los grupos de mayor marginación mediante servicios públicos de bajo costo y la privatización de la producción estatal de bienes y servicios que conduce a una disminución de la cobertura del sector público respecto al privado" (NUÑEZ, 2002)

Durante la Presidencia de Nicanor Duarte se realizaron una serie de reformas en conjunto con políticas sociales que impactan los indicadores de desigualdad del país, como el uso de recursos de las hidroeléctricas binacionales, Itaipú y Yacyretá, para crear fondos sociales con el objetivo de invertir principalmente en zonas rurales, dándole prioridad a la educación así como otras áreas vinculadas al desarrollo de servicios básicos. Otro programa relevante fue la implementación de transferencias condicionadas en forma experimental durante los años 20052008 en las zonas rurales del Paraguay, llegando a unas 14 mil familias, impulsadas en un primer momento por los organismos internacionales.

De acuerdo con el Banco Mundial (2012) durante el periodo 2000-2008 se alcanzaron mejoras en el bienestar social de la población, disminuyendo las tasas de pobreza y de desigualdad de ingreso, esto se debe a las mejoras en la coyuntura política y económica del país y al impacto que tuvieron diversos programas sociales durante esa década, esto se observa en las siguientes cifras:

"la clase media en Paraguay aumentó en un 45 por ciento pasando de 1 millón a 1.5 millones de personas en la última década y representando el $24 \%$ de la población para el año 2009 (....) .Para Paraguay, la clase media aumentó en ese periodo en casi 500.000 personas más, cifra que representa un crecimiento de 7.6 por ciento de la población total del país que han podido acceder a la clase media en la última década" (BANCO MUNDIAL, 2012)

En el año 2008 se da un cambio importante en términos políticos por medio de la alternancia del partido colorado con la llegada del gobierno de Fernando Lugo, de acuerdo con (GARCÍA-LÓPEZ; ARIZPE, 2010) se dieron algunos avances en la dimensión social como la ampliación del programa de transferencias monetarias con corresponsabilidad así como la implementación del programa Tekopora ${ }^{117}$ y Tekoha $^{118}$ como un programa de apoyo para dar

\footnotetext{
117 "El Programa contempla las Transferencias Monetarias con Corresponsabilidad (TMC), y el acompañamiento socio-familiar por parte de técnicos sociales denominados "Guías Familiares", quienes se encargan de visitar los hogares para verificar el cumplimiento de las corresponsabilidades por parte de las familias, y brindar orientaciones vinculadas preferentemente al mejoramiento del hábitat familiar, así como los hábitos de higiene, ideas y acciones para mejorar la calidad de alimentos y la salud, además de orientar a las familias al acceso de los diversos servicios públicos".(SAS, 2015)

118 "Fue creado por el Decreto N ${ }^{\circ} 1767 / 2009$ del 3 de abril. Es un Programa del Gobierno Nacional implementado por la Secretaría de Acción Social, a fin de apoyar al desarrollo social de núcleos poblacionales urbanos y suburbanos. Se configura como un conjunto de acciones jurídicas, urbanísticas, medioambientales y sociales con el
} 
respuesta a los problemas habitacionales, con una fuerte influencia de las agencias multilaterales en el diseño de dichas políticas sociales.

En términos de educación se establece la obligatoriedad y gratuidad a nivel de la Educación Media, así como becas en este nivel de formación (ídem). Un avance importante fue el reconocimiento a la diversidad lingüística por medio de la Ley de Lenguas (dentro del territorio paraguayo se hablan más de 20 lenguas indígenas), siendo oficiales el Español y el Guaraní, velando por la pluriculturalidad, resaltando el papel de la lengua guaraní, estableciendo que "deberá ser objeto de especial atención por parte del Estado, como signo de la identidad cultural de la nación, instrumento de cohesión nacional y medio de comunicación de la mayoría de la población paraguaya" (Ley de Lenguas. № 4251).

En 2008 se implementaron dos estrategias en términos de salud, la descentralización de los servicios y la aprobación de una política exhaustiva sobre atención sanitaria universal, , reformando de esta forma el Sistema Nacional de Salud ${ }^{119}$, sustentándose "en los principios de universalidad, equidad, integralidad, interculturalidad y participación social” (ISAGS, 2012) siendo un avance importante, principalmente para aquellos en situación de exclusión .

El gobierno de Lugo se constituye como un período de cambio político, que se caracterizó por reformas sociales redistributivas y un aumento de la participación ciudadana en la política, en detrimento de los partidos tradicionales, este cambio del status quo tradicional trajo una crisis política que derivó en su destitución, los gobiernos que le precedieron dieron continuación a los programas de este gobierno.

Tomando en consideración este análisis es necesario resaltar que Paraguay es un país que necesita expandir sus políticas sociales, principalmente los programas vinculados a servicios básicos y lucha contra la pobreza, buscando su integralidad, para establecer una coordinación efectiva. El histórico de la sociedad paraguaya está marcado por elevados niveles de desigualdad y pobreza y al igual que muchos otros países de América del Sur sufre de inestabilidad política y una inserción rezagada, dependiente del sistema económico mundial, lo cual afecta aún más a una sociedad sin las herramientas básicas para salir de este contexto de exclusión. Este contexto complejo se observa en los indicadores:

objetivo de mejorar la calidad de vida, dando atención integral a familias en situación de pobreza y pobreza extrema, mejorando su hábitat a fin de fortalecer el desarrollo y el arraigo familiar, además de facilitar el acceso a los servicios públicos básicos en condiciones medio ambientales favorables". (SAS, 2015)

${ }^{119}$ Políticas lideradas por el Ministerio de Salud Pública y Bienestar Social 
Tabla 24: Paraguay: Relación Cohesión Social/ Calidad de la Democracia

\begin{tabular}{|l|l|l|l|l|l|l|}
\hline Años & 2003 & 2006 & 2008 & 2010 & 2012 & 2014 \\
\hline $\begin{array}{l}\text { Nivel de } \\
\text { Dificultad }\end{array}$ & 6,0 & 5,0 & 5,0 & 5,2 & 5,6 & 6,0 \\
\hline $\begin{array}{l}\text { Calidad de la } \\
\text { Democracia }\end{array}$ & 5,60 & 6,60 & 6,75 & 7,00 & 7,00 & 6,55 \\
\hline
\end{tabular}

Fuente: Transformation Index, 2015

Paraguay es un país que refleja un contexto complejo en términos de cohesión social, entre el 2003 y el 2006 se produce la mejora más elevada en el indicador Nivel de Dificultad pasando de 6,00 a 5,00. En términos de calidad democrática, las mejoras en el Nivel de Dificultad acompañan a la calidad democrática con un aumento progresivo de 5,60 a 7,00 en el 2012, presentando una disminución en el 2014 a 6,55 que se vincula al aumento del nivel de dificultad en ese año.

\subsubsection{Perú}

Durante los años 90, se implementaron políticas drásticas de ajuste posteriores al consenso de Washington, con una gran influencia por parte del Banco Mundial y el BID en el diseño y la financiación de políticas, generando una reforma estructural profunda, incrementando las desigualdades ya existentes. Aun cuando se alcanzaron mejoras en términos macroeconómicos tales como una disminución de la inflación y crecimiento del PIB, se incrementaron las diferencias sociales "el $20 \%$ más rico de los peruanos concentra el $50 \%$ del ingreso nacional y el 20\% más pobre tiene escasamente el 5\% del ingreso" (BELLO, 2002)

La sociedad peruana atravesó un proceso de conflicto civil debido a la actuación por parte del Sendero Luminoso ${ }^{120}$ y las Fuerzas Armadas, generando un impacto profundo en los niveles de violencia. Para el año de 1992 durante el gobierno de Fujimori, este movimiento había perdido fuerzas, aun así las consecuencias fueron graves "el conflicto armado causó más de 25 mil muertes, 2 mil personas desaparecidas, 600 mil personas desplazadas de manera forzada, otros miles de niños huérfanos y decenas de ellos reclutados de manera forzosa por los grupos

\footnotetext{
120 "El Sendero Luminoso es una organización terrorista Marxista- Leninista en contra del gobierno de Perú y los Estados Unidos, que sigue las enseñanzas básicas de Mao Tse TUng y que alegadamente siguen las ideologías del Pol Pot's Khmer Rouge. A diferencia de las guerrillas peruanas de los años 60's que imitaban a Fidel Castro y al Che Guevara, los Sendero Luminoso proclamaban que los lideres por derecho del Perú eran los indios. Evoluciono de un grupo Maoista conocido como Bandera Roja que se dividió de la linea de Moscu en 1964". (MADRIGAL, 2012)
} 
armados" (BELLO, 2002), la recuperación de la sociedad peruana fue un proceso lento, dejando secuelas profundas producto de la fragmentación y la violencia.

La situación para finales de los años 90 en términos de acceso a condiciones de vida básicas, no había cambiado para las poblaciones afectadas por la guerra interna. El gobierno en este sentido le dio prioridad al retorno de grupos de población desplazada hacia sus comunidades de origen, el resultado de estas acciones fue insuficiente debido a que las medidas fueron acciones aisladas que no tuvieron la complementación de otro tipo de políticas, tales como el acceso a empleos dignos y de apoyo a la reconstrucción de las viviendas, en paralelo existía el problema de restablecer los lazos entre las personas enfrentadas por la violencia que afectó profundamente el sentido de pertenencia de la población (MEDINA; LÓPEZ-MORENO, 2011).

Es necesaria observar el papel de la población indígena en estas dinámicas, actor esencial dentro de la sociedad peruana y protagonista en muchos casos de procesos de exclusión. Hasta los años 90, no existían estadísticas precisas sobre la población indígena, ya que no se aplicaron censos de auto identificación étnica, posteriormente se determinó de acuerdo con Oliart (2009) que la proporción de la población que hablaba lengua indígena o dialecto originario era de $29 \%$ de totalidad, en la región de la sierra esta población representa casi el $90 \%$ del total y se encuentran a su vez los sectores más pobres del Perú (OLIART, 2009).

En este sentido debemos analizar el hecho de que existen profundas disparidades regionales, aumentando en lugares con mayor población indígena, siendo los departamentos de sierra aquellos con los peores indicadores, reflejando tasas elevadas de mortalidad infantil, niveles de desnutrición, deserción escolar, entre otros, este contexto complejo perpetúa los ciclos de pobreza (RIBOTTA, 2010).

Las dinámicas de exclusión de la población indígena dentro de la sociedad peruana tiene antecedentes históricos "ser indígena equivalía a estar situado en las capas más bajas de la sociedad y en zonas con mayor pobreza y rezago, incluido el educativo" (D'Emilio, 1994 apud (CUENCA; ZAVALA, 2007). De acuerdo con Oliart (2009) las presiones del BM y el BID en este sentido, tuvieron un impacto positivo, para que los gobiernos de la región sudamericana incluyeran en su agenda política la resolución de demandas indígenas, no necesariamente surgidas dentro de las fronteras nacionales, sino más bien ligadas a la agenda internacional. En paralelo se dieron cambios en términos de reconocimiento de la población originaria, tales como la modificación en la constitución de 1993, estableciendo al Perú como un estado multicultural y multilingüe (idem). 
Siguiendo esta línea, en lo que se refiere a la política educativa, durante los años 90 se implementaron tres ejes de acción fundamentales, la descentralización educativa, la capacitación de los docentes a nivel básico y medio y finalmente la distribución de materiales, bajo la influencia de la propuesta por parte del BM (UNESCO, 2013). De acuerdo con Bello (2002) se implementaron una serie de programas sociales en este sentido, entre ellos están "el Programa Nacional de Alfabetización, el Programa Nacional de Wawa Wasi (cuidado diurno de niños menores de tres años), el Programa Nacional de Desayunos Escolares y el Seguro Escolar Gratuito", con financiamiento del BM y del BID sumados al aporte nacional.

Durante este periodo de tiempo que comprende el gobierno de Fujimori se crearon diversas instituciones en términos de la dimensión social que de acuerdo con Oliart (2009) fueron usadas como una herramienta política entre la población más pobre por parte del gobierno. Se creó en primer lugar el Ministerio de Promoción de la Mujer y el Desarrollo humano (PROMUDEH) organismo implementado con el objetivo de distribuir los recursos destinados al gasto social, el cual implementó una serie de programas tales como el Programa de apoyo al repoblamiento ${ }^{121}$, de Cooperación Popular ${ }^{122}$ y el programa nacional de asistencia alimentaria.

Aun con la implementación de estos programas se observó un avance de la exclusión social, debido a la falta de medidas integrales y la naturaleza de estos programas al compensación y de carácter transitorio, de esta forma debe ser mencionado que:

\footnotetext{
"se trataba de paliar momentáneamente los efectos de estas políticas, atendiendo a la población más afectada, mientras aparecían los beneficios de las reformas. Se abandonó la pretensión de «universalidad», de llegar al conjunto de la población, y se optó por el camino de la focalización, dadas las restricciones fiscales" (TANAKA; TRIVELLI, 2002)
}

Estos programas fueron relativamente pequeños en relación al tamaño de la población en estado de pobreza, en este sentido es importante resaltar que la política social tuvo dos componentes de acuerdo con Tanaka y Trivelli (2002) uno permanente vinculado a la idea del gasto social convencional referido a la educación y salud y otro temporal que se vincula a "los programas de alivio de la pobreza" (ídem), lo complejo de este escenario es que ambos se desarrollaron de forma separada creando un contexto de descoordinación, disminuyendo el impacto y las mejoras dentro de la población.

\footnotetext{
121 “organismo público descentralizado que tiene como misión establecer las condiciones básicas para el desarrollo de las poblaciones desplazadas por la violencia terrorista, así como para el desarrollo integral de las zonas declaradas en emergencia a fin de consolidar la paz social.” (OLIART, 2009)

122 creado para "promover la creación de organizaciones sociales de base para la lucha contra la pobreza e impulsores del desarrollo de los sectores de menores recursos." (ídem)
} 
Durante el gobierno de Toledo se realizó una reformulación de las políticas sociales, en este sentido se crea el programa "Juntos"123 que es un programa nacional de apoyo a los más pobres (FILGUEIRA, 2013) y se crea el Programa Integral de Nutrición compuesto por dos áreas la alimentaria y otra educativa. En lo que se refiere a los asuntos indígenas se reivindica el término para la auto identificación, se realiza a su vez la "Declaración de Machu Picchu sobre la Democracia, los Derechos de los Pueblos Indígenas y la lucha contra la pobreza", buscando priorizar a nivel regional estos asuntos, siendo "la primera declaración comunitaria que vincula políticamente a los países andinos a seguir una línea de reconocimiento de la temática indígena" (GAMBOA, 2005)

El gobierno de Alan García dio énfasis durante su gobierno a generar un incremento en el desarrollo humano, estableciendo grupos de interés y definiendo a los sectores altamente vulnerables en dos "gestantes y los niños menores de 5 años" (PASCÓ-FONT; SAAVEDRA, 2001). Un aporte de su gobierno fue el diagnóstico realizado al respecto de los programas sociales por medio de una comisión de evaluación, la cual observo que la cantidad de programas sociales y la dispersión de los entes públicos responsables, generaba gran ineficiencia en los programas, sólo 16 de 34 programas evaluados contaban con normas específicas de creación (idem).

En el 2011 durante el gobierno de Ollanta Humala, se crea el Ministerio de Desarrollo e Inclusión Social, cambiando la estructura a través de la cual se ejecutaban políticas sociales, las cuales se planificaron en tres dimensiones temporales, a corto plazo en donde se encuentra el programa "Juntos" (al cual se le da continuación desde el gobierno de Toledo) y "Pensión 65", a mediano plazo por medio del FONCODES ${ }^{124}$ y a largo plazo con el Qali Warma que busca garantizar la nutrición de los niños dentro de la educación básica y Cuna mas buscando apoyar a las familias en el cuidado de sus hijos, (VASQUEZ HUAMAN, 2013).

En líneas generales, Perú es un país que ha pasado por diversas fases en lo que se refiere a la forma en que se interpretan las políticas sociales, ha evaluado y reestructurado los programas buscando alcanzar una eficiencia mayor en términos de articulación, aun así el contexto social es complejo debido a años de conflicto armado y exclusión de las minorías principalmente

\footnotetext{
${ }^{123}$ Juntos es un programa de transferencias monetarias condicionadas cuya finalidad consiste en contribuir al alivio de la pobreza y potenciar el capital humano de los hogares más pobres del Perú.

124 "Es un programa para la promoción de la autonomía económica sostenible de los hogares en situación de pobreza de las zonas rurales del país. Desarrolla capacidades y genera oportunidades económicas y productivas articuladas territorialmente, en alianza con los actores comprometidos con el desarrollo local”. (MIDIS, 2012)
} 
étnicas (grupos indígenas), generando un impacto moderado en los indicadores de cohesión y su vínculo con la democracia como se ve a continuación:

Tabla 26: Perú: Relación Cohesión Social/ Calidad de la Democracia

\begin{tabular}{|l|l|l|l|l|l|l|}
\hline Años & 2003 & 2006 & 2008 & 2010 & 2012 & 2014 \\
\hline $\begin{array}{l}\text { Nivel de } \\
\text { Dificultad }\end{array}$ & 6,0 & 5,0 & 4,8 & 4,4 & 4,6 & 4,6 \\
\hline $\begin{array}{l}\text { Calidad de la } \\
\text { Democracia }\end{array}$ & 6,80 & 6,85 & 6,60 & 6,70 & 6,70 & 6,75 \\
\hline
\end{tabular}

Fuente: Transformation Index, 2015

El indicador Nivel de Dificultad, presenta su mayor puntuación en el 2003 y va mejorando de forma progresiva hasta alcanzar 4,6 en el 2014, aun cuando el mejor nivel en términos de cohesión se presenta en el 2010, generando un incremento en términos de calidad de 6,70. Se observa que durante el periodo evaluado en términos de calidad democrática existe una fluctuación de los valores entre 6,80 y 6,60 que se considera un poco bajo, reflejando la falta de institucionalidad y confianza por parte de la ciudadanía en las estructuras gubernamentales. Los gobiernos peruanos durante la última década hicieron un esfuerzo en mantener una evaluación continua de los programas sociales aplicados así como creando condiciones para la expansión del gasto social, lo que generó mejoras en ciertas áreas, repercutiendo en la cohesión.

\subsubsection{Uruguay}

Históricamente Uruguay es un país que le ha dado mayor prioridad a la sectorialización de políticas, dejando de lado, en ciertos aspectos, al carácter pragmático que estas deben tener frente al contexto social, pero por otro lado fue prácticamente el único país suramericano que alcanzó una articulación positiva de las reformas estructurales, mejorando de esta forma los niveles de equidad dentro de la sociedad durante los últimos 20 años.

Los años noventa se caracterizan por dar inicio al proceso de integración regional del MERCOSUR, afectando las dinámicas existentes dentro del área financiera/comercial del Uruguay, a su vez se observa una reforma en su modelo de desarrollo, que a diferencia de otros países de América del Sur, no siguió las directrices resultantes del Consenso de Washington, se implementó una "heterodoxia reformista" esto debido a que: 
"El gasto público social incrementó su nivel durante la década; la reforma educativa adoptó un claro perfil estatista; la reforma de la seguridad social adoptó una modalidad heterodoxa que combinó dispositivos de mercado con participación estatal; los principales servicios públicos (telecomunicaciones, energía) quedaron en manos del estado; los programas de estabilización fiscal se alejaron de las estrategias de shock dominantes en la región. Estas características le ganaron al proceso de reformas la calificación de gradualista al calificar sus resultados agregados” (ALEGRE, 2008)

Durante el gobierno de Luis Alberto Lacalle (90-95), el Uruguay atravesó el proceso de reformas influenciadas por las transformaciones que vivió América del Sur, ejerciendo de esta forma, una impacto en menor escala en la adhesión de programas ortodoxos propuestos por los organismos internacionales en materia fiscal y monetaria (ídem). Dentro de las más importantes se encuentran las medidas fiscales y el trabajo, lo cual generó una mejora en los indicadores nacionales, de acuerdo con (ABOAL; ANDRÉS MORAES; FORTEZA, 2003) se observó una disminución del déficit del estado entre 1986-1998, “el cual pasó del 6,5\% del PBI en 1989 al $1 \%$ en $1998 \%$.

Este contexto positivo en términos del PIB hizo con que el gasto público el estado Uruguayo se mantuviese elevado de forma constante, de acuerdo con la evaluación realizada por la CEPAL (2004) “el gasto social pasó del 17\% del PBI en 1990 al 22\% en el 2001”. El enfoque de esta inversión por parte del estado priorizó dos áreas, la educación y la estructura de la seguridad social.

En el área educativa se dieron una serie de cambios que de acuerdo con (MINISTERIO DE EDUCACIÓN Y CULTURA DE LA REPÚBLICA DEL URUGUAY, 2014) en primer lugar durante el gobierno de La Calle se restaura la institucionalidad democrática dentro del sistema educativo y comienza un proceso de inversión, después de 1995, se implementa la "reforma educativa" y finalmente el periodo comprendido entre 2000-2005, en el que imperó cierta falta de desarrollo y promoción a las innovaciones impulsadas durante la reforma, esto se debió a la crisis que atravesó el estado en 2002 disminuyendo los recursos del país.

La reforma educativa implementada por el estado uruguayo buscó expandir la cobertura de la educación, principalmente la educación básica, lo cual tuvo la efectividad deseada como se observa en los indicadores del área educativa (ver CEPAL, 2004), en este sentido se alejó de las recomendaciones de los organismos internacionales, cuya propuesta era liberal, priorizando acciones de privatización en todos los niveles. De esta forma la reforma educativa se enfocó en cuatro áreas principales: 
“a) expansión de la cobertura estatal de educación inicial para los niños de 4 y 5 años; b) fortalecimiento institucional y expansión de cobertura de algunas políticas compensatorias de carácter focalizado (las «Escuelas de Tiempo Completo»), buscando así mejorar los aprendizajes de los alumnos de contextos de pobreza; c) reforma curricular del primer tramo de la educación media; d) expansión de la oferta de formación estatal de docentes." (MINISTERIO DE EDUCACIÓN Y CULTURA DE LA REPÚBLICA DEL URUGUAY, 2014)

Es importante resaltar que en paralelo se implementó el "Plan de Acción a favor de la Infancia”, creado en 1992 (OPP, 1992), que tenía como objetivo el bienestar infantil de forma integral, como el desarrollo del sistema educativo en Primaria, "educación inicial, baja de tasas de repetición, alimentación escolar, educación rural y protección de niños a través del INAME ${ }^{125}$ " (ídem), a su vez se plantearon programas de nutrición, atendimiento temprano, entre otros, los cuales resultaron en un impacto positivo principalmente durante el periodo de crisis comprendido entre 2002-2005.

En el área de la salud, aun con los esfuerzos de reforma se observa una gran fragilidad durante los años noventa en esta área, lo que fue denominado por (FILGUEIRA, 2013) un "desfondamiento" en términos de cobertura y la calidad de los servicios, presentando una disminución de los mismos como resultado de la falta de inversión. Aun cuando el gasto en esta área era de aproximadamente el 10\% del PIB (PNUD - UNICEF - CEPAL, 1999), una de las cifras más altas del mundo y de la región, sus logros son inferiores en comparación con otros países de la región (Chile o Cuba) (MINISTERIO DE EDUCACIÓN Y CULTURA DE LA REPÚBLICA DEL URUGUAY, 2014)

La bonanza de la década de los noventa se vio afectada por la crisis mundial a mediados del 2002, cuando el PIB tuvo una caída del 11\%, lo que trajo en consecuencia un incremento en los niveles de pobreza llegando al 30\% de la población, el desempleo creció de forma acelerada de 12\% en 1999 a 20\% en 2002 (INE, 2004 apud ALEGRO, 2008). Desde el 2002 hasta el año 2005 las políticas tomadas dentro del área social tuvieron carácter paliativo, en el año 2004 fue aprobada una reforma de ley que extendía los subsidios familiares a todos los hogares pobres que en ese momento no estuviesen cubiertos por el sistema nacional de apoyo familiar, siendo una consecuencia de la ruptura social generada por la crisis (PRIBBLE; HUBER, 2013).

Con la llegada del gobierno de Tabaré Vázquez en el año 2005, se dio una expansión en las prestaciones sociales, ya que fue creado el Ministerio de Desarrollo Social del Uruguay y el Plan de Emergencia Social (PANES) que buscaba proporcionar protección social por medio de

\footnotetext{
${ }^{125}$ Instituto Nacional del Menor
} 
un suplemento pequeño en sus ingresos definido como "ingreso ciudadano" (ídem). Otra red exitosa fue la RAIS, creada en durante este gobierno, la cual tenía como objetivo buscarle solución a los principales problemas sociales, uno de las áreas prioritarias de acción fue la implementación de programas definidos como "transferencias no contributivas" entre los que se encuentran:

\begin{abstract}
"1)Tarjeta Uruguay Social "es una transferencia monetaria dirigida a apoyar a los hogares en situación de pobreza extrema en el gasto en alimentación y artículos de limpieza", 2) Asignaciones Familiares Plan de Equidad (AFAM-PE) dirigidas a hogares pobres con menores de edad siendo esta remuneración condicional a través de la asistencia en la educación formal y a los centros de salud por parte de las familias" (CEPAL, 2013)
\end{abstract}

Ambas obtuvieron resultados positivos de acuerdo con el Informe Mides 2011-2012 126 debido a que eran implementadas como ayudas integrales, planificadas desde una visión amplia en la cual el alcance de un nivel de vida digno por parte de las familias dependía de varias dimensiones, no solo la monetaria, la obligación de la contraprestación fue efectiva en la mejora de los indicadores y la participación, impactando positivamente la reducción de la indigencia y, más levemente, en la pobreza.

Asimismo se encuentra en ejecución "Uruguay Trabaja", el cual tiene como objetivo proporcionar oportunidades de desempeño laboral transitorio (CEPAL, 2013). Este programa ha venido evolucionando a lo largo del tiempo y continuado en los gobiernos que precedieron a Tabaré Vásquez ampliando su oferta en formación laboral y generando vínculos alternativos con el sistema educativo formal.

Un vez concluida la ejecución del PANES, Uruguay puso en funcionamiento un plan de mediano y largo plazo denominado como "Plan de Equidad"127, buscando impactar de forma positiva y sostenida los niveles de desigualdad. El Plan de Equidad está estructurado a partir de la matriz de protección social, que de acuerdo con Gonzalez y Sambrini (2012) comprendía la ejecución de los siguientes aspectos: "la reforma tributaria; la reforma de salud; revisiones de las políticas de empleo; nueva política de vivienda y hábitat; la reforma educativa; el plan nacional

\footnotetext{
${ }^{126}$ Ver http://medios.presidencia.gub.uy/jm_portal/2013/noticias/NO_L723/Informe\%20MIDES\%202011-2012.pdf

127 " A estos se suman los componentes específicos que conforman una red moderna de asistencia e integración social que se estructuran en un conjunto de siete medidas y estrategias de acción iniciales: i) régimen de prestaciones sociales no contributivas o de transferencias monetarias (Asignaciones Familiares y Pensiones a la Vejez), ii) seguridad alimentaria, iii) políticas de educación para la infancia y adolescencia, iv) políticas asociadas al trabajo protegido, v) promoción de cooperativas sociales y emprendimientos productivos, vi) políticas de promoción e inclusión social y vii) políticas de atención de la discapacidad" (Presidencia de la República, Gabinete Social, Consejo Nacional de Coordinación de Políticas Sociales, 2007).
} 
de igualdad de oportunidades y derechos", siendo efectivo en la desarticulación del "núcleo duro" de la pobreza.

De esta forma se puede decir que Uruguay ha experimentado desde 2005 un crecimiento sostenido de la actividad económica que ha venido acompañado por una serie de políticas sociales que condujeron a una reducción de la pobreza. El porcentaje de personas por debajo de la línea de pobreza en 2012 se sitúa en 12,4\%, 10 puntos porcentuales por debajo del valor registrado en 2008 (CEPAL, 2013).

En el 2010 con la llegada de José Mujica se enfatiza en la mejora de la dimensión social, dando prioridad a la disminución de la pobreza, y la eliminación de la indigencia, su objetivo principal era el fortalecimiento del acceso de los sectores más vulnerables a servicios y prestaciones sociales (CEPAL, 2013). El gobierno se fundamentó en una estrategia integral y la consolidación del gasto público social el cual tuvo un aumento debido al incremento presupuestal producto del contexto económico positivo.

En términos educativos se continuaron políticas y programas del gobierno anterior las cuales tuvieron resultados ampliamente positivos tales como la universalización de la educación, el desarrollo de programas de inclusión (Maestros Comunitarios, Aulas Comunitarias, entre otros), y el Plan Ceibal (GARIBALDI; IBARRA, 2011) a su vez se extendió la educación terciaria a todo el país, buscando el desarrollo de políticas de educación formal y no formal para atender la educación de personas jóvenes y adultas.

El área de la salud continuó con el Sistema Nacional Integrado de Salud, iniciada en el gobierno anterior, pero se aplicó una ampliación de la protección a diversos sectores de la sociedad vistos como prioritarios, y se realizó un esfuerzo en la ampliación de los programas a nivel nacional. Las principales políticas desarrolladas tenían como foco el alcance de la universalización de la cobertura del "Seguro Nacional de Salud" mediante la incorporación progresiva de colectivos y en la mejora en el acceso a las prestaciones integrales de salud (ídem).

Otro aspecto importante fue el desarrollo políticas laborales que estuvieron orientadas a reducir la desigualdad social, de género e intergeneracional. En ese sentido, ha sido fundamental la contribución de la política salarial a la reducción de la pobreza y la desigualdad. Cabe destacar que el salario básico se duplicó en términos reales entre 2005 y 2014, de acuerdo con el Consejo Nacional de Políticas Sociales (2014), lo que genero un impacto importante en las dinámicas económicas del país, por otra parte se reforzaron los programas desarrollados por el INEFOP, principalmente en la capacitación laboral de los sectores más vulnerables, 
En lo que se refiere a la seguridad social se lograron avances en la inclusión y formalización de nuevos grupos sociales definidos como colectivos y se facilitaron las condiciones de acceso que anteriormente requerían de un proceso complejo, así como una mejora en el valor (CEPAL, 2013). Esto aun cuando generó un aumento en los gastos garantizó la inclusión de un importante sector de la población.

En todos los gobiernos evaluados a partir de los años 90, se observa el papel relevante de las ONG en el diseño y aplicación las políticas sociales, por medio del Programa de Inversión Social, que establece entre sus cometidos "la coordinación de proyectos referidos a políticas sociales y que sean financiados por organismos multilaterales"(OPP, 2002). Ha sido relevante principalmente en términos de coordinación y consulta, de acuerdo con (FERNANDEZ; DE LOS CAMPOS, 2004).

El estado uruguayo se diferencia del resto de la región debido a que la acción política de mayor relevancia en las últimas décadas ha sido la protección presupuestal acordada para mantener y continuar los Programas Sociales Prioritarios aun enfrentando dificultades generadas en consecuencia déficit fiscal generado en el contexto de recesión (CEPAL, 2013). La evolución positiva en términos de implementación de políticas sociales ha tenido un impacto importante en la cohesión social, de acuerdo con el MIDES (2014) desde 2005 a la fecha aumentó la cobertura educativa en todos los niveles de educación formal y en segundo lugar el período comprendido entre los años 2004 y 2012 el gasto público social ha exhibido un crecimiento anual de 9\% en promedio, lo que representa un $87 \%$ de crecimiento en el total del período.

La transformación en términos de políticas sociales por parte de los gobiernos uruguayos en las últimas dos décadas ha tenido un impacto importante en la cohesión de la sociedad uruguaya, reflejando la importancia de la continuidad en el tiempo de las políticas así como de instituciones gubernamentales sólidas, como se observa a continuación:

Tabla 27: Uruguay: Relación Cohesión Social/ Calidad de la Democracia

\begin{tabular}{|l|l|l|l|l|l|l|}
\hline Años & 2003 & 2006 & 2008 & 2010 & 2012 & 2014 \\
\hline $\begin{array}{l}\text { Nivel de } \\
\text { Dificultad }\end{array}$ & 3,0 & 2,4 & 2,2 & 1,8 & 1,8 & 1,4 \\
\hline $\begin{array}{l}\text { Calidad de la } \\
\text { Democracia }\end{array}$ & 10,00 & 9,90 & 9,90 & 9,90 & 9,95 & 9,95 \\
\hline
\end{tabular}

Fuente: Transformation Index, 2015 
Uruguay es el país de la región con los mejores indicadores de cohesión social la cual ha mantenido una mejora de forma continua desde el 2003, presentando las mejores puntuaciones de la región, lo que se observa de igual forma en el indicador Calidad de la Democracia que se mantiene de forma sólida a lo largo del periodo evaluado entre 10,00 y 9,90, reflejando una solidez institucional y confianza en los mecanismos democráticos por parte de la sociedad uruguaya.

Las políticas sociales han sido una prioridad en todos los gobiernos vistas como una responsabilidad por parte del estado, aun dentro de un contexto de crisis se mantuvo el financiamiento de los programas implementados, se ha venido incrementando el gasto público social impactando positivamente en los indicadores de pobreza, la educación ha sido uno de los ejes orientadores de los programas sociales en paralelo con las transferencias condicionadas hacia los sectores más excluidos.

\subsubsection{Venezuela}

Durante la década de los 90, al igual que en otros países de la región fueron implementados programas de ajuste macroeconómicos siguiendo la línea liberal acelerando el proceso privatizador de diversos sectores del Estado. Debido al impacto de estos ajustes dentro de la sociedad fueron formulados una serie de programas sociales para lidiar con el contexto de desigualdad. Es importante resaltar que la política social venezolana, estaba definida por su carácter universalista desde el inicio del período democrático, con el paso del tiempo esta se vio afectada debido a la crisis en el modelo económico y la falta de implementación por parte del Estado de un modelo integrador.

Este contexto convulsionado trajo como consecuencia en 1989 el "Caracazo"128, evento que generó cambios profundos tanto en términos históricos como sociales, trayendo consigo una nueva visión del papel del estado, las políticas sociales pasan de ser un elemento secundario de la política económica a tener un papel central, estructurando un replanteamiento de la cuestión social en el país (Jacome, 2011).

La inestabilidad continuó a lo largo del gobierno de Carlos Andrés Pérez con un incremento negativo en los indicadores sociales ${ }^{129}$, aún en este escenario complejo se da origen a

\footnotetext{
${ }^{128}$ Revuelta popular que estalló en Caracas y una parte significativa del mapa urbano del país el 27 de febrero de 1989 como consecuencia del paquete de medidas económicas implementadas durante el gobierno de Carlos Andrés Pérez (JACOME; GRATIUS, 2011)

${ }^{129}$ Ver "El Índice de la miseria en Venezuela" (CRESPO, 2011)
} 
la implementación de políticas sociales compensatorias buscando equilibrar las grandes desigualdades, producto de las fuertes medidas económicas, consideradas como necesarias para estabilizar la crisis en el país:

“...dicha relevancia no implicó un mejoramiento de las condiciones de vida de los venezolanos como tampoco una mejoría considerable en la eficiencia de dichos programas a lo largo del tiempo. Esta relevancia de las políticas sociales se debió más bien a la combinación de un proceso de cambios sociales y políticos que ha vivido la sociedad venezolana desde la crisis de los ochenta y a las expectativas sociales insatisfechas que la población ha tenido desde entonces que fueron traduciéndose cada vez más en objeto de discursos políticos". (GONZALEZ; LA CRUZ, 2008)

Basándose en una concepción neoliberal del Estado, se buscó actuar por medio de canales diferentes a los existentes para lograr compensar el impacto social que significaba la aplicación del programa de ajuste denominado como "paquete económico" (ídem), por medio de medidas que limitaban la actuación del estado en el sistema económico. Se define, entonces, una política social compensatoria y otra estructural por medio de las redes tradicionales de carácter permanente y universal.

La política social compensatoria tenía la intención de atender a los grupos más vulnerables y evitar las consecuencias negativas del ajuste, para esto se crea un "Plan de Enfrentamiento a la Pobreza”, González y LaCruz (2007) compuesto por las siguientes áreas prioritarias: 1)Nutrición: Beca Alimentarias y Comedores Escolares, 2)Salud: Programa Alimentario Materno-Infantil y Programas para la ampliación de la atención primaria en salud. 3)Educación: Dotación de uniformes y útiles escolares, Ampliación de la cobertura de los pre-escolares, Capacitación y Empleo Juvenil, Subsidio al Pasaje Estudiantil, 4)Área de Protección Social: Hogares de Cuidado Diario, 5)Área de Empleo y Seguridad Social: Seguro de Paro Forzoso, Programa de Apoyo a la Economía Popular, Programa Nacional de Beca Salario. 6)Área de Vivienda e Infraestructura Social: Vivienda Rural, Programa de Inversión Social Local.

Aun con la implementación de estos programas para enfrentar el choque generado por los ajustes económicos se mantuvo el escenario de inestabilidad política, ya que la efectividad de los mismos no acompañó la crisis social al ritmo que esta se estaba desarrollando, lo cual generó una pérdida de legitimidad del gobierno de Pérez, resultando en el golpe de 1992 y posteriormente en su impeachment en 1993 antes de finalizar su mandato (ídem).

Rafael Caldera (96-98) dio continuación a las orientaciones establecidas por medio del acuerdo entre el gobierno y el FMI. Este nuevo contexto económico tuvo que lidiar con la herencia de la administración anterior, caracterizada por una recesión y elevados niveles de 
inflación, lo que hizo que se ejecutarán nuevas medidas por medio del plan denominado como "Agenda Venezuela", dando continuación a un grupo de programas que ya se encontraban activos ((GUERRA; PONCE DE MORENO, 2005). Se implementaron 14 programas sociales, de los cuales seis continuaron la línea definida en el "Plan de enfrentamiento de la Pobreza" originado durante el gobierno de Carlos Andrés Pérez ((GOMEZ, 1987).

Aun con la ampliación en el número de programas se observa una disminución en el gasto social a lo largo de la década, debido al contexto de crisis económica que afectó el desarrollo y en consecuencia su efectividad. El foco principal por parte de este gobierno fue la inversión en medidas para generar estabilización financiera y fiscal. Haciendo una evaluación amplia podemos concluir que los programas implementados tanto por Pérez como por Caldera en el área social tuvieron un carácter paliativo y estuvieron alejados del objetivo primordial que era generar desarrollo social, equidad e inclusión de forma sostenida.

El contexto de insatisfacción dejado por los gobiernos anteriores trajo consigo un escenario propicio para un cambio profundo, , esta fue la propuesta de Hugo Chávez dando inicio a su gobierno en 1999. Se establecieron una serie de medidas de forma rápida con el objetivo de reformular el "establishment" venezolano, una de las principales fue la realización de un referéndum constituyente, que resultó en la aprobación de una nueva constitución, con un nuevo modelo político denominado "democrático-participativo y protagónico"130, dando prioridad a la responsabilidad compartida entre los ciudadanos y el estado, por otra parte se da un retroceso en la descentralización de los procesos estatales, las decisiones se focalizaron de forma casi integral en la figura del presidente.

Durante este período definido como la V República, el valor de los commodities y el petróleo alcanza niveles elevados, lo que genero recursos para financiar la estrategia gubernamental, basándose en la "Plena Soberanía Económica" (LOPEZ MAYA, 2004) que se caracterizó por no estar condicionados al FMI y al BM, en consecuencia el gasto público tiene una tendencia ascendente lo que también genero un incremento en el gasto social.

Una fue la centralización de los fondos sociales, de acuerdo con González y LaCruz (2007) esto se realizó a través de una única fuente de financiamiento, definida como el Fondo Único social. Otra reforma institucional que impacto la dimensión social fue el fortalecimiento de los fondos de inversión social destinados a la promoción de la "economía social" definida como aquella:

\footnotetext{
${ }^{130}$ Ver Constitución de la República Bolivariana de Venezuela
} 
“teóricamente orientada a propiciar la inclusión socioeconómica de los sectores más pobres de nuestra sociedad y potenciar su protagonismo sociopolítico como base de sustentación de los cambios de la economía y del Estado procurados desde su alta dirección. Se persigue la democratización de la economía con base en la participación de los sectores populares organizados en procesos equitativos de producción y distribución, para concretar el "Estado Social de Derecho" delineado en la Constitución de la República Bolivariana de Venezuela” (FREITEZ, 2007)

Siguiendo esta línea se implementó el "Plan de Desarrollo Económico y Social de la Nación" (2001-2007), instrumento creado para orientar las políticas públicas. En este plan se establecieron la mayor cantidad de instituciones y programas implementados en el área social en la historia republicana de Venezuela, aun cuando la apología a la cantidad no implica la efectividad de los mismos.

Un aspecto atípico en términos institucionales fue la participación de las Fuerzas Armadas en diversos asuntos sociales. Para reforzar este escenario se crea la Milicia Bolivariana (2007), como un complemento de carácter cívico-político a las Fuerzas Armadas. El gobierno de Chávez, se caracterizó por ser una "revolución armada" o de "pueblo en armas", este aspecto se reforzó a partir de la Constitución del 99 “de orientación presidencialista, centralizadora y militarista" (Angulo, 2001), este nuevo contexto escenario se caracterizó por ser controversial:

"los señalamientos críticos sostienen que las fuerzas armadas no son un recurso político sino militar del Estado, y su misión profesional sólo puede cumplirse debidamente a condición de ser focalizada en el campo estratégico, bajo la conducción superior de un mando político" (ANGULO RIVAS, 2011)

Los años posteriores a la aprobación de la Constitución se caracterizaron por confrontaciones políticas producto de la polarización, lo que hizo que el enfoque por parte del gobierno tuviese como prioridad el manejo de las tensiones políticas más que la efectividad de los programas sociales. El paro petrolero y el consecuente golpe de estado en el 2002, conllevan a que la agenda gubernamental tuviese un foco mayor en el control político, el referéndum de 2004 cambia este escenario trayendo nuevamente a la política social como un asunto prioritario.

En esta fase del gobierno se implementaron, debido a lo favorable de la situación económica del país, un grupo de programas que cambio la forma en que se estructuraban las políticas sociales en Venezuela, denominados como Misiones Sociales. En términos positivos, lograron mejorar todos los indicadores vinculados a desigualdad y pobreza, alcanzando a las poblaciones más vulnerables, en el espectro negativo estos programas fueron altamente 
politizados y con un carácter clientelar lo que profundizó aún más la polarización del país, entre estas se encuentran:

Tabla 28: Misiones Sociales implementadas durante el mandato de Hugo Chávez

\begin{tabular}{|c|c|c|}
\hline Nombre de la Misión & Fecha de Creación & Área de Impacto \\
\hline Mercal & Diciembre/2003 & Alimentación \\
\hline Árbol & Junio/2006 & Ecológico \\
\hline Barrio Adentro & Diciembre/2003 & Salud \\
\hline Ciencia & Febrero/2006 & Ciencia y Tecnología \\
\hline Cultura & Octubre/2004 & Cultura \\
\hline Guaicaipuro & Octubre/2003 & Población Indígena \\
\hline Identidad & Agosto/2004 & Cedulación \\
\hline Madres del Barrio & Marzo 2006 & Madres y Amas de casa \\
\hline Milagro & Julio/2004 & Salud \\
\hline Miranda & Octubre 2003 & Reserva de las FAN \\
\hline Negra Hipólita & Enero 2006 & Población en pobreza extrema y situación de indigencia \\
\hline Piar & Octubre 2003 & Minería \\
\hline Revolución Energética & Noviembre 2006 & Energía \\
\hline Justicia & Febrero 2005 & Justicia \\
\hline Ribas & Octubre/2003 & Educación \\
\hline $\begin{array}{l}\text { Barrio Adentro } \\
\text { Deportivo }\end{array}$ & Diciembre 2004 & Deporte \\
\hline Robinson I y II & Junio 2003 & Educación \\
\hline Alma Mater & Septiembre 2007 & Educación Superior \\
\hline Sonrisa & Noviembre 2006 & Salud \\
\hline Sucre & Septiembre/2003 & Educación \\
\hline Villanueva & Septiembre 2006 & Distribución espacial de la población \\
\hline $\begin{array}{c}\text { Hábitat/ Misión } \\
\text { Vivienda }\end{array}$ & Julio 2004 & Vivienda y ordenamiento urbano \\
\hline Vuelvan Caras & Marzo 2004 & Desarrollo \\
\hline Zamora & Enero 2005 & Tierras \\
\hline
\end{tabular}


Fuente: http://www.gobiernoenlinea.ve/miscelaneas/misiones.html; http://www.misionesbolivarianas.gob.ve/; D’Elia, 2006; El Nacional, “La Misión Cristo”, Domingo 28 de octubre 2007, pp.3 apud GOZALEZ; LACRUZ, 2007.

Estos programas estructuralmente presentan una serie de aspectos que los hacen sujetos de críticas, en primer lugar se crearon sin un plan definido de desarrollo y siendo altamente centralizados, lo que dificulto su control y gestión, ya que no poseen mecanismos de medición definidos (D’ELIA, 2006). Otro aspecto importante es que su financiamiento se obtiene a partir de diferentes instituciones, lo que resulta en un escenario complejo en términos de transparencia de presupuesto, su creación se dio en medio de un contexto de abundancia de recursos por lo cual no tienen una proyección a largo plazo en términos de sustentabilidad, en último lugar las misiones fueron creadas de forma paralela con otros mecanismos ya existentes, dificultando la coherencia de las mismas.

Por otro lado es innegable su efecto positivo en la sociedad en términos de acceso a derechos básicos y condiciones de vida digna, la ciudadanía encontró un lugar para la participación en el diagnóstico de los problemas. Las que han tenido un alcance mayor dentro de la sociedad se encuentran Barrio Adentro y Mercal que de acuerdo con (D’ELIA; CABEZAS, 2008) con cifras de Datanalisis alcanzaron una expansión del 30\% de la población (7.2 millones de personas), en el caso de las misiones Robinson I y II llegaron a 10\% de la población (2.7 millones de personas), Vuelvan Caras y Vivienda Hábitat fueron las de menor cobertura llegando a 3\% de la población.

Tomando en consideración este análisis la creación de las misiones cambio la forma en que la sociedad venezolana interpretaba su relación con el estado, generando un sentimiento de identificación tanto con el estado, como con el gobierno, a su vez "se establecieron otros mecanismos que resultaron perversos: la exclusión de sectores opositores o no seguidores del Proyecto Revolucionario. Esto es producto de la politización de las políticas sociales" (GONZALEZ; LA CRUZ, 2008)

Observando en el análisis presentado anteriormente en lo que se refiere a la implementación de políticas sociales, vemos que la transformación profunda que sufrió Venezuela en términos políticos, económicos y sociales impacto profundamente a la sociedad venezolana: 
Tabla 29: Venezuela: Relación Cohesión Social/ Calidad de la Democracia

\begin{tabular}{|l|l|l|l|l|l|l|}
\hline Años & 2003 & 2006 & 2008 & 2010 & 2012 & 2014 \\
\hline $\begin{array}{l}\text { Nivel de } \\
\text { Dificultad }\end{array}$ & 3,0 & 2,4 & 2,2 & 1,8 & 1,8 & 1,4 \\
\hline $\begin{array}{l}\text { Calidad de la } \\
\text { Democracia }\end{array}$ & 5,60 & 6,20 & 5,65 & 4,55 & 4,40 & 4,52 \\
\hline
\end{tabular}

Fuente: Transformation Index, 2015

La evaluación de nuestros indicadores demuestra una mejora considerable en el Nivel de Dificultad de 3,0 en el 2003 a 1,4 en el 2014, en el caso de la Calidad de la Democracia se observa una disminución progresiva del indicador de 5,60 en el 2003 a 4,52 en el 2014, lo que refleja un empeoramiento del contexto político-institucional del país. Sin duda alguna Venezuela es un caso atípico en la región, como consecuencia de la gran inversión social durante la última década vemos cambios acentuados en los indicadores de cohesión, pero a la hora de evaluar estos avances por medio del espectro político vemos una sociedad profundamente convulsionada y polarizada, en este sentido uno de los grandes déficits de Venezuela se refiere a su sentido de pertenencia.

\subsection{Síntesis de la implementación de las políticas sociales en América del Sur}

La revisión de la implementación de políticas sociales en los países que conforman América del Sur tuvo como objetivo principal establecer la efectividad en términos de cohesión dentro de las sociedades, así como su relación con el comportamiento de la calidad de la democracia. Estos países han logrado avances importantes en la dimensión social, como resultado de una serie de factores, entre ellos el crecimiento económico, que impulsó un conjunto amplio y diverso de políticas destinadas a eliminar el contexto histórico de exclusión, sin contar con una estructura específica de cohesión ni fondos específicos para su financiamiento.

Dentro de los resultados positivos de estos procesos tenemos la conformación de un nuevo estrato social ubicado entre los pobres y la clase media, individuos que tuvieron acceso a la salud y a la educación y que a su vez adquirieron capacidad de acción ciudadana, estos grupos sociales son ampliamente vulnerables a la desaceleración económica debido a que se encuentran en el proceso de consolidación de su capacidad de desarrollo.

Por otro lado, de acuerdo con Briceño (2015) a diferencia de otras regiones, América del Sur posee ventajas comparativas en términos de cohesión ya que existe un elemento transversal 
identitario común, por lo cual debe ser interpretada su sociedad como una "unidad dentro de la diversidad", esto debido a que:

"hubo un pasado común, ibero, español-portugués, así como un elemento religioso, que en las sociedades es extremadamente importante, como cristiano-católico y una serie de experiencias en la vida internacional común, una posición subordinada en el sistema internacional, el tener que enfrentar la agresividad de potencias externas como los Estados Unidos en el Caribe, o gran Bretaña en el Atlántico Sur, que crean elementos para una identidad común". Entrevista concedida por Briceño, Jose. Entrevista I. [jun, 2015]. Entrevistador: Erika Medina. São Paulo, 2010. La entrevista integral se encuentra transcrita en el Apendice A de esta tesis.

En este sentido la unidad a partir de la identidad, no es sinónimo de unidad en lo político o de unidad en lo económico, porque es esencial evaluar otras variables, pero debe ser considerado como un aspecto catalizador, visto como una variable interviniente, a ser tomada en consideración, en conjunto con variables de mayor relevancia en términos de impacto en la sociedad, como son las políticas sociales multidimensionales interpretadas como políticas de cohesión.

Aún con este contexto positivo en lo que se refiere a las estructuras sociales suramericanas, las políticas sociales se caracterizaron por una falta de planificación, así como desarticulación, ya que se implementaron dos visiones a la hora de disminuir los procesos de exclusión, una enfocada a los sectores básicos y otra que buscaba combatir la pobreza de forma aislada, generalmente en términos de emergencia y a corto plazo.

El dialogo social/político suramericano trajo consigo cambios vinculados con los procesos de democratización, por medio del fortalecimiento de las instituciones y una mayor participación ciudadana. Aún con estos avances, América del Sur continúa siendo una de las regiones más inequitativas del mundo con dinámicas constantes de inestabilidad política, presentando grandes dificultades para avanzar en la disminución de la desigualdad y la justicia distributiva.

Por medio de esta evaluación se observa que la concepción de las políticas sociales cambió profundamente en los países que conforman la región, la nueva visión se basa en un aumento considerable de la inversión pública en diversas áreas como la educación, salud y seguridad social, en la consolidación de programas de transferencias monetarias condicionadas y en la aceptación de un enfoque universal de las políticas sociales basadas en la noción de derechos y participación ciudadana. 
Durante las dos últimas décadas se observan similitudes en la forma en que se aplicaron las políticas, permitiendo una comprensión amplia de las debilidades y fortalezas dentro de nuestra región en términos de cohesión social. A continuación serán definidas las políticas sociales que mejoraron los indicadores nacionales de forma específica, las cuales se ven reflejadas en diversos países de esta región:

- Refuerzo de las políticas universales, tanto dentro del área de la salud como de la educación, buscando la igualdad en el acceso de los ciudadanos por medio de una fuerte inversión pública, desarrollando programas con foco en la protección social, dirigidos a la población excluida, planteando de esta forma estructuras de cobertura masiva con el objetivo de crear capital humano.

- Transferencias monetarias, programas dirigidos a la población más pobre usando la transferencia de renta con retorno a través de contrapartidas por parte de los beneficiarios como mecanismo de ejecución.

- Institucionalización de las estructuras sociales originarias, concibiendo a las sociedades como pluriétnicas, multiculturales y multilingües a nivel constitucional, implementación programas para mejorar las condiciones de vida y promover el desarrollo con identidad de los pueblos indígenas, en los ámbitos económico, social, cultural por medio de una apertura en el diálogo con los pueblos indígenas. (Principalmente en los países andinos)

- Incremento del gasto social durante las últimas dos décadas, como consecuencia de un contexto económico positivo.

- La descentralización y la reformulación en la prestación de servicios sociales

- Reformulación de la política social como un mecanismo orientado a crear "ciudadanía" por medio de un enfoque de derechos, estableciendo mecanismos de control social de las instituciones públicas por medio de una sociedad civil organizada.

- Se observa un incremento en la relevancia de las $O \mathrm{NG}^{\prime} \mathrm{S}$ en el diseño y aplicación las políticas sociales, se establecen mecanismos de control social de las instituciones públicas por medio de una sociedad civil organizada

- Creación de fondos sociales con el objetivo de invertir principalmente en zonas rurales, dándole prioridad a áreas vinculadas al desarrollo de servicios básicos.

- Creación de ministerios específicos a asuntos sociales para centralizar la implementación de políticas, evitando la yuxtaposición de las mismas, cambiando la estructura a través de la cual se ejecutaban políticas sociales. 
Tomando como referencia el contexto histórico en el cual se desarrollaron las políticas sociales en América del Sur y su relación con la cohesión se puede establecer una evaluación en lo que se refiere al impacto por medio de indicadores. La cohesión no es una condición objetiva que se puede medir fácilmente, en este sentido se implementó el instrumento de medición desarrollado por el BTI para determinar hasta un nivel aproximado el desarrollo de la cohesión por medio de un indicador general.

Para la evaluación de las políticas de Cohesión Social, se examina de forma específica si el conjunto de programas que integran estas políticas se encuentran organizados de manera consistente y coherente, de tal forma que los principios, las acciones y las actividades específicas de cada uno de ellos se muevan en la misma dirección, contribuyendo así en la solución del mismo problema, definido como procesos de exclusión (AGUILAR, 2008). Tomando en consideración esta revisión, se observa el comportamiento por país de la cohesión social dentro de la región de América del sur:

\section{Gráfico 15: Comportamiento del Nivel de Dificultad en América del Sur}

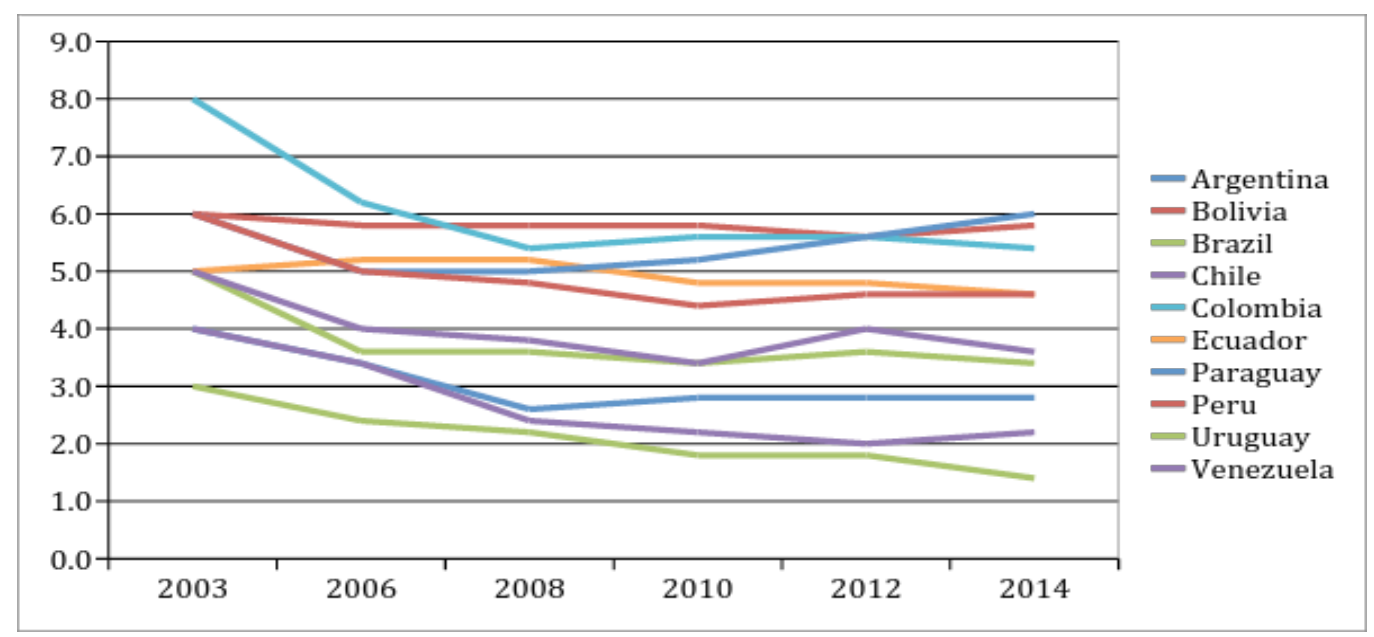

Fuente: Elaboración propia

De forma general podemos afirmar que la región avanzo en términos de cohesión durante la última década, todos los países reflejaron avances significativos, algunos de forma más acelerada que otros, como lo fue el caso de Colombia, el país en donde se observa la mejora más elevada, presentando una disminución de 8,0 en el 2003 a 5,2 en el 2014, esto debido a la 
disminución del conflicto armado por medio del proceso de paz y su inversión en la dimensión social alcanzando 6,0 en el Nivel de Dificultad para el 2014

El país con los mejores indicadores en el periodo evaluado es Uruguay, debido a la implementación de forma gradual de las reformas estructurales y la priorización de la dimensión social a la par de la económica estructurando un estado de bienestar sólido, como observado en nuestra evaluación por país, seguido por Chile que avanzo de 4,0 en el 2003 a 2,1 en el 2014. Paraguay presenta el peor desempeño en términos de cohesión al final del período evaluado, es el único país que refleja un aumento en el indicador Nivel de Dificultad. Bolivia presenta la mejora más moderada en el grupo de países de 6,0 en el 2003 a 5,9 en el 2014.

Brasil, Argentina y Venezuela presentan avances considerables en términos de cohesión, resultado de los elevados niveles de inversión social a través de diversos programas. Esto debe encuadrarse dentro del contexto de bonanza económica que vivió la región, lo que permitió mejoras de todos los países de la región.

Los países evaluados reflejan la relación Cohesión Social/ Calidad de la Democracia, presentada en el Capítulo 1, siendo afectada la calidad democrática por las mejoras en el Nivel de Dificultad, ya que las sociedades suramericanas cuentan con una acceso a elementos básicos que les permiten desarrollarse e incorporar características de ciudadanía activa, como se observa en el siguiente gráfico resultado de nuestro modelo:

\section{Grafico 4: Tendencia de la relación entre la cohesión social y la calidad} de la democracia en América del Sur

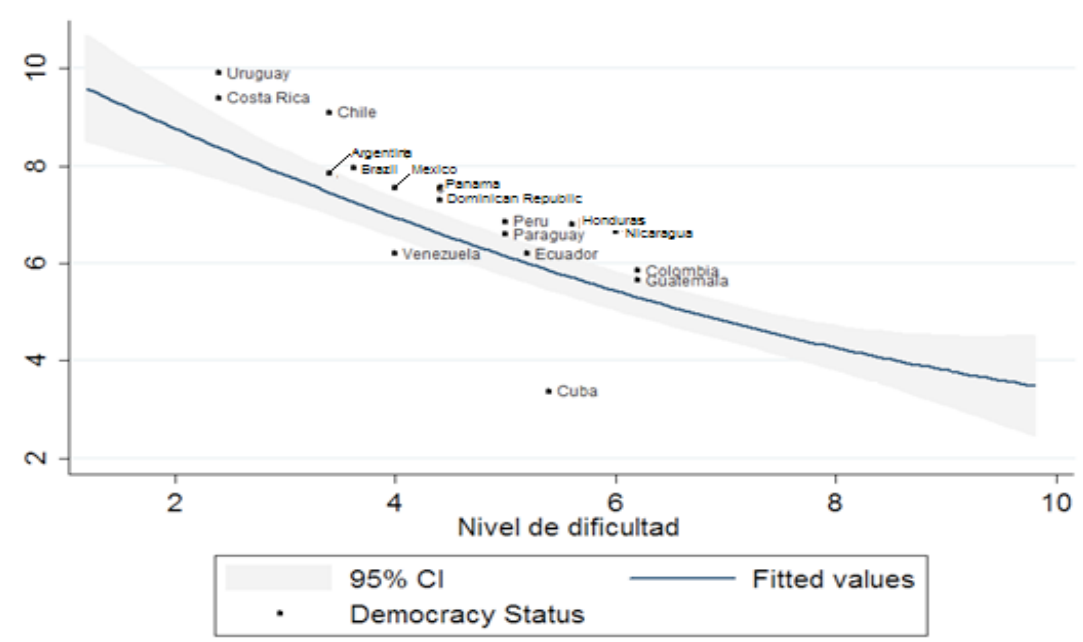

En la última década de acuerdo con el Banco Mundial (2014) se ha logrado sacar a más de 70 millones de personas de la pobreza, por medio de políticas enfocadas en la educación, 
infraestructura, seguridad social, inclusión de la población originaria y servicios de salud de mejor calidad, elementos que se constituyen como la estructura base de las políticas de cohesión.

De acuerdo con Briceño entender la equidad y las políticas sociales como un complemento es un equívoco:

"porque las políticas sociales no son un complemento, estas forman parte de un proyecto de construcción de las sociedades. Necesitamos construir democracias, necesitamos construir desarrollo económico, transformación productiva y también necesitamos construir equidad y esta se construye, en parte, con políticas sociales". Entrevista concedida por Briceño, Jose. Entrevista I. [jun, 2015]. Entrevistador: Erika Medina. São Paulo, 2010. La entrevista integral se encuentra transcrita en el Apéndice A de esta tesis.

El análisis expuesto busca comprender no solo como fue la evolución de los estados en términos de cohesión, sino también, prevenir cómo será la evolución en el futuro. La construcción de sociedades democráticas requiere de un crecimiento equitativo y de proporcionar a los individuos de herramientas que les permitan desarrollarse como ciudadanos activos y participativos en el contexto democrático. Para lograr una cohesión social en América del Sur hay que trabajar variables económicas, variables políticas y variables institucionales, como un todo, así como estructurarlos de forma sostenible a través del tiempo como un componente esencial dentro de una estrategia nacional. La cohesión es fundamental dentro de un marco de desarrollo y de construcción de calidad democrática en los países, por eso su relevancia.

\subsection{CONCLUSIONES}

Esta investigación busco realizar una aproximación de las dinámicas de cohesión a nivel mundial, con este objetivo se evaluaron los países que componen regiones específicas, Europa del Este y América del Sur. Estas dos regiones fueron seleccionadas por estar integradas por países en vías de desarrollo y por haber superado profundas transformaciones económicas, políticas y sociales, que afectaron la forma en que se desarrollaban las dinámicas de las sociedades, impactando de forma directa la estructura política. Vislumbrando problemas similares que se desarrollan en ambas regiones, en los cuales a pesar de la diversidad entre los países que las conforman, se comparten procesos y tendencias comunes.

La dimensión social de los sistemas estatales, continua presentando un elevado nivel de fragilidad, esto se ratifica por medio de la revisión realizada de la implementación de políticas sociales a través del Indicador Nivel de Dificultad. Las políticas evaluadas tienen un efecto directo sobre la cohesión social, lo que supone la existencia de una identidad colectiva 
fundamentada en la presencia de valores, intereses y motivaciones compartidas que pueden ser fortalecidas y desarrolladas por medio de este tipo de políticas.

El análisis de Europa del Este y América del Sur permitió la clasificación de las experiencias exitosas en términos de políticas sociales orientadas a generar cohesión, en este sentido el alcance de logros sustanciales y efectivos se debe fundamentar en el fortalecimiento del capital humano, reduciendo la vulnerabilidad de los individuos y promoviendo sus capacidades ciudadanas para alcanzar democracias con calidad.

Aun siendo regiones con características específicas en términos históricos, económicos, políticos y sociales, se ven afectadas por problemas sociales comunes vinculados a las ideas de inclusión/exclusión. Es importante resaltar que el fortalecimiento de la cohesión social se desarrolló por medio de una serie de aspectos tales como la progresiva universalización de la protección social; mejoramiento de la calidad y ampliación del acceso a los servicios públicos y a la justicia, sobre todo para los sectores más pobres de la población, por medio de la implementación de políticas activas de empleo y la ampliación de los derechos de los trabajadores, generando en consecuencia mecanismos sociales progresivos y solidarios, como sucedió en el caso Europeo.

Este fortalecimiento se dio por medio de la definición de tres aspectos comunes dentro de los países de ambas regiones, primero una vocación a resolver problemas concretos, implementación de un enfoque multidisciplinario, y la necesidad de establecer relaciones con lo mencionado anteriormente y el conocimiento para para mejorar la democracia y la dignidad humana, estos procesos se dieron en niveles diferentes en cada una de las regiones evaluados.

Se confirma que los países con políticas sociales multidimensionales presentan mejoras en los indicadores de cohesión, al observar el comportamiento de nuestros indicadores Nivel de Dificultad y Calidad de la democracia dentro de los países de América del Sur y Europa del Este, en donde fueron implementadas una serie de políticas que buscaban el establecimiento de estructuras sociales sólidas para alcanzar una ciudadanía activa y participativa, con capacidades de exigir derechos y ejercer control social para el funcionamiento de democracias con calidad, en algunos casos siendo efectivas y en otras manteniendo las estructuras de exclusión.

En el caso de Europa del Este, se implementaron reformas sociales solidas a la par de las reformas económicas por medio de un modelo dual con elementos del sistema de bienestar, características de redistribución sólidas y la garantía de derechos sociales universales. El enfoque de políticas sociales que se implementó en estos países es consistente con el debate científico en 
lo que se refiere a inversión social, confrontando los problemas estructurales y aumentando la eficiencia y efectividad de las políticas sociales.

En América del Sur aun cuando se observa un desarrollo positivo en la evaluación de la cohesión social dentro de la mayoría de los países, existe todavía una falta de comprometimiento por parte de los gobiernos en lo que se refiere a la implementación de políticas que tuviesen como foco la solución de problemas estructurales a largo plazo vinculados a la inclusión, se observa, en este sentido, que la implementación de políticas de carácter emergencial ha sido la constante durante las últimas dos décadas.

Por medio de nuestra evaluación para las dos regiones, aun con sus diferencias estructurales, se observan una serie de políticas multidimensionales que impactaron de forma directa y positiva los procesos de cohesión de ambas regiones, entre ellas tenemos:

- Fortalecimiento y fomento de la capacidad de acción de las ONG y de la sociedad civil, facilidades para la obtención de financiación extranjera, la cual estaba dirigida principalmente a la construcción de la sociedad civil

- Procesos de descentralización en la mayoría de funciones de bienestar social, colocándolas bajo la autoridad de los gobiernos autónomos locales

- Prioridad al desarrollo de las necesidades culturales de los grupos sociales minoritarios en el caso suramericano a las poblaciones originarias (principalmente en Bolivia, Perú y Chile), por medio de la creación de las condiciones para facilitar el acceso a valores culturales, determinando las posibilidades de desarrollo percibiendo a la cultura como un mecanismo integrador

Países con estructuras sociales en donde se ven reflejados elevados niveles de exclusión, falta de confianza y poco sentido de pertenencia tienden a sufrir de grandes limitaciones en la implementación de reformas políticas, como se observa principalmente en el caso de Bolivia y Paraguay con un Nivel de Dificultad superior a 5,0 y en el caso Europeo, en un nivel comparativa y proporcionalmente menor en Letonia y Rumania entre 2,9 y 3,0.

Los procesos en el ámbito social tuvieron ritmos diferentes en los países que conforman cada una de las regiones evaluadas, esto debido a las características diferenciadas en términos de recursos y sus contextos históricos particulares. En Europa del Este la intensidad de la inversión de la ayuda per cápita por parte de la Unión Europea para la dimensión social fue una de las mayores en el conjunto de la UE, en el caso suramericano no se contó con financiamiento para el desarrollo de políticas sociales por parte de los mecanismos de integración, tampoco se 
implementó una política conjunta entre los países, aun así los esfuerzos en términos de inversión social tuvieron efectos positivos, lo que se ve reflejado a continuación:

Grafico 17: Comparación del Nivel de Dificultad

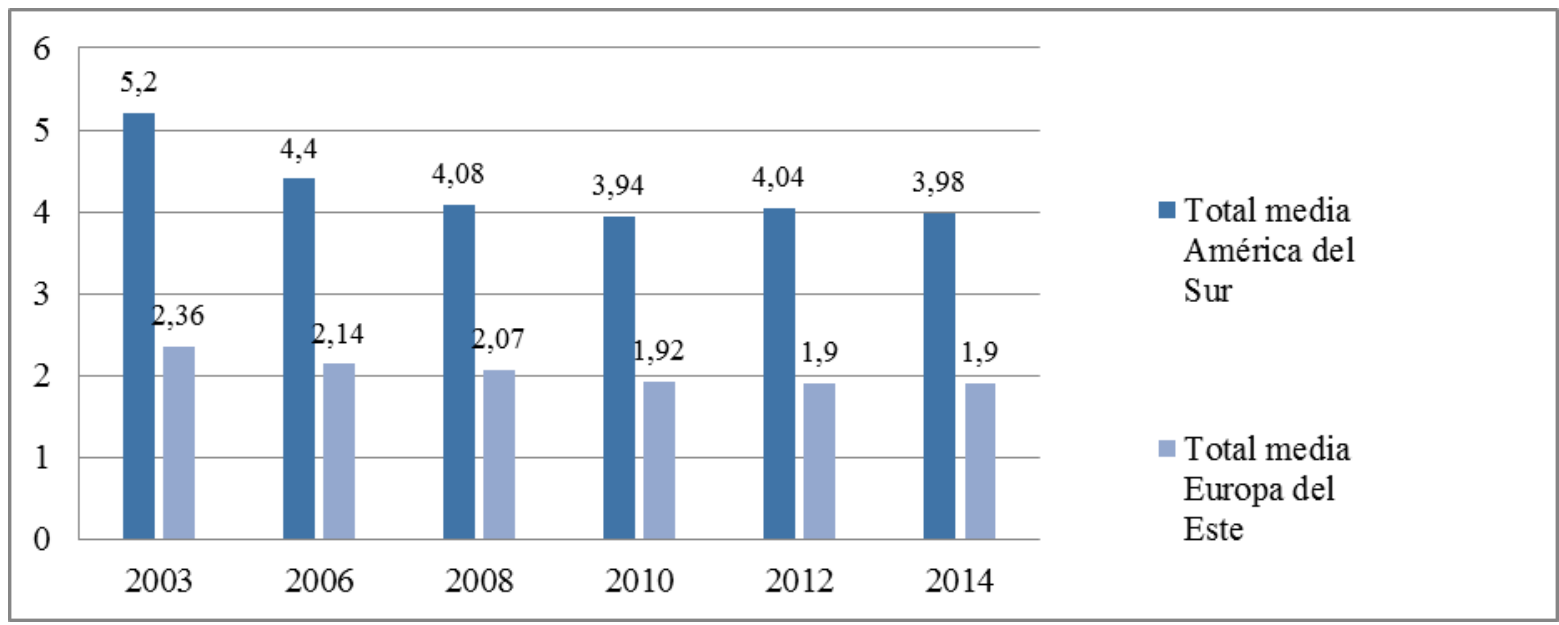

Fuente: Elaboración propia

Se observa una mejora progresiva en ambas regiones durante el período evaluado, como consecuencia del cambio en la forma que eran implementadas las políticas sociales. En Europa del Este el enfoque de cohesión proporcionado por la UE así como el financiamiento de diversos programas en el área, propicio mayores niveles de inclusión. En el caso suramericano también se dieron mejoras considerables, debido al contexto económico y a la reforma de la visión a través de la cual eran implementadas las políticas de cohesión, aun cuando los niveles de exclusión y desigualdad continúan siendo elevados y a la continuación de la pobreza multidimensional.

En definitiva podemos decir que los enfoques normativos de la cohesión están sometidos a una fuerte determinación histórica, respondiendo a características, trayectorias y necesidades propias, por esto la relevancia de nuestro análisis por medio del cual se observaron las características de las regiones de forma particular lo que generó una comprensión amplia de las complejas dinámicas que se desarrollan dentro de sus sociedades.

Como resultado de la evaluación realizada se afirma que América del Sur presenta ventajas su sentido de pertenencia e identidad cultural facilitando la implementación de políticas de cohesión social. La regiones el único caso de construcción de una identidad supranacional continental basada en una historia y civilización comunes, es una región posee fuertes valores familiares y religiosos, que influenciaron las dinámicas sociales a lo largo de su historia, en este sentido se caracteriza por tener estructuras ventajosas en términos de sentido de pertenencia y raíces culturales, con elementos tales como la comunidad y el mestizaje. 
Está caracterizada por tener factores subjetivos ligados a la cohesión social en términos históricos, culturales y religiosos, que tienen sus orígenes en las raíces iberoamericanas, lo que comprende valores, actitudes y percepciones que responden a múltiples señales que promueven la idea de una identidad común, presentando, un elemento transversal de identidad común definido como un sentido de pertenencia solido a la hora de establecer comparaciones con otras regiones, principalmente con Europa del Este, que posee características complejas en términos históricos, lingüísticos y culturales.

Esta identidad suramericana general facilita la implementación de las políticas sociales, ya que no se presentan grandes escenarios de exclusión debido a la reducida cantidad de conflictos étnicos y armados durante el siglo pasado, siempre buscando la resolución por medios pacíficos, con ventajas en los que se refiere a la homogeneidad lingüística, religiosa y raíces histórico-culturales. Este conjunto de países presenta un componente cultural común, aun cuando los países de América del Sur no ha contado con un mecanismo de integración promotor en términos financieros de este tipo de políticas sistémicas y a nivel nacional, tampoco se ha dado un compromiso político robusto en implementar estrategias de cohesión.

El contexto de crecimiento positivo suramericano durante la última década demuestra que las políticas sociales implementadas generaron procesos inclusivos importantes que se reflejan en el indicador de cohesión, aun con el contexto complejo de exclusión, demostrando que el papel de la comunidad es esencial en el avance para un desarrollo sostenible y democrático de las sociedades, en donde se debe abordar la pertenencia como un concepto dinámico, necesario para alcanzar estructuras sociales cohesionadas.

Aún con estos elementos positivos varios países de la región continúan presentando un modelo de autoridad que sigue la tradición paternalista dificultando la acción de estructuras diversificadas de implementación de políticas, principalmente en el área social, como lo es el caso de Venezuela, Argentina, Brasil, Bolivia y Ecuador, como lo refleja nuestra evaluación.

Europa del Este, por otro lado, presento una difícil transición a sociedades inclusivas estables, principalmente por la renovación de conflictos interétnicos, especialmente en los estados de Croacia, Rumania y Eslovaquia. Estos países tuvieron que buscar en la Unión Europea no sólo apoyo económico, acceso a mercados y asistencia técnica sino también el reconocimiento de su condición de "Europeos", es decir, de aquel sentido de pertenencia al continente. Estos países post comunistas, al contrario de algunos de sus homólogos occidentales, han sido objeto de políticas sociales ambiciosas y grandes reformas, por medio de la 
incorporación paulatina de una cultura de gobernanza con el apoyo de la cooperación internacional, en segundo lugar la consolidación de los espacios de concertación, mecanismos dedicados al diálogo y la participación de la sociedad civil para la implementación de políticas públicas sociales.

Los países que conforman Europa del este tuvieron que hacer una inversión amplia para desarrollar estos aspectos y crear un sentimiento de arraigo europeo por medio de programas como "EUROIDENTIDADES", que busco fortalecer el sentido de una unidad Europea, el "ENRI-East" enfocado en minorías nacionales y étnicas aisladas en términos históricos o en el "lado opuesto" de las fronteras nacionales de Europa del Este, el programa "CRIC" el cual busco el refinamiento de la comunicación entre los grupos integrantes de la UE, a través de la mediación y el enlace intercultural en áreas post-conflicto tales como la paz y la reconciliación, aspectos fundamentales en esta dimensión

El sentido de pertenencia y la identidad de una sociedad se constituyen como factores fundamentales para alcanzar el desarrollo y deben ser interpretados como un catalizador de la cohesión social, evitando la fragmentación y la pérdida de los lazos sociales estables, además de actuar como una herramienta frente a las brechas sociales ya existentes, la individualización y el debilitamiento de lo público. La región suramericana presenta un gran potencial en términos del desarrollo de la cohesión debido a lazo social estructurado a nivel ciudadano, que debe ser fomentado por medio de políticas multidimensionales que proporciones herramientas para generar una ciudadanía activa y participativa.

Otra conclusión importante es la afirmación de que las brechas sociales son el principal obstáculo para alcanzar desarrollo de la cohesión dentro de una sociedad. Se observa que América del Sur refleja de forma directa este postulado, históricamente se identificaron a la pobreza y la desigualdad como elementos constantes de sus sociedades afectando profundamente el desarrollo, por lo cual la mayoría de las políticas implementadas estuvieron focalizadas.

En los países que conforman América del Sur se observan varias constantes, en primer lugar las políticas sociales han sufrido de falta de continuidad, así como de la ausencia de un enfoque sistémico, para la disminución de las desigualdades, para alcanzar efectividad es necesario evaluar el contexto de forma amplia considerando a la dimensión social en conjunto con las dimensiones económicas, fiscales, laborales y medioambientales, garantizando su éxito frente a los desafíos multidimensionales que son el reflejo de una realidad con altos niveles de exclusión. 
En los últimos 20 años la región ha implementado de forma casi exclusiva políticas sociales de emergencia, focalizadas a asuntos específicos, las cuales concentran sus efectos sobre los grupos más pobres, esta situación creó un incremento en la segmentación, segregación y polarización social en diferentes niveles, demostrando que las políticas focalizadas pueden tener costos sociales/políticos elevados para una región con gran desigualdad. Esto nos lleva a concluir que las tensiones sociales, institucionales y culturales en América de Sur son numerosas, en comparación con otras regiones, y se caracterizan por un alto grado de participación ciudadana.

Durante el periodo de bonanza económica se dio un incremento considerable el gasto social de los países de la región suramericana como porcentaje del PIB, variación que dependiendo del país, vio duplicado el monto por habitante. Aún con este incremento positivo las políticas implementadas eran a corto plazo, de carácter emergencial, en conjunto con la ausencia de estructuras que permitiesen su sustentabilidad a lo largo del tiempo.

La complejidad de una estrategia estatal/regional por medio de políticas de cohesión, es que esta involucra a diversos actores políticos, ultrapasando limites jurisdiccionales y a su vez sectoriales, en este sentido la región suramericana se caracteriza por una estructura burocrática y con profundos problemas de articulación entre las distintas áreas del estado. Por lo tanto, las mejoras distributivas no solo son el resultado del incremento del gasto sino que dependen, de la capacidad para incorporar y mejorar los mecanismos de transferencia solidaria. Estas políticas implican el desafío de integrar la lógica de los incentivos con los de la construcción de mecanismos de solidaridad. Deben ser considerados aspectos como el agotamiento de la seguridad social como mecanismo de inclusión, el papel de la nueva protección social, así como la modernización de las políticas públicas.

Debe ser considerado a su vez que si bien la región ha buscado la reducción de la pobreza y la desigualdad en la última década por mecanismos tradicionales, también ha contribuido a aumentar el acceso a la tecnología a millones de personas en la región las cuales han incrementado sus niveles de educación, internacionalmente interconectados y participantes activos en las diversas redes sociales, teniendo una capacidad mayor en el acceso a la información.

Si se compara a América del Sur con Europa de Este, se observa que el éxito del desarrollo acelerado, en términos de cohesión, se dio por una serie de elementos, voluntad política, prioridad en la reducción de las desigualdades y una distribución positiva de los ingresos, situación que difícilmente iba a ser superada solo con la promoción del crecimiento a 
través del mercado sin necesidad de intervención del Estado, a su vez el contexto europeo no era caracterizado por brechas sociales profundas.

La adopción de un enfoque de cohesión en lo que se refiere a políticas públicas en un escenario que presenta recursos escasos para su financiamiento, implica la aceptación de una estrategia que abarque a la sociedad como un todo, evitando de esta forma procesos de exclusión, por medio de un Estado planificado que privilegie la protección social para evitar fracturas sociales, particularmente en la sociedad contemporánea que presenta altos niveles de individualización y exclusión. Este contexto genera dentro de las sociedades un refuerzo en los lazos de solidaridad, en el sentido de pertenencia así como un impacto positivo en la promoción de la ciudadanía en los individuos, permitiendo de esta forma que los individuos y grupos sociales intervengan en la gestión pública de una forma más activa.

Las exacerbadas las brechas sociales afectaron a los individuos, organizaciones y partidos políticos, piezas fundamentales en el proceso de democratización de América del Sur, pero que se vieron debilitados por la falta de capacidad de representación en las sociedades y en su dificultad para la ampliación de las oportunidades, la promoción del desarrollo de las capacidades y la conformación de redes más inclusivas de protección en las sociedades, siendo considerados los ciudadanos como actores vulnerables de estos procesos.

El contexto de elevadas brechas sociales en conjunto con otros aspectos, tales como la corrupción, el atraso estructural (en comparación con otras regiones), falta de competitividad e inversión, así como el elevado nivel de violencia, propició una disminución en el estado de bienestar en la mayoría de los países de América del Sur, aun con el crecimiento económico experimentado, que impulsó un conjunto amplio y diverso de políticas inclusivas, ese no contaba con una estructura especifica de cohesión ni fondos específicos para su financiamiento lo que disminuyo la efectividad de este tipo de políticas. 


\section{VULNERABILIDAD DEMOCRÁTICA Y COHESIÓN SOCIAL, CASO VENEZOLANO: EL PAPEL DE LAS ORGANIZACIONES DE LA SOCIEDAD CIVIL EN EL FORTALECIMIENTO CIUDADANO}

\subsection{Introducción}

Las relaciones entre los diferentes actores sociales deben ser interpretadas como complejas, ya que dependen de una diversidad de factores históricos, culturales, económicos, políticos y sociales, formando parte de un contexto multidimensional. Las organizaciones de la sociedad civil, por lo tanto, se consideran un objeto de análisis relevante dentro de los procesos de globalización, con un incremento en su número y relevancia dentro de las sociedades ${ }^{131}$, convirtiéndose en causa y efecto de cambios democráticos y sociales, ya que fomentan un desarrollo equitativo y contribuyen a la realización de políticas públicas más efectivas, plurales y eficientes.

La selección de Venezuela como caso de estudio se realizó debido a que este país se ha caracterizado por ser un líder regional en la implementación de programas sociales a través de las misiones, caracterizadas como un incremento importante en el gasto social de la nación ${ }^{132}$, cambiando completamente el status quo de la forma en que son implementadas las políticas sociales. Por otro lado, se observan una serie de aspectos que han afectado de manera negativa a la sociedad, como la dificultad para el desarrollo de una ciudadanía sobre la base del reconocimiento plural del otro, contrarrestando las diferencias políticas y de clase. Las organizaciones de la sociedad civil históricamente han buscado engranarse en una interacción

\footnotetext{
131 "De acuerdo con el Anuario de Organizaciones Internacionales, se informó que aumentaron de 6.000 en 1990 a más de 66.000 en 2012. Las OSC también se han convertido en actores importantes en la ayuda para el desarrollo global, en conjunto con la Organización para la Cooperación y el Desarrollo Económico (OCDE) el número de organizaciones no gubernamentales internacionales estimándose que en 2011, USD\$ 19.3 mil millones en ayuda oficial al desarrollo se canalizó a través de las OSC". (Banco Mundial, 2015) Texto original: "According to the Yearbook of International Organizations, the number of international NGOs was reported to have increased from 6,000 in 1990 to more than 66,000 in 2012. CSOs have also become significant players in global development assistance, with the Organization for Economic Cooperation and Development (OECD) estimating that in 2011, USD\$19.3 billion in official development assistance was channeled through CSOs".

132 "La conformación de las Misiones Sociales, a partir de 2003, planteó un nuevo escenario para la intervención social del Estado. Estos programas se propusieron masificar -en un plazo breve- diversas medidas de atención, hacia los sectores populares y en pobreza en especial, en materias prioritarias como la alimentaria (Mercal y PDVAL), la educativa (Misiones Robinson, Ribas y Sucre), y la de salud (Misión Barrio Adentro) utilizando, en casos como los dos últimos, el Convenio Cuba-Venezuela -firmado en el 2000- para su desarrollo. Estas Misiones han ocupado (aunque con fluctuaciones) un lugar central en la agenda de prioridades gubernamentales y llegaron a representar entre 2006 y 2007 un estimado del 25\% del gasto social, convirtiéndose en la principal novedad de la política social gubernamental”. (APONTE, 2012)
} 
permanente con el Estado buscando conexiones y recursos, creando lazos entre diferentes formas de poder y a su vez con las masas de individuos que conforman la sociedad, lo cual en el contexto venezolano se ha visto dificultado y por estos motivos se considera como un país relevante a ser evaluado en términos de las dinámicas de cohesión dentro de su sociedad, con un foco en el papel de las organizaciones de la sociedad civil.

De acuerdo con García Guadilla (2003) existen una serie de aspectos que han generado este escenario, vinculados principalmente a la falta de institucionalidad, entre ellos: la falta de consenso para reconstruir democráticamente las instituciones que sustentan la Constitución de 1999, la carencia de una cultura política democrática que coadyuve en la resolución de los conflictos, el debilitamiento de las reglas de convivencia y la existencia de una alta polarización de clases sociales.

Esta polarización ha generado un impacto en las relaciones entre los individuos que forman parte de la sociedad, incluyendo a las organizaciones de la sociedad civil, que tienen como objetivo principal el desarrollo de actividades en diversas áreas (desarrollo social, político, ciudadano, medioambiental, derechos humanos, entre otros), consideradas como estructuras fundamentales en el ejercicio de la construcción y el fortalecimiento de ciudadanía, promoviendo la instauración de una cultura democrática y un sistema participativo. Surgiendo, como una respuesta a la problemática social que no era atacada de forma efectiva por parte de las instancias gubernamentales, dando continuación a los procesos de exclusión en los grupos de población con mayores necesidades.

En este contexto, las organizaciones de la sociedad civil venezolana vinculadas a la promoción de la Participación y los Derechos ciudadanos, han tenido un rol fundamental, debido a su capacidad para el establecimiento de mecanismos de conciliación y fortalecimiento ciudadano. Caracterizándose como un hecho evidente que al intervenir en la estructura pública, este tipo de organizaciones genera un impacto en la dinámica del poder político. Este impacto ha producido una serie de reacciones a nivel gubernamental afectando las relaciones OSCGobierno, viéndose reflejadas en modificaciones de leyes y en una dialéctica agresiva, tanto en la interpretación de las actividades desarrolladas como de las fuentes de financiamiento de estas organizaciones.

Estos cambios deben ser evaluados de forma detenida y objetiva, ya que se produjeron transformaciones tanto en la interpretación de este tipo de mecanismos por parte del gobierno como en las relaciones entre las organizaciones de la sociedad civil, dentro de las cuales se ha 
realizado un esfuerzo para ejecutar acciones, proyectos concertados y complementarios al Estado, aun en un escenario caracterizado por estereotipos vinculados a la existencia de posiciones irreconciliables en términos políticos.

Esta investigación busca evaluar las relaciones de las organizaciones de la sociedad civil en un contexto definido por un marco legal restrictivo y enfrentando prácticas gubernamentales que dificultan su autonomía en la cual se ha desarrollado una mayor articulación entre estos actores, tomando como base la interpretación de red por parte de Canto (2002):

-Una red está integrada, de manera más o menos estable, por un conjunto de organizaciones vinculadas por relaciones de interdependencia en torno de intereses u objetivos comunes;

-Se ubican en un entorno de crecimiento de la complejidad social, que tiende a rebasar la centralidad de cualquier actor social y que coexiste con múltiples formas de agregación social;

- Surgen a partir de las limitaciones que cada una de las organizaciones tiene en lo individual para el logro de sus objetivos, en este sentido, se plantean objetivos que no podrían ser alcanzados de manera individual.

-Se identifican en torno a un conjunto de valores compartidos a partir de los cuales se diseñan estrategias comunes.

De acuerdo con Knoke (1999) apud Lozares (2011) "los actores crean y movilizan sus conexiones reticulares dentro y entre organizaciones para conseguir acceso a los recursos de otros actores", por otro lado Portes (1998) establece que existe una "capacidad/habilidad de los actores para asegurarse beneficios por pertenecer a redes sociales". Baker (1990) lo considera como un recurso que los actores extraen de estructuras sociales específicas y que usan para sus intereses, generándose debido a los cambios de las relaciones entre actores.

Las redes se constituyen como un elemento fundamental a la hora de evaluar la cohesión dentro de una sociedad/colectivo, siendo interpretada como el proceso que genera redes sociales e infraestructuras que las sostengan para que los ciudadanos existan como sujetos reales humanos y sociales (Beck et al., 1997). De acuerdo con Lozares et al. (2011) la Cohesión social se compone de un componente formal de redes-relaciones definidas como bonding ${ }^{133}$, las cuales poseen como uno de sus indicadores la densidad de sus relaciones, que mide la intensidad de la

\footnotetext{
133 "Formas relacionales hacia dentro y horizontales, de distribución del Capital social en un colectivo" (Lozares et al, 2011)
} 
cohesión interpretada como un recurso relacional a partir de la distribución de Capital social. En este sentido se debe considerar a la cohesión como el "pegamento" que vincula la sociedad como conjunto, la solidaridad y las relaciones sociales, los valores e identidades, sin la Cohesión no se generan procesos de interacción y sin ella no hay identidad colectiva y vida social (Beck, 1997 apud Lozares, 2011).

Por medio de estas características se interpretan las redes de articulación establecidas en la actualidad entre las organizaciones de la sociedad civil en derechos y participación ciudadana, a traves de de una evaluación del contexto actual que propicie el desarrollo de estos lazos, que han buscado el fortalecimiento de los vínculos entre las OSC, para dar mayor solidez a las actividades y proyectos desarrollados por estas instituciones en un escenario complejo. El fortalecimiento de este tipo de relaciones es el aspecto en el cual radica nuestro interés, interpretando la forma en que se estructuran estos vínculos y su impacto en el desarrollo actual de las organizaciones.

\subsection{Metodología}

En este análisis se realiza un estudio referente a las interacciones de las Organizaciones de la sociedad civil promotoras de la participación y los derechos ciudadanos en Venezuela, por medio de encuestas cualitativas a ser evaluadas a partir de la teoría de redes sociales, analizando el conjunto de relaciones generadas entre este grupo de actores por medio de una red, buscando definir el comportamiento de los mismos, su densidad y el establecimiento de patrones. Este tipo de investigación de redes sociométricas ha sido profundamente influenciada por el campo de la Sociología por medio de la suposición de que la participación de los actores dentro de un sistema y las relaciones surgidas de estas interacciones presentan características relevantes (Waserman; Faust, 1994).

En este sentido, el análisis implementado buscó evaluar a organizaciones de la sociedad civil en el área de participación y derechos ciudadanos, que tienen como objetivo develar la estructura y la composición de esta red específica en el contexto de polarización política venezolana, por medio de relaciones tanto de contenido como de forma (Knoke;Kuklinksi, 1982 apud Molina; Maya, 2010), evaluando atributos y características, pero centrando la atención en las relaciones entre los actores, clasificando este estudio por medio de la definición de los siguientes aspectos: 
- Organizaciones de la sociedad civil que presentan elevados niveles de interconexión con sus pares

-Tipo de conexión entre los actores (existencia de relaciones de interdependencia, sentido de las relaciones)

-Fortaleza de los lazos entre los actores

-Aumento o disminución de las relaciones colaborativas a través del tiempo.

En este sentido, se definió una red de 27 organizaciones de la sociedad civil que trabajan específicamente con el tema de participación y promoción de derechos ciudadanos, tomando en consideración cuestiones relativas a las dinámicas entre ellas y observando la capacidad de relativizar el grupo observado con respecto a otros grupos de organizaciones. Con este objetivo, fue implementado un cuestionario entre los actores seleccionados, con preguntas vinculadas al tipo de relación existente con sus pares y desarrollo de proyectos conjuntos, buscando establecer la fortaleza de sus lazos en este contexto político complejo, trazando los cambios que se generan en un escenario atípico en términos políticos, económicos y sociales como lo es el venezolano.

La estructura implementada puede ser definida como mixta y explicativa, la cual tuvo su inicio con la recolección cuantitativa de los datos, complementada a través de preguntas cualitativas, definida como un análisis multinivel, generando las siguientes hipótesis:

1) "La polarización política venezolana ha reafirmado el papel de las organización de la sociedad civil como promotoras de la cohesión social"

2) la polarización y exclusión política fortalece el diálogo y la cooperación entre las organizaciones de la sociedad civil

Esta investigación busca realizar una aproximación a las dinámicas entre actores sociales y su efecto en el desarrollo de cohesión, que se da en distintos niveles tanto en el individual micro, como macro, por medio de este tipo de colectivos o entidades civiles que afectan las dinámicas estatales.

\subsection{Sociedad civil organizada y su papel como promotora de la cohesión}

La sociedad civil, en el mundo contemporáneo, es uno de los actores más importantes en lo que se refiere al alcance de derechos y cambios dentro de las sociedades, por medio de la acción conjunta de los individuos, ejerciendo una amplia influencia en la percepción de los ciudadanos. En un escenario que se caracteriza por: conflictos dentro de los Estados, dificultades para la profundización de la gobernabilidad democrática y un incremento de las desigualdades 
económicas, la acción ciudadana tiene un efecto fundamental en la consolidación de las capacidades de la democracia por medio de la acción colectiva. De acuerdo con Bobbio (1989) apud CIVICUS (2010) :

"la sociedad civil es la sede donde se forman, especialmente en los periodos de crisis institucional, los poderes que tienden a obtener su legitimidad incluso en detrimento de los poderes legítimos; donde, en otras palabras, se desarrollan los procesos de deslegitimación y de relegitimación. De aquí la frecuente afirmación de que la solución de una crisis grave que amenaza la sobrevivencia de un sistema político debe buscarse ante todo en la sociedad civil, donde se pueden encontrar nuevas fuentes de legitimación y, por tanto, nuevos espacios de consenso."

En este sentido, el contexto contemporáneo ha generado cambios en las relaciones de la sociedad civil en diferentes niveles. De acuerdo con Taylor-Gooby (2012) puede ser evaluado a partir de la transformación de la forma en que se interpretan diferentes corrientes teóricas. La economía política, de acuerdo con Jessop (2002), resalta la disminución de la influencia del Estado-nación y las instituciones colectivas de capital y trabajo vinculadas a este. La ciencia política, de acuerdo con Snow et al. (2004) apud Taylor-Gooby (2012), establece la existencia de cambios en la estructura de clases y la creciente diversidad de los intereses y movimientos sociales vinculados a ellos. La sociología, por su parte, se centra en el aumento de los niveles de la educación y la confianza de los individuos, la disminución de la deferencia social y la confianza en el gobierno (Giddens, 1994), así como en el desarrollo de una sociedad más conectada en redes, donde se establecen de forma más fácil las asociaciones, el debate y la transferencia de información (Castells, 2002). Todos estos elementos generan la estructura en la cual la sociedad civil organizada surge como uno de los actores esenciales para el desarrollo.

En este contexto de transformaciones, debe considerarse el enfoque de Putnam (1993), el cual, por medio de su análisis del capital social ${ }^{134}$, interpretado como rasgos de las organizaciones sociales, establece que la participación en las organizaciones de voluntarios y otras instituciones de la sociedad civil fortalecen, tanto la confianza en los demás ciudadanos, como en la capacidad de interactuar entre ellos, resultando en una cooperación social que se expande en beneficio mutuo de los actores. Este fenómeno de las organizaciones de la sociedad civil se ve reflejado por medio del capital social y el papel esencial de la sociedad en la promoción de la cohesión social, relevando su protagonismo al Estado.

\footnotetext{
134 "features of social organization, such as trust, norms and networks that can improve the efficiency of society by facilitating coordinated actions" (Putnam et al., 1993, p. 167)
} 
Por medio de esta visión, que ha recibido críticas por su carácter funcionalista, la promoción del capital social genera el establecimiento de un mayor nivel de cohesión dentro de una sociedad, Putnam (1993) señala que este incremento, en conjunto con la solución efectiva para disminuir las desigualdades, requiere de asociaciones conformadas entre los miembros de una comunidad, buscando superar las diferencias y generando, en consecuencia, una ciudadanía inclusiva y participativa, por lo tanto, su objeto debe ser interpretado como el colectivo.

Es relevante mencionar la visión de Coleman (1990) en lo que se refiere al Capital social por medio de la sociedad civil y el análisis de redes. El autor establece que el Capital Social está compuesto por una diversidad de entidades, con la característica común de constituir algún aspecto de la estructura social y de facilitar acciones, intereses y recursos para los individuos dentro de la estructura, "en este sentido, el Capital social es una estructura relacional y funcional" (Adler; Kwon, 2000 apud Lozares et al, 2011).

Inglehart (1997) vincula la idea de capital social a una "cultura de la confianza y tolerancia de la que emergen redes extensas de asociaciones del voluntariado", por lo que las organizaciones de la sociedad civil deben encuadrarse en este renglón, como producto del capital social desarrollado y generadoras de cohesión.

Tomando estos conceptos de cohesión y capital social, es importante resaltar que existen una serie de características específicas de la sociedad civil que deben ser resaltadas. De acuerdo con Sorj apud Jacome (2007) son dos principalmente. En primer lugar, su estructura "dinámica y diversa", la cual impide el establecimiento de generalizaciones en su concepto, ya que depende de la estructura en la cual está insertada en términos históricos, culturales, demográficos, etc, compuesta a su vez por una "pluralidad de actores, iniciativas y temáticas" (DARCY DE OLIVEIRA, 2005 apud JACOME, 2007), no teniendo una estrategia de poder definida. En segundo lugar debido a que representan intereses diversos de la ciudadanía y están compuestos de diversos actores, se establecen como formas alternativas de representación política. Y en último lugar busca la construcción de valores colectivos dentro de los espacios públicos.

De acuerdo con Sorj y Martucelli (2008) la sociedad civil volvió a estar "de moda" como consecuencia del periodo de lucha contra los regímenes militares autoritarios en América Latina y los regímenes totalitarios en Europa del Este, representando un conjunto extremadamente heterogéneo de actores unificados por un objetivo común de lucha entre ellos: los procesos de democratización. Posteriormente se transformaron en un elemento central de la vida política de las sociedades, abarcando diversas áreas de acción social, siendo considerados por el imaginario 
colectivo como una expresión de respuesta a la crisis de representación de las democracias contemporáneas.

En este sentido, podemos afirmar que en el contexto contemporáneo existe una revalorización de la sociedad civil, en lo que se refiere a las tendencias políticas existentes. Por un lado, las de izquierda, que separan a la sociedad civil de la idea del mercado y del estado, por el otro lado, las de derecha, estableciendo que este tipo de estructuras disminuirían el papel del estado (ídem). En este contexto ideológico la sociedad civil pasó a tener como principal actor a las organizaciones de la sociedad civil.

De acuerdo con Serva (1997), este tipo de organizaciones deben ser consideradas como aquellas que no poseen características estatales ni privadas, ejerciendo sus actividades en diversos sectores tales como educación, salud, defensa de las minorías, cultura, entre otros, sin fines de lucro, expandiéndose por la mayoría de los países, trayendo innovaciones en la configuración de la sociedad civil vinculadas a la diversidad de visiones.

De acuerdo con Sorj y Martucelli (2008), estas organizaciones representan a un público determinado, afirmando su legitimidad, colocándose como formuladoras de demandas hacia los gobiernos, no estando estructuradas como un grupo de acceso al poder del estado, las cuales se basan en:

"la fuerza moral de sus argumentos y no por su representatividad, estableciéndose como algo nuevo, un conjunto de organizaciones que promueven causas sociales sin recibir el mandato de las personas que dicen representar" (traducción libre del autor) ${ }^{135}$

Muchas de estas organizaciones de la sociedad civil han demostrado su capacidad para la movilización y la promoción de un gobierno responsable, por medio de la estructuración de demandas sociales, con miembros que ofrecen, muchas veces, de forma voluntaria, su tiempo y experiencia, para la ejecución y desarrollo de actividades vinculadas a estos objetivos (CIVICUS, 2011).

Estas deben ser interpretadas como un cambio profundo en lo que se refiere a la representación política. En el siglo pasado la representación de las causas sociales eran canalizadas por los sindicatos y por los partidos políticos (SORJ; MARTUCELLI, 2008), escenario que se vio profundamente transformado debido a las dinámicas económicas, políticas y

\footnotetext{
135 Texto original: "afirmam sua legitimidade na base da força moral de seus argumentos e não por sua representatividade, trata-se então de algo novo, de um conjunto de organizações que promovem causas sociais sem receber o mandato das pessoas que dizem representar"
} 
sociales, buscando establecer una relación más transparente, tanto con el sistema político, como con los movimientos sociales.

La acción de la sociedad civil, por medio de estas organizaciones, facilita la participación de los grupos sociales en situación de pobreza y con características de vulnerabilidad, en la implementación de políticas y programas de desarrollo que buscan alcanzar su bienestar, ya que se establecen como estructuras capaces de generar vínculos entre los individuos en situación de exclusión y la articulación de sus demandas.

Por medio de esta afirmación, la cohesión social aparece como un objetivo relevante dentro del contexto de las organizaciones de la sociedad civil, debido a que este tipo de mecanismo permite la adopción de estrategias integradas y adaptadas a la realidad de cada sociedad, para mejorar la interacción de las políticas que promuevan la inclusión social y el ejercicio de los derechos de ciudadanía, que de acuerdo con Martin Carretero (2008) pueden ser definidas en cuatro áreas: las políticas de creación de empleo, el acceso a los servicios de protección social, el acceso a la justicia (para generalizar el disfrute de los derechos) y el fomento del sentimiento de pertenencia a la comunidad política y la participación ciudadana en los asuntos públicos.

El enfoque de cohesión presenta características multidimensionales, las cuales, buscan establecer un marco metodológico, para interpretar el papel que puede jugar la sociedad civil organizada, en lo que se refiere a su promoción, por medio de propuestas que permiten definir una estructura para la participación de las organizaciones de la sociedad civil en el desarrollo de planes, acciones y estrategias orientadas a la cohesión social (ídem).

En la actualidad existen una serie de características que han reconfigurado el orden global hacia sociedades complejas y fragmentadas, en donde se observa que las estructuras tradicionales de construcción de ciudadanía, que se ven sobrepasadas por las nuevas realidades políticas, sociales y económicas, requieren de nuevas estrategias para reestructurar la inclusión y el desarrollo de sus sociedades. De acuerdo con Martin (2008), estas tendencias son: el incremento de la base tecnológica y el aumento exponencial de las posibilidades de comunicación, la prioridad de la tesis vinculada a la efectividad del libre mercado y capitalismo (aún con profundas críticas), la aparición de una incipiente estructura de gobernanza global, a través de las $\operatorname{organizaciones~internacionales~}^{136}$, la irrupción de nuevos sujetos económicos, políticos y

\footnotetext{
${ }^{136}$ Tales como el Banco Mundial, Fondo Monetario Internacional, Programa de Naciones Unidas para el Desarrollo
} 
sociales, que compiten con los Estados por la condición de protagonistas de la sociedad internacional ${ }^{137}$ y el desarrollo de procesos de integración regional.

En este sentido, la participación ciudadana por medio de las organizaciones de la sociedad civil surge como un medio, para mejorar los procesos inclusivos y democráticos, al aumentar la calidad de las políticas públicas, y como un fin, generando una mayor organización social lo cual deriva en un fortalecimiento cívico (ídem). Esto se debe a que este tipo de organización favorece la creación de consensos sociales y a su vez aumentan los niveles de legitimidad de las políticas gubernamentales, estableciendo nuevos cauces de comunicación en la identificación de demandas sociales y reforzando los vínculos sociales, lo que resulta en un fortalecimiento del sentimiento de pertenencia de una comunidad, generando capital social y robusteciendo los procesos de cohesión social.

\subsection{Organizaciones de la sociedad civil como mecanismo de cambio social: Venezuela, polarización y exclusión ciudadana}

Venezuela, a diferencia de los otros países de América del Sur, era considerada un ejemplo para la región, en términos políticos, debido a la solidez de su democracia y estabilidad social durante los años setenta y ochenta, sin embargo, de acuerdo con lo establecido por Tulchin y Rothenburg (2007), en la década de los noventa presentó características de tensión y crisis en aumento, con profundos debates en lo que se refiere a la consolidación de la democracia, las instituciones democráticas y las dinámicas de participación ciudadana.

Históricamente el concepto de sociedad civil tuvo dos interpretaciones (CIVICUS, 2010), la primera formulación tiene sus inicios durante los años setenta y se fundamenta en un discurso contra los partidos políticos estableciendo una oposición "maniquea" entre el Estado, caracterizado como corrupto, ineficiente y clientelar, y una mítica sociedad civil, entendida como la síntesis de todas las virtudes ciudadanas: creativa, con iniciativa, eficaz, honesta y participativa" (Lander, 2000 apud CIVICUS, 2010). La otra concepción, desarrollada posterior al debate constitucional de 1999 "rechaza la denominación sociedad civil, a la que identifica con

\footnotetext{
${ }^{137}$ Compañías transnacionales, las organizaciones intergubernamentales, el crimen organizado, las grandes organizaciones no gubernamentales de carácter internacional, los grandes conglomerados de medios de comunicación de masas
} 
atributos de clase social, utilizando en su lugar términos como pueblo organizado o soberano, siendo los movimientos populares el actor privilegiado", que marcó profundamente el desarrollo de la misma por medio de organizaciones.

Las profundas transformaciones políticas y económicas que atravesó Venezuela en las últimas décadas, afectaron el desarrollo del área social y la forma en que se organiza la sociedad civil, en este sentido, podemos observar tres fases vinculadas al desarrollo de la sociedad civil, de acuerdo con García-Guadilla (2003). La primera fase surge posterior al pacto de punto fijo en $1958^{138}$ y va hasta el final de la década de los setenta, caracterizándose por la formación de organizaciones sociales autónomas y movimientos sociales, por medio de la institucionalización de la democracia representativa. La segunda tiene su inicio a partir de los años ochenta en la cual se da una nueva fase de consolidación y diversificación de las organizaciones de la sociedad civil, debido a los procesos de descentralización que se generaron en todos los niveles del Estado, creando un contexto propicio para el surgimiento de las mismas, esta fase se extiende hasta 1998 .

Tabla 30: Principales características de la Sociedad Civil Venezolana

\begin{tabular}{|c|c|}
\hline $\begin{array}{c}\text { Contexto de la Sociedad Civil } \\
\text { Pre-Gobierno Chávez }\end{array}$ & $\begin{array}{l}\text { Contexto de la Sociedad Civil } \\
\text { durante el Gobierno Chávez }\end{array}$ \\
\hline - Crisis de los partidos políticos & $\begin{array}{l}\text { - Alta participación de las } \\
\text { organizaciones de la sociedad civil } \\
\text { en la nueva constitución de } 1999\end{array}$ \\
\hline $\begin{array}{l}\text { - Descentralización a nivel } \\
\text { institucional }\end{array}$ & - Democracia participativa \\
\hline $\begin{array}{l}\text { - Alianzas entre el Estado y las } \\
\text { organizaciones de la sociedad } \\
\text { civil para la prestación servicios }\end{array}$ & $\begin{array}{l}\text {-Auge de las organizaciones de la } \\
\text { sociedad civil, cívicas y los nuevos } \\
\text { movimientos populares }\end{array}$ \\
\hline $\begin{array}{l}\text { - Anti partidismo y } \\
\text { diversificación de la Sociedad }\end{array}$ & $\begin{array}{l}\text { - Establecimiento del Socialismo del } \\
\text { siglo XXI Proyecto Simón Bolívar y }\end{array}$ \\
\hline
\end{tabular}

\footnotetext{
${ }^{138}$ Pacto que sentó las bases de la alternabilidad política y la convivencia tanto política como social entre los partidos políticos existentes. A partir de este acuerdo, se desarrollaron las raíces de la democracia como se conoció los siguientes 40 años.
} 


\begin{tabular}{|l|l|} 
- Modelo Corporativista & $\begin{array}{l}\text { Poder Popular Polarización } \\
\text {-Dos tipo de sociedad civil } \\
\text { conviviendo en paralelo }\end{array}$ \\
\hline
\end{tabular}

Fuente: Elaboración propia con base en CIVICUS (2010)

La última fase tiene su inicio con la llegada al poder de Chávez en 1999, que trajo consigo profundos cambios económicos y políticos por medio de la implementación de la "revolución bolivariana". Este proceso de transformación se caracterizó por el conflicto político, a través de la confrontación de clases y la profundización de la conducta clientelista EstadoSociedad civil, trayendo consecuencias negativas dentro de la sociedad venezolana. De acuerdo con Jacome (2007), se generó una "mayor diversificación de las organizaciones de la sociedad civil en diversas áreas y se promovió una política conflictiva que condujo a una mayor fragmentación de este espacio social", esto tuvo su inicio con el proceso de refundación de la República y en consecuencia, la transformación de todas las estructuras institucionales repercutiendo en la ciudadanía.

El conjunto de reformas implementadas con el inicio del gobierno de Chávez generó un contexto convulso, que resultó en radicalismos políticos y en consecuencia una amplia polarización social. El concepto de polarización, de acuerdo con Lozada (2002), se define como "un posicionamiento radical de los individuos y grupos en las facciones que forman parte del conflicto, con aspectos vinculados a la exclusión" ya que ambas partes involucradas niegan la legitimidad o la existencia de la otra "generalmente con una fuerte carga emocional que involucra la vida personal dentro del conflicto político" (idem).

Es necesario hacer énfasis en las consecuencias negativas que traen este tipo de procesos de radicalización a una sociedad, debido a que son establecidas estructuras caracterizadas por la exclusión de los actores que forman parte de ella. De acuerdo con Álvarez (1996), en el nivel político generan:

"la deslegitimación de las instituciones que, dentro del Estado, están capacitadas para intervenir en la resolución de los conflictos: poder electoral, poder judicial, poder legislativo, etc., dejando a los/as ciudadanos/as en una especie de mezcla explosiva entre deriva, desesperanza, desconfianza y pesimismo"

Tomando en consideración estas estructuras, el caso venezolano surge como consecuencia de una serie de aspectos históricos, fomentando estos procesos de polarización 
social, procesos que deben ser considerados como relevantes para la comprensión de las transformaciones en Venezuela. De acuerdo con Mireles (2007) estos aspectos se pueden caracterizar de la siguiente forma:

1) Debilidad institucional del estado, ya que históricamente Venezuela se caracterizó por ser un país con elevados ingresos producto de la renta petrolera, con una administración poco eficaz de los recursos, imposibilitando la implementación de políticas apropiadas.

2) Inequidad en la distribución de la riqueza y agotamiento del modelo rentista para generar progreso

3) Desgaste del sistema político venezolano bipartidista y un proceso de deslegitimación de los espacios naturales de participación política, generando profundas crisis institucionales y sociales en la búsqueda de un contexto de renovación.

4) Desconocimiento de formas constructivas para la resolución de conflictos, afectando la tolerancia de la sociedad civil, debido a la falta de fortalecimiento de instituciones capaces de solucionar las pugnas existentes e impidiendo el florecimiento de organizaciones de la sociedad civil con la capacidad de aplicar formas alternativas de resolver esos conflictos.

5) Rol protagónico de los medios de comunicación en la vida política nacional, como una de las instituciones con mayor respaldo y confianza por parte de la ciudadanía, suplantado el rol que deberían cumplir los partidos políticos como instituciones de representación social.

Este escenario llevó a la búsqueda de una transformación económica, política y social por parte de la ciudadanía, que se vio identificada en el carismático liderazgo de Chávez, que reflejaba una respuesta a este clamor por parte de la sociedad venezolana. De acuerdo con Darcy de Oliveira (2005) apud Jacome (2007) este tipo de liderazgos populistas, es el resultado de una crisis de legitimidad estructural, producto de la desconfianza mutua entre las instituciones políticas y la ciudadanía, generando un escenario en el cual los actores se encuadran en dinámicas de polarización, como las observadas en la Venezuela contemporánea.

En este ambiente político complejo, las organizaciones de la sociedad civil se constituyen como espacios eficientes para expresar los conflictos y controversias que no son respondidos por parte de la estructura gubernamental, fomentando la interacción entre diversos actores sociales, principalmente aquellas que buscan la promoción de su participación y la defensa de sus 
derechos, convirtiéndose en herramientas para mediar en entornos que favorecen la radicalización y propiciar el desarrollo.

Tomando en consideración todos estos aspectos, se puede decir que en 1999 comienza un proceso que impactó profundamente a la sociedad civil y las dinámicas que se generanron dentro de ella. De acuerdo con Jacome (2007), a partir de este momento se diferencian tres fases en el gobierno de Chávez. La primera, que se caracteriza por el establecimiento de una nueva constitución, que propuso la profundización de la participación de la sociedad civil. Durante el proceso de reformulación constitucional, aun con la participación de ONG de diversas áreas de actuación e intereses se "revela cómo la heterogeneidad de la sociedad civil y de la diversidad de intereses no impidieron la cooperación y la solidaridad entre organizaciones" (idem).

Dentro de esta reforma, se define un vínculo prioritario entre el estado y la sociedad civil, por medio de la caracterización de una verdadera responsabilidad compartida, cambiando profundamente la estructura social, ya que se establece el poder soberano y el empoderamiento como los canales principales de participación política, siendo incorporadas a las "fases de la formulación, ejecución, evaluación y control de las políticas públicas" (JACOME, 2007).

Aun con este marco positivo, se observan contradicciones a nivel gubernamental, ya que la misma asamblea que promueve estos cambios establece una definición de sociedad civil que excluye a las organizaciones que habían recibido financiación desde el extranjero, generando amplias controversias entre los actores nacionales, con este objetivo el Tribunal Supremo de Justicia emitió una sentencia para definir a nivel jurídico los actores que conforman la sociedad civil:

\footnotetext{
"Los representantes de la sociedad civil son asociaciones, grupos e instituciones venezolanas ( $\sin$ subsidio externo) que por su objeto, permanencia, número de miembros o afiliados y actividad continua, han venido trabajando desde diversos ángulos de esa sociedad, para lograr para esta una mejor calidad de vida, desligadas del gobierno y de los partidos políticos. (TSJ, Sentencia 30-06-2000 apud CIVICUS, 2010)
}

En este entorno se da inicio a la segunda fase de las relaciones entre las organizaciones de la sociedad civil y el gobierno Chávez, entre el 2002 y el 2004. Periodo convulso debido a diversos hechos que se desarrollan en el ámbito político: la tentativa de golpe de estado (abril del 2002) y el paro petrolero (entre diciembre de 2002 y febrero de 2003) (LOPEZ MAYA, 2007) ${ }^{139}$. Lo que trajo, entre muchas otras cosas, la radicalización en lo que se refiere a las relaciones del

${ }^{139}$ Ver artículo "Venezuela 2001-2004: actores y estrategias" (LOPEZ MAYA, 2007) 
gobierno con actores de la sociedad civil, por medio de regulaciones fuertes que afectaron profundamente el desarrollo de sus actividades y, de acuerdo con la autora, trajo consigo "posiciones altamente diferenciadas y/o antagónicas entre sí, considerando que con ello obtienen dividendos favorables a sus proyectos o intereses políticos” (López Maya, 2010, pag.3).

Esta coyuntura generó un aumento de la polarización dentro del proceso político implementado por el gobierno, que denominó su propuesta como "socialismo del siglo XXI" impulsando de esta forma la "revolución". Posterior al año 2004, la política internacional pasa a ser una prioridad y comienza la lucha dentro de la "guerra asimétrica"140 , contexto que impacta profundamente a la sociedad civil. El presidente Chávez radicaliza su posición frente a estas organizaciones dando declaraciones como la siguiente:

"Aquí hay dos sectores enfrentados: la burguesía y sus aliados y el pueblo y sus aliados, y no hay reconciliación posible, no hay (...) Nosotros estamos y estaremos siempre en batalla y nuestros adversarios de la patria estarán siempre en batalla. Es irreconciliable esto" (Presidente Hugo Chávez, 02- 12-2009, en cadena de radio y televisión apud CIVICUS, 2010).

Por un lado, el sector de la oposición sufre una desmovilización y desencanto, que resultó en una disminución del activismo. Por el otro, se observa un fortalecimiento de las organizaciones vinculadas al gobierno. De acuerdo con Jacome (2007), se crean 4 corrientes dentro de la sociedad civil: 1) Organizaciones de trayectoria amplia, que mantuvieron sus directrices buscando la neutralidad entre los grupos de conflicto, 2)Sector crítico al gobierno o “opositor", 3)Grupos vinculados a proyectos del gobierno, 4) Grupos intermediarios que buscaban atenuar la polarización. De todos estos grupos los más beneficiados fueron los vinculados al gobierno y los más afectados los grupos intermediarios, que fueron perdiendo capacidad de acción y apoyo, como resultado del desencanto de la ciudadanía posterior a este periodo político convulso.

La tercera fase se ve marcada en el año 2006, cuando se establece el Proyecto de Ley de Cooperación Internacional dentro de la Asamblea Nacional, con el objetivo de regular el control de las actividades de las organizaciones de la sociedad civil que desarrollan actividades en Venezuela, tanto aquellas nacionales como internacionales, por medio de una serie de elementos:

\footnotetext{
140 "nueva doctrina de la FAN, según la cual era necesario prepararse para enfrentar una agresión imperialista contra la patria a través de una estrategia que involucra también a la milicia y a las organizaciones populares" (MUJICA, 2014)
} 
- Creación del Registro Integrado de organizaciones no gubernamentales, en el cual todas las organizaciones deben inscribirse de forma obligatoria, tanto aquellas nacionales como internacionales.

- Establecimiento del Fondo para la Cooperación y Asistencia Internacional, que se centrará en los recursos públicos y privados que entran en el país para la cooperación, distribuyendo de acuerdo a las prioridades establecidas "La defensa de los derechos humanos, civiles y electorales en general no están incluidos, ni cuestiones relacionadas con el fortalecimiento de la democracia"(idem)

- Obligación de informar a los organismos gubernamentales todas las actividades y programas que desarrollan y la rendición de cuentas en el uso de los recursos financieros.

Las características presentadas por medio de este proyecto, establecen un monopolio del estado, de los recursos asignados por organismos internacionales para el desarrollo de las actividades de las organizaciones de la sociedad civil, controlando en su totalidad el manejo de los recursos, buscando la alineación en lo que se refiere a sus temáticas de trabajo para el acceso a recursos, afectando de esta forma su independencia, generando a su vez el término de muchas organizaciones sin acceso a los recursos necesarios para su funcionamiento. Actualmente esta ley se encuentra en proceso de revisión y discusión dentro de la Asamblea Nacional ${ }^{141}$, que, en el caso de ser definitivamente aprobada, reforzará el poder discrecional del Ejecutivo nacional.

Otro mecanismo importante presentado por la Comisión Permanente de Seguridad y Defensa de la Asamblea Nacional fue la "Ley de Defensa de la Soberanía Política y Autodeterminación Nacional" ${ }^{, 142}$ (LODSPAN), que establece la prohibición de financiamiento internacional a organizaciones que tengan como objetivo la promoción y defensa del derecho a la participación política, así como la instalación en el año 2013 por parte de la Asamblea Nacional de la Comisión Especial para "Investigar el Financiamiento de las Oficinas u Organizaciones con Fines Políticos y Grupos que Actúan con el Propósito de Desestabilizar y Generar Conmociones Sociales y un Golpe de Estado para Atentar Contra el Hilo Constitucional de la República

\footnotetext{
141 "el 07 de octubre del 2015, el Presidente de la Asamblea Nacional, hizo un llamado a retomar y trabajar la ley de Cooperación Internacional, el 21 de octubre de 2015 la Comisión Permanente de Política Exterior, Soberanía e Integración de la Asamblea Nacional presentó el Informe sobre el Proyecto de Ley de Cooperación Internacional, con lo cual el mismo quedaría listo para su aprobación en Segunda Discusión. Este Informe fue presentado al Presidente de la Asamblea Nacional el 30 de octubre de 2015. La Asamblea Nacional el martes 3 de noviembre de 2015 incluyó en su agenda del día, la Segunda discusión el Proyecto de la Ley de Cooperación Internacional. No obstante, esta discusión fue diferida para el próximo martes 10 de noviembre de 2015, fecha en que no hubo sesión en la Asamblea Nacional por lo que desconocemos, al momento, en qué fecha se realizará la segunda discusión de la Ley de Cooperación Internacional" (NIETO, 2015)

${ }^{142}$ Publicada en Gaceta Oficial $N^{\circ} 6.013$ del 23.12.10.
} 
Bolivariana de Venezuela" (Informe elaborado por Organizaciones del Movimiento de Derechos Humanos en Venezuela para consideración de la CIDH sobre la situación de los defensores y defensoras de derechos humanos en Venezuela, durante el $156^{\circ}$ Período de Audiencias de la Comisión, 2015)

De acuerdo con CIVICUS (2010), tres aspectos definen a la sociedad civil venezolana actualmente "la polarización en un marco de discriminación, rápidas transformaciones como respuesta a un entorno volátil y un profundo arraigo de actitudes anti políticas”. Estos procesos convulsos han generado transformaciones en las dinámicas horizontales entre las organizaciones, como el interés por lo público por medio de la acción colectiva, ampliando de esta forma el tejido social, fomentando diversas formas de cooperación, confianza mutua entre las organizaciones que ejercen acción social para lidiar con el conflicto, existencia de un comportamiento cívico en busca de un bien común, la presencia de valores compartidos, la existencia de una identidad familiar y colectiva mediante la incorporación de nuevas organizaciones, esto como consecuencia de la falta del estado como la estructura encargada de mediar y proporcionar estabilidad social.

Evaluando el desarrollo social y político venezolano durante los últimos 15 años, puede decirse que el marco jurídico presenta características restrictivas, fortaleciendo los controles del Estado sobre el ciudadano, de igual forma se observó un incremento de las descalificaciones hacia el trabajo de las organizaciones no gubernamentales, presentándose un escenario poco favorable para la consolidación de una sociedad civil dinámica, la cual debe ser evaluada como uno de los elementos esenciales para la consolidación democrática, promoviendo una cultura institucional y social hostil hacia las organizaciones, perjudicando a las ciudadanía.

De acuerdo con Jacome (2007), estas convulsiones sociales, aun afectando la democracia, generaron una serie de procesos que pueden ser considerados como positivos. En primer lugar, fortalecieron las alianzas y el establecimiento de redes de cooperación. "Cuando hubo consenso y el reconocimiento común de objetivos específicos, el trabajo fue coordinado y eficiente entre las diferentes organizaciones; fue el fortalecimiento y fomento de la participación ciudadana" (idem). En segundo lugar, se valoró de forma más amplia el trabajo de acompañamiento por parte de las organizaciones en los proyectos implementados. En tercer lugar se dio prioridad a la formación ciudadana por medio del fortalecimiento de la participación consciente. $Y$ en último lugar, se adoptaron nuevas formas de comunicación permitiendo una eficiencia mayor en el desarrollo de las actividades. 


\section{Grafico 18: Fortalezas y debilidades internas de la sociedad civil según actores clave}

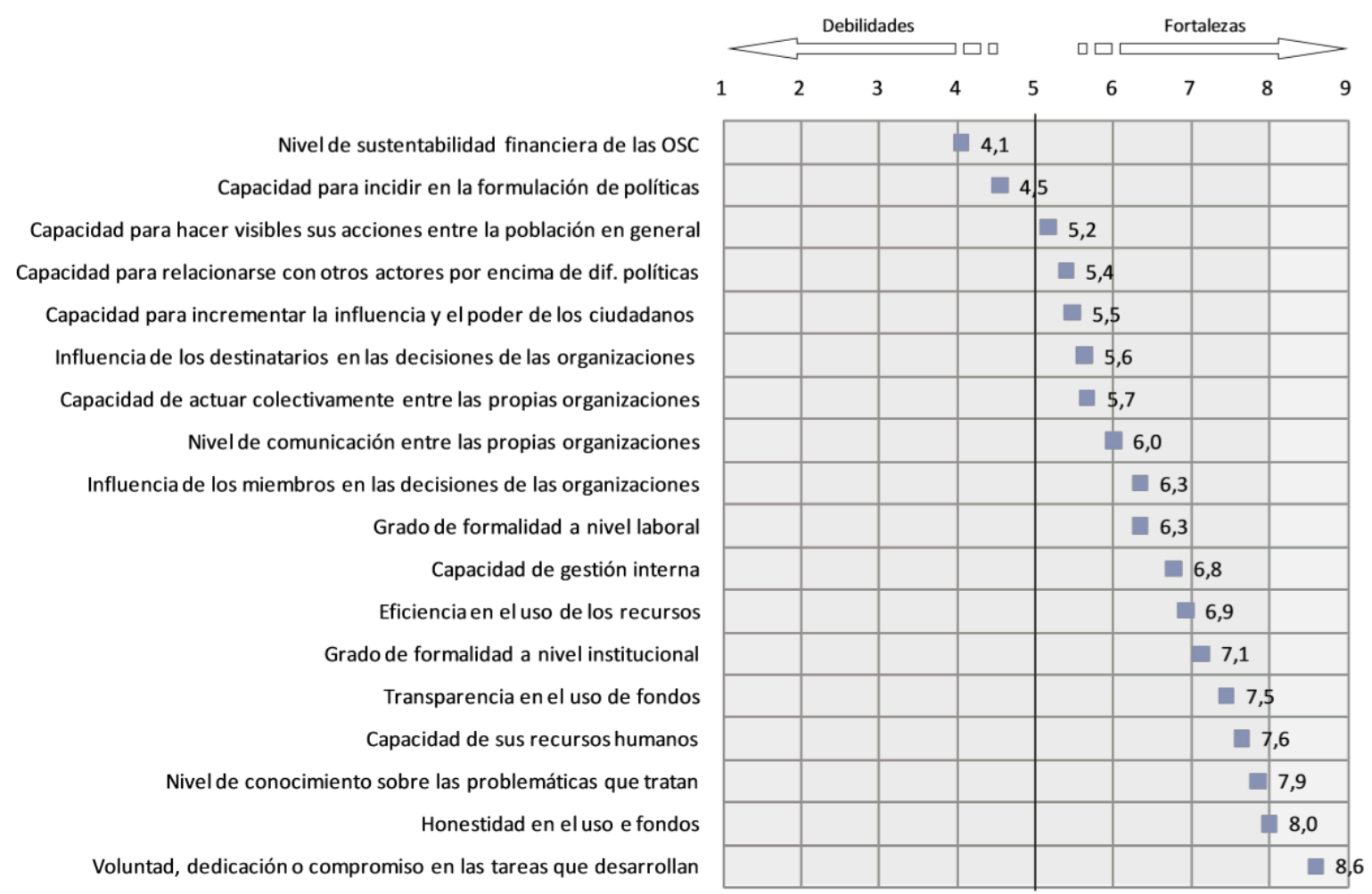

Fuente: CIVICUS, 2010

En este sentido, las organizaciones de la sociedad civil son actores que promueven la participación en la formulación y el control de las políticas públicas, a su vez, debido a la forma en la cual están estructuradas, promueven valores esenciales para la generación de cohesión, como lo son la solidaridad, la tolerancia y la equidad, por lo tanto, su actuación debe ser promovida e impulsada. Una de sus grandes fortalezas se encuentra en la legitimidad que estas poseen a la hora de compararlas con otros actores del sector público, lo que refuerza el papel de las mismas como agente de cambio (CIVICUS, 2010). La creación de redes entre este tipo de organizaciones cataliza sus acciones ya que tienen un alcance mayor. Esto, en algunos casos, se vincula a la "contracción del papel estatal en la prestación de servicios públicos" (SERRANO; REVILLA, 2002).

El contexto venezolano está caracterizado por una amplia fragmentación, lo que ha generado una falta de reconocimiento de toda la diversidad social existente dentro del conflicto por parte de estas organizaciones, sin una verdadera comprensión de la realidad y sin programas a largo plazo como consecuencia de la inestabilidad generada a nivel institucional/ gubernamental, que se observa tanto en el financiamiento como en la obstaculización para el 
desarrollo de actividades, tal como ocurre con la actuación obstaculizadora de diversos actores estatales como la Asamblea Nacional y el Poder Ejecutivo, que han disminuido el área de actuación de estos actores y su relevancia dentro de la sociedad.

Se considera esencial el fomento de la interacción entre este tipo de organizaciones, la ciudadanía y los partidos políticos venezolanos, para generar la integración en la forma de ejecutar políticas públicas efectivas que, en consecuencia, produzcan el fortalecimiento de la democrácia, dentro de una sociedad compleja en donde:

"En el terreno sociocultural, la tolerancia es limitada por la virtual ausencia de sentimientos de confianza en el otro y un espíritu cívico según el cual el venezolano reconoce la validez de las normas de convivencia pero no las cumple. En el ámbito de las relaciones Estado-sociedad un significativo conjunto de OSC se ha visto obligado a convivir con un marco legal restrictivo y a enfrentar prácticas gubernamentales que restringen su autonomía" (CIVICUS, 2010).

La complejidad para alcanzar una sociedad civil equilibrada e inclusiva, en el caso venezolano, se debe a la existencia de posiciones irreconciliables dentro de la dimensión política, así como la falta la de espacios de diálogo. En este sentido, las organizaciones de la sociedad civil están jugando un papel fundamental en la promoción de un contexto más inclusivo, así como una mayor interlocución en el desarrollo de proyectos y el diálogo para la construcción de un conocimiento colectivo, que logre eliminar los prejuicios existentes como consecuencia de la polarización.

\subsection{Participación Ciudadana y Derechos Civiles en Venezuela: Características, actuación y desafíos de las organizaciones de la sociedad civil}

El desarrollo de la participación ciudadana y la promoción de derechos civiles, dentro de la sociedad venezolana, han buscado contrarrestar tendencias vinculadas al conflicto político, que ha visto incrementada su gravedad como resultado de la profundización de la polarización en la población. Este tipo de organización ha desarrollado una serie de aspectos tales como la prestación de servicios de capacitación, asistencia en el desarrollo de actividades socigales, técnicas y de financiamiento, promoviendo actividades de formación y educación ciudadana, así como en la defensa de los ciudadanos frente a la estructura gubernamental.

Su relevancia alcanza su auge después del establecimiento de la Constitución de 1999, en medio de un nuevo régimen sociopolítico y económico, en donde la credibilidad de los partidos políticos y la vinculación de la ciudadanía a este tipo de actor estaba en una posición de desgaste, 
generando, de esta forma, nuevas concepciones de política social y nuevos protagonismos ciudadanos.

En la actualidad las organizaciones de la sociedad civil, en el área de la promoción de la ciudadanía y los derechos civiles, han aumentado su colaboración conjunta a partir de redes, produciendo un entorno positivo, lo cual "permite la coordinación de acciones y facilita la construcción de alianzas para la incidencia en asuntos públicos" (CIVICUS, 2010). Aun presentando este escenario positivo, la participación en redes puede dar lugar a amenazas a la autonomía, cuando su "agrupación en estos mecanismos implica subordinación a las órdenes impartidas desde un nivel superior" (ídem), esta visión está vinculada a la idea de la influencia gubernamental en el campo de acción de las organizaciones de la sociedad civil durante los últimos años.

Una "red social" debe interpretarse como "un conjunto de nudos o actores (personas u organizaciones) vinculados por relaciones sociales o lazos de un tipo específico" (CASTILLA; HWANG; GRANOVETTER; GRANOVETTER, 2000). Para nuestra evaluación tomaremos en consideración 27 organizaciones de la sociedad civil vinculadas a la promoción de la ciudadanía y los derechos ciudadanos, examinando la forma en que se desarrollan sus relaciones, por medio de un análisis de redes y su percepción del contexto político y social para el desarrollo de sus actividades en el escenario nacional, a partir de entrevistas. Las organizaciones evaluadas son:

1) Aliadas en Cadena: organización que presta apoyo a la mujer a través de programas de formación con énfasis en las TIC 's, que le brinden herramientas para el logro de su empoderamiento y emprendimiento económico y social.

2) Asociación Civil Consorcio Desarrollo y Justicia: promueve e incide en el fortalecimiento y democratización de las instituciones, especialmente del Sistema de Justicia, privilegiando el acceso y la participación de los ciudadanos.

3) Acceso a la Justicia: asociación que tiene como misión la defensa de la justicia, la democracia, la libertad, los derechos humanos, el estado de derecho, la separación de poderes y la independencia judicial en Venezuela.

4) Acción Campesina: organización que privilegia la participación de los poderes rurales y de sus organizaciones en función del desarrollo del país, impulsa la agricultura sostenible en corresponsabilidad con otros actores; 
5) CEDICE: asociación civil sin fines de lucro, privada e independiente, cuya misión es divulgar, formar, investigar y defender los principios del libre mercado y la libertad individual, para construir una sociedad de personas libres y responsables.

6) Centro de Investigación Social (CISOR): entidad autónoma, con la finalidad de hacer pertinentes, operativos y útiles los recursos de las ciencias sociales para su aprovechamiento por Investigación Social al servicio de desarrollo social del país.

7) Expresión Libre: tiene por objeto difundir el concepto de la libertad de expresión y propiciar la defensa absoluta de dicho concepto como derecho de toda sociedad democrática y el fortalecimiento del movimiento de comunicadores como éticos forjadores de opinión en una sociedad libre, pluralista y democrática.

8) Fundación para el Debido Proceso (FUNDEPRO): tiene como misión garantizar a las víctimas de violaciones de derechos Humanos, una investigación integral, representando y defendiendo sus derechos y buscando la reparación del daño causado, de acuerdo a lo estipulado en el ordenamiento jurídico vigente.

9) Gestión de Cambio: asociación sin fines de lucro, que reúne a un equipo de profesionales comprometidos con la modernidad y la modernización de Venezuela. Tiene como objetivo el mejoramiento de la calidad de vida de los habitantes de Venezuela, mediante la actuación concertada del Estado, las asociaciones no gubernamentales, las comunidades organizadas y los ciudadanos en general en ambiente de libertad, inclusión y democracia.

10) El Instituto Venezolano de Estudios Sociales y Políticos (INVESP): tiene como objetivo promover y desarrollar la investigación científica en el campo de las relaciones internacionales y de las ciencias sociales y políticas en general, con el fin de contribuir a la formalización e implementación de políticas a escala nacional e internacional.

11) Grupo Social CESAP: organización formada por 20 asociaciones y equipos de trabajo a nivel nacional, comprometida con la Acción Popular, promoviendo la construcción de una sociedad incluyente, justa y con equidad, impulsando la participación de los sectores populares como actores y autores de la transformación social.

12) Civitas: asociación civil sin fines de lucro, cuya misión es fortalecer la democracia construyendo ciudadanía

13) Liderazgo y Visión: asociación civil dedicada a promover el diálogo entre los venezolanos, en relación con nuestros problemas colectivos y sus posibles soluciones, y a incentivar la 
organización y la participación ciudadana y política. Todo ello en el marco de los valores de la democracia y la libertad.

14) Observatorio Hannah Arendt: organización sin fines de lucro, cuyos objetivos son la promoción de proyectos sociales que generen cambios en la sociedad democrática y estimulen la participación e investigación aplicada, además de consolidar e impulsar el desarrollo social, económico, cultural y bio-psico-social de la sociedad venezolana y la formación en todos los niveles y modalidades de la cultura en general, así como producir, estimular y difundir estudios e investigaciones asociadas con nuestros objetivos.

15) Una Ventana a la Libertad: capacitar a internos en Derechos Humanos, Beneficios Procesales y Fórmulas Alternativas de Cumplimiento de Condena.

16) Opción Venezuela: brindar una plataforma de responsabilidad social para que los universitarios participen y se involucren con la realidad del país.

17) Paz Activa: asociación civil dedicada a contribuir con el fortalecimiento del sector ciudadano y las instituciones del Estado, para asegurar el acceso igualitario de todos a la justicia, seguridad y convivencia social y a los espacios de toma de decisiones

18) Somos Posible: es una ONG, creativa, innovadora y comprometida con el país, que trabaja para impulsar el desarrollo humano, a través del fomento una cultura de paz y logro sustentable

19) Programa Venezolano de Educación-Acción en Derechos Humanos (Provea): organización no gubernamental especializada en la defensa y promoción de los derechos económicos, sociales y culturales (DESC), que tiene como fin la plena realización de los derechos humanos y el respeto al Estado de Derecho, en el marco de una sociedad democrática y participativa. Toda acción que lleva a cabo Provea busca beneficiar a las víctimas o potenciales víctimas a las que el Estado no les garantiza o les viola sus derechos humanos, propiciando su protagonismo y la concientización de sus derechos.

20) UNIANDES: organización de Desarrollo Social dedicada a la promoción de la participación comunitaria.

21) Venezuela Sin Límites: tiene como misión el fortalecimiento de los agentes de cambio con acciones innovadoras, sostenibles y de impacto, a través de alianzas estratégicas, tecnología y comunicación para la transformación social.

22) Instituto de Prensa y Sociedad (IPYS): organización no gubernamental que trabaja en la promoción, defensa y formación en libertad de expresión, periodismo de investigación y el derecho a la información. 
23) LACSO-Observatorio Venezolano de Violencia: recolecta y genera datos e información de calidad sobre la violencia interpersonal en Venezuela, con el fin de caracterizar los eventos y su ocurrencia para ofrecer a las autoridades, a las organizaciones de la sociedad civil y a la ciudadanía en general una información amplia y confiable sobre la violencia y generar discusiones y reflexión sobre esta problemática en el país.

24) COFAVIC: El Comité de Familiares de las Víctimas de los sucesos ocurridos entre el 27 de febrero y los primeros días de marzo de 1989 es una organización no gubernamental dedicada a la protección y promoción de los derechos humanos, independientemente de toda doctrina o institución partidista y religiosa, con personalidad jurídica como asociación civil sin fines de lucro.

25) CONVITE: trabajan por la promoción de los derechos sociales para todas las personas

26) SINERGIA: Fortalecimiento de organizaciones de la sociedad civil (Marco legal, gestión, financiamiento e incidencia pública). Promoción y defensa de los derechos de Participación y Libre Asociación Cultura Cívica y Formación Ciudadana.

27) Escuela de Ciudadanos: tiene como objetivo el fomento de la educación ciudadana.

Este conjunto de organizaciones ha desarrollado un extenso trabajo en la promoción y defensa de los derechos ciudadanos en Venezuela. En la actualidad debido al contexto convulso en términos políticos, económicos y sociales, se ha observado un incremento en la participación, por medio del intercambio y colaboración entre las organizaciones, principalmente en sistemas de redes, en donde se observa una mejora contundente en la comunicación y capacidad de coordinación entre las organizaciones. Se han establecido observatorios para el acompañamiento del contexto nacional, buscando asistir los cambios dentro de la sociedad y observar la forma y el tipo de acercamientos entre las comunidades y las organizaciones, siendo primordial la evaluación de cómo son establecidas las relaciones en la actualidad y entre quienes, para interpretar de esta forma sus niveles de cohesión.

Este tipo de organizaciones, de acuerdo con Barrantes (2003), han desarrollado proyectos de capacitación, asistencia social y preparación técnica, con resultados exitosos, aun en un entorno de inestabilidad, proveniente de la falta de respaldo de una estructura legal sólida y democrática, así como un ambiente de irrespeto entre los actores políticos. Un aspecto que puede ser considerado como una debilidad de este tipo de organización es la dependencia financiera, lo cual incide directamente en su capacidad para ejecutar, de manera decisiva y sin 
condicionamientos, el desarrollo de sus actividades, en los diversos momentos del proceso de ciudadanización de la macro esfera pública

\subsection{Resultados}

El abordaje de las redes sociales es un visión que viene siendo utilizada para explicar varios procesos y fenómenos que se desarrollan en las más variadas áreas de la sociedad, inclusive a nivel del tercer sector en el cual se enmarcan las organizaciones de la sociedad civil, las cuales han pasado a tener un papel relevante en la elaboración de políticas, en su estructura como mecanismo de dialogo Estado-sociedad así como catalizadores del desarrollo social, democrático y económico, basándose en la interpretación de que la acción del actor es influenciada por la estructura de redes sociales que participa en la conjunción con sus intereses (RAUD-MATTEDI, 2005).

Por medio de esta investigación y sus resultados, se establece una visión renovada en lo que se refiere a las redes establecidas entre estas organizaciones de la sociedad civil, el tipo de lazos que se generan entre ellas y su impacto en la Venezuela actual. De acuerdo con Granovetter (1982), los lazos sociales permiten procesos constructivos independientes de la necesidad de un actor superior controlador, por medio de variables de la estructura social (cultura, normas, valores, etc), refiriéndose a los procesos de interacción social de forma amplia, aun con las dificultades que implica abarcar estas variables en el análisis. No hay relación o red sin contenidos y de acuerdo con la visión sociológica, no hay estructura de red que no esté basada en relaciones-interacciones.

En el caso venezolano, el "actor" que ha ejercido este papel es el estado venezolano, que durante los últimos 15 años ha presentado característica de obstaculización del desarrollo de actividades y dialogo con estas organizaciones (CIVICUS, 2010), generando en consecuencia, un fortalecimiento de las relaciones de base entre estos actores, así como la producción de capital social por medio de redes, que deben ser interpretadas como estructuras con la capacidad de promover procesos de cohesión.

Por medio de la aplicación de un cuestionario fundamentado en la teoría de redes y con el objetivo de tener una visión objetiva de las relaciones entre las organizaciones de la sociedad civil en la Venezuela contemporánea, tanto en términos cuantitativos como en los cualitativos, se evaluaron las dinámicas de las relaciones entre algunas de las organizaciones de la sociedad civil 
vinculadas a la participación y defensa de los derechos ciudadanos, contando con el aporte de 27 organizaciones de la sociedad civil en Participación y Derechos ciudadanos, configurándose como una red cerrada. Sus relaciones son clasificadas como bonding, ya que consisten en las interacciones de tipo horizontal que se llevan a cabo intra los miembros de nuestra red, se observará el número y frecuencia de los bonding, los cuales pueden ser más o menos densos, estructurando la fortaleza de sus relaciones, vista a través del espectro de la cohesión (LOZARES ET AL., 2011). Entre mayor sea la densidad de los lazos mayor será la interconexión, promoviendo estructuras de confianza y comunicación que, de acuerdo con Putnam (1993), son definidas como relaciones fuertes, en busca de un beneficio mutuo, generando un fortalecimiento en su capacidad de actuación y efectividad de objetivos comunes

En primer lugar se deben establecer una serie de características relevantes al respecto del grupo de organizaciones. En el gráfico 1 se observa, la participación de las organizaciones de la sociedad civil dentro de redes tanto a nivel nacional como internacional. Se puede ver que 22 organizaciones pertenecen a una red, de lo cual se puede inferir que las organizaciones ven las alianzas como algo positivo para potenciar el impacto de sus proyectos.

\section{Grafico 19: Participación en redes de las organizaciones de la sociedad civil a nivel nacional e internacional}

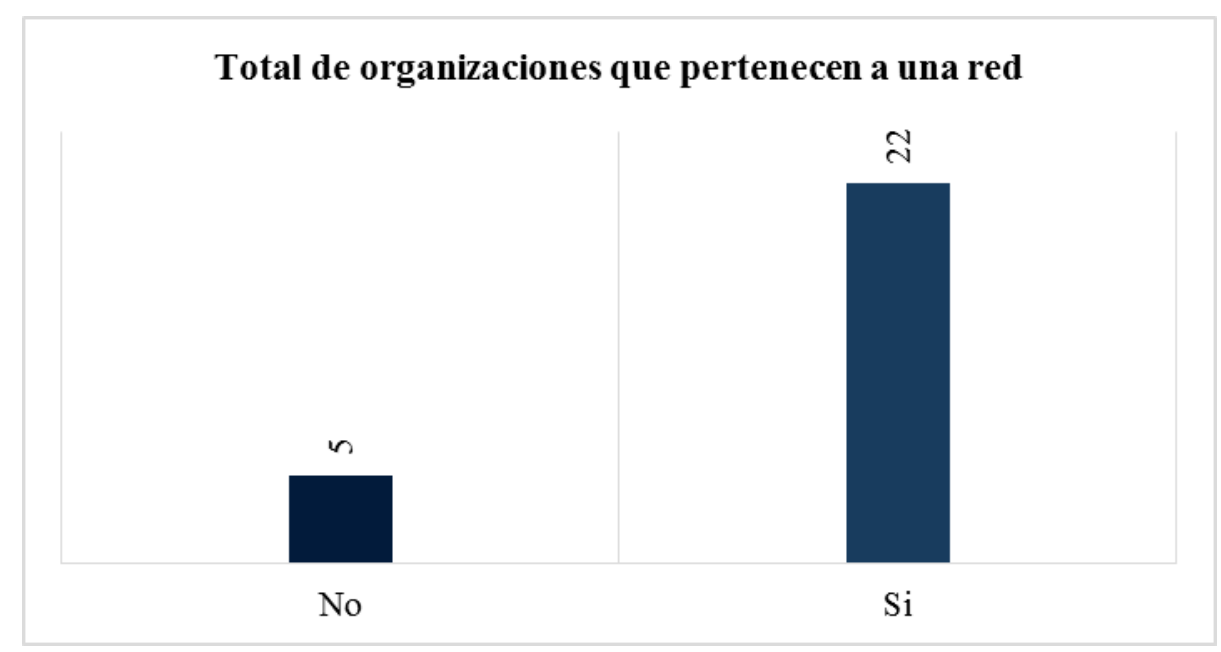

Fuente: Elaboración de la autora

El establecimiento de este tipo de relación, debe ser interpretado como bridging, término que se vincula a las relaciones externas, es decir, con las que se dan entre individuos de colectivos diferentes. En este caso es como se establecen las relaciones entre las organizaciones 
de la sociedad civil en Participación y Derechos Ciudadanos con redes nacionales e internacionales, lo cual supone el acceso a colectivos de pertenencia o referencia distintos del propio y en consecuencia a otros recursos del Capital social (Lozares et al, 2011).

Las redes a nivel nacional dentro de las que se encuadran las organizaciones se clasifican en: Alianza por la Libertad de Expresión, Coalición ProAcceso a la Información, Foro por la Vida, Grupo Social Cesap, Plataforma Venezolana de Redes de Organizaciones de la Sociedad Civil, Proacceso, Red de Acción Social de la Iglesia, Red Local para la Gestión del riesgo, SINERGIA, Red Venezolana de Organizaciones para el Desarrollo Social (Redsoc) y la Red por los DDHH de Niños, Niñas y Adolescentes.

En lo que se refiere a la participación de las organizaciones de la sociedad civil en redes se observa que la mayoría participa en la red de SINERGIA, plataforma que busca el fortalecimiento del tejido social, por medio de la articulación, cooperación y creación de oportunidades de participación democrática de las organizaciones de la Sociedad Civil, buscando una mayor equidad social. Por medio de nuestra evaluación se observa que 12 organizaciones de la sociedad civil forman parte de esta red, convirtiéndose como la de mayor relevancia.

Dentro de las redes nacionales, 20 de las organizaciones de sociedad civil evaluadas, son miembros activos de las 11 redes mencionadas anteriormente. La organización que participa en el mayor número de redes a nivel nacional es el Grupo Social CESAP, que busca la promoción de una sociedad incluyente, impulsando la participación de los "sectores populares como actores y autores de la transformación social" (CESAP, 2015), esta organización es tanto una red como una organización de la sociedad civil, promoviendo el establecimiento de estas plataformas debido a que interpretan estos mecanismos como catalizadores del desarrollo de este sector. 


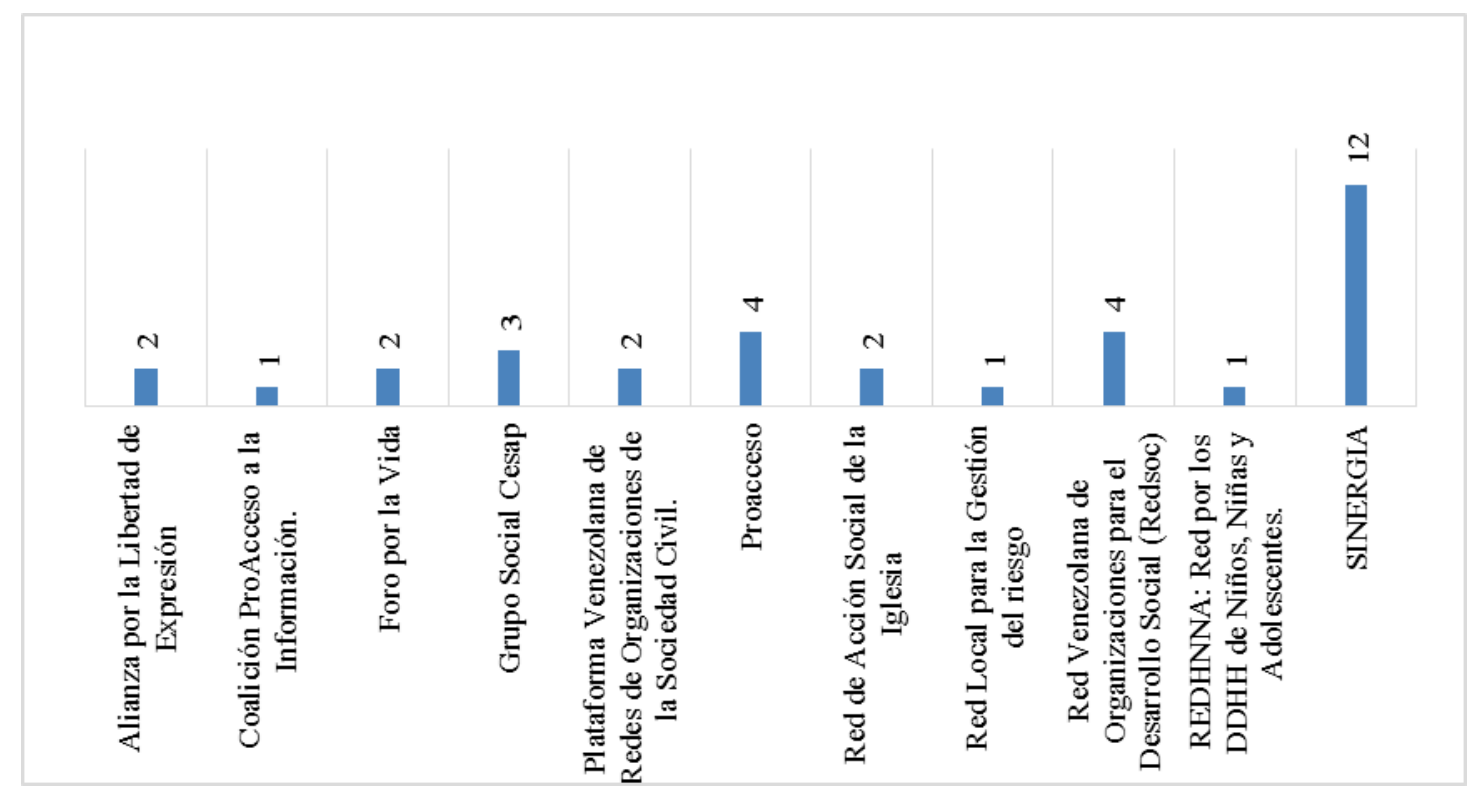

Fuente: Elaboración de la autora

En el caso de las 15 redes internacionales en las cuales participan las organizaciones evaluadas tenemos: Internacional Red liberal de América Latina, AGNA, Asociación Latinoamericana de Organizaciones de Promoción (ALOP), CADAL, Civicus, Consejo de Educación Popular de América Latina y el Caribe (CEAAL), IFEX, International Land Coalition (ILC), Mesa de Articulación de América Latina, Red Democracia Activa, Red Global de Organizaciones de la Sociedad Civil para la Reducción de Desastres, RedLad (Red Latinoamericana y del Caribe por la Democracia)

La red internacional en la cual se observa una mayor participación de las organizaciones de la sociedad civil evaluadas, es REDLAD. En este sentido de la totalidad de las 27 organizaciones de sociedad civil evaluadas, 12 son miembros activos de estas redes internacionales, las organizaciones que participan en el mayor número de redes a nivel internacional son Acción Campesina y SINERGIA 


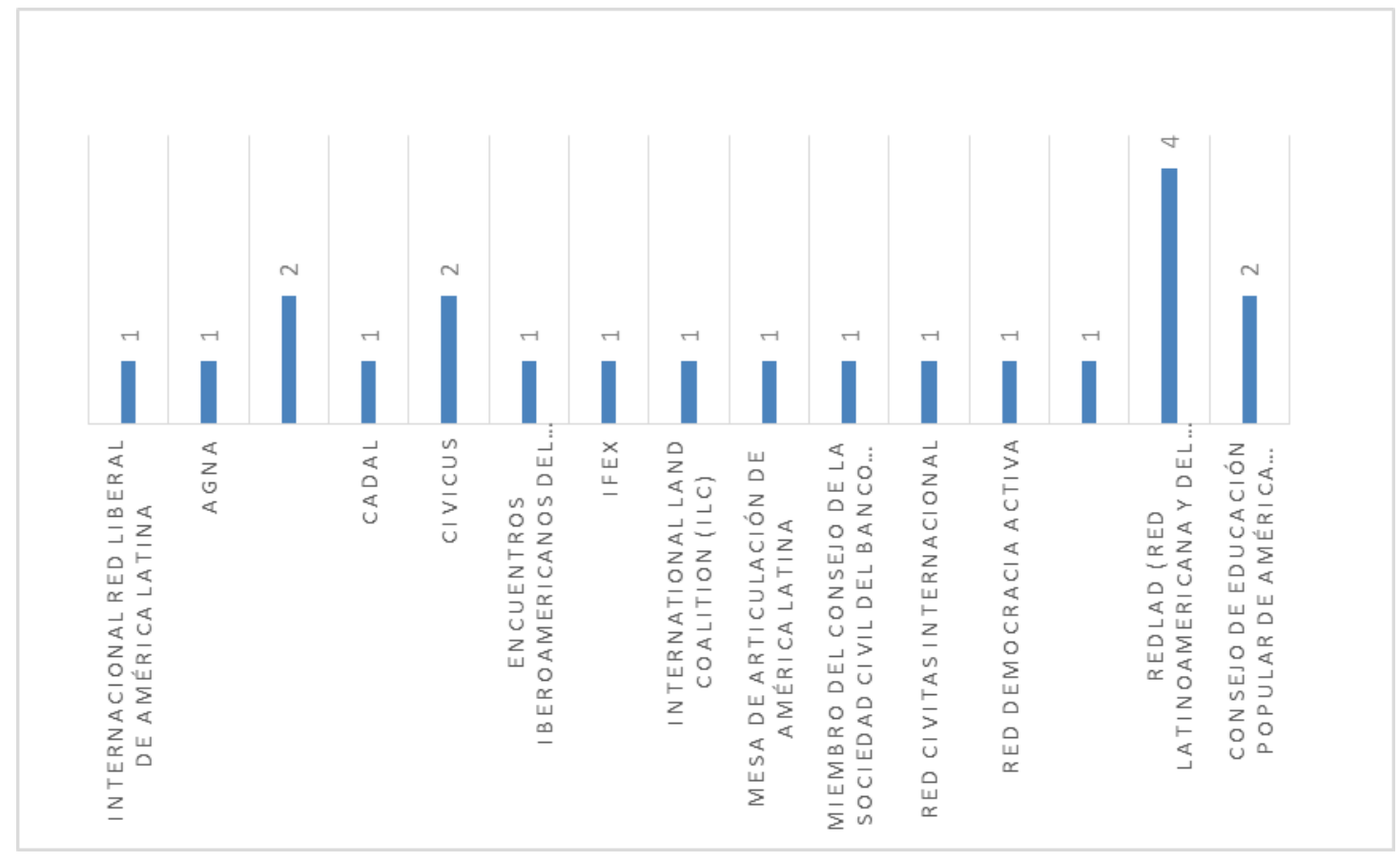

Fuente: Elaboración de la autora

Este tipo de redes, tanto a nivel nacional como internacional, buscan la cooperación para el desarrollo y promueven el acceso a la información, participación, y garantía de los Derechos Humanos, por medio de la estructuración de alianzas con otros actores de la Sociedad Civil, el Estado y el sector privado, a nivel nacional e internacional, buscando como objetivo central la consolidación de este tipo de organizaciones, así como su sustentabilidad por medio del dialogo a partir de plataformas tecnológicas y de comunicación, propiciando la interlocución de la sociedad civil venezolana. Es importante mencionar que de las 22 organizaciones que participan en redes nacionales o internacionales, 7 tienen participación en ambas.

Por medio del cuestionario realizado, se evaluaron otros aspectos del contexto venezolano, que han ejercido un impacto en términos de las dinámicas entre estas organizaciones y su percepción del ambiente político/social en el cual se desarrollan sus actividades. Se quiso evaluar la percepción de las OSC en relación al incremento de las alianzas entre ellas en los últimos cinco años. El 55, 56\% considera que hubo un cambio considerable, y solo el 3,7\% piensa que hubo un retroceso en este requisito. Lo que indica que las alianzas de las OSC se han incrementado de manera considerable, buscado una mayor interrelación con sus pares en los últimos cinco años. 
Grafico 22: Percepción de las alianzas entre las Organizaciones durante los últimos 5 años

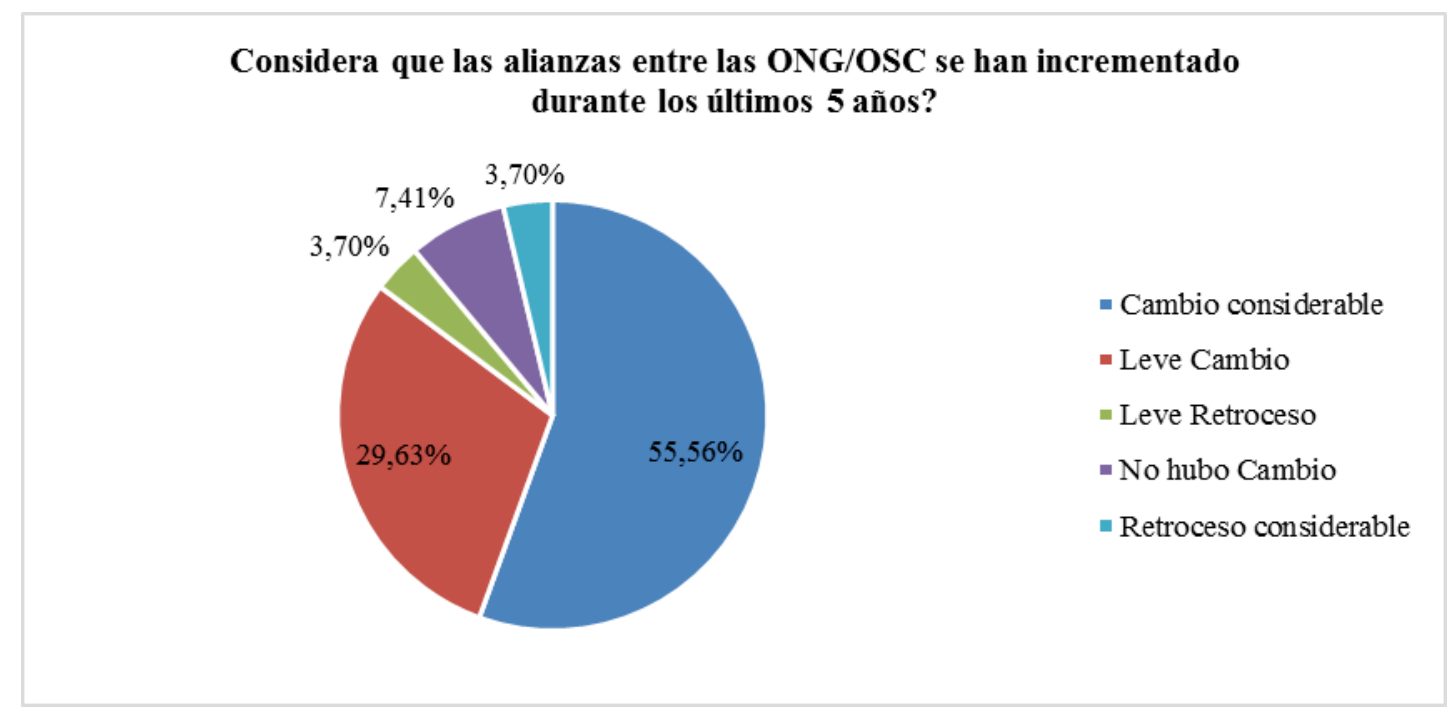

Fuente: Elaboración de la autora

En lo que se refiere a la relación Gobierno/ Organizaciones de la Sociedad civil, se observa que el apoyo de los entes gubernamentales ha sido mayoritariamente ejecutado a través de los gobiernos locales, que se caracteriza como apoyo a partir de órganos descentralizados del estado y no el gobierno central. Es importante destacar que solo 7 de las organizaciones evaluadas indicaron que durante el último año habían contado con algún tipo de apoyo por parte de entes gubernamentales, lo cual significa que la mayoría no ha recibido ningún tipo de apoyo por parte del estado. De estas 7 organizaciones, 4 manifestaron que tuvieron el apoyo de alcaldías.

\section{Grafico 23: Apoyo gubernamental para la realización de sus objetivos}

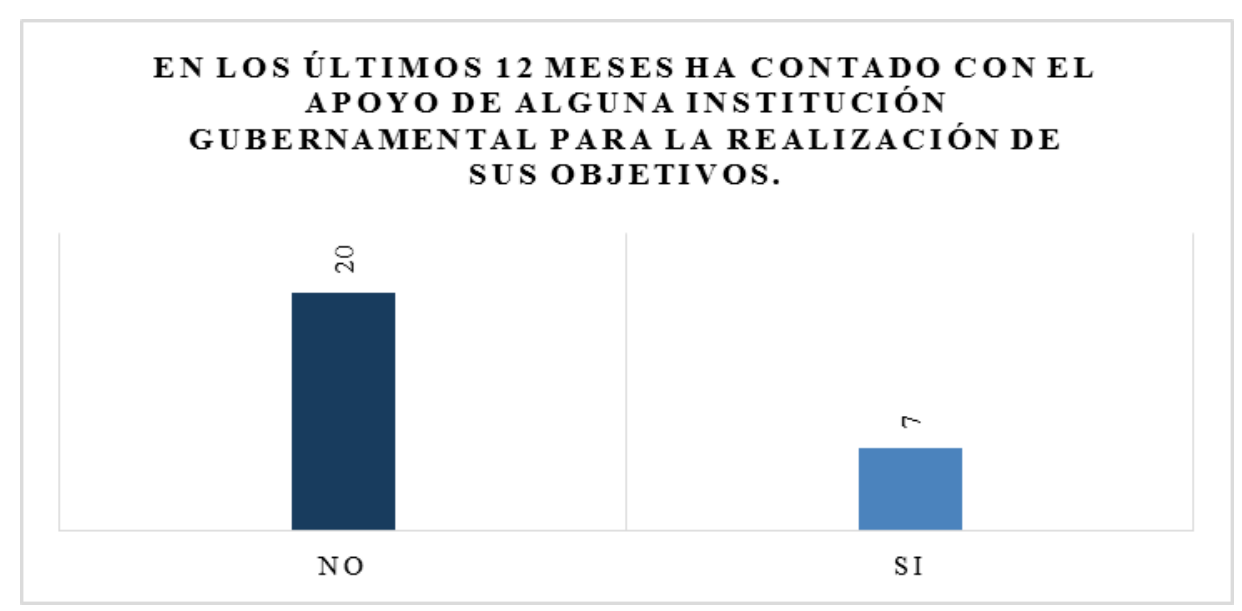

Fuente: Elaboración de la autora 
Grafico 24: Fuente de apoyo gubernamental para la realización de los objetivos de las organizaciones de la sociedad civil

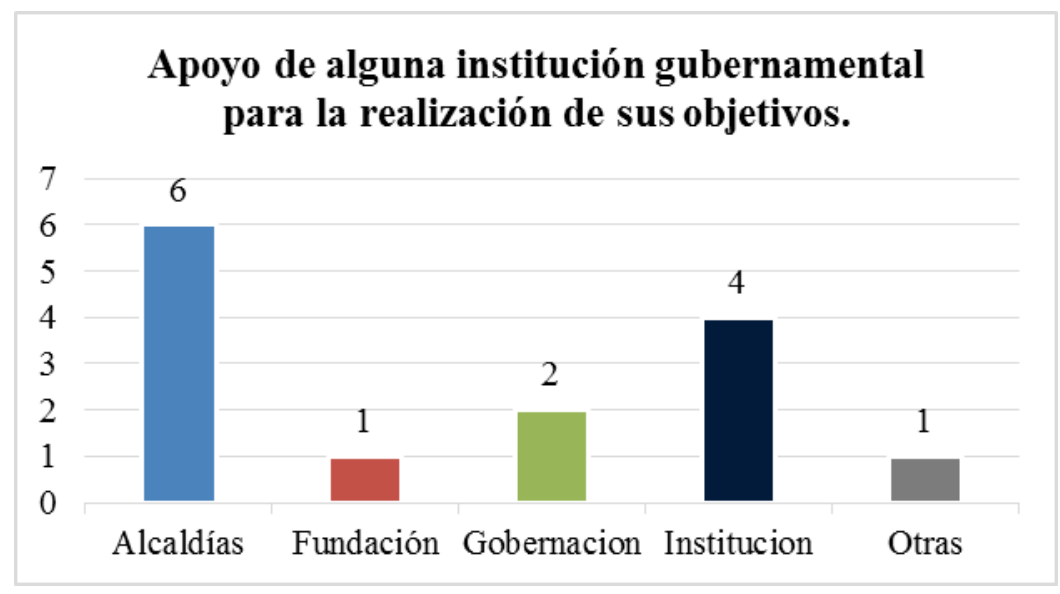

Fuente: Elaboración de la autora

En lo que se refiere al tema de polarización, la mayoría de las organizaciones evaluadas expresa que las alianzas entre las OSC y las instituciones del estado han sido afectadas, como resultado de la polarización política existente en Venezuela, en un contexto de déficit de cultura política democrática, en donde se observa un incremento de la desigualdad, la profundización de la polarización y una trasgresión de roles de los actores económicos y sociales, entre los que se encuentran los actores de las organizaciones de la sociedad civil. Como se observa en el gráfico 25:

Grafico 25: Impacto de la polarización política en la relación entre las organizaciones de la sociedad civil y las instituciones públicas

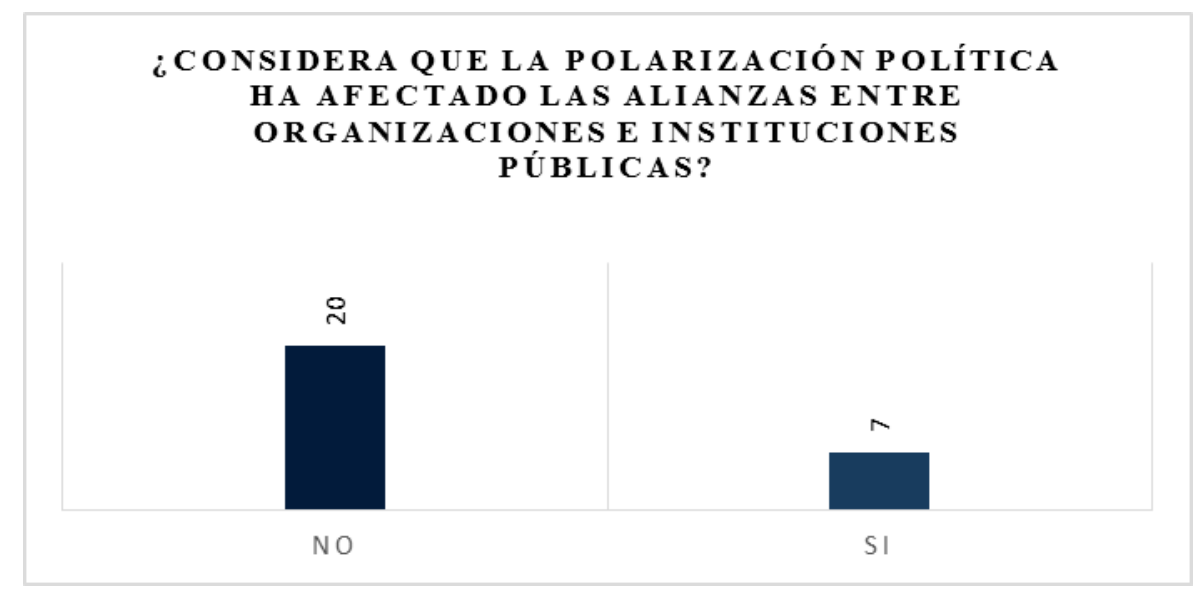

Fuente: Elaboración de la autora 
Por medio del análisis de redes, pueden observarse las interacciones entre las 27 organizaciones evaluadas, para lo cual partimos de datos mayormente cualitativos. Con el objetivo de determinar el nivel de cohesión de este grupo de actores en el contexto venezolano actual, se generaron gráficos para obtener una mayor comprensión de las interacciones. Fueron analizadas algunas medidas que expresan la relación de estos sujetos dentro de una red, como la densidad y los grados que pueden ser observadas por medio de los siguientes gráficos para simplificar su comprensión:

\section{Grafico 26: Red de organizaciones de la sociedad civil en derechos y participación ciudadana por grado (degree)}

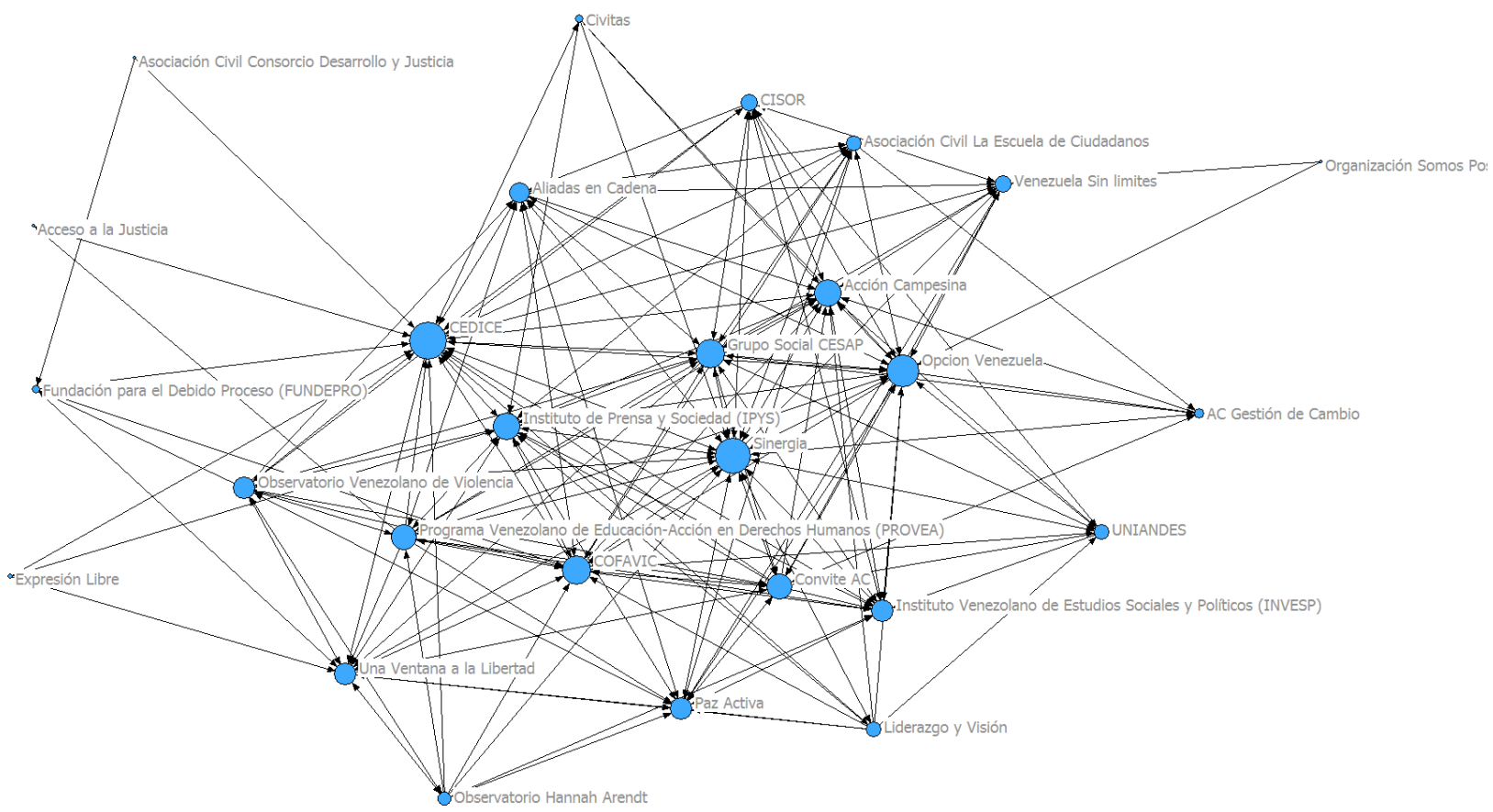

Fuente: Elaboración de la autora 


\section{Grafico 27: Vínculos de organizaciones de la sociedad civil en derechos y}

participación ciudadana con plataformas de redes nacionales e internacionales
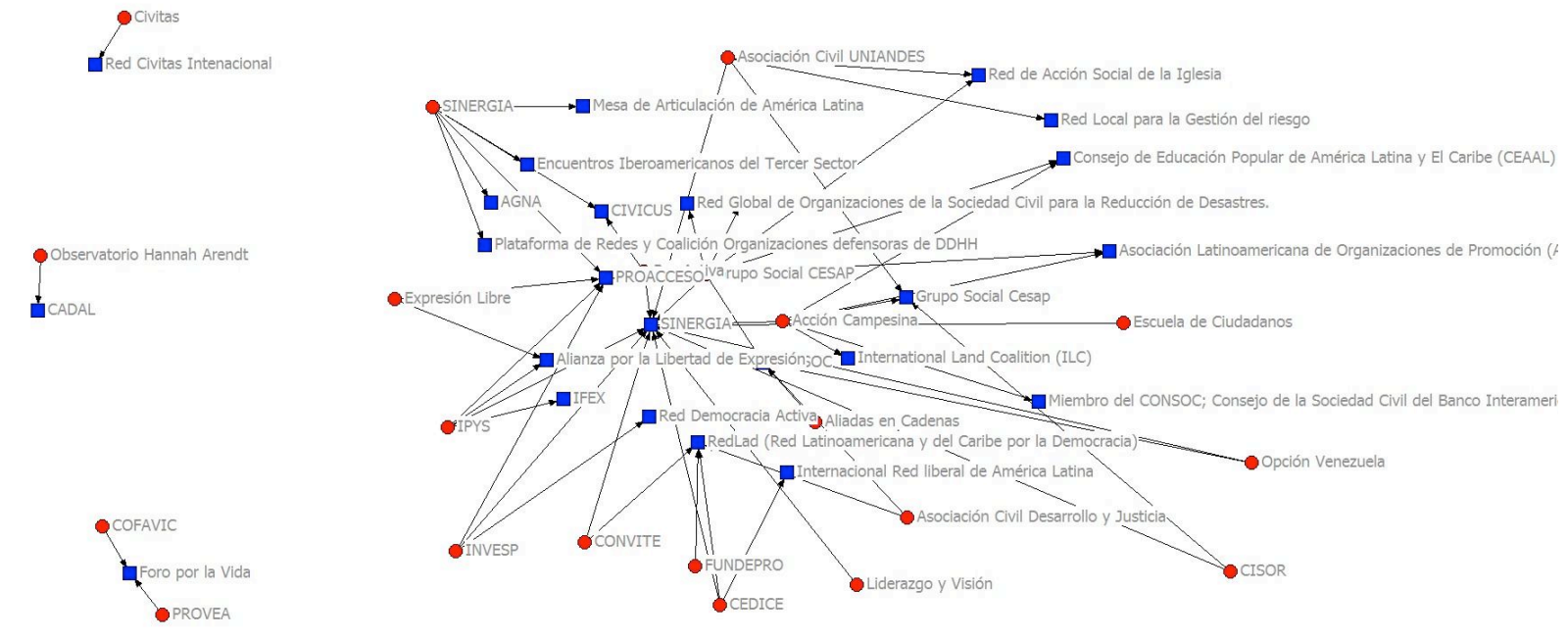

Fuente: Elaboración de la autora

Se observa una gran interacción entre los sujetos que conforman esta red cerrada de organizaciones de la sociedad civil analizadas en participación y derechos ciudadanos, debido a su conectividad a partir de lazos. De acuerdo con el grado, que se vincula a la idea del número de lazos que posee un nodo, vemos que las organizaciones que presentan mayor relevancia son CEDICE, CESAP, SINERGIA y Acción Campesina, convirtiéndose en los nodos centrales, en los patrones de esta red se observa una densidad amplia entre los actores que integran la red, comprobando la hipótesis de que existe una amplia colaboración e intercambio entre los actores evaluados.

En lo que se refiere al intercambio con otros tipos de plataformas de redes, tanto a nivel nacional como internacional, vemos que 22 de las 27 organizaciones evaluadas participan en por lo menos un tipo de plataforma. La red en la cual se observa una mayor participación de las organizaciones en derechos y participación ciudadana es SINERGIA, cuya participación abarca tanto redes nacionales como internacionales.

La revisión de nuestra red fue ejecutada por medio de un análisis down-up, que se refiere a analizar la red para observar hasta qué punto estas relaciones se extienden y los patrones dentro de los cuales se establecen. Nuestro análisis reafirma la relevancia que tiene la 
coordinación con este tipo de entes para garantizar la efectividad de las políticas, en este sentido, el discurso del buen gobierno debe incluir a los ciudadanos por medio de una dinámica establecida como gobernanza + redes + participacion, aun en un contexto de gran heterogeneidad estructural como lo es el venezolano.

\subsection{Conclusiones}

El análisis formal de este tipo de red, es un enfoque altamente valioso en términos conceptuales y metodológicos, proporcionando una representación de las relaciones en un momento específico en el tiempo, lo cual puede ayudar tanto a expresar y definir la estructura de estas dinámicas, como su influencia en la sociedad, abriendo nuevos cuestionamientos referentes a la forma en que se agrupan y sus consecuencias. Esto se realizó por medio de una visión general sobre el modus operandi de las organizaciones y las interacciones entre ellas, en donde se interpretó la fluidez en el contexto actual y como esto afecta sus articulaciones.

Este análisis se realizó por medio de una estrategia analítica cualitativa, basada en una estructuración de forma empírica, por medio de cuestionarios de las relaciones de la organizaciones de sociedad civil en Participación y Derechos ciudadanos en Venezuela, observando cómo se vieron afectadas por el comportamiento de otros actores políticos. Este tipo de representación refleja un intento de ordenar un mundo de relaciones sociales complejas y desordenadas, incrementando su complejidad a la hora de evaluarlas, esto se logra a partir de la simplificación de un escenario de interacciones abstracto, evaluando tanto el contexto en el cual estas se desarrollan como el impacto que tienen en su fluidez.

Por medio de este estudio se buscó presentar el contexto complejo del entramado político/económico venezolano en el cual desarrollan las actividades estas organizaciones y el papel relevante que tienen como agentes capaces de disminuir la polarización en la sociedad. Sin embargo, es una muestra de la realidad contemporánea en un micro nivel.

Para el establecimiento de tendencias es necesario evaluar y analizar un mayor número de organizaciones de sociedad civil, así como de actores en diferentes áreas de la sociedad civil. Este estudio refleja la interrelación entre las 27 organizaciones evaluadas, teniendo conocimiento que aunque estas tienen relación con otras organizaciones, para efectos de nuestro estudio se limitó a mostrar la interacción en una red cerrada de 27 organizaciones.

Las principales conclusiones de esta investigación se alcanzaron por medio del establecimiento de un vínculo entre el contexto político, económico y social venezolano que 
rodea a estas organizaciones y las dinámicas en las cuales se establecen sus relaciones, buscando una cuantificación y clasificación de estos procesos, para lograr una ampliación de los conocimientos acerca de las organizaciones de la sociedad civil venezolana y la definición del impacto de estas transformaciones en las relaciones entre ellas.

Las organizaciones de la sociedad civil reflejan los intereses públicos, sociales, colectivos y de los individuos que conforman una sociedad, estructurándose como mecanismos que aglutinan intereses plurales y buscan hacerlos efectivos por medio del diálogo con el estado. Tomando en consideración estos aspectos se definieron patrones de relaciones sociales, con el objetivo de extraer informaciones significativas por medio de la descripción de todos los posibles lazos entre los actores. De esta forma, la existencia de las relaciones obliga a formular los intereses de estas organizaciones como relativos, sometidos a las limitaciones y oportunidades ofrecidas por la estructura en que los individuos están inmersos, generando una serie de conclusiones:

- Se observa que la cohesión de estas organizaciones incrementa la movilización de capital social para servir a los objetivos de desarrollo, reafirmando el carácter de estos actores como instrumentos catalizadores de la promoción de la democracia y la transparencia por parte del estado.

- Las plataformas que agrupan un amplio número de organizaciones están en mayor capacidad de exigir y demandar soluciones desde la sociedad hacia el Estado, debido a su consolidación como actores y por ende actúan como un solo bloque de denuncias y exigencias, aglutinadas por una mayor cantidad de personas, sumando esfuerzos y aumentando la eficacia de la acción

- El proceso implementado por medio del Socialismo del Siglo XXI, ha dificultado la capacidad de acción de las organizaciones de la sociedad civil, lo que genero un incremento en el contacto entre estas entidades, en lo que se refiere a la cooperación para el desarrollo de proyectos e intercambio de información, así como la participación en redes nacionales e internacionales, en la búsqueda de su permanencia como actores activos dentro de la sociedad venezolana.

- El enfoque relacional de las organizaciones en Venezuela, opera de acuerdo con su área de especialización, en este caso se consideraron relevantes las organizaciones vinculadas a la participación y derechos ciudadanos, debido a que efectivamente están teniendo un impacto en la 
estructura democrática presentando actores que se constituyen como esenciales para el fomento de la participación ciudadana.

- Las alianzas entre las organizaciones son un factor clave para atender e incrementar su impacto en temas como la transparencia institucional, servicios públicos, educación, derechos humanos, entre otros, aspectos que han estado desatendidos por otros actores de la sociedad, como lo son los partidos políticos y las instituciones gubernamentales.

- La participación de la sociedad, se vuelve un requisito necesario para la elaboración de políticas públicas y el establecimiento de un interacción equilibrada y transparente GobiernoSociedad Civil.

- Podemos observar en las organizaciones encuestadas, una fuerte relación con las redes regionales, en especial con REDLAD, creada para el fortalecimiento de la democracia y el respeto a los derechos humanos a través de compartir información, buenas prácticas y estrategias de gobernabilidad para y con la sociedad civil organizada, demostrando el compromiso de las organizaciones de Sociedad Civil en Venezuela en promover este tipo de gobiernos.

En Venezuela, el análisis de redes aplicado a las organizaciones civiles se encuentra en su fase inicial, por lo cual es necesaria una agenda de investigación, para de esta forma entender las dinámicas de los actores vistos como colectivos, permitiendo la realización de estudios comparativos sistemáticos a lo largo del tiempo, explorando las implicaciones metodológicas de la conceptualización de las redes y sus representaciones en un sentido amplio.

Diversos análisis han demostrado empíricamente cómo los estados y los ciudadanos pueden beneficiarse cuando una densa red de organizaciones de la sociedad civil media la relación entre ellos (KRISHNA, 2000), debido a que se mejoran los programas y el impacto de la política implementada por el gobierno, resultado de un dialogo directo con el ciudadano, ya que en vez de interactuar con los ciudadanos como individuos dispersos, se realiza a través de grupos de ciudadanos organizados. Las relaciones entre las organizaciones de sociedad civil han tomado cada vez más importancia en el contexto contemporáneo, promoviéndose de esta forma la acción pública coordinada entre sus miembros y otros ciudadanos.

El análisis de redes estudia fenómenos sociales y culturales, generados a partir de la interacción observable, revelan patrones y estructuras que de otra forma no serian evidentes. como ocurre en el caso venezolano. Dentro de la teoría interorganizacional, la forma en que se establecen las relaciones entre actores permite la toma de decisiones adecuadas, así como modificar la posición dentro de la estructura, definiendo las relaciones que deben ser 
potenciadas, nuestro análisis demuestra que las relaciones de las OSC son densas como resultado de un contexto convulso.

Se hace relevante, entonces, la continuidad de este estudio para tener, más allá de una fotografía, una comparación de la interlocución entre estas organizaciones, tanto en los diferentes niveles gubernamentales como entre ellas, debido a que las dinámicas de este tipo de organización están en constante transformación, observándose el alcance e información que nos puede suministrar los estudios de redes, en especial en contextos como el de Venezuela. En este sentido Venezuela es un objeto de estudio que debe ser evaluado con mayor profundidad debido a los cambios volátiles que presenta su contexto actual ${ }^{143}$ y en el cual estas organizaciones juegan un papel fundamental.

\footnotetext{
${ }^{143}$ El triunfo del sector en las recientes elecciones parlamentarias del 6 de diciembre de 2015, y el con una amplia mayoría, cambia el escenario político venezolano y trae consigo un impacto en el desarrollo político-social de esta organizaciones y su rol como articuladores Estado-Sociedad Civil.
} 


\section{CONCLUSIONES}

Este estudio tuvo como objetivo profundizar las cuestiones relativas al papel de la cohesión social en el desarrollo de las sociedades, por medio de la promoción de valores democráticos y a partir de la pluralidad de las identidades sociales. Su contribución particular fue analizar las dinámicas sociales de inclusión, tanto a nivel mundial como regional, a partir de la observación de políticas públicas que afectan las condiciones objetivas de las sociedades, relacionadas con el bienestar y la calidad de vida, así como aspectos más subjetivos que se enfocan en el sentido de pertenencia de los individuos que forman parte de la sociedad.

En el escenario contemporáneo, en el cual se desarrolla la globalización, la cohesión no puede estar disociada de lo que implican los cambios y el conflicto social, debido a que las sociedades se encuentran en procesos de constante mutación, generando como resultado desintegración dentro de las sociedades e inviabilidad en lo que se refiere a su capacidad de legitimar las instituciones democráticas por medio de la confianza, pero al mismo tiempo se observa un escenario positivo, en donde el individuo es visto en términos de su papel como agente catalizador de la participación y demandas a nivel ciudadano, enfoque que se buscó consolidar por medio de esta investigación.

Referirse a las interacciones de las sociedades, en términos de cohesión, es tanto un asunto teórico como un problema político y de implementación de políticas públicas originadas en las instituciones gubernamentales. Fue necesario tomar en consideración la teoría desarrollada en esta área, que en muchos casos presenta características residuales en sus enfoques, con el objetivo de interpretar las dinámicas sociales, para lo cual se contextualizó la complejidad del concepto, así como la necesidad de su implementación para el alcance de un desarrollo sostenido de las sociedades, vinculándolo a la capacidad de los individuos hacia la cooperación y el compromiso cívico.

Existe una literatura amplia que sugiere que la falta de cohesión entre los grupos en la sociedad tiende a contribuir a la inseguridad, en lo que se refiere a la falta de confianza horizontal entre grupos y vertical con el Estado (Kaplan, 2008; Janotte, 2003; Easterly, 2006; Jensen, 1998, Norris, 1999; Cuellar, 2009, entre otros), lo cual resulta en un contexto de fragilidad de las instituciones estatales. En este sentido, este trabajo constató de forma cuantitativa que existe un impacto de los procesos vinculados a la cohesión en lo que se refiere a la consolidación democrática, siendo un aporte a las formulaciones futuras en términos de políticas gubernamentales. Esto representa una oportunidad para introducir en el debate público 
una visión renovada de los rumbos de las sociedades, enfatizando el papel de actores sociales y del espacio público, con el objetivo de implementar un enfoque "desde abajo" "144 dentro de la estructura de toma de decisiones.

En consecuencia. se observa que las políticas focalizadas, sin una articulación con los diversos niveles que componen la estructura institucional, dificultan la construcción de una ciudadanía social amplia, así como el desarrollo y crecimiento económico estable e incluyente. La cohesión social es un área de investigación en donde se observan intereses y proyectos antagónicos. La implementación de políticas, en este sentido, necesita tener como foco la reducción de la desigualdad social para garantizar procesos sociales equilibrados.

El enfoque interdisciplinario, por medio de la cohesión social, refleja la realidad del escenario contemporáneo, siendo un mecanismo para la comprensión de la complejidad de la vida en sociedad, la cual está constituida por sistemas autonómicos y diversos, constituyéndose en la base para relaciones verdaderamente pluralistas y la consolidación de estructuras institucionales efectivas, ya que los sistemas democráticos sólo podrán ser formados a partir del reconocimiento de subsistemas donde los individuos, vistos como ciudadanos, sean el foco de los procesos de desarrollo. En consecuencia, se puede afirmar que la insuficiencia en la implementación de políticas apropiadas y congruentes con la realidad de las sociedades, en conjunto con una baja calidad institucional, pueden ser identificadas como las causas para la falta de crecimiento, la pobreza endémica y el conflicto civil, que derivan a su vez en una baja calidad democrática.

El diagnóstico global, por medio de nuestra evaluación, presenta un contexto caracterizado por la existencia de un desfase entre las instituciones y la realidad social, denominado como déficit social, debido a la priorización de la dimensión económica en la implementación de las políticas, por parte de los estados. Una democracia de calidad no puede ser evaluada simplemente por su legitimidad y eficiencia, esta debe tomar en consideración su componente valorativo, en el que se incorporen las expectativas ciudadanas, creando una nueva lógica de relaciones entre el Estado, el mercado y la sociedad civil.

La literatura, en lo que se refiere a las dinámicas sociales de cohesión (CEPAL, 2001; SORJ, MATUCELLI, 2008; Coleman, 1998), reafirman que el camino a ser seguido se vincula a las oportunidades productivas, el fomento del desarrollo de las capacidades de las personas y a la conformación de sistemas más inclusivos enfocados en la protección ante las vulnerabilidades,

\footnotetext{
${ }^{144}$ Refiriéndonos a los individuos como miembros activos de las sociedades.
} 
principalmente para sectores en riesgo. Las acciones, en términos de las dinámicas sociales, deben evitar la reproducción de procesos de exclusión, que en muchos casos se han caracterizado como constantes dentro de las sociedades, modificando el acceso a derecho ciudadano y generando movilidad social, con el objetivo de superar el contexto de injusticia y desigualdad, creando un sentido de pertenencia, fundamentado en la participación, el diálogo y la concertación social.

El papel de la cohesión social, en la formulación de políticas, no es un proceso que se puede examinar sin tomar en consideración elementos como la identidad, fortalecimiento institucional, el desarrollo económico, la desigualdad y el conflicto. Esta investigación tuvo como uno de sus objetivos la mejor comprensión de las dinámicas sociales, ya que para el alcance de logros sustanciales y efectivos se debe promover el fortalecimiento del capital humano, reduciendo la vulnerabilidad de los individuos y promoviendo sus capacidades ciudadanas para alcanzar democracias con calidad.

El progreso en esta área se basa en el establecimiento de un esfuerzo en términos colectivos, por parte de todos los segmentos que conforman la sociedad y la existencia de, más allá de un sentimiento nacionalista por parte de los ciudadanos, un verdadero incremento de ciudadanía con las instituciones políticas, por medio de políticas sociales más justas y una verdadera transformación que apunte a un proyecto colectivo que genere creencias y valores compartidos dando respuesta a los asuntos relacionados con la disparidad, la desigualdad y la discriminación.

El análisis comparativo, realizado en diferentes países y regiones, presenta una revisión exhaustiva de cómo estas políticas han sido implementadas, para evaluar los estándares de efectividad, estableciendo cuáles han sido los efectos de estos cambios estructurales, tanto de forma positiva como negativa a lo largo del tiempo, ya que, al establecer comparaciones entre países diferentes, se puede lograr una clasificación de las experiencias exitosas y como estas deben ser implementadas en otras localizaciones geográficas, que aun, presentando características particulares de su contexto, se ven afectadas por problemas similares.

El enfoque presentado de la caracterización estas dos regiones: América del Sur y Europa del Este, definidos como polos de cohesión social, se establece en relación al conjunto de características demográficas, étnicas, lingüísticas (en algunos casos), culturales, etc. propias de estos territorios, con una área de vida en común. En donde, aun existiendo una gran dificultad para establecer una visión común de países con características tan diversas, se aplica una 
clasificación desde una perspectiva humana/geográfica, en donde, son consideradas las estructuras de relaciones humanas (económicas, políticas, etc.) y se puede evaluar la aplicación de políticas en términos estatales y regionales.

El estudio de la implementación de políticas sociales en los países que conforman América del Sur y Europa del Este tuvo como objetivo principal establecer la efectividad en términos de cohesión dentro de las sociedades, así como su relación con el comportamiento de la calidad de la democracia. Este análisis se consideró necesario para tener una visión más amplia de los procesos nacionales aun cuando estos dos niveles han carecido de dialogo para la implementación de políticas sociales de forma conjunta.

En el caso de Europa del Este, se implementaron reformas sociales sólidas a la par de las reformas económicas, por medio de un modelo dual con elementos del sistema de bienestar, características de redistribución sólidas y la garantía de derechos sociales universales. El enfoque de políticas sociales que se implementó en estos países es ampliamente consistente con el debate científico en lo que se refiere a inversión social, ya que buscaba al mismo tiempo confrontar los problemas estructurales y aumentar la eficiencia y efectividad de las políticas sociales, tomando en consideración los cambios claves en términos demográficos y sociales.

Por otro lado, América del Sur posee ventajas comparativas en términos de cohesión, ya que existe un elemento transversal identitario común. Aun cuando es importante resaltar que la unidad a partir de la identidad no es sinónimo de unidad en lo político o de unidad en lo económico, porque es esencial evaluar otras variables, pero debe ser considerado como un aspecto catalizador, visto como una variable interviniente, a ser tomada en consideración, en conjunto con variables de mayor relevancia en términos de impacto en la sociedad, como son las políticas sociales multidimensionales interpretadas como políticas de cohesión.

Esta evaluación refleja que las políticas sociales se caracterizan por una falta de planificación, principalmente en América del Sur, así como desarticulación en dos niveles a la hora de disminuir los procesos de exclusión. Uno, a partir del enfoque exclusivo en los sectores básicos y el segundo, por medio de la implementación de políticas para combatir la pobreza de forma aislada, generalmente en términos de urgencia y a corto plazo. Estas dinámicas generaron una disminución de la efectividad de las políticas. En lo que se refiere a los mecanismos de integración evaluados, estos no crearon un dialogo efectivo regional/nacional en la formulación de políticas sociales que alcanzasen a los sectores más excluidos de la región, ya que eran establecidos planes multidimensionales que no eran ejecutados por falta de voluntad política. 
Aun siendo regiones con características específicas en términos históricos, económicos, políticos y sociales, se ven afectadas por problemas sociales comunes vinculados a las ideas de inclusión/exclusión. Es importante resaltar que en ambas regiones se busco mejorar las desigualdades y los procesos de exclusión, por medio de una serie de aspectos específicos tales como la progresiva universalización de la protección social; mejoramiento de la calidad y ampliación del acceso a los servicios públicos y a la justicia, sobre todo para los sectores más pobres de la población, por medio de la implementación de políticas activas de empleo y la ampliación de los derechos de los trabajadores, generando en consecuencia mecanismos sociales progresivos y solidarios, como sucedió en el caso Europeo.

En definitiva se puede afirmar que el fortalecimiento se dio por medio de tres aspectos comunes dentro de los países de ambas regiones: 1) una vocación a resolver problemas concretos, 2) implementación de un enfoque multidisciplinario y 3) la necesidad de establecer relaciones y el conocimiento para para mejorar la democracia y la dignidad humana. Estos procesos se dieron en niveles diferentes en cada una de las regiones evaluados.

Finalmente, se realizó un análisis específico del caso venezolano a través de la forma en que se estructuran las redes de las organizaciones de la sociedad civil en derechos y participación ciudadana, vistas como catalizadoras de procesos inclusivos, siendo causa y efecto de cambios democráticos y sociales, ya que fomentan un desarrollo equitativo y contribuyen a la realización de políticas públicas más efectivas, plurales y eficientes. La evaluación del contexto político, económico y social, revelo una interpretación negativa por parte del estado venezolano en lo que se refiere al papel de este tipo de organizaciones dentro de la sociedad lo cual ha propiciado un incremento en la interacción para el desarrollo de proyectos, por medio de una un aumento en el diálogo y articulación, resultando en procesos cohesivos dentro de la sociedad.

Debido a que el análisis de redes estudia fenómenos sociales y culturales, generados a partir de la interacción observable, que se desarrollan en el tiempo, revelan patrones y estructuras que de otra forma no serían evidentes, como ocurre en el caso venezolano. Se hace relevante, entonces, la continuidad de este estudio para tener, más allá de una fotografía, una comparación de la interlocución entre estas organizaciones, tanto en los diferentes niveles gubernamentales como entre ellas, debido a que las dinámicas de este tipo de organización están en constante transformación. Observándose el alcance e información que nos puede suministrar los estudios de redes, en especial en contextos como el de Venezuela. 
El análisis expuesto busco comprender no solo como fue la evolución de los estados en términos de cohesión, sino también prevenir cómo será la evolución en el futuro. La construcción de sociedades democráticas requiere de un crecimiento equitativo, esto es posible al facilitar a los individuos herramientas que les permitan desarrollarse como ciudadanos activos y participativos en el contexto democrático. Trabajando variables económicas, variables políticas y variables institucionales, como un todo, así como estableciendo una estructuración sostenida por medio de un plan a nivel del estado y no solo del gobierno, constituyéndose como un área esencial dentro de una estrategia nacional. Buscando ordenar un mundo de relaciones sociales complejas y desordenadas, en muchos casos caracterizadas por presentarse de forma sutil, incrementando su complejidad a la hora de evaluarlas. Esto se logra a partir de la simplificación de un escenario de interacciones abstracto, evaluando tanto el contexto en el cual estas se desarrollan como el impacto que tienen en su fluidez.

Las políticas, en materia de cohesión social, necesitan tanto de una visión desarrollista multidimensional, como un compromiso a largo plazo, en conjunto con un escenario macroeconómico estable, con esto se establece que para que la inversión, en términos de políticas de cohesión, se vea reflejada, son necesarios periodos de tiempo prolongados que permitan obtener cambios profundos en la estructura. Un ejemplo característico son los niveles de educación dentro de una sociedad, el avance de este indicador requiere la implementación de políticas conjuntas en las diferentes dimensiones que la conforman: distancia (brechas sociales), institucionalidad y sentido de pertenencia.

En definitiva, por medio del esfuerzo realizado en esta investigación a partir del análisis de los diversos niveles en los cuales se desarrolla la cohesión social, podemos afirmar que es un elemento esencial a la hora de hacer referencia a una democracia con calidad, ya que una sociedad inclusiva y con un sentido de pertenencia solido posee la capacidad de influir en los procesos de decisión que afectan sus vidas, convirtiendo a la sociedad en un caracterizada por tener una ciudadanía activa que se aleja de las viejas ideas de la democracia clásica y se enfoca en la construcción de un modelo de democracia participativa. 


\section{REFERENCIAS BIBLIOGRAFICAS}

ABENTE, D. THE QUALITY OF DEMOCRACY IN SMALL SOUTH AMERICAN COUNTRIES: THE CASE OF PARAGUAY. Kellog Institute, 2007. . Disponible en: $<$ https://kellogg.nd.edu/publications/workingpapers/WPS/343.pdf > . Acceso en: 15 mar. 2015.

ABOAL, D.; ANDRÉS MORAES, J.; FORTEZA, A. (ed.). Economía política en uruguay: instituciones y actores políticos en el proceso económico. Montevideo, Uruguay: Ediciones Trilce, 2003.

ACKET, S.; BORSENBERGER, M.; DICKES, P.; SARRACINO, F. Measuring and validating social cohesion: a bottom-up approach. CEPS, 2011. Disponible en: $<$ http://www.oecd.org/dev/pgd/46839973.pdf>. Acceso en: 13 mar. 2015.

AgUERRONDO, I. El Nuevo Paradigma de la Educación para el siglo. OEI, 1993. Disponible en: <http://www.campus-oei.org/administracion/aguerrondo.htm>. Acceso en: 25 mar. 2014.

Albornoz, V.; OLEAS, S. Ecuador. In: Pobreza, Desigualdad de Oportunidades y Políticas Públicas en América Latina. [s.1.] Konrad-Adenauer-Stiftung, 2007.

ALEGRE, P. DEMOCRACIA Y REFORMAS EN EL URUGUAY: UN CASO DE GRADUALISMO PERVERSO. Revista Uruguaya de Ciencia Política, v. 17, n. 1, 2008. Disponible en: <http://www.redalyc.org/html/2973/297322673006/index.html>. Acceso en: 21 jul. 2015.

ALMEIDA TAVARES, M. H. T. de. The social policies of Lula's administration. Novos Estudos-CEBRAP, v. 1, n. SE, p. 0-0, 2005.

ALTMAN, D.; PEREZ-LIÑAN, A. Assessing the Quality of Democracy: Freedom, Competitiveness and Participation in Eighteen Latin American Countries. v. 9, n. 2, p. 85-100, 2002.

AMADEO, E. Argentina, de la crisis a la cohesión social. CEPAL, p. 102-125, 2008.

ANDERSEN, M. L.; TAYLOR, H. F. Sociology: understanding a diverse society. Belmont, CA: Wadsworth/Thomson Learning, 2000.

ANGULO RIVAS, A. Civiles, Militares y Política en Venezuela. FERMENTUM, v. 30, n. 11, p. 115-142, 2011.

ARAGONÈS, E.; SÁNCHEZ-PAGÉS, S. A Theory of Participatory Democracy Based on the Real Case of Porto Alegre. European Economic Review, v. 53, n. 1, p. 56-72, jan. 2009.

ARANGO, I. D. Dificultades de la democracia: bases de ética política. Medellín, Colombia: Editorial Universidad de Antioquia, 2010.

ARAUJO, I. Entre o centro e a periferia: contextos, mediações e produções de sentidos. Anais do Colóquio Mediações e Usos de Saberes e da Informação apresentado em COLÓQUIO 
MEDIAÇÕES E USOS DE SABERES E DA INFORMAÇÃO: UM DIÁLOGO FRANÇABRASIL. , 2008. .

ARAYA, R. Internet, política y ciudadanía. Nueva Sociedad, v. 195, p. 56-71, 2005.

AVDAVIG, S. Social Dialogue and the European Union AccessionOpen Society Institute, , 2001. .

BAEZA, M. Globalización y homogeneización cultural. Sociedad Hoy, v. 24, n. 9, 2006. Disponible en: <http://www.redalyc.org/pdf/902/90201002.pdf>. Acceso en: 4 nov. 2014.

BANCO MUNDIAL. Romania Povertyand Social PolicyBanco Mundial, 1997. Disponible en: $<\mathrm{http}: / / \mathrm{www}-$

wds.worldbank.org/servlet/WDSContentServer/WDSP/IB/1997/04/01/000009265_39708181030

24/Rendered/PDF/multi0page.pdf $>$. Acceso en: 3 mar. 2015.

BANCO MUNDIAL. Indicadores del desarrollo mundial 2009. Banco Mundial, 2009. . Disponible en: <http://data.worldbank.org/indicator>. Acceso en: 16 out. 2014.

BANCO MUNDIAL. Nuevo informe del Banco Mundial revela que la clase media en Paraguay aumentó en la última década. $\mathrm{BM}, 2012$. Disponible en: $<$ http://www.bancomundial.org/es/news/press-release/2012/11/14/paraguays-middle-classgrows $>$. Acceso en: 15 jun. 2014.

BARCA, F. Agenda for a reformed cohesion policy; a place-based approach to meeting european union challenges and expectations. Brussels: European Communities, 2009.

BARCA, F.; MCCANN, P.; RODRIGUEZ-POSE, A. The case for regional development intervention: place based versus place neutral approaches. Journal of Regional Science, v. 52, n. 1, p. 134-152, 2012.

BARREDA, M. La calidad de la democracia: Un análisis comparado de América Latina. Politica y gobierno, v. 18, p. 265 - 295, 2011.

BARR, N. Labour markets and social policy in central and eastern europe. Washington, DC: World Bank, 2005.

BARRO, R. J. Determinants of Democracy. Journal of Political Economy, v. 107, n. S6, p. S158-S183, dez. 1999.

BECK, U. The cosmopolitan perspective: sociology of the second age of modernity. British Journal of Sociology, v. 51, n. 1, p. 79-105, 2000.

BECK, W.; VAN DER MAESEN, L.; WALKER, A. Social quality: from issue to concept. In: The Social Quality of Europe. The Hague: Kluwer Law International, 1997. p. 263-297.

BEETHAM, D. Human rights and democracy. In: Understanding Democratic Politics. Londres: Sage, 2003. 
BÉLAND, D.; PETERSEN, K. Analysing social policy concepts and language: comparative and transnational perspectives. [s.1.] Policy Press, 2015.

BELLO, M. Equidad social y educación en los años '90. IIPE-UNESCO, 2002. Disponible en: $<$ http://sisbib.unmsm.edu.pe/bibvirtualdata/publicaciones/economia/24/a07.pdf $>$. Acceso en: 16 set. 2014.

BERGER, J.; ZELDITCH, M. (ed.). Sociological theories in progress: new formulations. Newbury Park: Sage, 1989.

BERGER, P. The Limits of Social Cohesion: Conflict and Mediation in Pluralist Societies. Westview, 1998.

BERNARD, P. La Cohésion sociale: critique d'un quasi-concept, Lien social et Politiques. RIAC, v. 41, p. 47-59, 1999.

BID. Programa Orígenes, Fase Ii: Desarrollo Integral De Pueblos Originarios. BID, 2014. Disponible en: $<$ http://idbdocs.iadb.org/wsdocs/getdocument.aspx?docnum=857369 $>$. Acceso en: 28 ago. 2015.

BOBBIO, N. O conceito de sociedade civil. Rio de Janeiro: Graal, 1994.

BÖHNKE, P. Perceptions of social integration and exclusion in an enlarged Europe. European Foundation for the Improvement of Living and Working Conditions, 2004. .

BOIX, C.; POSNER, D. Social Capital: Explaining Its Origins and Effects on Government Performance. British Journal of Political Science, v. 4, p. 686-693, 1998.

BOLLEN, K.; BRAND, J. A general panel model with random and fixed effects: a structural equation approach. Social Forces, v. 89, p. 1-34, 2010.

BONKER, F.; PETAK, Z.; BARTLET, W. Croatia ReportBTI, 2015. Disponible en: $<$ http://www.bti-project.org/uploads/tx_itao_download/BTI_2014_Croatia.pdf $>$. Acceso en: 25 maio. 2015.

BONKER, F.; WAGNER, A.; POP-ELECHES, G. 2015 Romania Report. Bertelmann Stiftung, 2015. Disponible en: <http://www.sgi-network.org/docs/2015/country/SGI2015_Romania.pdf $>$. Acceso en: 14 out. 2015.

BOTEK, O. 20 Years of Transformation of Social Policy in Slovakia-Current State and Main Challenges. Procedia - Social and Behavioral Sciences, v. 143, p. 852-856, ago. 2014.

BOTELLO, N. A.; CARMONA, V. L. L. Violencia y distancia social: una revisión. [s.1.] Universidad Autónoma del Estado de México, 2004.

BRICEÑO RUÍZ, J. La integración regional en américa latina y el caribe: procesos históricos y realidades comparadas. 1. ed. Mérida, Venezuela: Publicaciones Vicerrectorado Académico CODEPRE, 2007. 
CALDERON, F.; HOPENHAYN, M.; OTTONE, E. Esa esquiva modernidad : desarrollo, ciudadanía y cultura en América Latina y el Caribe. Caracas: Unesco, 1996.

CAMOU, A. (ed.). Los desafíos de la gobernabilidad. 1. ed. México: Plaza y Valdés, 2001.

CANAVIRE-BACARREZA, G.; AYAVIRI, M. M. Políticas macroeconómicas, choques externos y protección social en Bolivia. CEPAL. La Paz-Bolivia: Unidad de Análisis de Políticas Sociales $\mathbf{y}$ Económicas (UDAPE), 2010. Disponible en: $<$ http://www.gcanavire.com/images/publications/PoliticasMacroeconomicas.pdf $>$. Acceso en: 28 ago. 2015.

CARRETERO, S.; GARCES, J.; RÓDENAS, F. La politica social en Hungria. Cuadernos Const. de la Cátedra Fradique Furió Ceriol, v. 41/42, 20032002.

CARVALHO LOPES, M. H. Políticas sociales para las familias en Brasil y el programa“ Hambre Cero". En: Políticas hacia las familias, protección e inclusión sociales-LC/L. 2373P-2005-p. 11-15, 2005. Disponible en: <http://repositorio.cepal.org/handle/11362/6797>. Acceso en: 28 ago. 2015.

CASTELLS, M. Globalización, desarrollo y democracia: Chile en el contexto mundial. [s.1.] Fondo de Cultura Económica Chile, 2005.

CECCHINI, S.; FILGUEIRA, F.; MARTINEZ, R.; ROSSEL, C. Instrumentos de protección social Caminos latinoamericanos hacia la universalizaciónCEPAL, , 2015. . Disponible en: $<\mathrm{http}$ ://repositorio.cepal.org/bitstream/handle/11362/38821/S1500279_es.pdf?sequence=1>. Acceso en: 8 jun. 2015.

Centrangolo, O.; GOMEZ, J. C. Política tributaria en Argentina. Entre la solvencia y la emergencia. CEPAL, 2007. Disponible $<\mathrm{http}$ ://repositorio.cepal.org/bitstream/handle/11362/4866/S0700417_es.pdf?sequence=1>.

CEPAL. Cohesión social: inclusión y sentido de pertenencia en América Latina y el Caribe. CEPAL / AECI / SEGIB, 2007a. Disponible en: $<\mathrm{http}$ ://repositorio.cepal.org/handle/11362/2812>. Acceso en: 28 ago. 2015.

CEPAL. Estudio económico de América Latina y el Caribe 2006-2007. Santiago de Chile: CEPAL, 2007b. .

CEPAL. Equidad, desarrollo y ciudadanía. CEPAL, 2010. Disponible en: $<$ http://repositorio.cepal.org/bitstream/handle/11362/2686/S2006536_es.pdf?sequence=2>. Acceso en: 24 abr. 2014.

CEPAL. DOCUMENTO DE PÁIS SOBRE LAS POLÍTICAS ORIENTADAS A LAS FAMILIAS PARA LA REDUCCIÓN DE LA POBREZA Y LA CONCICLIACIÓN DE LA VIDA LABORAL Y FAMILIA: URUGUAYCEPAL, 2013. Disponible en: $<$ http://dds.cepal.org/infancia/actividades/taller-regional-capacitacion-27-29-agosto2013/docs/DDS-taller-2013-08-27_Documento-Uruguay-sobre-politicas-orientadas-a-lasfamilias.pdf $>$. Acceso en: 14 jun. $\overline{2015 .}$ 
CERAMI, A. Social policy in central and eastern europe: the emergence of a new european welfare regime. [s.l.] LIT Verlag Münster, 2006.

CHAN, J.; TO, H.-P.; CHAN, E. Reconsidering social cohesion: Developing a definition and analytical framework for empirical research. Social indicators research, v. 75, n. 2, p. 273-302, 2006.

CHINDRIŞ-VĂSIOIU, O.; UNGUREANU, C.; OTHERS. Importance of Economic and Social Cohesion Policy for Romania. Journal of Knowledge Management, Economics and Information Technology, v. 1, n. 6, 2011. Disponible en: <http://www.scientificpapers.org/wpcontent/files/1200_CHINDRIS_UNGUREANU_Importance_Of_Economic_And_Social_Cohesi on_Policy_For_Romania.pdf $>$. Acceso en: 27 ago. 2015.

CHOLLEY, A. La géographie: guide de l'étudiant. Paris: Presses universitaires de France, 1951.

CIPRUT, J. V. (ed.). Ethics, politics, and democracy: from primordial principles to prospective practices. Cambridge, Mass: MIT Press, 2008.

CONAPSO. Estrategia social boliviana. La Paz: CONAPSO, 2004.

CORNEJO, B.; NARANJO, M.; PAREJA, F.; MONTUFAR, M. Ecuador. CEPAL, 2003. . Disponible en: <http://www.cepal.org/publicaciones/xml/8/4648/ecuador.pdf $>$. Acceso en: 23 nov. 2015.

COTLER, J. La cohesión social en la agenda de américa latina y de la unión europea. Lima: Instituto de Estudios Peruanos (IEP) y Observatorio de las Relaciones Unión Europea - América Latina (OBREAL), 2006.

CRESPO, R. El índice de miseria en Venezuela. Nueva Economía, v. 34, p. 187-194, 2011.

CUELlAR, R. Cohesión Social y Democracia. IDEA, 2009. Disponible en: $<$ http://www.idea.int/resources/analysis/upload/ES_Cuellar_low_2.pdf $>$. Acceso en: 22 nov. 2015.

CUENCA, R.; ZAVALA, V. (ed.). Nuevos maestros para américa latina. Madrid: Cochabamba, Bolivia : Bonn, Alemania: Ediciones Morata ; GTZ ; InWEnt, 2007.

CUNSKA, Z.; MURAVSKA, T. SOCIAL POLICY IMPLEMENTATION IN LATVIA POST EU ACCESSION. In: Promotion of Social Policies-an investment in the future. Riga: European Communitie Representation in Latvia/ University of Latvia, 2009.

DAHL, R. La democracia. Buenos Aires: Taurus, 1999.

DAHL, R. Sobre a democracia. Brasilia: UnB, 2001.

DALTON, R. J. Political cleavages, issues, and electoral change. In: Comparing Democracies: Elections and voting in global perspective. [s.l: s.n.]p. 319-342. 
DÁVILA, M.; SOUTULLO, X. S. ¿De qué se habla cuándo se habla de políticas públicas? Estado de la discusión y actores en el Chile del bicentenario. Estado, Gobierno y Gestión Pública, n. 17, p. pp-5, 2011.

DAWSON, D. J. Cultures of democracy in serbia and bulgaria: how ideas shape publics. [s.1.] Ashgate Publishing, Ltd., 2014.

DEACON, B. Social policy, social justice and citizenship in eastern europe. Avebury: Aldershot, 1992.

DE LA ROSA, G. Teoría democrática. Joseph Schumpeter y la síntesis moderna. Nueva Epoca, v. 23, p. 177-199, 2010.

D’ELIA, Y. Las Misiones Sociales en Venezuela: una aproximación a su comprensión y análisis. ILDIS, 2006. . Disponible en: <http://library.fes.de/pdffiles/bueros/caracas/50458.pdf $>$. Acceso en: 10 maio. 2014.

D’ELIA, Y.; CABEZAS, L. F. La política social en Venezuela. ILDIS, 2008. Disponible en: $<$ http://www.ildis.org.ve/website/p_index.php?ids=7\&tipo=P\&vermas=127>. Acceso en: 11 out. 2015 .

DERLIEN, H.; SZABLOWSKI, G. Regime Transitions, Elites, and Bureaucracies. Eastern Europe. Governance, Special Issue, v. 3, n. 6, p. 303-348, 1993.

DESA. Working Definition of Social Integration. UN Department of Economic and Social Affairs, 2006.2 Disponible $<\mathrm{http}$ //www.un.org/esa/socdev/sib/peacedialogue/soc_integration.htm>. Acceso en: 24 abr. 2014.

DGEEC. Principales resultados de pobreza y distribución de ingresoSecretaría Técnica de Planificación de la Presidencia de la República, , 2013. . Disponible en: $<$ http://www.dgeec.gov.py/Publicaciones/Biblioteca/eph2014/Boletin\%20de\%20pobreza\%20201 4.pdf>. Acceso en: 23 mar. 2015.

DIAMOND, L. Developing democracy. to- ward consolidation. Baltimore: John Hopkins University Press, 1999.

DIAMOND, L. J.; LINZ, J. J.; LIPSET, S. M. (ed.). Democracy in developing countries. Boulder, Colo. : London: L. Rienner; Adamantine Press, 1988.

DIAMOND, L.; MORLINO, L. The Quality of Democracy. Journal of Democracy, v. 15, n. 4, p. 20-31, 2004.

DINAN, D. Ever closer union: an introduction to european integration. 4th ed ed. Boulder, Colo: Lynne Rienner Publishers, 2010.

DRAIBE, S. A política social no período FHC e o sistema de proteção social. Tempo social, v. 15, n. 2, p. 63-101, 2003. 
DRAIBE, S.; ARRETCHE, M. T. Políticas Sociales y Programas de Combate a la Pobreza en Brasil. In: Rede de Centros de Investigación Económica Aplicada. Santiago: Banco Mundial de Desarrollo, 1995. p. 97-162.

DRAKE, P. W.; JAKSIC, I. EI modelo chileno: democracia y desarrollo en los noventa. [s.1.] Lom Ediciones, 1999.

DUHAIME, G.; SEARLES, E.; USHER, P.; MYERS, H.; FRÉCHETTE, P. Social Cohesion and Living Conditions in the Canadian Arctic: From Theory to Measurement. Social Indicators Research, v. 66, n. 3, p. 295-318, 1 maio 2004.

DURKHEIM, E. La división del trabajo social. México: Prem, 1989.

EASTERLY, W.; RITZEN, J.; WOOLCOCK, M. SOCIAL COHESION, INSTITUTIONS, AND GROWTH. Economics and Politics, v. 18, n. 2, p. 103-120, jul. 2006.

ESPING-ANDERSEN, G. The three worlds of welfare capitalism. Princeton: Princeton University Press, 1990.

EUROPARAT (ed.). Concerted development of social cohesion indicators: methodological guide. Strasbourg: Council of Europe Publ, 2005.

FALKNER, G.; NENTWICH, M. Enlarging the European Union: the short-term success of incrementalism and de-politicisation. [s.1.] MPIfG working paper, 2000. . Disponible en: $<$ http://www.econstor.eu/handle/10419/41701>. Acceso en: 26 ago. 2015.

FARÍAS, C. R. Los desafíos de la protección social en un país de renta alta: el caso chileno. Revista Uruguaya de Ciencia Política, v. 22, n. 2, p. 123-144, 2013.

FARINETTI, M. Clientelismo y protesta: cuando los clientes se rebelan. Apuntes de Investigación, v. 2/3, 2000.

FAUNDEZ, R. Ciudadanía de baja intensidad el aporte conceptual y algunas pistas para su estudio en el caso chileno. 2006. Universidad Alberto Hurtado, Santiago de Chile, 2006.

FAZEKAS, K.; KOLLO, J. European priorities and some characteristics of the Hungarian labour market. In: Evaluation of Hungarian labour market policy from the angle of European Employment. Budapeste: HAS IoE, 2005.

FELDMAN, G. The migration apparatus security, labor, and policymaking in the european union. Palo Alto: Stanford University Press, 2011.

FERGE, Z.; JUHÁSZ, G. Accession and social policy: the case of Hungary. Journal of European Social Policy, v. 14, n. 3, p. 233-251, 2004.

FERNANDEZ, J. E.; DE LOS CAMPOS, H. Análisis de las políticas y programas sociales en Uruguay: La acción pública para prevenir y combatir el trabajo de niños, niñas y adolescentes. OIT, 2004. . 
FILGUEIRA, F. Hacia un modelo de protección social universal en América LatinaCEPAL, 2013. . Disponible en: <http://dds.cepal.org/proteccionsocial/sistemas-de-proteccionsocial/2013-12-seminario-politicas-publicas-igualdad/docs/Seminario-Fernando-Filgueira2013.pdf $>$. Acceso en: 30 nov. 2015.

FILIPOVIČ HRAST, M.; IGNJATOVIĆ, M. GROWING INEQUALITIES AND THEIR IMPACTS IN SLOVENIAGINI, , 2013. . Disponible en: <http://giniresearch.org/system/uploads/506/original/Slovenia.pdf?1372768022>. Acceso en: 26 nov. 2015.

FOA, R. The Economic Rationale for Social Cohesion -The Cross-Country Evidence. OECD Publishing, 2011. Disponible $<$ http://www.oecd.org/development/pgd/46908575.pdf >. Acceso en: 13 mar. 2015.

FRASER, N. Social Justice in the Age of Identity Politics: redistribution, recognition and participation. In: Standford University. Anais... In: THE TANNER LECTURES ON HUMAN VALUES. Standford University: Standford University, 1996.

FRAZER, H.; MARLIER, E. Strengthening social inclusion in the europe 2020 strategy by learning from the past. Bruselas: PIE Peter Lang, 2010.

FREITEZ, N. Alcances y límites de la Economía Social en la Venezuela Actual. Serie Dialogo Democrático, p. 2-18, 2007.

FURET, F. Tocqueville e o problema da revolução francesa. Rio de Janeiro: Paz e Terra, 1989.

GAMBOA, C. (ed.). Aportes andinos sobre derechos humanos: investigaciones monográficas. Primera edición ed. Quito: Universidad Andino Simón Bolívar, Sede Ecuador : Ediciones Abya-Yala, 2005.

GANEV, G.; POPOVA, M.; BONKER, F. 2015 Bulgaria Report. Bertelmann Stiftung, 2015.

GARCIA CANCLINI, N. Diferentes, desiguales y desconectados. Barcelona: Gedisa, 2004.

GARCIA JURADO, R. Poliarquía y Democracia. Estudios Filosofía. Historia. Letras, v. 47, p. $1-10,1997$.

GARCÍA-LÓPEZ, G. A.; ARIZPE, N. Participatory Processes in the Soy Conflicts in Paraguay and Argentina. Ecological Economics, v. 70, n. 2, p. 196-206, dez. 2010.

GARIBALDI, L:; IBARRA, M. PLAN CEIBAL: MUCHO MÁS QUE DISTRIBUCIÓN DE COMPUTADORAS. La Educación, v. 145, n. OEA, p. 1-18, 2011.

GASTIL RAYMOND D. Freedom in the world: political rights \& civil liberties, 19841985. Washington: Greenwood Heinemann, 1985.

GIARDIELLO, M. The Generative Theory of Social Cohesion and Civic Integration. European Scientific Journal, v. 10, n. 10, 2014. Disponible en: $<$ http://www.eujournal.org/index.php/esj/article/view/3696>. Acceso en: 21 ago. 2015. 
GIDDENS, A. Beyond left and right: the future of radical politics. Standford: Stanford University Press, 1994.

GIMÉNEZ, G. La identidad social o el retorno del sujeto en sociología. Identidad III Coloquio Paul Kirchhoff. UNAM, 1996. Disponible $<$ http://148.206.107.15/biblioteca_digital/estadistica.php?id_host=6\&tipo=ARTICULO\&id=210 9\&archivo=7-139-

2109erg.pdf\&titulo=La\%20identidad $\% 20$ social $\% 20 \mathrm{o} \% 20 \mathrm{el} \% 20$ retorno $\% 20 \mathrm{del} \% 20$ sujeto $\% 20$ en $\% 20$ sociolog\%C3\%ADa>. Acceso en: 28 ago. 2015.

GOBIERNO DE BOLIVIA. Gaceta oficial de Bolivia No 29272, 2006. . Disponible en: $<$ http://www.cienciaytecnologia.gob.bo/uploads/boliviaplan_desarrollo_nac_ds_29272.pdf>. Acceso en: 25 ago. 2014.

GOERTZ, G. Social science concepts a user's guide. Princeton: Princeton University Press, 2011.

GOMEZ, L. Los movimientos sociales: democracia emergente en el sistema político venezolano. In: Venezuela hacia el año 2000. Desafíos y opciones. Caracas ed. [s.1: s.n.]p. 337-367.

GONZALEZ, C. Transformaciones socioeconómicas en Hungría desde 1989. Papeles del Este: transiciones postcomunistas, v. 1, 2001. Disponible en: <www.ucm.es/BUCM/CEE/PAPELES/01/ACTAS.HTM>. Acceso en: 24 oct. 2015.

GONZALEZ, L.; LA CRUZ, T. POLÍTICA SOCIAL EN VENEZUELA. Temas de Formación Sociopolítica, v. 35, p. 4-98, 2008.

GONZALEZ LOPEZ, F. La Democracia como concepto Sociopolítico. In: TEORÍA POLÍTICA Y GESTIÓN PÚBLICA. Santiago de Chile: Konrad-Adenauer-Stiftung, 2010.

GOUGH, I.; OLOFSSON, G. Capitalism and social cohesion. Basingstoke: Macmillan, 1999.

GOULD, R.; HARRIS, S. Welfare Reform and Disability in Slovakia: exploring neoliberalism, social justice and employment policy. Disability Studies Quaterly, v. 32, n. 2, 2012.

GRAZIANO DA SILVA, J.; DEL GROSSI, E.; GALVÃO, C. Fome zero a experiência brasileira. Brasilia: MDA, 2010.

GRUZEVSKIS, B.; BLAZIENE, I. Social and Employment Situation in LithuaniaEuropean Parliament's Committee on Employment and Social Affairs (EMPL), , 2013. . Disponible en: $<$ http://www.europarl.europa.eu/RegData/etudes/note/join/2013/507447/IPOLEMPL_NT\%282013\%29507447_EN.pdf>. Acceso en: 27 ago. 2015.

GRYNSPAN, R.; LOPEZ-CALVA, L. F. Democracia y gobernabilidad en la región latinoamericana. Cohesión social en Iberoamérica algunas asignaturas pendientes, v. 1, n. 2, 2007.

GUERRA, A.; PONCE DE MORENO, B. Un modelo político para la gerencia pública en Venezuela, 2006. Disponible en: <www.eumed.net/libros/2005/agbp/>. Acceso en: 25 oct. 2015. 
GUOGIS, A.; BERNOTAS, D. LITHUANIAN SOCIAL POLICY MODEL. FACTA UNIVERSITATIS, v. 7, n. 1, 2008.

HAAS, E. Beyond the nation state. Stanford: Stanford Univ. Press, 1964.

HARDY, C. RETOS DE COHESIÓN SOCIAL EN AMÉRICA LATINAEUROSOCIAL, 2014. Disponible en: <http://www.sia.eurosocial-ii.eu/files/docs/1413879355Retos\%20cohesion\%20social\%20AL_Hardy.pdf>. Acceso en: 27 set. 2015.

HECLO, H.; WILDAVSKY, A. B. The private government of public money: community and policy inside british politics. California: Univ of California Press, 1974.

HEGRE, H. Democracy and Armed Conflict. Journal of Peace Research, v. 51, n. 2, p. 159172, 1 mar. 2014.

HELD, D. Models of democracy. 2nd ed ed. Stanford, Calif: Stanford University Press, 1996.

HELD, D.; KEANE, J. Socialism and the limits of state action. New Socialist, v. Marzo-Abril, 1984.

HELLIWELL, J. F.; PUTNAM, R. D. Economic growth and social capital in Italy. Eastern Economic Journal, v. 21, n. 1, p. 295-307, 1995.

HERNANDEZ, C. Experiencias en los procesos de diálogo para la cohesión social: Europa Central y Oriental. In: Asunción, Paraguay. Anais... In: ENCUENTRO DE INTERCAMBIO Y PROGRAMACIÓN: CONSTRUCCIÓN DE CONCENSOS PARA LA COHESIÓN SOCIAL. Asunción, Paraguay: European Partnership for Democracy, 2011.

HERNANI-LIMARINO, W.; FUNDACIÓN, A. R. U. Understanding changes in social cohesion in Bolivia, 2010. Disponible en: $<$ http://fundaru.org/REPEC/pdf/understandingchanges-in-social-cohesion-bolivia.pdf $>$. Acceso en: 28 ago. 2015.

HOPENHAYN, M. Nuevas formas de ser ciudadano: ¿la diferencia hace la diferencia? relea, n. Universidad Central de Venezuela, 2000.

HOPENHAYN, M. ¿Integrarse o subordinarse? Nuevos cruces entre política y cultura. In: Cultura, política y sociedad Perspectivas latinoamericanas. Buenos Aires: CLACSO, 2005. p. $17-40$.

ILIEVA, M. Regional Differences and Regional Cohesion: Case Study of Bulgaria. Journal of Urban and Regional Analysis, v. 2, p. 153-168, 2013.

IMAS, V. Paraguay. In: Pobreza, Desigualdad de Oportunidades y Políticas Públicas en América Latina. [s.1.] Konrad-Adenauer-Stiftung, 2007.

ISAGS. Sistemas de salud en Suramérica: desafíos para la universalidad la integralidad y la equidad. La Asunción: ISAGS, 2012.

JACOME, F.; GRATIUS, S. VIOLENCIA, INSEGURIDAD Y POLARIZACIÓN POLÍTICA EN VENEZUELAFRIDE, 2011. . Disponible en: <http://www.ifp- 
ew.eu/pdf/201111IfPEWFRIDEViolenciaInseguridadEnVenezuela.pdf $>$. Acceso en: 22 jun. 2015.

JEANNOTTE, S. Social cohesion around the world: An international comparison of definitions and issues. Hull: Strategic Research and Analysis Directorate, 2000.

JEMIO, L. C. REFORMAS, POLÍTICAS SOCIALES Y EQUIDAD EN BOLIVIACEPAL, 1999. Disponible en: <http://iidee.net/archivos/LC\%20JEMIO/ID012\%20cepal_equidad.pdf $>$. Acceso en: 21 nov. 2015.

JENSEN. Mapping Social Cohesion: The State of Canadian Research. Strategic Research and Analysis Directorate, , 1998. .

JENSON, J. Mapping Social Cohesion: The State of Canadian Research. CPRN, 1998. .

JUBERIAS, C. Estudios sobre la Europa oriental. Valencia: Editorial Universidad de Valencia, 2002.

KABEER, N. Inclusive citizenship: meanings and expressions. London: Zed Books, 2005. v. 1

KALLASTE, E.; LEETMAA, R.; LEPPIK, L.; PHILIPS, K. EU Enlargement and its Impact on the Social Policy and Labour Markets of Accession and Non- Accession CountriesEstonia ReportPRAXIS, , 2003. . Disponible en: <http://www.praxis.ee/wpcontent/uploads/2014/03/2003-EL-enlargement-and-its-impact-estonia.pdf $>$. Acceso en: 21 ago. 2015 .

KAUFFMANN, D.; KRAAY, A.; MASTRUZZI, M. The Worldwide Governance Indicators: Methodology and Analytical IssuesWorld Bank, 2010. . Disponible en: $<$ http://papers.ssrn.com/sol3/papers.cfm?abstract_id=1682130>. Acceso en: 23 jun. 2014.

KEOHANE, R. O.; NYE, J. S. Power and interdependence. 4th ed. Boston: Longman, 2012.

KEYES, C. L. M. Social well-being. Social psychology quarterly, p. 121-140, 1998.

KLIKSBERG, B. El capital social: dimensión olvidada del desarrollo. Venezuela: Editorial Texto, CA, Universidad Metropolitana; Distribuidora Panactua, CA, 2001.

KOSSELLECK, R. Futuro pasado: para una semántica de los tiempos. Barcelona: Paidos, 1993.

KSIEZOPOLSKI, M. "Social Policy in Poland in the Period of Political and Economic Transition: Challenges and Dilemmas." Journal of European Social Policy 3, v. 3, 1993.

KUGELMAS, E. Revisitando o desenvolvimento. Revista brasileira de Ciências Sociais, v. 22, n. 63 , p. 7-10, 2007.

KUSA, Z.; GERBERY, D. Europeanization of Slovak Social Policy. In: SOCIAL POLICY IN EUROPE: CHANGING PARADIGMS IN AN ENLARGING EUROPE?, Viena, Austria. Anais... In: ESPANET CONFERENCE. Viena, Austria: Espanet, 2007. 
LA PORTA, R.; LOPEZ-DESILANES, F.; SCHLEIFER, A.; VISHNY, R. The quality of government. Journal of Law, Economics and Organization, v. 15, n. 1, p. 222-279, 1999.

LARRAÑAGA, O. ¿Qué puede esperarse de la política social en Chile? Serie de Documentos de Trabajo (SDT) $\mathbf{N}^{\mathbf{0}} \mathbf{2 4 5}$. Departamento de Economía de la Universidad de Chile, 2007. Disponible en: <http://www.econ.uchile.cl/uploads/publicacion/54fa1185-0e98-41da-88cf7f3bc83af6b6.pdf>. Acceso en: 28 ago. 2015.

LAVIGNE, M. The economics of transition: from socialist economy to market economy. 2da. ed. London: Palgrave Macmillan, 1999.

LEPORE, E.; MORENO, C. Confianza Pública y Participación Ciudadana en la Argentina Post- Devaluación.Observatorio de la Deuda Social Argentina, , 2007. . Disponible en: $<$ http://bibliotecadigital.uca.edu.ar/greenstone/cgi-

bin/library.cgi? $\mathrm{a}=\mathrm{d} \& \mathrm{c}=$ investigacion $\& \mathrm{~d}=$ confianza-publica-participacion-ciudadana-argentina $>$. Acceso en: 14 jun. 2015.

LEWIS, P. G. Political parties in post-communist eastern europe. London; New York: Routledge, 2000.

LIJPHART, A. Patterns of democracy: government forms and performance in thirty-six countries. 2nd ed ed. New Haven: Yale University Press, 2012.

LINDBLOM, C. E.; GOÑI, E. Z. El proceso de elaboración de políticas públicas. Madrid: Ministerio para las Administraciones Públicas, 1991.

LIPSET, S. M. The Social Requisites of Democracy Revisited: 1993 Presidential Address. American Sociological Review, v. 59, n. 1, p. 1-22, 1994.

LOAYZA, M. Gasto público social en la década de los noventa. Revista de Análisis Económico (UDAPE), $\quad$ v. $17, \quad 1999 . \quad 10$ Disponible $<$ http://www.udape.gob.bo/portales_html/analisiseconomico/analisis/vol17/ART03.pdf $>$. Acceso en: 28 ago. 2015.

LOCKWOOD, D. Civic integration and social cohesion. In: Capitalism and social cohesion: Essays on Exclusion and Integration. [s.1.] Palgrave, 1999.

LÓPEZ-MANTEROLA, A. EVOLUCION DE LA POLITICA COMUNITARIA DE AYUDA A LOS PAISES DE EUROPA CENTRAL Y ORIENTAL. EL PROGRAMA PHARE Y LOS NUEVOS INSTRUMENTOS PREADHESION. ICE-Europa del Este diez años después, n. 786, 2000. Disponible en: <http://www.revistasice.com/CachePDF/ICE_786_93101_A2A6A18E8E4821E3C20FF8BEFDBF3BEE.pdf>. Acceso en: 21 nov. 2014.

LOPEZ MAYA, M. Venezuela 2001-2004: actores y estrategias. CDC, v. 21, n. 56, p. 109-132, 2004.

LUHMANN, N. Sistemas sociales. Barcelona: Anthropos-UIA-CEJA, 1984. 
MACHINEA, J. L.; UTHOFF, A. Integración económica y cohesión social: lecciones aprendidas y perspectivas. CEPAL-SRE-Comisión Europea, 2005. Disponible en: $<$ http://repositorio.cepal.org/handle/11362/3932>. Acceso en: 28 ago. 2015.

MAINWARING, S.; PEREZ-LIÑAN, A. REGIME LEGACIES AND DEMOCRATIZATION: EXPLAINING VARIANCE IN THE LEVEL OF DEMOCRACY

IN LATIN AMERICA, 1978-2004kellog Institute, 2008. Disponible en: $<$ https://www3.nd.edu/ kellogg/publications/workingpapers/WPS/354.pdf $>$. Acceso en: 1 maio. 2015.

MARROCU, E.; PACI, R. Regional development and creativity. International Regional Science Review, v. 36, n. 3, p. 354-391, 2013.

MATEI, L.; VAŠIČEK, D.; KAŠTELAN-MRAK, M. European administrative space balkan realities. Bucharest: Matei Lucica, 2011.

MATHIEU, C.; STERDYNIAK, H. O Modelo Social Europeu e a Europa Social. Conferência Para outra Política Económica, para uma outra Europa, para uma Europa Social. In: Conferência Para outra Política Económica, para uma outra Europa, para uma Europa Social, Coimbra, Portugal. Anais... Coimbra, Portugal: Faculdade de Economia, Universidade de Coimbra, 2008. Disponible en: <https://hal-sciencespo.archives-ouvertes.fr/hal-01053173/>. Acceso en: 27 ago. 2015.

MCNEISH, J.-A. Stones on the road: the politics of participation and the generation of crisis in Bolivia. Bulletin of Latin American Research, v. 25, n. 2, p. 220, 2006.

MEDINACELI, M. Impuesto directo a los hidrocarburos: origen, destino y usos. Bolivia: International Institute for Democracy and Electoral Assistance, 2015.

MEDINA, J. M.; LÓPEZ-MORENO, S. Changes in perceived health in war-displaced population, Ayacucho, Peru: 1980-2004. Ciência \&amp; Saúde Coletiva, v. 16, n. 3, p. 16991708, mar. 2011.

MÉNDEZ, J. N.; CUESTA, L. Las trampas de pobreza en Colombia; ¿Qué hacer? Diseño de un programa contra la extrema pobreza. Colombia: Universidad de los Andes, 2002. Disponible en:

$<$ http://www.researchgate.net/profile/Laura_Cuesta/publication/4832638_LAS_TRAMPAS_DE _POBREZA_EN_COLOMBIA_QUE_HAC̄ER_DISEO_DE_UN_PROGRAMA_CONTRA_L A_EXTREMA_POPBREZA/links/53ed03c30cf $2 \overline{3} 733 \mathrm{e} 80549 \overline{\mathrm{ad}} . \mathrm{pdf}>$. Acceso en: $\overline{2} 8$ ago. $201 \overline{5}$.

MINISTERIO DE EDUCACIÓN Y CULTURA DE LA REPÚBLICA DEL URUGUAY. A 140 AÑOS DE LA EDUCACIÓN DEL PUEBLO: APORTES PARA LA REFLEXIÓN SOBRE LA EDUCACIÓN EN URUGUAYMEC, 2014. Disponible en: $<$ http://www.mec.gub.uy/innovaportal/file/927/1/libro_140_anos_varela_-_web.pdf $>$. Acceso en: 27 set. 2014.

MINISTERIO DE PLANIFICACIÓN DE CHILE. Cohesión Social, 2007. . Disponible en: $<$ http://segib.org/upload/File/COHESIONSOCIALXVIICumbreIberoamericanaes.pdf $>$. Acceso en: 20 ago. 2015. 
MIROŠEVIĆ, J. Inclusive education in CroatiaUNESCO, 2007. . Disponible en: $<$ http://www.ibe.unesco.org/fileadmin/user_upload/Inclusive_Education/Reports/sinaia_07/croat ia_inclusion_07.pdf>. Acceso en: 30 set. 2015.

MITRANY, D. The funcionalist alternative. New York: Hartcourt Brace College Publishers, 1994.

MOISES, J. A. O significado da democracia segundo os brasileiros. CADERNOS DO NUPPS, v. 02 , n. 1, p. 1-41, 2009.

MONASTIRIOTIS, V. The Emergence of Regional Policy in Bulgaria: regional problems, EU influences and domestic constraints. Hellenic Observatory Papers on Greece and Southeast Europe, n. LSE, 2008.

MORALES, J. A.; SACHS, J. D. Bolivia's economic crisis. In: Developing country debt and the world economy. [s.1.] University of Chicago Press, 1989. p. 57-80.

MORLINO, L. What is a "Good" Democracy? Theory and Empirical Analysis. In: Berkeley. Anais... In: THE EUROPEAN UNION, NATIONS STATE, AND THE QUALITY OF DEMOCRACY. LESSONS FROM SOUTHERN EUROPE. Berkeley: University of California, 2002.

MORLINO, L. Changes for democracy: actors, structures, processes. Oxford: Oxford University Press, 2012.

MULLER, P.; SUREL, Y. L’analyse des politiques publiques. Paris: Montchrestien, 1998.

MURILLO, J.; HERNANDEZ, R. TRABAJAR POR LA JUSTICIA SOCIAL DESDE LA EDUCACIÓN. Revista Iberoamericana sobre Calidad, Eficacia y Cambio en Educación, v. 9, n. 4, 2011.

NAIM, M.; KING, R. "Hemispheric Economic Integration: Big Bang, Gradual Evolution, or Fading Hope? In: Washington, DC. Anais... In: LATIN AMERICA 2010 SEMINAR. Washington, DC: National Defence University, 1996.

NAKROSIS, V. Effectiveness of implementing the EU cohesion policy in Lithuania. In: Paper for the Fourth Pan-European Conference on EU Politics of the ECPR, Anais... In: CONFERENCE ON EU POLITICS OF THE ECPR. 2008.

NERI, M.; MELO, L.; SACRAMENTO, S.; LIPKIN, P. Pobreza, Igualdad de Oportunidades e Innovaciones de Política Social en Brasil. In: Pobreza, Desigualdad de Oportunidades y Políticas Públicas en América Latina. Rio de Janeiro: Konrad-Adenauer-Stiftung, 2012.

NORRIS, P. Democratic deficit: critical citizens revisited. New York: Cambridge University Press, 2011.

NUÑEZ, E. La reforma educativa en Paraguay en la década del noventa. Informe final del concurso: Fragmentación social y crisis política e institucional en América Latina y el Caribe, n. CLACSO, Consejo Latinoamericano de Ciencias Sociales, 2002. 
O’DONNELL, G. Reflections on Contemporary Latin American Democracies. Journal of Latin American Studies, n. Otoño, p. 67-82, 2001.

O’DONNELL, G. La democracia en América Latina: Hacia una democracia de ciudadanas y ciudadanos. Buenos Aires: PNUD, , 2004. .

OECD. Regions matter: economic recovery, innovation and sustainable growth. Paris: OECD Publishing, 2009a.

OECD. How regions grow. Paris: OECD Publishing, $2009 \mathrm{~b}$.

OECD. Perspectives on Global Development 2012: Social Cohesion in a Shifting World. OECD, 2011. Disponible en: <http://www.oecd.org/site/devpgd2012/49067954.pdf >. Acceso en: 20 ago. 2015.

OECD. Estudios económicos de la OCDE COLOMBIAOECD Publishing, 2013. Disponible en: <http://www.oecd.org/eco/surveys/Colombia_Overview_ESP\%20NEW.pdf $>$. Acceso en: 23 jul. 2014.

OECD. Society at a glance 2014 2014. Disponible en: < http://www.keepeek.com/Digital-AssetManagement/oecd/social-issues-migration-health/society-at-a-glance-2014_soc_glance-2014en\#page1>. Acceso en: 16 ago. 2015.

OLIART, P. El Estado Peruano y las Políticas sociales dirigidas a los Pueblos Indígenas en la década de los 90. Self-sustaining Community development y Comparative Perspective, $\mathrm{n}$. Instituto de Estudios Peruanos-University of Texas, 2009. Disponible en: $<$ http://lanic.utexas.edu/project/laoap/claspo/dt/0009.pdf $>$. Acceso en: 24 maio. 2015.

OPP. Análisis del Marco Normativo - Cometidos. Oficina de planeamiento y presupuesto, 2002. . Disponible en: <http://www.opp.gub.uy/index.php/analisis-del-marco-normativocometidos>. Acceso en: 5 dez. 2015.

ORDUNA, M. G. Identidad e identidades: Potencialidades para la cohesión social y territorial. URBAL, 2012. . Disponible en: <https://www1.diba.cat/uliep/pdf/52259.pdf $>$. Acceso en: 25 maio. 2014.

ORENSTEIN, M. Transitional Social Policy in the Czech Republic and Poland. Czech Sociological Review, III, $1995 . \quad$ Disponible en: $<$ http://sreview.soc.cas.cz/uploads/2231268ef95aee3ddf3f0d5a6198cc9d81a78c50_464_179ORE NS.pdf $>$. Acceso en: 30 mar. 2015.

PAHL, R. E. The Search for Social Cohesion: From Durkheim to the European Commission. European Journal of Sociology, v. 32, n. 02, p. 345, nov. 1991.

PALMA IRARRÁZAVAL, A. P. Las políticas públicas que no contribuyen a la cohesión social. Chile: FLACSO, 2009.

PARADA BARRERA, C. Hacia un nuevo concepto de ciudadanía global. Via Iuris, v. 7, n. Julio-Diciembre, p. 98-111, 2009. 
PARSONS, T. Un enfoque analítico de la teoría de la estratificación social. Ensayos de teoría sociológica, 1967.

PASCÓ-FONT, A.; SAAVEDRA, J. REFORMAS ESTRUCTURALES Y BIENESTAR UNA MIRADA AL PERÚ DE LOS NOVENTAGRADE, 2001. . Disponible en: $<$ http://www.grade.org.pe/download/pubs/libros/Reformas.pdf $>$. Acceso en: 22 nov. 2015.

PETERLEVITZ, T. Conceituando e medindo a democracia em colômbia e Venezuela. 2011. USP, São Paulo, 2011. Disponible en: <http://www.teses.usp.br/teses/disponiveis/8/8131/tde09042012-135450/pt-br.php>. Acceso en: 7 nov. 2015.

PHINNEMORE, D. (ed.). The eu and romania: accession and beyond. London: Federal Trust, 2006.

PICKLES, J.; SMITH, A. Introduction. theorising transition and the political economy of transformation. New York: Routledge, 1998.

PNUD. La democracia en América Latina. PNUD, 2004. . Disponible en: $<$ http://www2.ohchr.org/spanish/issues/democracy/costarica/docs/PNUD-seminario.pdf $>$.

Acceso en: 8 dez. 2015.

PNUD - UNICEF - CEPAL. EI gasto público en servicios sociales básicos en diez países de américa latina y el caribe: análisis desde la perspectiva de la iniciativa 20/20. Santiago: PNUD, 1999.

POTLUKA, O. Impact of EU Cohesion Policy in Central Europe. Leipzig: Leipziger Universitätsverlag, 2010. . Disponible en: $\quad<\mathrm{http}: / / \mathrm{km} . v s e . c z / w p-$ content/uploads/2011/06/Impact-of-EU-Cohesion-Policy-in-Central-Europe-print-WWW.pdf>.

Acceso en: 26 ago. 2015.

POTUCEK, M. Accession and social policy: the case of the Czech Republic. Journal of European Social Policy, v. 14, n. 3, p. 253-266, 2004.

PRIBBLE, J.; HUBER, E. Social Policy and Redistribution: Chile and Uruguay. In: The Resurgence of the Latin American Left,. Baltimore: John Hopkins University Press, 2013.

PUERTA, M. I. EI debate entre democracia representativay democracia participativa: elementos teórico-conceptuales. Valencia, Venezuela: APUC, 2010.

PUTNAM, R. D. The Prosperous Community: Social Capital and Public Life. The American Prospect, p. 35-42, 1993.

RACZYNSKI, D. Políticas sociales y programas de combate a la pobreza en Chile: balance y desafíos. Colección estudios. CIEPLAN, v. 39, n. 1992, p. 29-69, 1994.

RAJEVSKA, F. Social policy in Latvia: Welfare state under double pressure. Fafo-report, v. 498, 2005. Disponible en: <http://www.fafoarkiv.no/pub/rapp/498/498.pdf>. Acceso en: 27 ago. 2015. 
RAMIREZ GALLEGOS, F.; MINTEGUIAGA, A. El nuevo tiempo del Estado. La política pos neoliberal del correísmo. OSAL, n. clacso, 2007. Disponible en: $<$ http://bibliotecavirtual.clacso.org.ar/ar/libros/osal/osal22/D22RamirezGMinteguiaga.pdf $>$. Acceso en: 14 jul. 2015.

RAMÍREZ, P. Evolución de la Política Social en la Década de los Noventa: Cambios en la Lógica, la Intencionalidad y el Proceso de Hacer la Política Social. Fundación Corona-Área de Gestión Local y Comunitaria, 2002. . Disponible en: $<$ http://lanic.utexas.edu/project/laoap/claspo/dt/0007.pdf>. Acceso en: 28 ago. 2015.

RAMOS, V. ¿Existe una identidad latinoamericana? Mitos, realidades y la versátil persistencia de nuestro ser continental. Utopía y Praxis Latinoamericana, v. 8, n. 21, p. 117-126, 2003.

RAWLS, J. A theory of justice. Rev. ed ed. Cambridge, Mass: Belknap Press of Harvard University Press, 1999.

RAZ, J. The Rule of Law and its Virtue. The law quaterly review, n. 93, p. 198-201, 1977.

RIBOTTA, B. Diagnóstico Sociodemográfico de los Pueblos Indígenas de PerúCEPAL, $2010 . \quad$. Disponible en: $<$ http://www.cepal.org/celade/noticias/paginas/6/40386/peru_julio2010.pdf $>$. Acceso en: 22 nov. 2015.

RITZEN, J. Social Cohesion, Public Policy, and Economic Growth: Implications for OECD Countries. Social Cohesion Nexus, v. 4, n. Canadian Policy Research Networks, 2000.

RIVERA VELEZ, F. Análisis de las políticas y programas sociales en Ecuador. OIT/Oficina Regional para las Américas/Programa IPEC Sudamérica, Lima, 2003. Disponible en: $<$ http://www.oit.org.pe/WDMS/bib/publ/doctrab/dt_167.pdf>. Acceso en: 28 ago. 2015.

RODRIGUEZ LARRETA, E. Cohesión Social, Globalización y Culturas de la Democracia en América LatinaCIEPLAN, 2008. . Disponible en: $<$ http://www.plataformademocratica.org/publicacoes/publicacao_21_em_06_04_2008_19_27_3 9.pdf $>$. Acceso en: 21 nov. 2015.

RODRÍGUEZ MANZANO, I. Funcionalismo, neo funcionalismo y relaciones internacionales : Dos contribuciones doctrinales al estudio de la organización internacional. Dereito: Revista Xurídica da Universidade de Santiago de Compostela, v. 5, n. 1, p. 289-303, 1996.

ROSALES LOPEZ, C. Hacia una ciudadanía inclusiva ¿Un reto a la complejidad educativa? Revista Educación Inclusiva, v. 2, n. 3, p. 97-110, 2009.

ROTHSCHILD, J.; WINGFIELD, N. M. Return to diversity. New York: Oxford University Press, 1993.

SABORIDO, M. El Programa Chile Barrio: lecciones y desafíos para la superación de la pobreza y la precariedad habitacional. 2005. Disponible en: $<$ http://repositorio.cepal.org/handle/11362/3721>. Acceso en: 28 ago. 2015. 
SARIENGA, N. La Participación Ciudadana en la Argentina. Centro de Estudios Nacionales, 2014. Disponible en: <http://www.centroestudiosnacionales.org/instituciones-participacionciudadana/>. Acceso en: 21 nov. 2015.

SARTORI, G. La política: lógica y método en las ciencias sociales. México D.F.: Fondo de Cultura Económica, 1996.

SASSEN, S. A sociology of globalization. New York: W.W. Norton and Co., 2007.

SECRETARIA DE ASUNTOS SOCIALES DEL PARAGUAY. APP y Convenios de Cooperación para reducir la pobreza a corto y mediano plazo, 2015. . Disponible en: $<$ http://nanduti.sas.gov.py/cap/boletin/b2a101.html>. Acceso en: 28 jun. 2015.

SEN, A. Development as freedom. 1. ed., 6th print ed. New York: Knopf, 2001.

SERBIN, A. Globalización y sociedad civil en los procesos de integración. Nueva Sociedad, v. 147, p. 44-55, 1997.

SHIFTER, M.; NEILL, S. Democracy and Human Rights, the Summit and Beyond. In: Washington, DC. Anais... In: SUMMIT OF THE AMERICAS INTEGRATION. Washington, DC: 1996.

SIRI, G. Los fondos de inversión social en América Latina. Revista de la CEPAL, 1996. Disponible en: $<\mathrm{http}: / /$ repositorio.cepal.org/handle/11362/12027>. Acceso en: 28 ago. 2015.

SIROVÁTKA, T.; RÁKOCZYOVÁ, M. The Strategy of Social Inclusion in the Czech Republic. In: Viena, Austria. Anais... In: ESPANET CONFERENCE. Viena, Austria: 2007.

SOLÉ PUIG, C. El desafío de la inmigración en un mundo global: la cuestión de la ciudadanía. El desafío de la inmigración en un mundo global, 2010.

SOLÉ PUIG, C.; SORDÉ MARTÍ, T.; SERRADELL PUMAREDA, O; ALCALDE, R.; FLECHA FERNÁNDEZ DE SANMAMED, A.; PETTROFF, A. G.; CAVALCANTI, L.; PARELLA, S.; PÁVEZ, I.; SANTAMARÍA, E.; GARZÓN, L. Cohesión social e inmigración. Aportaciones científicas y discursos político. Revista Internacional de Sociología, v. 69, n. 1, p. 9-32, 30 mar. 2011.

SOLIMANO, A. Hacia nuevas políticas sociales en América Latina. Revista de la CEPAL, v. 87, p. 45, 2005.

SOMMA, N.; VALENZUELA, E. The Paradoxes of Social Cohesion in Latin America. REVISTA DEL CLAD REFORMA Y DEMOCRACIA, v. 61, n. CLADLATINOAMERICANO ADMINISTRACION DESARROLLO, 2015.

SORJ, B. Latin america's elusive democracies. Rio de Janeiro: Edelstein Center for Social Research, 2007.

SORJ, B.; FAUSTO, S. (ed.). América latina, transformaciones geopolíticas y democracia. 1. ed ed. Ciudad Autónoma de Buenos Aires: Siglo XXI : Plataforma Democrática, 2010. 
SORJ, B.; MARTUCCELLI, D. EI desafío latinoamericano: cohesión social y democracia. Buenos Aires: Siglo XXI, 2008.

STARĘGA-PIASEK, J.; MATELA, P. Rescaling Social Welfare Policies in PolandThe european centre for social welfare policy and research, , 2006. . Disponible en: $<$ http://www.euro.centre.org/rescalingDocuments/files/Poland.pdf $>$. Acceso en: 30 jul. 2014.

STRUWIG, J.; DAVIDS, Y. D.; ROBERTS, B.; SITHOLE, M.; TILLEY, V.; WEIR-SMITH, G.; MOKHELE, T. Towards a social cohesion barometer for South Africa. 2012. Disponible en: $<$ http://www.psppd.org.za/MediaLib/Downloads/Home/ResearchEvidence/Researchprojects/To wards $\% 20 \mathrm{a} \% 20$ social $\% 20$ cohesion $\% 20$ barometer $\% 20$ for $\% 20$ South $\% 20$ Africa_FINAL.pdf $>$. Acceso en: 21 ago. 2015.

STUBBS, P.; SINIŠA, Z. Extended Social Europe?: social policy, social inclusion and social dialogue in Croatia and the European Union'. In: Croatian Accession to the European Union: facing the challenges of negotiations. Zagreb: IJF and FES, 2005. p. 161-184.

SVATOŠOVÁ, V.; SMOLÍK, J. The Scenarios of Social Policy Development in the Czech Republic. Acta Universitatis Agriculturae et Silviculturae Mendelianae Brunensis, v. 63, n. 5, p. 1749-1767, 2015.

SVETLIK, I. REFORM OF SOCIAL POLICY IN SLOVENIA: A SOFT APPROACH. Journal of European Social Policy, v. 3, p. 196-208, 1993.

TANAKA, M.; TRIVELLI, C. Las trampas de la focalización y la participación. Pobreza y políticas sociales en el Perú durante la década de Fujimori. Documentos de Trabajo-Sociología y Política, v. 31, p. 49, 2002.

THOENING, J.-C. Política Pública y acción pública. Gestión y Política Pública, v. VI, n. 1, p. 19-37, 1997.

TIRADO MEJÍA, A. Integración y democracia en américa latina y el caribe. Buenos Aires: Inst. para la Integración de América Latina y el Caribe, 1997.

TIRONI, E. Cohesión social en Chile: el retorno de un viejo tema. Quórum: Revista de pensamiento iberoamericano, n. 18, p. 42-50, 2007.

TOMEI, M. Fondos de inversión social: el caso de chile. [s.1.] OIT, 1997.

TOMEŠ, I. "Social Reform: A cornerstone in Czechoslovakia 's new economic structure". International Labour Review, v. 130, n. 2, p. 191-198, 1991.

TOURAINE, A. (ed.). Solidarity: the analysis of a social movement: poland, 1980-1981. Cambridge [Cambridgeshire]; New York: Paris: Cambridge University Press; Editions de la Maison des sciences de l'homme, 1983.

TRUMM, A. Recent developments of Estonia's social protection system. Background Paper Prepared for the EU8 Social Inclusion Study. Document of the World Bank, v. 52, 2006. Disponible 
$<$ http://siteresources.worldbank.org/INTECONEVAL/Resources/EstoniaSocialPolicyReview.pdf >. Acceso en: 13 jun. 2015.

TUSSEL, A. La calidad de la democracia y sus factores determinantes Un análisis comparado de 60 países. Política y Sociedad, v. 52, n. 1, p. 179-204, 2015.

UNESCO. LAS POLITICAS EDUCATIVAS DE AMERICA LATINA Y EL CARIBEOREALC/ UNESCO Santiago, , 2013. . Disponible en: $<$ http://www.unesco.org/new/fileadmin/MULTIMEDIA/FIELD/Santiago/pdf/las-politicaseducativas-america-latina-caribe.pdf $>$. Acceso en: 25 maio. 2015.

UNRISD. Social Integration: Approaches and Issues. UNRISD, 1996. Disponible en: $<$ http://www.unrisd.org/80256B3C005BCCF9/(httpAuxPages)/510920DA18B35A6880256B650 04C6A7B/\$file/bp1.pdf>. Acceso en: 23 mar. 2014.

VACCINO, J. M. La integración regional y las negociaciones del ALCA. Aldea Mundo, v. 12, n. 6, p. 5-14, 2002.

VALENZUELA, E.; SCHWARTZMAN, S.; BIEHL, A.; VALENZUELA, S. Vínculos, creencias e ilusiones la cohesión social de los latinoamericanos. [s.1.] UQBAR, 2008.

VARGAS-CULELL, J. Avanzando en el estudio de la estatalidad en América Central: Metodología y algunos hallazgos ilustrativos. Revista de Ciencia Politica, v. 32, n. 3, p. 703$721,2012$.

VARGAS FAULBAUM, L. H. La construcción de pactos y consensos en materia de política social. CEPAL, 2014. $\quad$ Disponible en: $<$ http://www.cepal.org/publicaciones/xml/8/53748/LaConstrucciondePactosyConsensos.pdf $>$. Acceso en: 30 abr. 2015.

VARGAS-MACHUCA, R. La calidad de la Democracia. Claves de Razón Práctica, v. 165, p. 34-41, 2006.

VÁSCONEZ, A.; CÓRDOBA, R.; MUÑOZ, P. La construcción de las políticas sociales en ecuador durante los años ochenta y noventa: sentidos, contextos y resultados. Paris: United Nations Publications, 2005. v. 105

VASQUEZ HUAMAN, E. Las políticas y programas sociales del gobierno de Ollanta Humala desde la perspectiva de la pobreza multidimensional. Centro de Investigación de la Universidad del Pacífico, $2013 . \quad$ Disponible en: $<$ http://srvnetappseg.up.edu.pe/siswebciup/Files/DD1307\%20-\%20Vasquez.pdf $>$. Acceso en: 22 nov. 2015.

VILLAR, R. El tercer sector en Colombia: evolución, dimensión y tendencias. Bogotá: Confederación Colombiana de Organizaciones No Gubernamentales Bogota, 2001.

VOS, R. Quien se beneficia del gasto social en Ecuador?. SIISE, 2002. Disponible en: $<$ http://www.siise.gob.ec/siiseweb/PageWebs/pubsii/pubsii_0047.pdf $>$. Acceso en: 23 nov. 2015. 
WAllace, H.; POLlaCK, M. A.; YOUNG, A. R. Policy-making in the european union. Oxford: Oxford university press, 2015.

WALZER, M. Política e paixão. São Paulo: Martins Fontes, 2008.

WISNIEWSKI, J. Convergence toward the European Social Model? Impact of EU accession on Polish social policy. Review of European and Russian Affairs, v. 1, n. 1, 2005. Disponible en: $<$ http://carleton.ca/rera/wp-content/uploads/Vol1-1-Wisneiwski.pdf>. Acceso en: 26 ago. 2015.

WORSLEY, P. O conceito de populismo. In: Ideologias - populismo. Rio de Janeiro: Eldorado, 1973. 


\section{Apéndice 1- Revisión de las políticas de Cohesión Social en la Unión Europea}

Este mecanismo de integración es un caso excepcional en la forma en que se crean políticas sociales y su impacto en las sociedades, un marco de referencia para cualquier iniciativa orientada a medir la cohesión. Basado en un modelo de solidaridad y de reducción de las disparidades entre grados de bienestar (MANZELLA; MENDEZ, 2009).

El concepto de cohesión social europeo, así como las políticas derivadas en consecuencia, surgen de la necesidad de crear un espacio de convergencia entre las dos grandes tradiciones políticas: la social-demócrata, con su énfasis en el Estado, la política y los derechos, y la socialcristiana, con su acento en la familia, la sociedad civil y la vida comunitaria. Este modelo europeo-continental se articula sobre la base de un Estado de Bienestar con un fuerte componente redistributivo, y la garantía de derechos sociales universales (TIRONI; SORJ, 2007). La Unión Europea se convirtió en una entidad completamente diferente en los últimos 20 años, mucho más diversa, fraccionada y multifacética que antes, aumentando su población de 380 millones a 500 millones (DINAN, 2010), por eso hubo la necesidad de fortalecer la dimensión social del mecanismo.

Históricamente la idea de Cohesión Social es mencionada dentro de la Unión Europea por primera vez en el Tratado de Roma de 1957, donde se establece en el preámbulo que dicho instrumento tendrá por objetivo la "reducción de las diferencias existentes entre varias regiones y el atraso de las regiones menos favorecidas". En la Reunión de Jefes de Estado Europeos de 1972, fue establecida como prioridad la disminución de los desequilibrios dentro de la CE. Siguiendo dichas instrucciones las propuestas de reformas, en términos de Cohesión Social, fueron definidas en el "Reporte de la Ampliación Europea" o "Reporte Thompson" (ídem), donde se vislumbró que las políticas regionales, en este sentido, eran más que una herramienta compensatoria.

La Cohesión Social fue definida e implementada de forma más definitiva, dentro de la UE, con la aprobación del Tratado de Maastricht en el año de 1992, también fue creado, en este período, el Fondo de Cohesión, con el objetivo de cofinanciar proyectos de infraestructura en los Estados Miembros con mayores niveles de pobreza (idem). Este tipo de políticas surgen en Europa para atender la disparidad en lo que se refiere al desarrollo y los ingresos, mediante acciones que estimulen a los grupos y regiones de menor desarrollo relativo entre los países (DE LA FUENTE MORENO, 2003). 
Desde la década de los ochenta, la actividad de la UE en la arena social se ha incrementado. Posteriormente, medidas más fuertes que se dedican a la lucha contra las amenazas a la cohesión social, como consecuencia del deterioro del medio ambiente, la calidad de vida, la exclusión social y la exclusión de la sociedad de la información (JEANNOTTE, 2000). Estas amenazas generaron una falta de sentido de identidad europeo y de ciudadanía por parte de los individuos. Frente a este tipo de amenazas, fueron aplicadas una serie de medidas que podemos sintetizar de la siguiente forma:

Tabla 31: Medidas de la Unión Europea para abordar las Amenazas a la Cohesión Social

\begin{tabular}{|c|c|c|}
\hline Dimensiones & Amenazas & Principales medidas para hacer frente a las amenazas \\
\hline Política & $\begin{array}{l}\text { Falta de un sentido de } \\
\text { Identidad Europeo/ } \\
\text { Ciudadanía/ Déficit de } \\
\text { Derechos }\end{array}$ & $\begin{array}{l}\text { * Investigación de políticas (por ejemplo, Comité de Sage - 1995- } \\
\text { 1996) * Conferencia Intergubernamental } 1996 \\
\text { * Consultas con la sociedad civiL * Programa de Cultura } 2000 * \\
\text { Carta de los Derechos Fundamentales de la UE }\end{array}$ \\
\hline \multirow[t]{4}{*}{ Económica } & Desempleo & $\begin{array}{l}\text { *Fondos estructurales *Iniciativas de Empleos (NOW, } \\
\text { HORIZON, YOUTHSTART, INTEGRA, ADAPT) } \\
\text { * Estrategia Europea de Empleo * Directrices para el empleo en } \\
\text { los países miembros }\end{array}$ \\
\hline & $\begin{array}{l}\text { Pobreza/Desigualdad de } \\
\text { ingresos }\end{array}$ & *Fondos estructurales y de Cohesión \\
\hline & $\begin{array}{l}\text { Privación rural / disparidad } \\
\text { regional }\end{array}$ & $\begin{array}{l}\text { *Fondos estructurales y de Cohesión * Iniciativa de Liderazgo - } \\
\text { Política Agrícola Común }\end{array}$ \\
\hline & Malestar Urbano & $\begin{array}{l}\text { * La investigación de políticas (por ejemplo, los informes de la } \\
\text { Fundación Europea para la Mejora de las Condiciones de Vida y } \\
\text { de Trabajo) - Fondos Estructurales (desde 2000) y la Iniciativa } \\
\text { URBAN }\end{array}$ \\
\hline \multirow[t]{2}{*}{ Social } & $\begin{array}{l}\text { Deterioro del Medio } \\
\text { ambiente / Calidad de Vida }\end{array}$ & $\begin{array}{l}\text { * Fondos Estructurales y de Cohesión } \\
\text { * Iniciativa ENVIREG } \\
\text { * Investigación de Políticas (por ejemplo, los informes de la } \\
\text { Fundación Europea para la Mejora de las Condiciones de Vida y } \\
\text { de Trabajo) }\end{array}$ \\
\hline & Exclusión Social & $\begin{array}{l}\text { * Investigación de políticas (por ejemplo, los informes de la } \\
\text { Fundación Europea para la Mejora de las Condiciones de Vida y } \\
\text { de Trabajo) } \\
\text { * Fondos Estructurales- Iniciativas NOW, HORIZON, INTEGRA } \\
\text { y YOUTHSTART } \\
\text { * Agenda Social de la UE } \\
\text { * reforma de los regímenes de protección social (incluido el }\end{array}$ \\
\hline
\end{tabular}




\begin{tabular}{|c|c|}
\hline & Fondo Social Europeo)* Programa de Exclusión Social (2000) \\
\hline $\begin{array}{l}\text { Exclusión de la Sociedad de } \\
\text { la Información }\end{array}$ & $\begin{array}{l}\text { *Investigación de políticas (por ejemplo, el Libro Ecológico de } \\
\text { Vivir y trabajar en la sociedad de la información, 1994, Cohesión } \\
\text { Social y Económica en la Sociedad de la Información, 1996) } \\
\text { * La forma Europea a la Sociedad de la Información (1994) } \\
\text { * Acción de la Sociedad de la Información (1994) } \\
\text { * Mercado Dimensión Social y de la Información Sociedad: } \\
\text { primero la Sociedad (respuesta al Libro Ecológico- 1997) } \\
\text { * Red Transeuropea de Telecomunicaciones * Programa de } \\
\text { Tecnologías de la Sociedad de la Información (1998-2002)* } \\
\text { Iniciativa eEurope (2000) }\end{array}$ \\
\hline
\end{tabular}

Fuente: Jeanotte, 2000

Las medidas que tuvieron un impacto mayor en el fortalecimiento de la cohesión social fueron los Fondos Estructurales y el Fondo de Cohesión Europeo (1992), los cuales pueden ser considerados como hitos para el desarrollo de este tipo de políticas. Tomando esta síntesis como referencia, dentro de la Unión Europea las iniciativas de cohesión social se han enmarcado dentro de un proceso de integración que prioriza la transferencia de fondos desde las regiones más prósperas, en términos económicos, hacia las regiones menos favorecidas.

La convergencia de estos aspectos dentro de los países tuvo como objetivo la promoción de condiciones y elementos que mejoran el crecimiento, conduciendo a las sociedades a una verdadera sinergia entre los Estados miembros y las regiones menos desarrolladas. La política, en materia de cohesión, de la UE de acuerdo con Parlamento Europeo (2015), aumentó de forma excepcional con el paso del tiempo, esto debido al impacto positivo en las dimensiones que la integran, el aumento se dio principalmente en términos de presupuesto y se convirtió, en conjunto con la política agrícola común, en una de las políticas de la Unión más significativas en términos cuantitativos.

El marco en el cual fueron implementadas las políticas de cohesión, buscaba la reducción de disparidades, como se observa en los objetivos presentados anteriormente, buscando un avance conjunto de los países miembros por medio de la redistribución de recursos, disminuyendo las asimetrías en términos económicos y sociales. Para medir el impacto de las políticas de cohesión social, fueron implementados indicadores que buscaban interpretar el porqué de los procesos de desvinculación social así como el origen de la ruptura de los procesos que tenían una tendencia hacia la exclusión (Consejo de Europa, 2001). 
Estos indicadores fueron denominados como los "Indicadores de Laeken", siendo clasificados en primarios, que cubrían las áreas más importantes de la exclusión social y los secundarios, que se encargan de describir otras dimensiones de los problemas y se pueden llegar a establecer indicadores terciarios con el fin de definir áreas específicas, ayudando a la interpretación de los indicadores primarios y secundarios, todos estos se desarrollan en términos cualitativos y cuantitativos como podemos observar a continuación:

Tabla 32: Indicadores de cohesión social de la Unión Europea (indicadores “Laeken”)

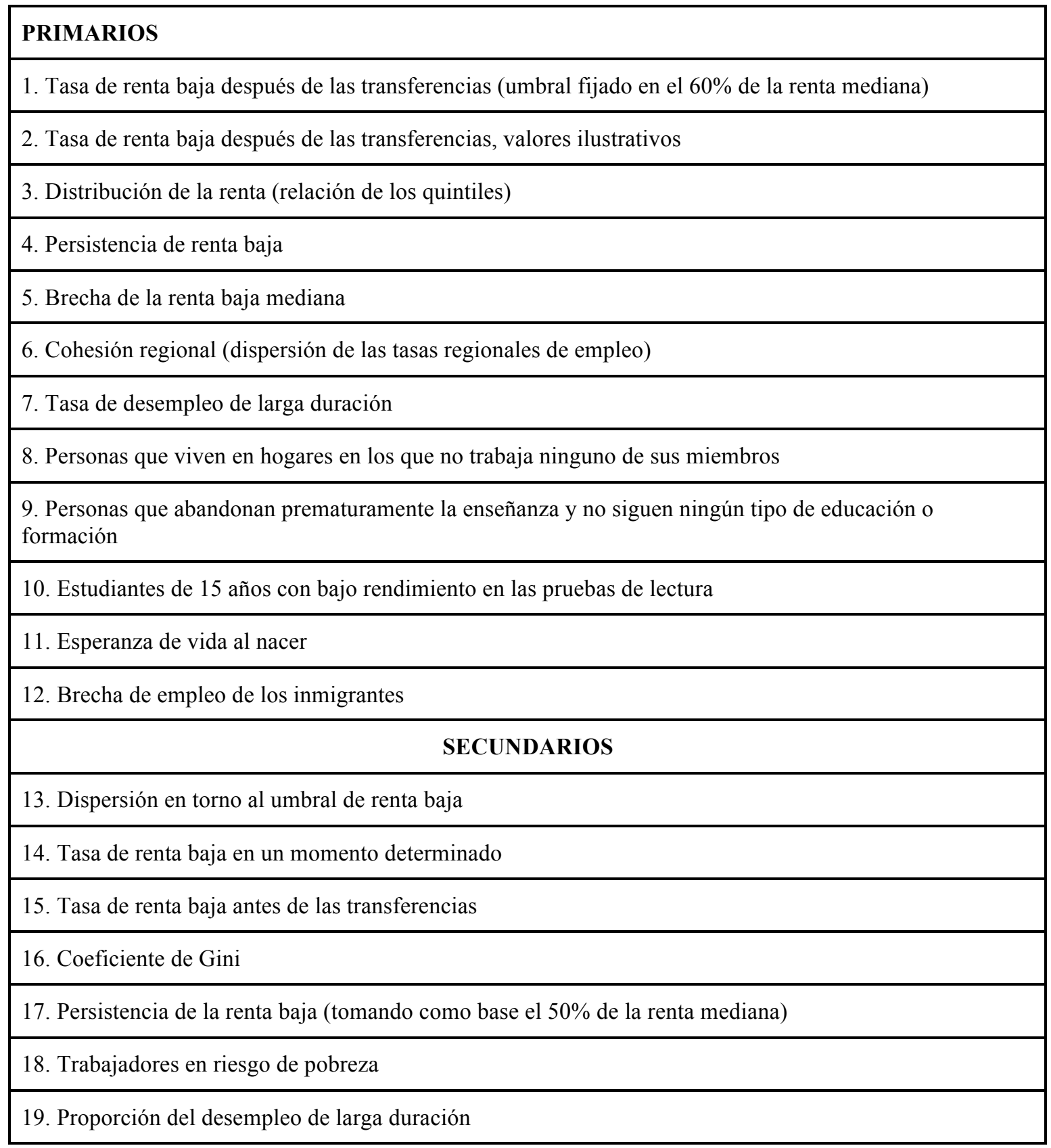


20. Tasa de desempleo de muy larga duración

21. Personas con bajos niveles educativos

Fuente: (CECCHINI, 2006)

Por medio de esta clasificación se buscó una "armonización de los indicadores y la homogeneización de las metodologías, sin dejar de reconocer la heterogeneidad de los países miembros" (CEPAL, 2007), tomando en consideración que cada país posee características propias que los diferencian en términos económicos, políticos y sociales.

Esta revisión teórica e histórica de la forma en que se implementa el concepto de la cohesión social dentro de los países que conforman la UE, permite definirlos como una referencia a cualquier iniciativa que busca medir la cohesión social. De acuerdo con Lepineaux (2005) los enfoques normativos de la cohesión están sometidos a una fuerte determinación histórica, ya que responden a características, trayectorias y necesidades propias, por esto la necesidad de analizar las regiones de forma particular para entender las complejas dinámicas que se desarrollan dentro de sus sociedades. 


\section{Apéndice 2- Revisión de las políticas de cohesión en los Mecanismos de integración CAN y MERCOSUR}

\section{1) Mercosur y su agenda de Cohesión Social}

El MERCOSUR no surge como un mecanismo regional promotor de políticas sociales, desde sus inicios tuvo como foco el desarrollo económico. Esta estructura es denominada como un bloque económico por medio del establecimiento de una zona de libre comercio y aranceles comunes, posteriormente fueron agregados una serie de acuerdos en materia migratoria, laboral, cultural y social, en esta última dimensión evaluaremos el impacto en los países miembros Argentina, Brasil, Paraguay y Uruguay y más recientemente Venezuela y Bolivia (en proceso de adhesión).

En lo que se refiere a la agenda social, desde sus inicios esta no era vista como autónoma, ni tampoco independiente en relación a otros aspectos desarrollados por el MERCOSUR, aún cuando algunas de sus dimensiones se implementaron en paralelo al crecimiento del mecanismo, tales como los derechos laborales y aquellos vinculados al área de la salud. La complejidad en lo que se refiere a la integración de políticas sociales, se refleja en la diversidad de intereses de los países de forma individual, así como la falta de compromiso, continuidad política y la voluntad de implementación.

En la década de los noventa, la dimensión de las políticas sociales fue tomando relevancia, este proceso de ampliación se debe a diversos factores, uno de ellos es que se generó una percepción por parte de los miembros del sistema de integración del cambio constante en el escenario internacional, tanto en términos económicos como políticos, lo que trajo consecuencias dentro de las sociedades que conforman la región, haciendo más tangibles las desigualdades existentes, (GENEYRO; VASQUEZ, 2006). Esto motivó la expansión de la agenda social, incluyendo el tema de la inclusión social en el discurso del Mercado Común , quitando el eje de acción de la agenda a lo exclusivamente comercial.

Tabla 33: Documentos vinculados a la Cohesión Social dentro del Mercosur

\begin{tabular}{|l|l|}
\hline DOCUMENTO & Fecha \\
\hline
\end{tabular}




\begin{tabular}{|l|l|}
\hline $\begin{array}{l}\text { Declaración de los Presidentes de los países del Mercado Común del Sur. } \\
\text { (Extractos)., Colonia del Sacramento, Uruguay). MERCOSUR. V Cumbre de } \\
\text { Presidentes del MERCOSUR. }\end{array}$ & 17 de enero de 1994 \\
\hline Recomendación no 5/97: Políticas de Promoción del Empleo. & 1997 \\
\hline Declaración Socio-laboral de MERCOSUR. & 1998 \\
\hline $\begin{array}{l}\text { Carta de Buenos Aires sobre Compromiso Social. (XVIII Reunión, Cumbre } \\
\text { Presidencial del MERCOSUR,Buenos Aires) }\end{array}$ & 30 de junio de 2000 \\
\hline $\begin{array}{l}\text { Declaración de Santa Cruz de la Sierra. (Primera Reunión de Ministros de } \\
\text { Trabajo del Mercosur y la Comunidad Andina de Naciones. Santa Cruz de la } \\
\text { Sierra) }\end{array}$ & 11 de octubre de 2000 \\
\hline $\begin{array}{l}\text { Recomendación del Consejo del Mercado Común sobre el “Carácter prioritario } \\
\text { del Empleo". }\end{array}$ & 2003 \\
\hline
\end{tabular}

Fuente: Elaboración propia con base en datos del IBEROBSERVATORIO.

Es importante destacar los avances dentro de la dimensión social, como la implementación de la Secretaría Social Permanente del MERCOSUR, que buscó consolidarse como un "eje fundamental en el proceso de construcción de la región por medio de la investigación, intercambio, articulación y difusión de políticas sociales regionales, contribuyendo a la reducción de las asimetrías y a la promoción del desarrollo humano integral" (INSTITUTO SOCIAL DEL MERCOSUR, 2015).

La necesidad de espacios institucionales, con características inclusivas por parte de la sociedad civil, dio paso a la implementación de una serie de programas e instituciones buscando la aproximación con las sociedades, ya que los estados están provistos de áreas responsables de crear y fortalecer espacios nacionales y comunes para la participación social en el proceso de integración, debido al gran potencial del establecimiento de un acuerdo federal para permitir la compatibilidad, siendo esta afirmación parte de un debate sugestivo.

Entre los principales espacios destinados al desarrollo de la dimensión social de acuerdo con la ALOP; CLAEH; CCU (2015), se encuentran:

1) Mercociudades (1995): es la red que reúne a las Alcaldías, Intendencias Municipales y Alcaldía de los centros urbanos del Mercosur, debido a la complejidad de su estructura su actuación no ha sido muy efectiva.

2) Instituto Social del Mercosur (ISM): fue creado con el intuito de promover el diseño participativo de las políticas sociales por medio de la cooperación horizontal. Desarrollando 
proyectos, programas y políticas para la inclusión social y proporcionando un acompañamiento técnico para la elaboración, ejecución y evaluación de políticas públicas.

3) Parlamento del Mercosur: genera un espacio para la participación de la ciudadanía en los asuntos regionales.

4) Programa Somos Mercosur: articular la agenda de los gobiernos y de la sociedad civil con el propósito de rescatar la dimensión social, política y cultural del Mercosur

5) Cumbres Sociales del Mercosur: participación numerosa de organizaciones de la sociedad civil, ampliando considerablemente el pluralismo y el espacio de intercambio y debate entre actores sociales y políticos.

En conjunto con estos espacios, una estructura que merece atención en lo que se refiera a la Cohesión Social en la región, es el Fondo de Convergencia Estructural del Mercosur (FOCEM), cuyo diseño se asemeja al del Fondo de Cohesión de la Unión Europea (SAHANUJA apud CARRILLO FLÓREZ, 2009) un mecanismo de financiación creado para disminuir las asimetrías estructurales en lo que se refiere a niveles de desarrollo, ingreso per-cápita, infraestructura, así como las asimetrías originadas por políticas públicas discrecionales. (GODOY, 2011), entre los cuales están: 1)Convergencia Estructural, 2) Desarrollo de la Competitividad MERCOSUR (Idem), 3)Cohesión Social: proyectos enfocados en el desarrollo social, 4)Fortalecimiento de la Estructura Institucional y del Proceso de Integración: profundización del proceso de integración.

En paralelo con estos espacios fue implementada la política de ciudadanía común entre los países que conforman el mecanismo de integración, este proceso no ha alcanzado todavía su activación plena pero ha tenido grandes avances. Esta estructura está vinculada a la idea de derechos sociales mínimos comunes, que debe ser interpretada como una política social unificada. La complejidad de dichos procesos, en términos de adopción de estructuras y cambios en términos legislativos e institucionales, genera atrasos en lo que se refiere a su efectividad y alcance, como ha sucedido en el caso de la ciudadanía común y en otros como lo ocurrido en materia educativa a respecto de la compatibilización de créditos y de los diplomas.

Estableciendo un balance crítico en términos de políticas de Cohesión, el MERCOSUR se observa como un mecanismo que ha buscado darle relevancia a la dimensión social, pero que ha tenido poco éxito. Cómo establecido por Dreiba (2007) el MERCOSUR busca la conciliación de 
dos estrategias diferentes, en lo que se refiere a las instituciones sociales, opera con una estrategia de baja efectividad (minimalista) y por el contrario en lo que se refiere a los objetivos y conceptos de integración busca la unificación de políticas sociales a nivel supranacional (maximalista), esto genera en consecuencia contradicciones en las estrategias, ya que no son considerados los modelos de desarrollo económico y social para sustentar el proceso de constitución de una ciudadanía social cohesionada.

Por otra parte la unificación stricto sensu de las políticas encuadradas en el marco de la cohesión no ha sido ejecutada de forma efectiva, debido a que la retórica ha tenido un papel de mayor relevancia en detrimento de la aplicación efectiva de políticas, obteniendo en consecuencia resultados modestos en la concretización de la integración social, reforzando la necesidad de políticas inclusivas.

\section{2) La CAN y su agenda de Cohesión Social}

Históricamente la Comunidad Andina ha sido considerada por muchos como un complejo sistema de asociación principalmente en materia económica, de la misma forma que se dio en el MERCOSUR, los asuntos sociales se han ido incluyendo gradualmente en la agenda, los cuales no fueron considerados como una prioridad desde sus orígenes. Este sistema fue definido como una "organización subregional con personalidad jurídica internacional"145 compuesta por los Estados Soberanos Bolivia, Colombia, Ecuador, Perú y Venezuela así como a los órganos e instituciones que conforman el denominado Sistema Andino de Integración.

De acuerdo con PAREJA (2011) dentro de la CAN la cohesión económica y social expresa el proceso mediante el cual se construyen, reafirman y consolidan un conjunto de políticas orientadas al logro de la integración regional y que buscan afrontar con éxito y en democracia el conjunto de desafíos económicos, sociales, políticos, culturales, ambientales que afectan a nuestros países.

La necesidad de abordar estos temas como consecuencia del escenario de crisis y el desarrollo de procesos de globalización a nivel internacional, han permitido lograr un avance significativo en el desarrollo de los indicadores presentando un crecimiento de $20 \%$ en los últimos 30 años (IDH apud CAN, 2015) con una tasa de crecimiento promedio anual de 0,6\%. sin embargo,

\footnotetext{
${ }^{145}$ Artículo 48 del Acuerdo de Cartagena
} 
actualmente $42 \%$ de ciudadanos andinos viven en condiciones de pobreza (idem).

Los tres instrumentos principales de fomento de la cohesión fueron: el Convenio Hipólito Unanue, creado para coordinar y apoyar los esfuerzos de forma individual o colectiva, entre los países miembros en lo que se refiere al área de salud, dando prioridad a la integración y la comunicación entre los países para subsanar las lagunas de las políticas públicas de salud en la CAN (BERGAMASCHINE MATA DIZ, 2009).

El segundo instrumento a ser considerado es el Convenio Andrés Bello (CAB) enfocado en el desarrollo de políticas conjuntas entre los países miembros, en materia de educación, ciencia, tecnología y la cultura ${ }^{146}$, creado en 1970 y sustituido posteriormente por el tratado de Madrid de 1990, en donde se establece que Estados no miembros de la CAN pueden formar parte del mismo $^{147}$ (RAMÍREZ, 2003).

El desarrollo del $\mathrm{CAB}$ ha enfrentado obstáculos a lo largo de sus más de treinta años principalmente en lo que se refiere a articulación y financiamiento, así como lo que se refiere a la concepción economicista de los procesos de integración. En este sentido el CAB requiere de una participación sólida de la sociedad civil, que propicie un diálogo por medio de las coyunturas institucionales entre los países miembros, ya que la cohesión de las sociedades suramericanas recae fuertemente en la dimensión de la educación.

El último instrumento se refiere al Convenio Simón Rodríguez, vinculado a la integración sociolaboral de los países andinos y dentro del cual se considera la formación profesional como una de las prioridades de la armonización de políticas de la región, promoviendo el encuentro de actores sociales, como establecido por Ramírez (2003) “evaluando los modelos sobre los cuales se basan sus metodologías educativas, buscando con ello responder a las demandas producidas por las transformaciones en el contexto laboral, tecnológico, económico, educativo y social".

La Agenda Social Andina ha sido desarrollada desde 2003 por el Plan Integrado de Desarrollo Social (PIDS), el cual tuvo como objetivo atender los problemas de brechas sociales en la región así como las asimetrías, asumiendo como objetivo principal el desarrollo de proyectos sociales comunitarios, la convergencia de objetivos y metas sociales (en el marco de los Objetivos de

\footnotetext{
146 "Asumió el compromiso de atender lo cultural de modo separado de dos esferas igualmente culturales como lo son la educación y el área conformada por la ciencia y la tecnología, en virtud de que cada una de ellas tiene un objeto de conocimiento distinto y por ende una lógica diferente de estudio" (RAMIREZ, 2003).

${ }^{147}$ Actualmente está integrado por Bolivia, Ecuador, Chile, Perú, Colombia, Venezuela, Panamá, España, Cuba y Paraguay (CAB, 2015)
} 
Desarrollo del Milenio), y el programa de cooperación técnica horizontal (VARILLAS, 2011), posteriormente se implementó la OANDES $^{148}$ y EACES ${ }^{149}$, las cuales significaron una actualización de la agenda debido a los cambios en términos internacionales que afectaron la región.

Tomando en consideración el escenario presentado anteriormente, se estima que el promedio del crecimiento de las economías andinas bordea el 5\% (CONTRERAS, 2011) y en donde se observa una inversión ascendente. En lo que se refiere a las políticas sociales implementadas en los países de la CAN una gran mayoría ha tenido su foco en la Cohesión Social (Ver tabla XXX), de acuerdo con datos de la CEPAL (apud CONTRERAS, 2011) el 29\% estaría concentrado en programas de asistencia a la población en situación de pobreza y extrema pobreza; el empleo ocupa un lugar relevante tomando en consideración que $24 \%$ de la inversión social tiene como objetivo el incremento de salarios y el $19 \%$ en la generación de empleos, el 5\% atiende la seguridad social.

Tabla 34: Documentos vinculados a la Cohesión Social dentro de la CAN

\begin{tabular}{|l|l|}
\hline DOCUMENTO & FECHA \\
\hline Carta Social Andina & 1994 \\
\hline Declaración de Ureña & 2000 \\
\hline $\begin{array}{l}\text { Declaración de Arequipa de los Consejos Consultivos Empresarial y Laboral Andinos } \\
\text { (Extractos) }\end{array}$ & 2000 \\
\hline $\begin{array}{l}\text { Declaración de Machu Picchu sobre la Democracia, los Derechos de los Pueblos Indígenas y la } \\
\text { Lucha contra la Pobreza Lima-Machu Picchu. . Extractos) }\end{array}$ & 2001 \\
\hline $\begin{array}{l}\text { Declaración de Santa Cruz de la Sierra. (Primera Reunión de Ministros de Trabajo del } \\
\text { Mercosur y la Comunidad Andina de Naciones) }\end{array}$ & 2000 \\
\hline $\begin{array}{l}\text { Decisión 553. Consejo Andino de Ministros de Relaciones Exteriores. Lineamientos para la } \\
\text { Formulación del Plan Integrado de Desarrollo Social. }\end{array}$ & 2003 \\
\hline $\begin{array}{l}\text { Declaración Andina sobre Desarrollo Social. } \\
\text { Decisión 601 del Consejo Andino de Ministros de Relaciones Exteriores. Plan Integrado de } \\
\text { Desarrollo Social. }\end{array}$ & 2004 \\
\hline $\begin{array}{l}\text { Declaración Andina sobre Políticas Integrales para el Desarrollo, el Trabajo y la } \\
\text { Competitividad. }\end{array}$ & 2004 \\
\hline
\end{tabular}

${ }_{148}^{148}$ Objetivos Andinos de Desarrollo Social al año 2019

${ }^{149}$ Estrategia Andina de Cohesión Económica y Social. 


\begin{tabular}{|l|l|}
\hline $\begin{array}{l}\text { Propuesta del Presidente Evo Morales Ayma: Presidente de la República de Bolivia } \\
\text { Construyamos con nuestros pueblos una verdadera Comunidad Sudamericana de Naciones para } \\
\text { "Vivir bien". (Extractos). }\end{array}$ & 2006 \\
\hline $\begin{array}{l}\text { Decisión } 647 \text { de la Comisión de la Comunidad Andina: Sistema de indicadores sociales de la } \\
\text { comunidad andina. }\end{array}$ & 2006 \\
\hline $\begin{array}{l}\text { Declaración de Santa Cruz de la Sierra. (XVI Reunión Ordinaria del Consejo Consultivo } \\
\text { Laboral Andino (CCLA) }\end{array}$ & 2007 \\
\hline $\begin{array}{l}\text { Declaración Final. V Conferencia Andina sobre el empleo, 15-16 de febrero de 2010 Cartagena } \\
\text { de Indias - Colombia. }\end{array}$ & 2010 \\
\hline
\end{tabular}

Fuente: Elaboración propia con base en datos del IBEROBSERVATORIO.

La implementación de políticas sociales en la región ha generado una disminución en los índices de pobreza, en el año 2002 el promedio de la población en situación de pobreza en la región andina alcanzaba el 44\%, este promedio el año 2010 desciende al 32\% (CONTRERAS, 2011), la orientación de las políticas andinas ya no se dirige como hace pocos años hacia la solución de situaciones de crisis la Comunidad Andina ha asumido como su prioridad la construcción de la Estrategia Andina de Cohesión Económica y Social, a fin de responder a los grandes desafíos de eliminar la pobreza y lograr un desarrollo con inclusión y justicia social.

Uno de los principales problemas de las políticas de cohesión dentro de los mecanismos de integración está vinculado a la existencia procesos de exclusión y la complejidad de implementar acciones conjuntas. Los mecanismos de integración aun en este contexto de falta de articulación, son actores esenciales, ya que tienen la capacidad de desarrollar estándares mínimos supranacionales a ser alcanzados por los estados que los conforman, aun cuando en la actualidad el papel central en términos de políticas de cohesión lo tienen los estados nacionales. 


\section{Apéndice 3- Entrevista Prof. Dr. Jose Briceño Ruiz}

\section{1) América del Sur es una región con profundos problemas estructurales, en su opinión,}

¿cuál es el principal obstáculo para alcanzar cohesión social dentro de las sociedades que conforman la región?

Es una pregunta que abarca un contenido amplio. En efecto, si hay problemas estructurales y yo creo que tienen principalmente una raíz histórica, la forma como se conformaban las sociedades latinoamericanas, las cuales fueron en muchos aspectos jerarquizadas, sectores recibiendo muchos privilegios y otros sectores prácticamente excluidos de esos privilegios. Entonces, es un tema complejo, porque tiene variables económicas, políticas e institucionales, que tienen que ser tratadas con el objetivo de resolver las desigualdades o, en este caso, mayor cohesión social.

En primer lugar, la cohesión social nos plantea un escenario de sociedades más justas, sociedades más integradas en distintos sectores. No como en América Latina, que son sociedades en las cuales un $5 \%$ de la población continúan concentrando un $80 \%, 70 \%$ o $90 \%$ de los ingresos. Se refiere entonces a sociedades donde la distribución sea más justa. Ahí hay problemas de tipo económico, político e institucional.

En primer lugar, económico, porque la idea de cohesión social en el fondo plantea un problema distributivo, distribuir la riqueza, de manera mas justa, pero el problema es que para distribuir la riqueza en primer lugar, hay que crearla y para crear riqueza tenemos que tener sistemas económicos modernos, funcionales, que permitan la actividad económica tanto del sector privado, que es fundamental en la creación de riqueza, como del sector publico. Yo en lo personal no soy enemigo de que el estado participe como actor en la economía, lo que si critico es la economía planificada, el estado como único actor en la economía. Yo creo que hay áreas en las cuales el estado debe desempeñar un papel importante. Necesitamos economías sanas, economías sin déficit, en las cuales no exista déficit fiscal, en las cuales la inflación haya sido controlada, en las cuales haya un escenario de garantía para el inversionista nacional y extranjero, que se creen las condiciones, en consecuencia, para un crecimiento sostenido y continuo de los distintos países.

Si no hay crecimiento económico, no puede haber cohesión social porque si no hay crecimiento económico, ¿cómo se va a distribuir lo que no se tiene?. Yo creo que uno de los grandes dramas que atraviesan los países de América Latina, en este momento, como Brasil, 
Venezuela con sus particularidades, es eso, que durante un periodo de bonanza y crecimiento, por el aumento de los precios de las commodities, se aplicaron y se desarrollaron políticas distributivas, que yo creo, que nadie critica. Por ejemplo, las misiones, en Venezuela, difícilmente, independiente del juicio que pueda existir sobre los gobiernos de Chávez o de Maduro, no pueden ser criticadas, ya que eran necesarios. El plan Fome Zero en Brasil. Las políticas de inclusión de mas de 30 millones de brasileros que salieron de la pobreza, nadie critica eso. El problema es que, buena parte de esas políticas, fueron financiadas por un boom en los precios de las commodities, que le daban a los países, a Venezuela y a Brasil, enormes ingresos que, a diferencia de otras épocas, eran concentrados en las elites. Estos fueron redistribuidos.

Pero, ¿qué fue lo que sucedió?. Las commodities cayeron. Hace unos 3 años comenzaron a caer sus precios, y en consecuencia, las fuentes de esos financiamientos, de esos programas, se redujeron y, por lo menos en el caso de Venezuela, ¿qué es lo que se ha hecho?. A pesar de que las fuentes de financiamiento de los programas se redujeron, el gobierno las mantuvo, acudiendo a políticas económicas expansionistas, emisión de dinero, etc., que no tienen fundamento en la economía y lo que han generado es una crisis, una inflación muy grande y escasez para el país, que, en vez de ayudar a generar cohesión, genera exclusión, de la estructura económica del país. Entonces, en primer lugar, se necesitan políticas económicas serias y a mí no me gustan los fanatismos. Cuando hablo de política económica, es porque, obviamente, no creo en los discursos neoliberales, de que solo los mercados son los factores que generan la riqueza. La historia económica demuestra que los mercados son importantes, pero que los mercados necesitan de regulación y los estados tienen un papel importante en esa regulación. Pero, fundamentalmente, lo que se necesita es coherencia, estado, mercado, mas estado, menos mercado, coherencia en las políticas económicas. Si no hay coherencia, no hay crecimiento económico, si no hay crecimiento económico, difícilmente podemos hablar de cohesión.

El segundo tipo de variables son las variables políticas, porque la cohesión social al igual que la economía, dependen mucho de la estabilidad política. Hay países que viven en una eterna crisis, en las eternas refundaciones de sus sistemas políticos. Difícilmente dan señales para que haya crecimiento económico y difícilmente dan señales para que, a partir de ese crecimiento económico, haya políticas redistributivas y una mayor cohesión social.

Se necesitan proyectos políticos inclusivos que, de nuevo, estén más allá de retoricas ideológicas y discursos, casi "fin mundistas", de que el mundo comienza de nuevo. Se necesitan instituciones 
políticas, democráticas modernas que piensen en la gente en su conjunto, que piensen en la sociedad en su conjunto y que eviten la fragmentación, la división, la polarización. Ahí hay una interrelación entre la economía y la política muy fuerte, muy, muy fuerte. Necesitamos un proyecto político democrático.

Yo no quiero entrar en esa discusión de participativo o representativo, porque creo que en el fondo ese no es el tema de la cuestión, un proyecto político verdaderamente democrático con control de poderes, con mecanismos de participación de la sociedad civil. Esto me va llevar un poco a la idea del ultimo eje, la cuestión institucional, elementos de la sociedad civil, partidos políticos fuertes, un sistema político que realmente funcione y que dé garantías a los operadores económicos. Y que dé garantías de metas en el área social, en el área de cohesión social. En realidad, los sistemas nacionales (los países) son sistemas, si hay uno de los elementos que para de funcionar, el sistema deja, de alguna manera, de funcionar.

Eso nos lleva al último elemento, que es que la cohesión depende de la calidad institucional de los países, que se refiere a las reglas del juego sobre las cuales funciona la sociedad. En sociedades profundamente corruptas, ¿cuántos recursos no podrían haber sido aplicados en programas o en inversión social (como suelen llamarlo algunos de una posición más de izquierda), con el dinero que se va en delitos de corrupción, por ejemplo?.

Necesitamos instituciones que sepan manejar el problema de la corrupción. Necesitamos, además, que se escuchen las voces de los distintos actores y ahí voy al tema de la participación de los distintos actores de la sociedad civil, donde los actores tengan voces. Porque uno de nuestros problemas, en América Latina, es que tenemos una tendencia terrible a ver los temas de políticas públicas y de políticas en general, desde la perspectiva de la polarización ideológica y eso nos hace daño.

Hay que superar la polarización ideológica y entender que en el diseño de políticas públicas, políticas de cohesión social, tiene que haber lugar para todos los actores. Que cuando se habla de participación de la sociedad civil, no se está yendo en contra del sector privado, del estado, se necesita de la participación de todos y que la participación de la sociedad civil es un elemento fundamental en el diseño de las políticas públicas, aun cuando estas siguen estando en manos del estado y de los actores del sector productivo, que no hacen políticas públicas, pero tienen poder de lobby, e inciden en esas políticas públicas.

Entonces, tenemos que mirar el área de las políticas públicas, y en especial de las políticas de cohesión, como una arena, una arena política en la cual hay un proceso de 
politización y en la cual, en ese proceso de participación para determinar la forma final que va a tener una política, por ejemplo, en el área de la salud, o del empleo que es mucho más sensible, va a ser resultado de mínimos comunes denominadores entre la posición del estado, actores del sector productivo y la sociedad civil.

Si nos separamos, cada quien defendiendo o dándole primacía a un sector, difícilmente se observara un progreso. Eso es un poco el caso de Venezuela con las comunas. Las comunas, como lo plantea el poder popular, lo que hacen es que entregar a un sector específico de la sociedad civil (los críticos dicen que muy cercano al gobierno) el manejo de ciertas políticas públicas, excluyendo al estado y excluyendo a otros actores que no, necesariamente, son parte de las comunas.

¿Cuáles han sido los logros de las comunas en Venezuela?. Hasta ahora no ha habido muchos estudios que yo conozca, tampoco soy propiamente un especialista en el tema, pero entiendo que los logros han sido limitados. En este sentido, vuelvo a la idea de que si no se da un campo de politización, donde participan intereses distintos, que tratan de conseguir un consenso (hay muchos actores a los que les da prurito la idea de un consenso), la política es solo el espacio de enfrentamiento de intereses distintos, pero al final tenemos que lograr un consenso mínimo para poder tener políticas públicas, sino como funcionaríamos en un estado de permanente conflictividad.

Entonces, esto es lo que pasa con las comunas, que parte de esa conflictividad expresa una posición ideológica, por esta razón no creo que vayan a aportar mucho a la cohesión social. En mi opinión, para lograr una cohesión social en América Latina hay que trabajar estas variables, variables económicas, variables políticas y variables institucionales, como un todo, sino los logros van a ser limitados.

\section{2) Nuestra identidad latinoamericana es el primer y único caso de construcción de una identidad supranacional continental basada en una historia y civilización comunes ¿se puede hablar en este sentido de una verdadera identidad latinoamericana común?}

Yo, personalmente, si creo que tenemos una identidad latinoamericana, pero hay una frase que siempre se nos olvida, es aquel slogan de "unidad en la diversidad". En primer lugar, el tema de la identidad involucra una enorme complejidad, porque toca elementos históricos, sociológicos, antropológicos, culturales, en fin. Hay un cierto consenso, sobretodo en la ultima literatura constructivista en el área sociológica, también en la teoría de las relaciones 
internacionales, de que las identidades son construidas, son construcciones sociales, las identidades, por ejemplo, regionales, la identidad de una región. Dentro de un país, por ejemplo, en Venezuela, el hecho de ser andino frente a ser oriental. $\mathrm{O}$ en un continente, ser suramericano, frente a ser norteamericano. Son procesos construidos socialmente. Y en el caso de América Latina, como hubo un pasado común, ibero, español-portugués, un elemento religioso, que en las sociedades es extremadamente importante, como cristiano-católico y una serie de experiencias en la vida internacional común, una posición subordinada en el sistema internacional, el tener que enfrentar la agresividad de potencias externas como los Estados Unidos en el Caribe, o gran Bretaña en el Atlántico Sur, que crean elementos para una identidad común. Entonces, yo si creo que existe un elemento transversal identitario común.

Ahora, este elemento identitario transversal común es matizado, y de ahí viene la idea de la unidad en la diversidad, porque las historias posteriormente se desarrollan en un plano nacional, ¿qué quiero decir con esto?. Cuando llegaron los españoles y luego los portugueses, son, mas o menos, 200 años en que todos los territorios españoles constituyeron una unidad política común. Y lo que hoy es Brasil constituye una unidad política común. Y, mas o menos, a pesar de la distancia y la geografía, desarrollan instituciones que son comunes.

Las leyes de india de España eran para todas las colonias españolas. Llega el proceso de independencia y nos fragmentamos en países. Se crea la republica Argentina en 1800 y tanto. Después de la guerra del puerto y las provincias, se crea Chile. Venezuela, Colombia y Ecuador después de la separación de la Gran Colombia. Los procesos nacionales empiezan a contar y empiezan a desarrollarse también identidades nacionales o identidades regionales, porque empiezan a crearse espacios geoculturales en América Latina. Centroamérica es un espacio geocultural. La región andina es un espacio geocultural. Aunque Venezuela ahí es un país medio extraño, porque es un país andino, pero al mismo tiempo es un país caribeño, tiene relaciones muy cercanas con Rep. Dominicana, Cuba, Puerto Rico, por nuestra forma de ser. El cono sur, Argentina, Uruguay, son enormemente similares, Paraguay aunque distinto, entro en ese juego, entonces esas dinámicas, digamos históricas y particulares, yo no se si la expresión es relativizan, porque quizás no relativizan, esa idea de identidad, pero matizada, de que somos todos latinoamericanos, compartimos una identidad cultural común. Pero, hay una forma conosuriana de ser latinoamericano, hay una forma andina de ser latinoamericano, hay una forma brasileña de ser latinoamericano, hay una forma centroamericana de ser latinoamericano, 
caribeño-hispana, dominicana, cubana de ser latinoamericano y mexicana, que es un caso muy particular, como Brasil, por el hecho de la cercanía con Estados Unidos.

Esto hace que existan ciertos matices. Y además, el problema de las identidades, es que al final somos híbridos, como dijo Garcia Canclini. Somos culturas hibridas que están en constante proceso de transformación. Las identidades, originalmente españolas, fueron transformadas y la forma en que fueron transformadas, fue variando en subregiones por factores externos, como la llegada masiva de migraciones de Europa a Argentina y Uruguay (hecho que no sucedió en la región andina porque hay una presencia masiva de pueblos indígenas), hace que la identidad latinoamericana del cono sur, tienda un poquito más de tonalidad hacia lo europeo, que la andina, en donde el papel de los pueblos originarios es mucho más fuerte.

Ahora, a pesar de esas particularidades, yo sigo pensando que hay una unidad, cierta unidad cultural, que no es garantía de integración. Eso está históricamente comprobado, no solo en el caso de América latina. Un caso mucho mayor es el de los países árabes, todos hablan árabe. No hay esa división que hay en América del Sur y el Caribe de: inglés, portugués, francés creole (si incluimos a Haití en este cuento). Todos hablan, desde el Magreb hasta Arabia Saudita, excepto Israel, el árabe. Todos son musulmanes. Sin embargo, el califato dejo de existir hace ya mucho tiempo.

La unidad identitaria no es sinónimo de unidad en lo político, de unidad en lo económico, porque ahí entran en juego otras variables. Yo hablo del tema de la importancia de la identidad, como factor aglutinador en una región. Me parece que es importante, pero no sé si es lo más importante, es mas bien una variable interviniente, tal vez hay variables más importantes en términos de políticas concretas, como son los intereses, o las ideas, las narrativas sobre cómo debe ser un país, una sociedad, una región, en fin.

\section{3) Si observamos el caso europeo, ellos tuvieron que trabajar todo: el tema de identidad, las} diferencias lingüísticas e históricas. ¿Usted no considera que América del Sur, en ese caso, tiene ventajas en el tema de identidad?

Sí, claro que las tiene. Pero insisto, esas ventajas no son garantía, esas variables son intervinientes. Si lo planteáramos en términos explicativos y quisiéramos hablar de la unidad, como variable dependiente, porque hay unidad y porque no hay unidad, entonces la variable independiente seria que no hay interdependencia económica. A mayor interdependencia económica mayor integración. Cuando la interdependencia económica es muy baja, la 
integración es baja. Pudiéramos decir identidad como variable independiente. ¿Cuándo hay mucha identidad hay mucha integración y cuando hay poca identidad hay poca integración?. No. Porque en Europa, si los europeos hablaran de identidad, sería un desorden peor que el nuestro. Por ejemplo, los franceses tienen una identidad muy marcada, los alemanes ni que decir, los ingleses... Pero incluso los pueblos que han tenido menos expansión fuera de su continente, húngaros, finlandeses, etc., tienen una identidad marcada. Entonces no es una variable independiente. Sería más bien una variable interviniente que incide sobre las variables independientes que, más bien, en mi opinión, serian interdependencia económica, intereses geopolíticos comunes.

\section{4) ¿Cuál ha sido la fragilidad de las políticas sociales implementadas en los últimos años?}

Han habido dos momentos que implican ruptura. El primer momento viene cuando se comienzan a aplicar las políticas sociales como respuesta al consenso de Washington y al ajuste estructural, porque ahí las políticas sociales se entienden como un mecanismo para compensar a los sectores excluidos, que se veían afectados por las políticas de ajuste. O sea, las políticas sociales eran mecanismos compensatorios del ajuste y eso, de entrada, es una versión errada de comprender, porque tu entiendes que, las políticas sociales son mecanismos que deben, junto con una sana política económica de crecimiento sostenido de la economía, funcionar para lograr una mayor equidad (para usar una expresión de la CEPAL), en el proceso de transformación de las economías y de las sociedades latinoamericanas. Es decir, nosotros somos sociedades que todavía tenemos que madurar y crecer, tanto en el plano político como en el plano económico. Somos democracias, la mayoría de ellas de 30 años, las más viejas. Venezuela, más bien viviendo un periodo de retroceso, en términos de institucionalidad democrática. Quizás Costa Rica (la más duradera). Tenemos que trabajar para consolidar estos aspectos y es igual en el ámbito económico. En esta área todavía tenemos que construir crecimiento económico sostenido, debemos generar una diversificación de las estructuras.

Somos sociedades que todavía estamos en proceso de construcción. Para que ese proceso de construcción se realice de manera adecuada se necesita coherencia en las políticas, crecimiento económico y equidad. La equidad es necesaria, sino el proceso queda truncado, limitado. En la CEPAL algunos autores, como Fernando Fajnzylber, han hablado de eso, se intentó hacer eso: un desarrollo industrial, una modernización industrial sin incluir a los sectores sociales. Eso fue como trabajar con un casillero vacío. 
Entonces, para mí, los programas de ajustes, entender la equidad y las políticas sociales como un complemento son un equívoco, porque las políticas sociales no son un complemento, estas forman parte de un proyecto de construcción de las sociedades, pero insisto, están en construcción. Necesitamos construir democracias, necesitamos construir desarrollo económico, transformación productiva y también necesitamos construir equidad. Y esta se construye, en parte, con políticas sociales. La equidad se logra de la mejor manera en sociedades en permanente crecimiento económico, donde todos se van a beneficiar. Ahora, políticas sociales existen incluso en países desarrollados. El estado social existe en Suecia, en Inglaterra. Por lo tanto, no es un elemento exclusivo de los países del sur. Entonces, no hay que ver la idea de políticas sociales como un elemento provisorio en sociedades desiguales, no, incluso en sociedades igualitarias también, porque tienen políticas sociales efectivas.

Esa manera de entender las políticas sociales en América latina colapsa, porque en realidad había una gran contradicción en la forma de entender las políticas sociales. Se hablaba de políticas sociales, pero se estaba privatizando, se estaban mercantilizando sectores de la vida que no eran objeto de actividad mercantil y comercial. Con base en esto, se produjo un debate muy interesante en los años noventa, sobre como áreas que fueron convertidas en derechos a partir de luchas sociales en el siglo XIX y en el siglo XX, como el derecho a la salud y el derecho a la educación, que eran derechos sociales (hubo luchas sociales en Europa y en América Latina para que esos fueran derechos y que tuvieran acceso todos los miembros de la sociedad), a partir de los ajustes de la década de los noventa se convierten en mercancía, dejando de ser derechos y pasando a ser objeto de la mercantilización y empieza el proceso de privatización en el área de la salud, entre otros.

El caso de Chile es bastante descriptivo, en el caso de la educación y de la salud. Pero Estados Unidos es el mayor ejemplo. Había una contradicción y es altamente sensible en los Estados Unidos (con el Obama Care se trató de corregir esto). Estamos hablando de una sociedad dinámica en crecimiento, la economía más importante del mundo, con niveles de desigualdad que no se comparan con los países del tercer mundo.

Imagínese cuales serían los efectos en países, estructuralmente e históricamente, desiguales como lo son los países de América Latina, que en la colonia estaba el señor encomendero y los indios que estaban sometidos a su encomienda. Era una segmentación de la sociedad. Eso marco la hacienda. Después el conuquero, que era el equivalente del encomendado, por asi decirlo, y el hacendado, que era el equivalente al encomendero. Las 
sociedades tienen continuidades estructurales que no son fáciles de romper, se rompen gradualmente con el tiempo.

Cuando se implementan los programas de ajuste en el año 93, sobretodo en Argentina, colapsan y el ajuste estructural entra en un periodo de descredito. Esa manera de entender los programas sociales empieza a ser revisada, porque hay cambios políticos en la región, el ascenso de los Kirchner, de Evo Morales en Bolivia, del PT en Brasil y particularmente el caso de Venezuela, que es un caso muy sobresaliente.

Cuando Chávez obtiene su victoria en el referéndum revocatorio, se da en paralelo un incremento de los precios de las commodities, sobretodo del petróleo, de esta forma el gobierno tiene muchos recursos y comienza a invertir en los programas sociales, incluso el chavismo cambia la denominación de programas sociales y comienza a usar la denominación inversión social, porque es una inversión en la generación de riqueza del país. Entonces, los programas sociales dejan de ser entendidos como una simple compensación a programas de ajuste y más bien, empiezan a ser entendidos como derechos que se le dan a los ciudadanos.

El enfoque en el fondo no es criticable. Los programas sociales como cualquier política pública, tienen problemas de acción colectiva. ¿Quienes deciden quienes son los beneficiarios?. En primer lugar, hay un elemento financiero, administrativo, porque alguien tiene que pagar los programas sociales, esa es la verdad, entonces, esa es una de las críticas que se le suele hacer.

Aunque el enfoque es el adecuado, porque me parece que los programas sociales son parte del proceso de construcción de sociedades, junto con la construcción política, democrática, junto con la construcción económica de economías modernas. Porque no me gusta decir economías de mercado, esa "deificación" del mercado puro, pero tampoco soy un anti mercado, este es una institución social muy eficiente, con limitaciones, con deficiencias que el estado puede suplir. Porque la única otra institución con un poder semejante al mercado, creada por los humanos es el estado. Porque tanto el estado como el mercado son creaciones humanas, no son leyes naturales, eso es mentira.

Cuando se crean los programas sociales, volviendo a la pregunta, debe definirse ¿quiénes son los beneficiarios? ¿Son beneficiarios porque son simplemente excluidos de nuestra sociedad? o ¿son beneficiarios porque tienen una afinidad ideológica con quien en determinado momento están manejando el gobierno y el estado?, ¿esa afinidad ideológica es una precondición?, ¿es usada de una forma manipuladora con el objeto de implementar políticas públicas?. Este aspecto ha generado debates en el caso de Venezuela. 
Se señala que muchas de las misiones sociales, de indiscutible valor, han sido ampliadas porque no puede discriminarse en términos de salud y educación, pero otras, en cambio, han sido manejadas en términos clientelares, apoyando el proyecto ideológico y hegemónico en Venezuela. Actualmente, esto es un tema para el debate, en el cual yo no tengo la última palabra y el segundo elemento es ¿quién financia? y ¿porque no ha sido posible consolidar?, esto es porque se requieren políticas públicas que estén más allá del clientelismo político y el segundo argumento es que se necesitan de políticas públicas con un financiamiento estable, con coyunturas estructurales de la economía mundial. Porque hasta ahora lo que está pasando, en Brasil, Venezuela, en Ecuador y vamos a ver qué pasa en Argentina, dependiendo de las elecciones de este año, es que buena parte de las políticas sociales han tenido que ser revisadas, porque las fuentes de mantenimiento, de sustento económico de ellas eran los precios altos de las commodities. No era por impuestos nacionales, era porque las commodities estaban muy altas. Cuando las commodities bajaron, empezaron a surgir problemas fiscales, hubo que revisar, la presidente Dilma ha tenido que revisar algunos programas sociales, como el seguro desempleo. Por ejemplo, ¿quiénes tienen derecho a seguro desempleo?. Porque simplemente no hay más dinero para seguir manteniendo el gasto en el ritmo que estaba antes.

En el caso venezolano, se han querido mantener programas sociales aun cuando se obtienen menos recursos. Entonces, se ha incurrido en la trampa mayor para la inflación, que es emitir dinero orgánico. La maquinita del banco central emitiendo dinero para mantener programas públicos, expandiendo la oferta monetaria en el país. Y los que saben lo mínimo de economía tienen noción de que se está generando, en consecuencia, un proceso inflacionario indetenible, actualmente en un $150 \%$. Con esto no quiero decir que la inflación en Venezuela sea resultado de políticas que financian programas sociales. Parte del financiamiento de las políticas sociales se hicieron de esta manera y parte del problema inflacionario responde a esto, pero a su vez responde a otras variables, porque esa expansión monetaria no solo se utiliza para programas sociales sino para otras serie de áreas. También porque el país está cerrado al crédito, no tiene financiamiento, pero eso es otro tema que no tiene que ver con la pregunta.

Entonces, para que haya políticas sociales eficientes al final ¿qué es lo que se requiere?. Un crecimiento económico, una economía sana. Es muy difícil en una economía inflacionaria, inestable, en crisis, en recesión, pensar en cohesión social, en políticas sociales eficientes, es muy difícil. 
5) Tanto la CAN como el MERCOSUR han implementado políticas de cohesión. ¿Es posible pensar en políticas de cohesión para toda la región?

Yo soy un poco escéptico de esto, por varias razones. A pesar que soy un creyente fervoroso en la integración, como es bien conocido por ser mi trabajo de investigación, esto no me impide ser crítico. Soy, digamos crítico, por varias razones, porque yo sigo pensando que el problema de cohesión social que se relaciona con la distribución de riqueza, con la pobreza, desigualdad, que son cosas distintas, por lo menos en este nivel de desarrollo humano, todavía es un problema nacional, no es un problema de macro regiones internacionales, ni de organizaciones internacionales globales. Eso no quiere decir que organizaciones globales como las naciones unidas o regionales, como el MERCOSUR, no puedan ayudar.

Pueden ayudar, y ahí va la segunda respuesta a esta pregunta, pueden tener un rol, pero el rol fundamental es nacional, de los estados. Entonces no se puede pretender darle un papel mayor a la integración del que tiene, puede contribuir, por lo menos en el ámbito laboral, a crear patrones o estándares laborales mínimos, que garanticen condiciones de trabajo dignas para los trabajadores, en los países que forman parte del mecanismo de integración. Colaborando en la promoción de programas educativos de calidad común, en programas de salud para evitar enfermedades que, por su naturaleza, no miran las fronteras. Tiene y puede tener, en el área de la salud, de la educación, un papel, pero insisto, no es el papel central.

Ahora, porque soy escéptico con la CAN y el MERCOSUR en este respecto, este escepticismo deriva de que en los últimos años fui fervoroso creyente de que la integración no puede limitarse a la eliminación de aranceles, debe existir una integración productiva de transformación de las estructuras productivas del país, que es el otro gran rol, y coadyuvar con los estados nacionales en los procesos que se llaman de cohesión social. Colaborar, e insisto en el argumento, porque es una función central del estado nacional, pero al hacer esa función de colaborar hay que usar las estrategias más adecuada. La estrategia que usaron la CAN y el MERCOSUR fue inadecuada, porque usaron macro proyectos de cohesión social.

El caso de la CAN lo conozco menos, pero el caso del MERCOSUR lo conozco más y planteo un "Plan estratégico de acción social", aprobado en el 2011. Este plan comprehende 11 ejes y cada eje comprende 4 o 5 subprogramas, que van desde la eliminación de analfabetismo a las enfermedades. Una serie de objetivos que en teoría suenan muy bien, ¿quien en la región estaría en contra de eliminar esos objetivos?. Nadie. Pero el problema es que no son realistas, porque no existe la institucionalidad del MERCOSUR que permita que se haga esto, sería una 
autoridad supranacional en materia social que, utilizando la expresión de Ernst Haas, "se tomaria para sí, por encima de los estados nacionales, la jurisdicción de los temas sociales", cesión de soberanía, ningún estado va a ceder soberanía. En primer lugar, eso es irreal. En un sistema intergubernamental es imposible, o no sé si es posible, pero es extremadamente complicado plantearse una política común, por lo menos en el tema de salud pública, porque los intereses nacionales, la forma de entender las políticas sociales, varían entre los países.

Por lo menos, Uruguay, es un país con una enorme tradición en políticas sociales, que viene de la época de Jorge Balladi, es la caracterización del estado de bienestar, junto con Costa Rica. Los dos ejemplos de estado de bienestar de más éxito en América Latina. Pero por otro lado tenemos a Paraguay que no conoce de políticas sociales, fue gobernado desde la época de Stroessner como una hacienda, donde los peones eran tratados a golpes.

Argentina es más parecida a Uruguay, tuvo un estado social más avanzado, pero después de la dictadura empezó a desmantelarse ese estado social. Y Brasil es una gran contradicción por la enorme desigualdad histórica que ha tenido, el esclavismo en el siglo XIX y el trato que tuvo esa población después de que fueron liberados, entre otros aspectos. Entonces, la dimensión social de las políticas del estado brasileño son muy limitadas estructuralmente. Con culturas tan distintas y un sistema intergubernamental, plantean un desafío en el cómo avanzar en políticas sociales, es un sistema muy complejo, ese es el primer problema.

El segundo problema (se relaciona con algo que respondí en la pregunta previa) es, quien paga esas políticas, porque en Europa hay un IVA comunitario, nosotros no tenemos un IVA comunitario. Se creó el FOCEM, que es un fondo de convergencia estructural, que tiene como uno de los elementos la cohesión social, no el único, porque el FOCEM se utiliza hasta para mejorar la calidad de las instituciones, hay plata del FOCEM que se utiliza para mejorar la secretaria del Mercosur en Montevideo, cosa absurda, en mi opinión, pero es así. Entonces, los recursos del FOCEM son muy pocos, no hay recursos y las políticas sociales implican recursos.

En tercer lugar, y creo que resume los dos anteriores, que es una estrategia globalista, queriendo abarcar todo, cuando el momento no ha estado para eso. Yo plantee hace poco en un artículo que escribí, que quizás lo que se debería hacer es que, si la integración quiere coadyuvar a ser un socio de los estados nacionales y los bloques regionales quieren ser un socio de sus países miembros, en la resolución de los problemas sociales en América latina, deben tener una estrategia más realista y esto implica mirar áreas específicas, en las cuales exista consenso y recursos para avanzar en estas áreas, e ir avanzando de verdad. No proponernos un programa de 
reducción de la pobreza, de erradicación de enfermedades infecciosas, de la discriminación de los indígenas, todas estas cosas que se dicen en el proyecto estratégico de acción social, que por cierto se aprobó en el 2011, y estamos en el 2015, y hasta donde yo sé, incluso he hecho entrevistas a personas cercanas al tema, en Argentina, al menos, no se ha aprobado un solo programa.

En vez de eso, plantearnos una operación en el área de la educación, como se estaba haciendo un poco antes del programa de acción social. Lo que pasa es que se había avanzado en áreas muy formales como el reconocimiento de títulos, eso está bien, pero ir un poco más allá en el área de la educación. Hay países que tienen mas capacidad en la formación de maestros que otros. Argentina tiene una formación que viene de Sarmiento, ¿porque Argentina no puede ayudar en la formación de maestros a Paraguay, que tiene menos historia y menos historial allí?. O el Uruguay también, en el área de la salud. Hay países que están más avanzados que otros. ¿Porque no crear un programa específico para enfrentar el dengue?, que es un problema transnacional, sobre todo muy asociado con Paraguay y Brasil, porque quizás en el Uruguay y Argentina, por estar más al sur, no se reproduce tan fácilmente el mosquito. Es decir, cosas más concretas, más específicas, que no son costosas de financiar y que son efectivas, porque nadie va a molestarse con que le vayan a tocar la soberanía nacional, porque quieren resolver un problema de salud pública, por ejemplo, sería demasiado insensato. Por eso creo que se debe revisar la estrategia, ya que ha sido inadecuada, los resultados han sido muy débiles. Si los evaluamos, aunque conozco más el caso del Mercosur que el de la CAN, me temo que en la CAN no sería muy distinto. En definitiva creo que estos programas han contribuido muy poco.

6) Estamos frente a la necesidad de una modernización en las políticas públicas buscando una mayor calidad y equidad dentro de las sociedades. En este sentido ¿puede considerarse la descentralización, la cohesión territorial, y la tributación, muy especialmente, la búsqueda de solvencia y equidad a través de la tributación, como las salidas al escenario de desigualdad suramericano?

Yo creo que son elementos que colaboran, no necesariamente van a resolver. Yo creo fuertemente en la descentralización, justamente programas, como las comunas en Venezuela, van en contra de la descentralización y acaban concentrando el poder en el ejecutivo, que es el que tiene la última palabra en la organización de las comunas. Pero yo creo que hay otras variables además de eso. Estos son elementos, si usted quiere, operativos o funcionales, que ayudan en la 
resolución de los problemas. Yo creo que hay elementos estructurales e incluso históricos, en las sociedades latinoamericanas que, con la simple descentralización, no se van a resolver. Tenemos que construir proyectos de sociedad realmente inclusivas, no creo en los radicalismos de grupos que quieren refundar países, como si toda la historia previa fuese inútil, pero también creo que la gente, los grupos hegemónicos de América Latina tienen que, finalmente, entender que sociedades más justas, más equitativas, son mejores para todos, para el desarrollo de sus intereses económicos, de sus empresas, etc.

Es muy difícil pensar en EUA, Japón o Alemania como potencias mundiales, sino hubiesen logrado el nivel de cohesión social antes de ser potencias. Es muy difícil pensar en una potencia mundial, pensando en Brasil, en su obsesión de ser un global power, y yo creo que si lo es, honestamente lo digo, pero es muy difícil pensar en Brasil como un global power, si 50\% de la población está excluida. Los global power no funcionan de esa manera, una de sus reglas es la equidad social. Lo que necesitamos realmente es un pacto para entender que desarrollo económico y democracia están asociadas a la cohesión social, es como si tuviéramos una mesa de tres patas, no funciona de esa manera.

\section{7) ¿Que considera usted, en este sentido, de la tributación (área fiscal)?}

La parte fiscal es fundamental, incluso forma parte de lo que estaba hablando anteriormente, el elemento fiscal es muy importante porque una de las cosas de la cultura latinoamericana, que nos diferencia por ejemplo de EUA, es que la cultura fiscal ha sido siempre muy pobre, el compromiso para el pago de impuestos es muy bajo, hasta hace muy poco era muy fácil evadir fiscalmente, no pagando y haciendo trampa. Los recursos fiscales son una de las maneras más eficientes del welfare state, sobretodo de los estados más conocidos por ser ejemplos, como los estados nórdicos. Por ejemplo, buena parte de la consolidación de esos estados de bienestar se deben a políticas fiscales muy rigurosas y muy eficientes en donde quien tiene más ingresos, (al mismo tiempo que tiene todas las facilidades para la actividad comercial, sin leyes en contra de la inversión, tampoco se le pone requisitos nacionales, ya que son estados liberales que le garantizan todas las condiciones a una empresa para que participe), tiene un compromiso fiscal que cumplir, tiene que pagar los impuestos en base a la riqueza que ha obtenido de la sociedad. A través de los impuestos es la vía redistributiva que permite que se financien los programas sociales. Pero esto me lleva a uno de los temas de la primera pregunta, 
para eso se necesita calidad institucional, si no tenemos instituciones, podemos recaudar todo el dinero del mundo, pero si son instituciones corruptas, los recursos son desviados.

Yo soy muy institucionalista y de la variable latinoamericana que esta próxima a la CEPAL. Yo creo que sin instituciones de calidad, ni el desarrollo económico, ni los mercados, ni el estado, funcionan. Un estado con instituciones corruptas e ineficientes es un estado fallido, una economía de mercado sin instituciones que funcionen es simplemente un mercado imperfecto y eso es muy válido cuando hablamos de política social, de cohesión social. Si no hay calidad institucional, el dinero que de China, el Banco Mundial, termina siendo utilizado para otras cosas, de eso tenemos larga historia en América Latina, infelizmente. Hay dos excepciones, Uruguay y Costa Rica, que en cierto momento Venezuela lo fue también, en los años 60, en calidad institucional. En los índices que mide Transparencia Internacional, asociados a la calidad institucional, de esos dos países, siempre aparecen muy bien rankeados/ colocados, pero el resto de los países de la región no.

Aunque, Chile en la última evaluación de transparencia apareció muy bien, Peru, que son economías en crecimiento. Brasil que tuvo crecimiento desde el año 2000 hasta el 2011, sin embargo, en el tema de la calidad institucional sigue apareciendo como el reprobado de la clase, siempre.

\section{8) ¿Es posible afirmar que en América del Sur no se han implementado verdaderas políticas de cohesión?}

En realidad se han implementado de forma errada, errática, no ha habido consistencia y eso explica que los logros hayan sido escasos, si es que ha habido algunos. La experiencia de las misiones en Venezuela, que siempre se utiliza como caso paradigmático de éxito en políticas sociales fuertemente redistributiva, se pudo haber considerado exitoso, pero el problema es su sustentabilidad, ¿cómo va a ser sustentable una política que era mantenida bajo un régimen económico coyuntural de precios altos de commodities?. Y además, sustentabilidad que también se mira en el lado económico, porque era un sistema paralelo a la institucionalidad existente, lo que implicaba un doble uso de recursos, es decir, tenía los programas educativos de las misiones y el sistema educativo formal, por lo tanto tenía un presupuesto legal que recibías del ministerio de educación y el presupuesto de las misiones, doble uso de los recursos y los recursos siempre son escasos, hay gente que dice pero Briceño "es como liberal cuando dice esas cosas", pero es que los recursos son escasos, no son ilimitados. 
El problema de los programas de cohesión social, hablando seriamente, es de cómo hacerlos sostenibles, continuos, que se puedan sostener en el tiempo y además entendiéndolos como un componente dentro de una estrategia nacional. La cohesión es importante dentro de un marco serio de desarrollo y de construcción de calidad democrática en los países, sino la cohesión queda en el aire, por eso su relevancia. 


\section{ANEXO I- INDICADOR NIVEL DE DIFICULTAD (BTI) ${ }^{150}$ CLASIFICADO POR REGIONES}

1) Indicador Nivel de Dificultad para Asia y Oceanía

\begin{tabular}{|l|r|r|r|r|r|r|r|}
\hline País & $\mathbf{2 0 0 3}$ & $\mathbf{2 0 0 6}$ & $\mathbf{2 0 0 8}$ & $\mathbf{2 0 1 0}$ & $\mathbf{2 0 1 2}$ & $\mathbf{2 0 1 4}$ & $\begin{array}{r}\text { Media } \\
\text { Total }\end{array}$ \\
\hline Afganistán & 10,0 & 9,8 & 9,8 & 10,0 & 9,8 & 9,4 & 9,8 \\
\hline Bangladesh & 7,0 & 7,8 & 7,8 & 7,4 & 7,4 & 7,6 & 7,5 \\
\hline Bután & & & 8,0 & 7,4 & 7,4 & 7,0 & 7,5 \\
\hline Camboya & 8,0 & 7,6 & 7,2 & 7,2 & 7,4 & 7,6 & 7,5 \\
\hline China & 6,0 & 5,6 & 5,6 & 5,8 & 6,2 & 6,0 & 5,9 \\
\hline India & 5,0 & 6,4 & 6,2 & 6,2 & 6,2 & 6,0 & 6,0 \\
\hline Indonesia & 7,0 & 6,0 & 5,8 & 5,8 & 6,4 & 5,8 & 6,1 \\
\hline Laos & 7,0 & 7,2 & 7,0 & 7,0 & 7,4 & 7,2 & 7,1 \\
\hline Malasia & 5,0 & 4,2 & 4,0 & 3,8 & 3,8 & 3,8 & 4,1 \\
\hline Birmania & 9,0 & 8,0 & 7,8 & 8,0 & 9,0 & 9,0 & 8,5 \\
\hline Nepal & 8,0 & 9,4 & 8,8 & 8,4 & 8,6 & 8,0 & 8,5 \\
\hline Corea del Norte & 8,0 & 7,0 & 7,0 & 7,2 & 7,8 & 7,6 & 7,4 \\
\hline Paquistán & 7,0 & 8,2 & 8,2 & 8,4 & 8,2 & 8,2 & 8,0 \\
\hline Papúa Nueva & & & & & & & \\
Guinea & 7,0 & 7,4 & 7,6 & 7,6 & 7,8 & 7,8 & 7,5 \\
\hline Filipinas & 6,0 & 5,2 & 5,0 & 5,2 & 5,6 & 5,2 & 5,4 \\
\hline Singapur & 4,0 & 2,2 & 2,2 & 2,2 & 2,4 & 2,2 & 2,5 \\
\hline Corea del Sur & 3,0 & 2,2 & 2,2 & 2,2 & 2,2 & 2,2 & 2,3 \\
\hline Sri Lanka & 6,0 & 5,8 & 5,6 & 5,8 & 5,4 & 5,0 & 5,6 \\
\hline Taiwán & 4,0 & 2,6 & 2,6 & 2,4 & 2,2 & 2,0 & 2,6 \\
\hline Tailandia & 4,0 & 4,6 & 4,6 & 5,2 & 5,8 & 5,6 & 5,0 \\
\hline Vietnam & 6,0 & 6,2 & 6,0 & 5,8 & 6,6 & 6,4 & 6,2 \\
\hline Media Total & 6,4 & 6,2 & 6,1 & 6,1 & 6,4 & 6,2 & 6,2 \\
\hline
\end{tabular}

2) Indicador Nivel de Dificultad para Eurasia (post Unión Soviética)

\begin{tabular}{|l|r|r|r|r|r|r|r|}
\hline País & $\mathbf{2 0 0 3}$ & $\mathbf{2 0 0 6}$ & $\mathbf{2 0 0 8}$ & $\mathbf{2 0 1 0}$ & $\mathbf{2 0 1 2}$ & $\mathbf{2 0 1 4}$ & $\begin{array}{r}\text { Media } \\
\text { Total }\end{array}$ \\
\hline Armenia & 6,0 & 4,4 & 4,2 & 4,2 & 4,6 & 4,2 & 4,6 \\
\hline Azerbaiyán & 7,0 & 5,6 & 5,2 & 5,0 & 4,6 & 4,8 & 5,4 \\
\hline Bielorrusia & 6,0 & 4,2 & 4,4 & 4,0 & 4,0 & 3,6 & 4,4 \\
\hline Georgia & 8,0 & 6,0 & 5,8 & 6,2 & 5,6 & 5,6 & 6,2 \\
\hline Kazakstán & 6,0 & 4,4 & 4,2 & 4,0 & 3,6 & 3,8 & 4,3 \\
\hline Kyrgyzstan & 7,0 & 5,6 & 5,6 & 5,4 & 6,2 & 6,2 & 6,0 \\
\hline Moldavia & 8,0 & 6,2 & 6,2 & 6,0 & 6,2 & 6,0 & 6,4 \\
\hline Mongolia & 7,0 & 5,6 & 5,6 & 5,6 & 5,8 & 5,6 & 5,9 \\
\hline Rusia & 6,0 & 4,0 & 4,2 & 3,8 & 3,8 & 3,6 & 4,2 \\
\hline Tayikistán & 9,0 & 7,6 & 6,6 & 6,4 & 6,6 & 6,6 & 7,1 \\
\hline
\end{tabular}

${ }^{150}$ Ver base de datos Transformation Index: http://www.bti-project.org/downloads/bti-2014/ 


\begin{tabular}{|l|r|r|r|r|r|r|r|} 
Turkmenistán & 8,0 & 5,2 & 5,2 & 5,4 & 5,2 & 5,0 & 5,7 \\
\hline Ucrania & 6,0 & 4,0 & 4,2 & 4,0 & 4,0 & 3,8 & 4,3 \\
\hline Uzbequistan & 7,0 & 6,0 & 5,8 & 6,0 & 6,2 & 6,2 & 6,2 \\
\hline Media Total & 7,0 & 5,3 & 5,2 & 5,1 & 5,1 & 5,0 & 5,4 \\
\hline
\end{tabular}

\section{3) Indicador Nivel de Dificultad para Sureste Africano}

\begin{tabular}{|l|r|r|r|r|r|r|r|}
\hline País & $\mathbf{2 0 0 3}$ & $\mathbf{2 0 0 6}$ & $\mathbf{2 0 0 8}$ & $\mathbf{2 0 1 0}$ & $\mathbf{2 0 1 2}$ & $\mathbf{2 0 1 4}$ & \multicolumn{2}{l|}{\begin{tabular}{l} 
Tedia \\
\hline Angola
\end{tabular}} & 10,0 & 8,6 & 7,2 & 7,0 & 7,0 & 6,8 & 7,8 \\
\hline Botsuana & 4,0 & 4,2 & 4,8 & 3,8 & 3,6 & 3,4 & 4,0 \\
\hline Burundi & 9,0 & 9,6 & 8,2 & 8,6 & 8,8 & 8,6 & 8,8 \\
\hline Eritrea & 8,0 & 7,4 & 7,6 & 8,2 & 9,0 & 8,8 & 8,2 \\
\hline Etiopia & 9,0 & 8,6 & 8,6 & 8,6 & 8,8 & 8,4 & 8,7 \\
\hline Kenia & 6,0 & 6,4 & 6,2 & 6,6 & 6,4 & 6,0 & 6,3 \\
\hline Lesoto & $\mathrm{n} / \mathrm{a}$ & $\mathrm{n} / \mathrm{a}$ & $\mathrm{n} / \mathrm{a}$ & 6,2 & 7,0 & 7,2 & 6,8 \\
\hline Madagascar & 8,0 & 7,2 & 6,4 & 7,2 & 7,8 & 7,6 & 7,4 \\
\hline Malawi & 8,0 & 7,0 & 7,0 & 7,4 & 7,8 & 7,6 & 7,5 \\
\hline Mauritius & & 4,6 & 4,0 & 3,2 & 2,8 & 2,6 & 3,4 \\
\hline Mozambique & 7,0 & 7,4 & 6,8 & 7,6 & 7,6 & 7,8 & 7,4 \\
\hline Namibia & 5,0 & 5,0 & 4,8 & 5,2 & 5,0 & 4,8 & 5,0 \\
\hline Ruanda & $\mathrm{n} / \mathrm{a}$ & 8,8 & 8,0 & 8,2 & 8,4 & 8,2 & 8,3 \\
\hline Somalia & 10,0 & 9,0 & 9,4 & 9,6 & 9,8 & 9,8 & 9,6 \\
\hline África del Sur & 5,0 & 4,0 & 4,0 & 4,4 & 4,0 & 4,2 & 4,3 \\
\hline Tanzania & 7,0 & 7,2 & 7,4 & 7,0 & 7,4 & 7,0 & 7,2 \\
\hline Uganda & 7,0 & 6,6 & 6,6 & 6,4 & 6,8 & 6,8 & 6,7 \\
\hline Zambia & 7,0 & 6,2 & 6,8 & 6,2 & 6,6 & 6,6 & 6,6 \\
\hline Zimbabue & 9,0 & 5,8 & 6,6 & 6,6 & 7,4 & 7,0 & 7,1 \\
\hline Media Total & 7,5 & 6,9 & 6,7 & 6,7 & 6,9 & 6,9 & 7,0 \\
\hline
\end{tabular}

4) Indicador Nivel de Dificultad para Medio Oriente y Norte de África

\begin{tabular}{|l|r|r|r|r|r|r|r|}
\hline País & $\mathbf{2 0 0 3}$ & $\mathbf{2 0 0 6}$ & $\mathbf{2 0 0 8}$ & $\mathbf{2 0 1 0}$ & $\mathbf{2 0 1 2}$ & $\mathbf{2 0 1 4}$ & $\begin{array}{l}\text { Media } \\
\text { Total }\end{array}$ \\
\hline Argelia & 8,0 & 6,4 & 6,2 & 5,8 & 5,8 & 5,4 & 6,3 \\
\hline Bahréin & 5,0 & 3,4 & 3,4 & 3,2 & 3,4 & 4,2 & 3,8 \\
\hline Egipto & 7,0 & 6,4 & 5,4 & 5,4 & 5,6 & 5,8 & 5,9 \\
\hline Irán & 7,0 & 5,6 & 5,8 & 5,0 & 4,8 & 5,2 & 5,6 \\
\hline Iraq & 9,0 & 9,2 & 9,2 & 8,2 & 8,0 & 8,2 & 8,6 \\
\hline Jordán & 6,0 & 5,0 & 5,2 & 5,2 & 5,2 & 5,4 & 5,3 \\
\hline Kuwait & & & 4,2 & 3,4 & 4,2 & 3,8 & 3,9 \\
\hline Líbano & 6,0 & 5,0 & 4,6 & 4,6 & 4,4 & 4,4 & 4,8 \\
\hline Libia & 8,0 & 4,6 & 4,6 & 3,6 & 3,8 & 4,8 & 4,9 \\
\hline Marruecos & 7,0 & 6,8 & 6,4 & 6,2 & 5,8 & 6,2 & 6,4 \\
\hline Omán & & & 3,6 & 3,6 & 3,6 & 3,8 & 3,7 \\
\hline Qatar & & & & 3,4 & 3,2 & 3,4 & 3,3 \\
\hline Arabia Saudita & 8,0 & 5,0 & 4,8 & 4,2 & 4,2 & 4,2 & 5,1 \\
\hline
\end{tabular}




\begin{tabular}{|l|r|r|r|r|r|r|r|} 
Sudan & 10,0 & 9,2 & 8,4 & 8,2 & 8,6 & 8,8 & 8,9 \\
\hline Siria & 8,0 & 6,6 & 6,6 & 6,0 & 6,8 & 7,6 & 6,9 \\
\hline Túnez & 5,0 & 4,8 & 4,4 & 4,8 & 4,8 & 5,6 & 4,9 \\
\hline Turquía & 4,0 & 5,2 & 4,2 & 3,6 & 4,0 & 4,2 & 4,2 \\
\hline $\begin{array}{l}\text { Émiratos } \\
\text { Árabes Unidos }\end{array}$ & & 4,6 & 4,0 & 3,4 & 3,6 & 3,6 & 3,8 \\
\hline Yemen & 9,0 & 8,4 & 7,6 & 7,6 & 8,2 & 8,6 & 8,2 \\
\hline Media Total & 7,1 & 6,0 & 5,5 & 5,0 & 5,2 & 5,4 & 5,6 \\
\hline
\end{tabular}

5) Indicador Nivel de Dificultad para África occidental y central

\begin{tabular}{|c|c|c|c|c|c|c|c|}
\hline País & 2003 & 2006 & 2008 & 2010 & 2012 & 2014 & $\begin{array}{l}\text { Media } \\
\text { Total } \\
\end{array}$ \\
\hline Benín & 6,0 & 7,0 & 6,8 & 6,8 & 6,4 & 6,2 & 6,5 \\
\hline Burkina Faso & 7,0 & 7,2 & 7,0 & 7,0 & 7,0 & 7,4 & 7,1 \\
\hline Camerón & 8,0 & 7,6 & 6,8 & 6,8 & 7,0 & 7,0 & 7,2 \\
\hline $\begin{array}{l}\text { República } \\
\text { Central de } \\
\text { África }\end{array}$ & 10,0 & 8,6 & 9,0 & 9,2 & 9,2 & 9,4 & 9,2 \\
\hline Chad & 8,0 & 9,0 & 9,0 & 9,0 & 8,6 & 8,6 & 8,7 \\
\hline $\begin{array}{l}\text { República } \\
\text { Democrática } \\
\text { del Congo }\end{array}$ & $\mathrm{n} / \mathrm{a}$ & 9,6 & $\mathrm{n} / \mathrm{a}$ & 8,6 & & 7,0 & 8,4 \\
\hline $\begin{array}{l}\text { República del } \\
\text { Congo }\end{array}$ & $\mathrm{n} / \mathrm{a}$ & $\mathrm{n} / \mathrm{a}$ & 8,0 & 7,4 & 7,2 & $\mathrm{n} / \mathrm{a}$ & 7,5 \\
\hline Côte d'Ivoire & 7,0 & 8,0 & 8,4 & 8,2 & 8,6 & 8,2 & 8,1 \\
\hline Ghana & & 6,8 & 6,6 & 6,4 & 6,0 & 5,6 & 6,3 \\
\hline Guinea & 8,0 & 7,2 & 8,0 & 8,2 & 8,0 & 8,0 & 7,9 \\
\hline Liberia & & 9,2 & 8,4 & 8,0 & 7,8 & 8,0 & 8,3 \\
\hline Mali & 6,0 & 6,8 & 7,2 & 7,4 & 7,2 & 8,0 & 7,1 \\
\hline Mauritania & $\mathrm{n} / \mathrm{a}$ & $\mathrm{n} / \mathrm{a}$ & 8,0 & 8,2 & 8,2 & 8,0 & 8,1 \\
\hline Níger & 8,0 & 8,6 & 7,8 & 8,4 & 8,2 & 8,2 & 8,2 \\
\hline Nigeria & $\mathrm{n} / \mathrm{a}$ & 8,4 & 8,0 & 7,6 & 7,6 & 7,8 & 7,9 \\
\hline Senegal & $\mathrm{n} / \mathrm{a}$ & 6,8 & 7,2 & 7,4 & 7,2 & 6,8 & 7,1 \\
\hline Sierra Leone & $\mathrm{n} / \mathrm{a}$ & 8,2 & 8,4 & 8,2 & 8,2 & 8,0 & 8,2 \\
\hline Togo & 8,0 & 7,0 & 7,6 & 7,6 & 7,0 & 6,8 & 7,3 \\
\hline Media Total & 7,8 & 7,9 & 7,8 & 7,8 & 7,6 & 7,6 & 7,7 \\
\hline
\end{tabular}

6) Indicador Nivel de Dificultad para América Latina y el Caribe

\begin{tabular}{|l|r|r|r|r|r|r|r|}
\hline País & $\mathbf{2 0 0 3}$ & $\mathbf{2 0 0 6}$ & $\mathbf{2 0 0 8}$ & $\mathbf{2 0 1 0}$ & $\mathbf{2 0 1 2}$ & $\mathbf{2 0 1 4}$ & $\begin{array}{l}\text { Media } \\
\text { Total }\end{array}$ \\
\hline Argentina & 4,0 & 3,4 & 2,6 & 2,8 & 2,8 & 2,8 & 3,1 \\
\hline Bolivia & 6,0 & 5,8 & 5,8 & 5,8 & 5,6 & 5,8 & 5,8 \\
\hline Brasil & 5,0 & 3,6 & 3,6 & 3,4 & 3,6 & 3,4 & 3,8 \\
\hline
\end{tabular}




\begin{tabular}{|l|r|r|r|r|r|r|r|} 
Chile & 4,0 & 3,4 & 2,4 & 2,2 & 2,0 & 2,2 & 2,7 \\
\hline Colombia & 8,0 & 6,2 & 5,4 & 5,6 & 5,6 & 5,4 & 6,0 \\
\hline Costa Rica & 3,0 & 2,4 & 2,6 & 2,4 & 2,8 & 2,4 & 2,6 \\
\hline Cuba & 7,0 & 5,4 & 5,2 & 3,8 & 4,4 & 4,0 & 5,0 \\
\hline Republica & & & & & & & \\
Dominicana & 5,0 & 4,4 & 4,2 & 4,4 & 4,6 & 4,4 & 4,5 \\
\hline Ecuador & 5,0 & 5,2 & 5,2 & 4,8 & 4,8 & 4,6 & 4,9 \\
\hline El Salvador & 5,0 & 5,0 & 5,0 & 4,6 & 4,6 & 5,2 & 4,9 \\
\hline Guatemala & 6,0 & 6,2 & 6,2 & 6,2 & 6,8 & 7,2 & 6,4 \\
\hline Haití & 9,0 & 8,4 & 8,6 & 8,4 & 8,6 & 8,4 & 8,6 \\
\hline Honduras & 6,0 & 5,6 & 5,4 & 5,4 & 6,2 & 6,0 & 5,8 \\
\hline Jamaica & 3,0 & 3,8 & 3,8 & 3,6 & 3,4 & 3,2 & 3,5 \\
\hline México & 5,0 & 4,0 & 3,8 & 3,6 & 4,0 & 4,4 & 4,1 \\
\hline Nicaragua & 6,0 & 6,0 & 5,6 & 5,6 & 6,0 & 6,0 & 5,9 \\
\hline Panamá & & 4,4 & 4,0 & 3,4 & 3,4 & 3,4 & 3,7 \\
\hline Paraguay & 6,0 & 5,0 & 5,0 & 5,2 & 5,6 & 6,0 & 5,5 \\
\hline Perú & 6,0 & 5,0 & 4,8 & 4,4 & 4,6 & 4,6 & 4,9 \\
\hline Uruguay & 3,0 & 2,4 & 2,2 & 1,8 & 1,8 & 1,4 & 2,1 \\
\hline Venezuela & 5,0 & 4,0 & 3,8 & 3,4 & 4,0 & 3,6 & 4,0 \\
\hline Media Total & 5,4 & 4,7 & 4,5 & 4,3 & 4,5 & 4,5 & 4,7 \\
\hline
\end{tabular}

7) Indicador Nivel de Dificultad para Europa Centro-Oriental

\begin{tabular}{|l|r|r|r|r|r|r|r|}
\hline País & $\mathbf{2 0 0 3}$ & $\mathbf{2 0 0 6}$ & $\mathbf{2 0 0 8}$ & $\mathbf{2 0 1 0}$ & $\mathbf{2 0 1 2}$ & $\mathbf{2 0 1 4}$ & $\begin{array}{l}\text { Media } \\
\text { Total }\end{array}$ \\
\hline Albania & 6,0 & 5,0 & 4,8 & 4,6 & 4,6 & 4,6 & 4,9 \\
\hline $\begin{array}{l}\text { Bosnia and } \\
\text { Herzegovina }\end{array}$ & 8,0 & 5,0 & 4,4 & 4,4 & 4,4 & 4,4 & 5,1 \\
\hline Bulgaria & 4,0 & 3,2 & 3,2 & 3,0 & 2,8 & 2,8 & 3,2 \\
\hline Croacia & 4,0 & 2,6 & 2,6 & 2,4 & 2,4 & 2,0 & 2,7 \\
\hline $\begin{array}{l}\text { República } \\
\text { Checa }\end{array}$ & 1,0 & 1,2 & 1,2 & 1,2 & 1,2 & 1,2 & 1,2 \\
\hline Estonia & 3,0 & 2,0 & 2,4 & 1,8 & 2,0 & 1,8 & 2,2 \\
\hline Hungría & 1,0 & 1,4 & 1,4 & 1,4 & 1,6 & 1,6 & 1,4 \\
\hline Kosovo & $\mathrm{n} / \mathrm{a}$ & $\mathrm{n} / \mathrm{a}$ & $\mathrm{n} / \mathrm{a}$ & 5,2 & 5,4 & 4,4 & 5,0 \\
\hline Letonia & 3,0 & 2,6 & 2,2 & 2,2 & 2,2 & 2,4 & 2,4 \\
\hline Lituania & 1,0 & 2,0 & 1,6 & 1,6 & 1,6 & 1,8 & 1,6 \\
\hline Macedonia & 6,0 & 4,8 & 4,4 & 4,2 & 4,4 & 4,2 & 4,7 \\
\hline Montenegro & & & 3,8 & 3,6 & 3,0 & 2,8 & 3,3 \\
\hline Polonia & 2,0 & 2,0 & 1,8 & 1,6 & 1,6 & 1,6 & 1,8 \\
\hline Romania & 4,0 & 4,0 & 3,6 & 3,2 & 2,8 & 2,8 & 3,4 \\
\hline Serbia & & & 3,6 & 3,4 & 3,0 & 2,8 & 3,2 \\
\hline Eslovaquia & 2,0 & 1,4 & 1,8 & 1,8 & 1,8 & 1,8 & 1,8 \\
\hline Eslovenia & 1,0 & 1,2 & 1,0 & 1,0 & 1,0 & 1,2 & 1,1 \\
\hline Media Total & 3,5 & 2,9 & 2,7 & 2,7 & 2,7 & 2,6 & 2,8 \\
\hline
\end{tabular}


